\title{
LEONARDO BONTEMPO
}

Produção e caracterização elétrica de filmes finos de telureto com nanopartículas de ouro depositados pela técnica sputtering para aplicação em memórias

São Paulo 


\section{LEONARDO BONTEMPO}

Produção e caracterização elétrica de filmes finos de telureto com nanopartículas de ouro depositados pela técnica sputtering para aplicação em memórias

\section{Versão Revisada}

Tese apresentada à Escola Politécnica da Universidade de São Paulo para a obtenção do título de Doutor em Ciências - Programa de Pós-Graduação em Engenharia Elétrica.

Área de concentração: Microeletrônica

Orientadora: Profa. Dra. Luciana Reyes Pires Kassab

São Paulo 
Este exemplar foi revisado e corrigido em relação à versão original, sob responsabilidade única do autor e com a anuência de seu orientador.

São Paulo, de de

Assinatura do autor:

Assinatura do orientador:

\section{Catalogação-na-publicação}

\section{Bontempo, Leonardo}

Produção e caracterização elétrica de filmes finos de telureto com nanopartículas de ouro depositados pela técnica sputtering para aplicação em memórias / L. Bontempo -- versão corr. -- São Paulo, 2017.

$$
128 \mathrm{p} \text {. }
$$

Tese (Doutorado) - Escola Politécnica da Universidade de São Paulo. Departamento de Engenharia de Sistemas Eletrônicos.

1.Nanopartículas de ouro 2.Filmes finos 3.Teluretos 4.Sputtering 5.Memória não volátil I.Universidade de São Paulo. Escola Politécnica. Departamento de Engenharia de Sistemas Eletrônicos II.t. 
Nome: BONTEMPO, Leonardo

Título: Produção e caracterização elétrica de filmes finos de telureto com nanopartículas de ouro depositados pela técnica sputtering para aplicação em memórias

Tese apresentada à Escola Politécnica da Universidade de São Paulo para a obtenção do título de Doutor em Ciências - Programa de Pós-Graduação em Engenharia Elétrica. Área de concentração: Microeletrônica.

Aprovado em:

Banca Examinadora

Prof. (a) Dr. (a)

Instituição:

Julgamento:

Prof. (a) Dr. (a)

Instituição:

Julgamento:

Prof. (a) Dr. (a)

Instituição:

Julgamento:

Prof. (a) Dr. (a)

Instituição:

Julgamento:

Prof. (a) Dr. (a)

Instituição:

Julgamento: 


\section{AGRADECIMENTOS}

À toda a minha família e amigos, pela amizade, companheirismo, suporte e paciência; e especialmente aos meus pais pelo apoio permanente.

À Prof ${ }^{a}$. Dra. Luciana Reyes Pires Kassab, pela orientação, amizade e apoio irrestrito demonstrados ao longo do doutorado.

Ao Prof. Dr. Sebastião Gomes dos Santos Filho, do Laboratório de Sistemas Integráveis da Escola Politécnica da Universidade de São Paulo, pela co-orientação. Seu apoio, colaboração, discussões e sugestões se mostraram essenciais para o desenvolvimento do trabalho.

Ao técnico de laboratório, Me. Ricardo Rangel, pelo apoio durante as medidas e processos realizados no Laboratório de Sistemas Integráveis.

Ao técnico de laboratório, José Augusto Martins Garcia e ao Dr. Thiago Alexandre Alves de Assumpção, pela realização de medidas de Microscopia Eletrônica de Transmissão.

Ao Laboratório de Sistemas Integráveis da Escola Politécnica da Universidade de São Paulo (LSI/EPUSP) pela infraestrutura cedida.

Ao Laboratório Nacional de Nanotecnologia (LNNano) do Centro Nacional de Pesquisa em Energia e Materiais (CNPEM), e ao Instituto de Química (IQ) da Universidade de São Paulo (USP), pelo uso dos microscópios eletrônicos de transmissão.

Ao Laboratório de Materiais e Feixes Iônicos (LAMFI) do Instituto de Física da Universidade de São Paulo (IFUSP), pela realização das medidas de Espectrometria por Retroespalhamento de Rutherford.

À Faculdade de Tecnologia de São Paulo (FATEC-SP), pelo espaço cedido pelos Laboratórios de Tecnologia em Materiais Fotônicos e Optoeletrônicos (LTMFO) e Laboratório de Processamento e Caracterização de Materiais (LPCM), para uso da infraestrutura necessária para a pesquisa.

À Coordenação de Aperfeiçoamento de Pessoal de Nível Superior (CAPES), pela bolsa de doutorado, e ao Instituto Nacional de Ciência e Tecnologia (INCT-Fotônica/CNPq), pela compra de materiais de consumo e auxilio na participação de congressos.

Aos colegas do Laboratório de Tecnologia em Materiais Fotônicos e Optoeletrônicos pelo companheirismo e apoio, e a todos, que direta ou indiretamente, contribuíram de alguma forma para a realização deste trabalho. 


\section{RESUMO}

Esse trabalho teve como objetivo a produção e a caracterização elétrica de filmes finos de telureto com nanopartículas de ouro, depositados pela técnica sputtering, para aplicação em dispositivos de memória. Os filmes finos foram produzidos a partir de alvos cerâmicos de telureto $\left(\mathrm{TeO}_{2}-\mathrm{ZnO}\right)$ e foram nucleadas nanopartículas de ouro para observar sua influência no comportamento de memória. Foi desenvolvida metodologia adequada para a nucleação das nanopartículas por meio de tratamento térmico.

Foram produzidos filmes com diferentes concentrações e tamanhos de nanopartículas e diferentes fluxos de oxigênio durante a deposição. Os filmes foram caracterizados por técnicas como Microscopia Eletrônica de Transmissão (TEM), Perfilometria, Espectrometria por Retroespalhamento de Rutherford (RBS) e extração de curvas de Corrente x Tensão (I-V).

Por meio das medidas I-V foi possível identificar as melhores condições para aplicações em memória e correlacioná-las com as variáveis de processo estudadas. Resultados obtidos mostraram que a melhor condição para aplicações em memória não volátil foi encontrada em filmes com $100 \mathrm{~nm}$ de espessura e depositados com fluxo de oxigênio de 1 sccm, abertura do shutter em 50 e tratados termicamente por 10 ou 20 horas à $325^{\circ} \mathrm{C}$. Nesses casos, foi observado um abrupto aumento na corrente (4 ordens de grandeza) em aproximadamente $6,5 \mathrm{~V}$ para 10 horas de tratamento térmico e $3,5 \mathrm{~V}$ para 20 horas de tratamento térmico, indicando a transição do estado inicial de baixa condutividade para outro de alta condutividade.

As nanopartículas de ouro proporcionam maior capacidade de armazenamento de elétrons e não favorecem o transporte de corrente através do isolante; elas atuam como armadilhas para as cargas elétricas, o que reduz a corrente de fuga para níveis mais baixos. Foi estudada a influência do diâmetro e da concentração volumétrica das nanopartículas de ouro no valor da tensão elétrica associada à transição abrupta da corrente. Este parâmetro desempenha um papel importante no efeito de memória, pois determina a facilidade/dificuldade em se preencher e saturar as armadilhas (nanopartículas de ouro) com elétrons. Os materiais estudados neste trabalho mostraram-se promissores para aplicações em dispositivos de memória não volátil e possuem características semelhantes aos materiais orgânicos usados para o referido fim.

Palavras chave: Nanopartículas de ouro; Filmes finos; Teluretos; Sputtering; Memória não volátil 


\begin{abstract}
This work has the objective to fabricate and characterize electrically tellurite thin films containing gold nanoparticles, deposited by the sputtering technique, for application in memory devices. Thin films were produced from ceramic tellurite targets and gold nanoparticles were nucleated in order to observe their influence on memory behavior. An appropriate method was developed for the nucleation of the nanoparticles by means of heat treatment.

Films with different nanoparticles sizes and concentration and different oxygen fluxes during the deposition, were produced. The films were characterized by techniques such as Transmission Electron Microscopy (TEM), Profilometry, Rutherford Backscatter Spectrometry (RBS) and current x voltage (I-V) curves.

Using I-V measurements, it was possible to identify the best conditions for memory applications and correlate them with the process variables studied. The results showed that the best condition for memory applications was found in films with $100 \mathrm{~nm}$ thickness and deposited with oxygen flow of $1 \mathrm{sccm}$, opening shutter in 50 and heat treated for 10 or 20 hours at $325^{\circ} \mathrm{C}$. In these cases, current abrupt increase (4 orders of magnitude) was observed at about $6.5 \mathrm{~V}$ for 10 hours of heat treatment and $3.5 \mathrm{~V}$ for 20 hours of heat treatment, indicating the transition from high impedance state to low impedance state.

Gold nanoparticles provide a larger electron storage capability, and do not favor the electric transport through the insulator; they act as traps for electrical charges, which reduces the leak current to lower levels. It was studied the influence of the gold nanoparticles diameter and volumetric concentration on the voltage associated to the abrupt current. These parameters played an important role in the memory effect, as they determined the facility/difficulty to fill and saturate the traps (Au nanoparticles) with electrons. The materials studied in the present work, based on $\mathrm{TeO}_{2}-\mathrm{ZnO}$ thin films with $\mathrm{Au}$ nanoparticles, are promising for applications in nonvolatile memory device with similar characteristics to organic materials used for the same purpose.
\end{abstract}

Keywords: Gold nanoparticles; Thin films; Tellurite; Sputtering; Non-volatile memory 


\section{LISTA DE FIGURAS}

FIGURA 2.1 - COMPORTAMENTO I-V DA AMOSTRA PRODUZIDA COM CONCENTRAÇÃO DE 0,01 M DE HAUCL4 EM MATRIZ ORGÂNICA PMSSQ [26] ......................................................2

FIGURA 2.2 - NANOPARTÍCULAS DE OURO CRESCIDAS COM VARIAÇÃO NA CONCENTRAÇÃO

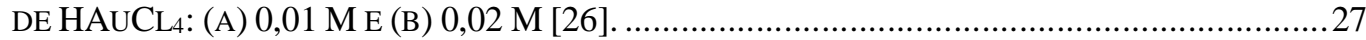

FIGURA 2.3 - COMPORTAMENTO I-V DO DISPOSITIVO DE NANOFIBRAS DE POLIANILINA COM NANOPARTÍCULAS DE OURO: (A) PRIMEIRA VARREDURA, (B) SEGUNDA VARREDURA E (C) PRIMEIRA VARREDURA APÓS O RESET [56] ....................................................................28

FIGURA 2.4 - COMPORTAMENTO I-V DO DISPOSITIVO DE PARILENO COM NANOPARTÍCULAS

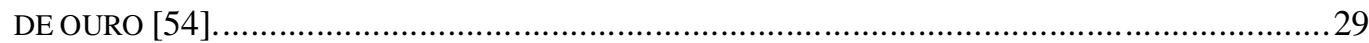

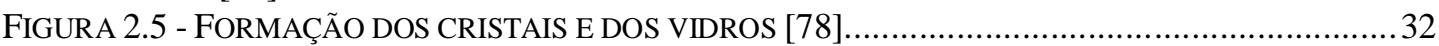

FIGURA 2.6 - ESTRUTURA BIDIMENSIONAL DE UM VIDRO: (A) FORMADO POR SI-O E (B) FORMADO POR SI-O ${ }^{-} \mathrm{NA}^{+}$.

FIGURA 2.7 - ESTRUTURAS BÁSICAS PRESENTES EM VIDROS DE TELURETO COM NÚMEROS DE COORDENAÇÃO 4, 3+1 E 3, RESPECTIVAMENTE EM (A), (B) E (C) [86] .....................................36

FIGURA 2.8 - FoRMAÇÃO DA ESTRUTURA TEO ${ }_{3+1}$ A PARTIR DE UMA ESTRUTURA TEO $\mathrm{T}_{4} \ldots \ldots \ldots \ldots \ldots \ldots . . . . . . . .37$

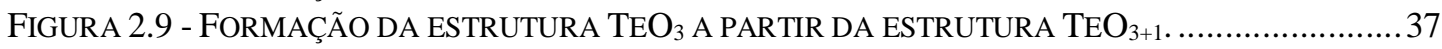

FIGURA 2.10 - ELETRODO USADO NA CONSTRUÇÃO DE UM EQUIPAMENTO PARA DEPOSIÇÃO POR SPUTTERING.

FIGURA 2.11 - DIAGRAMA ESQUEMÁTICO DE UM SISTEMA DE SPUTTERING COM DEMONSTRAÇÃO DA FORMAÇÃO DOS ÍONS, BOMBARDEAMENTO DO ALVO E OS GASES DE PROCESSO.

FIGURA 2.12 - SISTEMA PARA DEPOSIÇÃO POR CO-SPUTTERING .................................................. 43

FIGURA 2.13 - CINÉTICA DE PARTÍCULAS: (A) SPUTTERING CONVENCIONAL E (B) MAGNETRON SPUTTERING.

FIGURA 2.14 - CONFIGURAÇÃO DO PLASMA: (A) SPUTTERING CONVENCIONAL (B) MAGNETRON SPUTTERING.

FIGURA 2.15 - DIAGRAMA DE CARGAS ESPACIAIS PARA UM CAPACITOR PMOS: A) ACUMULAÇÃO B) DEPLEÇÃO E C) INVERSÃO.

FIGURA 2.16 - REPRESENTAÇÃO DA CAPACITÂNCIA DO ÓXIDO $\left(C_{o x}\right)$ E DA CAPACITÂNCIA DO SILÍCIO $\left(C_{S_{I}}\right)$ DE UM CAPACITOR MOS.....

FIGURA 2.17 - CURVA C-V EM BAIXA FREQUÊNCIA (BF) E ALTA FREQUÊNCIA (AF) DE UM CAPACITOR MOS.

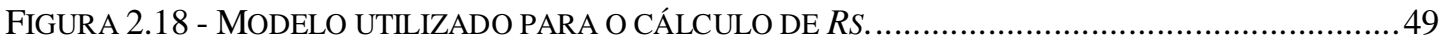

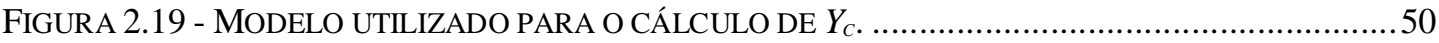

FIGURA 2.20 - ESTRUTURA E OPERAÇÃO DE UM TRANSISTOR MOS EM COMPARAÇÃO COM A ESTRUTURA E OPERAÇÃO DE UMA UNIDADE DE MEMÓRIA FLASH .........................................52

FIGURA 2.21 - ESTRUTURA DE UMA UNIDADE DE MEMÓRIA FLASH COM PORTA FLUTUANTE

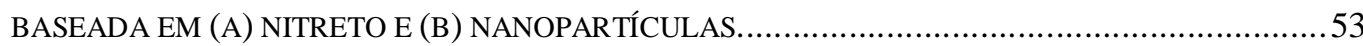

FIGURA 2.22 - DIAGRAMAS DE BANDA ESQUEMÁTICOS DO MECANISMO DE TRANSPORTE SCLC: (A) CONDUÇÃO POR PORTADORES GERADOS TERMICAMENTE; (B) COM ARMADILHAS; (C) ARMADILHAS QUASE CHEIAS E (D) ARMADILHAS CHEIAS [25]. ..................55

FIGURA 2.23 - RESULTADO I-V DA MEMÓRIA PS+AU-NPS (LINHA SÓLIDA) E DA MEMÓRIA

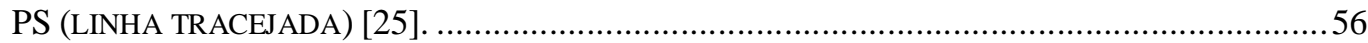

FIGURA 2.24 - CURVA LOG I - LOG V DO COMPORTAMENTO DE MEMÓRIA DA AMOSTRA PS+AU-NPS. O INSERT MOSTRA O COMPORTAMENTO LOG I - LOG V DA AMOSTRA PS. ..........58

FIGURA 3.1 - FLUXOGRAMA DAS PRINCIPAIS ETAPAS UTILIZADAS NA PRODUÇÃO DOS ALVOS

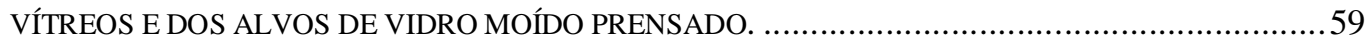

FIGURA 3.2 - (A) ALVO VÍTREO (B) ALVO DE VIDRO MOÍDO PRENSADO.......................................... 60

FIGURA 3.3 - FLUXOGRAMA DAS PRINCIPAIS ETAPAS UTILIZADAS NA PRODUÇÃO DOS ALVOS CERÂMICOS. 
FIGURA 3.4 - ALVO CERÂMICO.

FIGURA 3.5 - ALVO DE OURO.

FIGURA 3.6 - (A) PROCESSO DE FABRICAÇÃO DOS ALVOS CERÂMICOS. (B) REAGENTES CONSTITUINTES DO ALVO NO MOLDE ANTES DA PRENSAGEM. (C) ALVO CERÂMICO APÓS O TRATAMENTO TÉRMICO DE SINTERIZAÇÃO [107]

FIGURA 3.7 - EQUIPAMENTO DE MAGNETRON CO-SPUTTERING DO LABORATÓRIO DE

MATERIAIS FOTÔNICOS E OPTOELETRÔNICOS DA FATEC-SP.

FIGURA 3.8 - INTERIOR DA CÂMARA DE DEPOSIÇÃO DO EQUIPAMENTO DE CO-SPUTTERING. ...........66

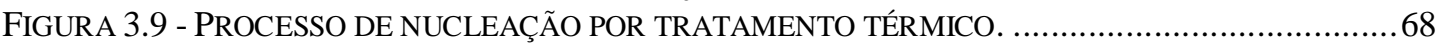

FIGURA 3.10 - (A) MÁSCARA MECÂNICA E (B) ESTRUTURAS MIS.

FIGURA 3.11 - MICROSCÓPIOS ELETRÔNICO DE TRANSMISSÃO UTILIZADOS: (A) IQ-USP (B)

IFUSP E (C) LNNANO. . .71

FIGURA 3.12 - CÂMARA ESCURA UTILIZADA DURANTE AS MEDIDAS I-V.

FIGURA 4.1 - EXEMPLO DE LOCAL UTILIZADO PARA MEDIDA DE ESPESSURA.

FIGURA 4.2 - RBS DAS AMOSTRAS M0, M0,5, M1, M2 E M7. EFEITO DO FLUXO DE OXIGÊNIO NA CONCENTRAÇÃO DOS ELEMENTOS DAS MATRIZES SEM TRATAMENTO TÉRMICO

FIGURA 4.3 - RBS DAS AMOSTRAS M0, M0,5, M1, M2 E M7. EFEITO DO TRATAMENTO TÉRMICO NA CONCENTRAÇÃO DOS ELEMENTOS DAS MATRIZES TRATADAS TERMICAMENTE POR 10 HORAS.

FIGURA 4.4 - CORRENTE DE FUGA EM FUNÇÃO DA TENSÃO PARA AS AMOSTRAS M0 - 0H E $10 \mathrm{H}$......

FIGURA 4.5 - CORRENTE DE FUGA EM FUNÇÃO DA TENSÃO PARA AS AMOSTRAS M0,5, M1 E M2 SEM TRATAMENTO TÉRMICO: $1^{A}$ VARREDURA. .80

FIGURA 4.6 - CORRENTE DE FUGA EM FUNÇÃO DA TENSÃO PARA AS AMOSTRAS M0,5, M1 E M2 SEM TRATAMENTO TÉRMICO: $1^{\mathrm{A}}$ E $2^{\mathrm{A}}$ VARREDURAS.

FIGURA 4.7 - CORRENTE DE FUGA EM FUNÇÃO DA TENSÃO PARA AS AMOSTRAS M0,5 E M1, SEM TRATAMENTO TÉRMICO E COM TRATAMENTO TÉRMICO DE 10 HORAS..............................8 82

FIGURA 4.8 - CORRENTE DE FUGA EM FUNÇÃO DA TENSÃO PARA A AMOSTRA M2 - 10H: $1^{\mathrm{A}}$ VARREDURA PARA TRÊS DISPOSITIVOS.

FIGURA 4.9 - CORRENTE DE FUGA EM FUNÇÃO DA TENSÃO PARA A AMOSTRA M1 - 0H: $2^{A}$ VARREDURA APÓS APLICAÇÃO DE CICLO DE TENSÃO NEGATIVA.

FIGURA 4.10 - CORRENTE DE FUGA EM FUNÇÃO DA TENSÃO PARA A AMOSTRA M7 - 0H. ...............85

FIGURA 4.11 - CORRENTE DE FUGA EM FUNÇÃO DA TENSÃO PARA A AMOSTRA M7 - 10H. .............86

FIGURA 4.12 - RBS DAS AMOSTRAS PRODUZIDAS COM DIFERENTES ABERTURAS DE SHUTTER, ESPESSURA DE 100 NM E TRATAMENTO TÉRMICO DE 10 HORAS.

FIGURA 4.13 - RBS DAS AMOSTRAS PRODUZIDAS COM DIFERENTES ABERTURAS DE SHUTTER, ESPESSURA DE 500 NM E TRATAMENTO TÉRMICO DE 10 HORAS.

FIGURA 4.14 - RBS DAS AMOSTRAS PRODUZIDAS COM MESMA ABERTURA DE SHUTTER, SEM TRATAMENTO TÉRMICO, ESPESSURA DE 100 NM E DIFERENTES FLUXOS DE OXIGÊNIO............91

FIGURA 4.15 - RBS DA AMOSTRA STOT_100_7, COM DIFERENTES TEMPOS DE TRATAMENTO TÉRMICO E 7 W DE POTÊNCIA APLICADA AO ALVO DE OURO.

FIGURA 4.16 - IMAGENS OBTIDAS POR TEM DA AMOSTRA S40_100_4 - 0H E HISTOGRAMA DE DISTRIBUIÇÃO DE TAMANHOS CORRESPONDENTE.

FIGURA 4.17 - NANOPARTÍCULAS EM PROCESSO INICIAL DE FORMAÇÃO. IMAGENS OBTIDAS POR TEM DA AMOSTRA S40_100_4-0H.

FIGURA 4.18 - DIFRAÇÃO DE ELÉTRONS DA AMOSTRA S40_100_4 - 0H ACOMPANHADA DA DETERMINAÇÃO DOS ANÉIS DE DIFRAÇÃO.

FIGURA 4.19 - IMAGENS OBTIDAS POR TEM DA AMOSTRA S40_100_4 - 0H.................................99

FIGURA 4.20 - ESPECTRO DE EDS EXTRAÍDO DA REGIÃO A MOSTRADA NA FIGURA 4.19 .............99

FIGURA 4.21 - ESPECTRO DE EDS EXTRAÍDO DA REGIÃO B MOSTRADA NA FIGURA 4.19 .............99

FIGURA 4.22 - IMAGEM OBTIDA POR TEM DA AMOSTRA S40_100_4 - 10H E HISTOGRAMA DE DISTRIBUIÇÃO DE TAMANHOS CORRESPONDENTE. 
FIGURA 4.23 - DIFRAÇÃO DE ELÉTRONS DA AMOSTRA S40_100_4 - 10H ACOMPANHADA DA (A) DETERMINAÇÃO DOS ANÉIS DE DIFRAÇÃO E (B) PONTOS (SPOTS) DE DIFRAÇÃO NUMERADOS

FIGURA 4.24 - IMAGEM OBTIDA POR TEM DA AMOSTRA S50_100_1 - 10H E HISTOGRAMA DE

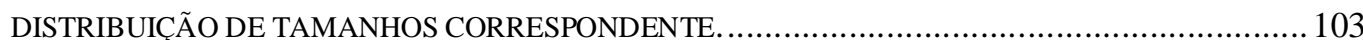

FIGURA 4.25 - IMAGEM OBTIDA POR TEM DA AMOSTRA S50_100_1 - 20H E HISTOGRAMA DE

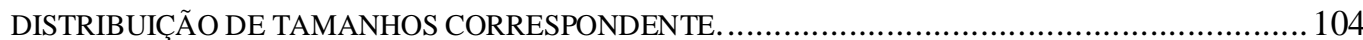

FIGURA 4.26 - DIFRAÇÃO DE ELÉTRONS DA AMOSTRA S50_100_1 - 20H. IMAGEM ORIGINAL À ESQUERDA E DETERMINAÇÃO DOS ANÉIS DE DIFRAÇÃO À DIREITA.................................... 105

FIGURA 4.27 - CORRENTE DE FUGA EM FUNÇÃO DA TENSÃO PARA A AMOSTRA S40_100_4 -

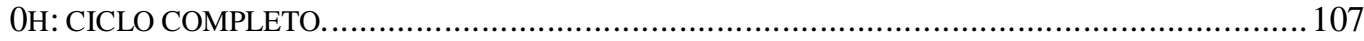

FIGURA 4.28 - CORRENTE DE FUGA EM FUNÇÃO DA TENSÃO PARA A AMOSTRA S40_100_4 -

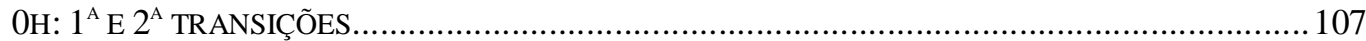

FIGURA 4.29 - CORRENTE DE FUGA EM FUNÇÃO DA TENSÃO PARA A AMOSTRA S50_100_2 -

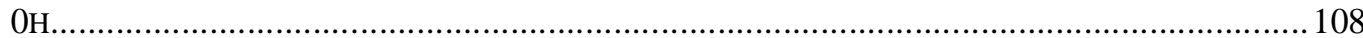

FIGURA 4.30 - CORRENTE DE FUGA EM FUNÇÃO DA TENSÃO PARA A AMOSTRA S60_100_7 -

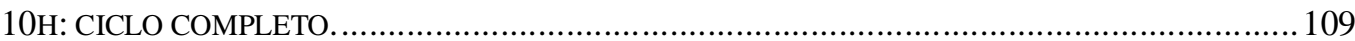

FIGURA 4.31 - CORRENTE DE FUGA EM FUNÇÃO DA TENSÃO PARA A AMOSTRA S60_100_7 -

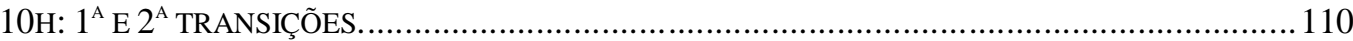

FIGURA 4.32 - CORRENTE DE FUGA EM FUNÇÃO DA TENSÃO PARA A AMOSTRA S60_100_7 10H: COMPORTAMENTO DA MEMÓRIA APÓS O ESTABELECIMENTO DE VÁRIOS CICLOS DE OPERAÇÃO.

FIGURA 4.33 - CORRENTE DE FUGA EM FUNÇÃO DA TENSÃO PARA A AMOSTRA STOT_100_7 $0 \mathrm{H}$......

FIGURA 4.34 - CORRENTE DE FUGA EM FUNÇÃO DA TENSÃO PARA A AMOSTRA S50_100_1 -

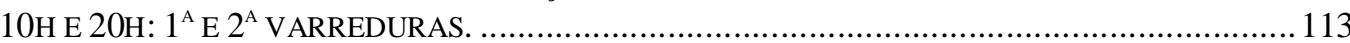

FIGURA 4.35 - CORRENTE DE FUGA EM FUNÇÃO DA TENSÃO PARA A AMOSTRA S50_100_1 10H E 20H E S50_500_1 - 10H: $1^{\mathrm{A}}$ VARREDURA.

FIGURA 4.36 - MECANISMOS DE CORRENTE AJUSTADOS AO COMPORTAMENTO I-V TÍPICO DOS FILMES COM 100NM DE ESPESSURA, COM NANOPARTÍCULAS DE OURO E TRATADOS TERMICAMENTE POR 10 HORAS. 


\section{LISTA DE TABELAS}

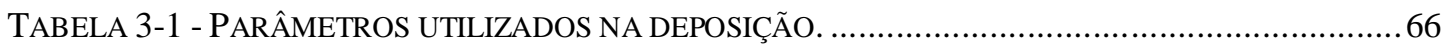

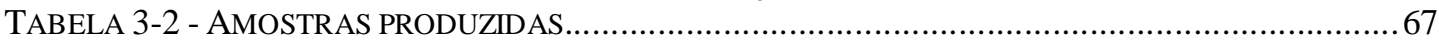

TABELA 4-1 - AMOSTRAS PRODUZIDAS SEM OURO, COM ESPESSURA DE 100 NM, TRATADAS TERMICAMENTE POR 0 E 10 HORAS E COM DIFERENTES FLUXOS DE OXIGÊNIO........................75

TABELA 4-2 - DADOS EXTRAÍDOS POR RBS DAS AMOSTRAS SEM OURO. ………...........................76

TABELA 4-3 - AMOSTRAS PRODUZIDAS COM OURO E COM DIFERENTES ESPESSURAS, FLUXOS DE OXIGÊNIO, TEMPOS DE TRATAMENTO TÉRMICO E ABERTURAS DO SHUTTER. EM TODOS OS CASOS FOI USADA POTÊNCIA DE $50 \mathrm{~W}$ NO ALVO DE TEO ${ }_{2}$-ZNO ............................. 88

TABELA 4-4 - DADOS EXTRAÍDOS POR RBS DAS AMOSTRAS COM OURO.......................................93

TABELA 4-5 - CONCENTRAÇÃO PLANAR DE OURO E TAMANHO MÉDIO DAS NANOPARTÍCULAS PARA AMOSTRAS COM 100 NM (SEM TRATAMENTO E TRATADAS TERMICAMENTE POR 10 E 20H) E 500 NM (TRATADAS TERMICAMENTE POR 10 E 20H). 


\title{
LISTA DE ABREVIATURAS
}

\author{
AF - Alta Frequência \\ AFM - Microscopia de Força Atômica (Atomic Force Microscopy) \\ APCVD - Deposição Química em Fase de Vapor em Pressão Atmosférica (Atmospheric \\ Pressure Chemical Vapor Deposition) \\ BF - Baixa Frequência \\ CAPES - Coordenação de Aperfeiçoamento de Pessoal de Nível Superior \\ CD - Compact Disc \\ CNPEM - Centro Nacional de Pesquisa em Energia e Materiais \\ CNPq - Conselho Nacional de Desenvolvimento Científico e Tecnológico \\ C-V - Capacitância x Tensão Elétrica \\ CVD - Deposição Química em Fase de Vapor (Chemical Vapor Deposition) \\ DC - Corrente Direta (Direct current) \\ DI - Água Deionizada \\ DVD - Digital Versatile Disc \\ EDS - Espectroscopia de Energia Dispersiva (Energy Dispersive Spectroscopy) \\ EDX - Espectrometria de Fluorescência de Raios-X \\ EEPROM - Electrically-Erasable Programmable Read-Only Memory \\ EPROM - Erasable Programmable Read-Only Memory \\ EPUSP - Escola Politécnica da Universidade de São Paulo \\ FATEC-SP - Faculdade de Tecnologia de São Paulo \\ HDPCVD - Deposição Química em Fase de Vapor com Plasma de Alta Densidade (High \\ Density Plasma Chemical Vapor Deposition) \\ IFUSP $\quad$ - Instituto de Física da Universidade de São Paulo \\ INCT - Instituto Nacional de Ciência e Tecnologia \\ IQ - - Instituto de Química \\ ITA - Instituto Tecnológico da Aeronáutica \\ I-V - Corrente Elétrica x Tensão Elétrica \\ K - Kelvin \\ LAMFI - Laboratório de Materiais e Feixes Iônicos \\ LECVD - Deposição Química em Fase de Vapor Estimulada por Laser (Laser \\ Enhanced Chemical Vapor Deposition)
}




\begin{tabular}{|c|c|}
\hline LFF & - Laboratório de Filmes Finos do IFUSP \\
\hline LNNano & - Laboratório Nacional de Nanotecnologia \\
\hline LPCM & - Laboratório de Processamento e Caracterização de Materiais \\
\hline \multirow[t]{2}{*}{ LPCVD } & - Deposição Química em Fase de Vapor em Baixa Pressão (Low Pressure \\
\hline & Chemical Vapor Deposition) \\
\hline LPD & - Deposição em Fase Líquida (Liquid Phase Deposition) \\
\hline LSI & - Laboratório de Sistemas Integráveis \\
\hline LTMFO & - Laboratório de Tecnologia em Materiais Fotônicos e Optoeletrônicos \\
\hline MEMS & - Sistema Microeletromecânico \\
\hline MEV & - Microscópio Eletrônico de Varredura \\
\hline MIS & - Metal - Isolante - Semicondutor \\
\hline MOS & - Metal - Óxido - Semicondutor \\
\hline \multirow[t]{2}{*}{ MOSFET } & - Transistores de Efeito de Campo Metal - Óxido - Semicondutor (Metal - \\
\hline & Oxide - Semiconductor Field Effect Transistor) \\
\hline NPs & - Nanopartículas \\
\hline \multirow[t]{2}{*}{ PECVD } & - Deposição Química em Fase de Vapor Estimulada por Plasma (Plasma \\
\hline & Enhanced Chemical Vapor Deposition) \\
\hline PMOS & - Metal - Óxido - Semicondutor tipo $p$ \\
\hline POLI & - Politécnica \\
\hline PS & - Poliestireno \\
\hline PVD & - Deposição Física em Fase de Vapor (Physical Vapor Deposition) \\
\hline RBS & - Espectrometria por Retroespalhamento de Rutherford \\
\hline RCA & - Radio Corporation of America \\
\hline RF & - Radiofrequência \\
\hline $\mathrm{ROM}$ & - Read-Only Memory \\
\hline SCCM & $\begin{array}{l}\text { - Centímetros cúbicos por minuto padrão (standard cubic centimeters per } \\
\text { minute) }\end{array}$ \\
\hline SCLC & - Space-Charge-Limited Current \\
\hline SOG & - Spin on Glass \\
\hline SONOS & - Silicon-Oxide-Nitride-Oxide-Silicon \\
\hline TEM & - Microscopia Eletrônica de Transmissão (Transmission Electron Microscopy) \\
\hline USP & - Universidade de São Paulo \\
\hline
\end{tabular}




\section{LISTA DE SÍMBOLOS}

\begin{tabular}{|c|c|}
\hline $\mathrm{T}_{\mathrm{g}}$ & - Temperatura de transição vítrea ("glass transition temperature”) \\
\hline $\mathrm{T}_{\mathrm{c}}$ & - Temperatura de cristalização \\
\hline $\mathrm{k}$ & - Constante dielétrica \\
\hline$K$ & - Constante de Boltzmann \\
\hline $\mathrm{V}_{\mathrm{G}}$ & - Tensão elétrica de porta ("gate voltage") \\
\hline $\mathrm{V}_{\mathrm{FB}}$ & - Tensão elétrica de banda plana ("flat band voltage") \\
\hline Qss & - Carga elétrica no óxido \\
\hline $\mathrm{V}_{\mathrm{T}}$ & - Tensão elétrica de limiar (“threshold voltage”) \\
\hline $\mathrm{V}_{\mathrm{t}}$ & - Tensão elétrica de transição \\
\hline$\phi_{\mathrm{M}}$ & - Função trabalho do metal \\
\hline$\phi_{\mathrm{si}}$ & - Função trabalho do silício \\
\hline $\mathrm{N}_{\mathrm{A}}$ & - Impurezas aceitadoras \\
\hline$t_{\mathrm{ox}}$ & - Espessura do óxido \\
\hline $\mathrm{W}_{\mathrm{d}}$ & - Largura da região de depleção \\
\hline $\mathrm{W}_{\mathrm{dmáx}}$ & - Largura máxima da região de depleção \\
\hline $\mathrm{C}_{\mathrm{T}}$ & - Capacitância total \\
\hline $\mathrm{C}_{\mathrm{ox}}$ & - Capacitância do óxido \\
\hline $\mathrm{C}_{\mathrm{si}}$ & - Capacitância do silício \\
\hline$\varepsilon_{0}$ & - Permissividade elétrica do vácuo $\left(8,84 \times 10^{-14} \mathrm{~F} / \mathrm{cm}\right)$ \\
\hline$\varepsilon_{\mathrm{ox}}$ & - Permissividade elétrica do óxido \\
\hline $\mathrm{E}$ & - Campo elétrico \\
\hline $\mathrm{E}_{0}$ & - Barreira de potencial \\
\hline $\mathrm{A}$ & - Área do capacitor \\
\hline $\mathrm{C}_{\mathrm{D}}$ & - Capacitância de depleção \\
\hline$\varepsilon_{\mathrm{Si}}$ & - Permissividade do silício $\left(11,7 \times 10^{-13} \mathrm{~F} / \mathrm{cm}\right)$ \\
\hline $\mathrm{C}_{\mathrm{I}}$ & - Capacitância de inversão \\
\hline $\mathrm{C}_{\mathrm{ma}}$ & - Capacitância medida \\
\hline $\mathrm{G}_{\mathrm{ma}}$ & - Condutância medida \\
\hline $\mathrm{R}_{\mathrm{s}}$ & - Resistência série \\
\hline$f$ & - Frequência \\
\hline
\end{tabular}


$\mathrm{C}_{\max }$

$\mathrm{n}+$

J

n

$\mathrm{n}_{\mathrm{t}}$

$\mu$

L

C

V

I

Id

$\mathrm{V}_{\mathrm{A}}$

$\mathrm{N}_{\mathrm{p}}$

$\mathrm{N}_{\mathrm{v}}$

$\mathrm{d}_{\mathrm{p}}$

$\mathrm{N}_{\mathrm{vp}}$
- Frequência angular

- Admitância

- Capacitância do óxido (com a correção de $\mathrm{R}_{\mathrm{s}}$ )

- Capacitância máxima da curva corrigida

- Região fortemente dopada com impurezas doadoras

- Transporte de corrente elétrica

- Concentração de portadores livres

- Concentração de cargas elétricas armadilhadas

- Mobilidade do portador livre

- Espessura da camada dielétrica

- Capacitância

- Tensão elétrica

- Corrente elétrica

- Corrente elétrica de dreno

- Tensão elétrica de Ativação

- Concentração planar de ouro

- Concentração volumétrica de ouro

- Tamanho médio das nanopartículas

- Concentração volumétrica das nanopartículas 


\section{SUMÁRIO}

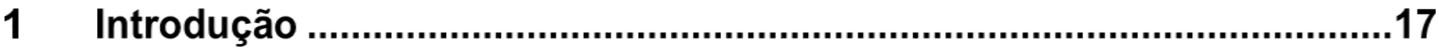

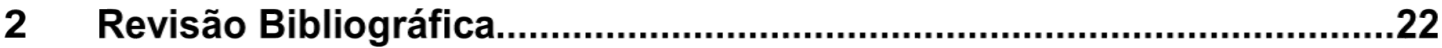

$2.1 \quad$ Estado da Arte..........................................................................22

$2.2 \quad$ Vidros de Telureto.................................................................................30

$2.3 \quad$ Filmes Finos......................................................................................38

2.3.1 Processos para Produção de Filmes Finos..........................................39

2.3.2 Deposição por Sputtering................................................................40

2.3.3 Deposição por Co-sputtering ...........................................................43

2.3.4 Magnetron Sputtering.........................................................................43

$2.4 \quad$ Propriedades Elétricas ........................................................................45

2.4.1 Capacitor MOS .............................................................................45

2.4.2 Equações Básicas do Capacitor MOS .................................................49

2.4.3 Memória Não Volátil.........................................................................51

2.4.4 Memória Biestável de Matriz $\mathrm{TeO}_{2}-\mathrm{ZnO}$ com Nanopartículas de Ouro e o Mecanismo de Transporte de Portadores ...........................................53

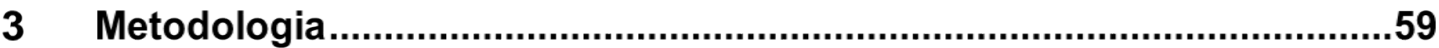

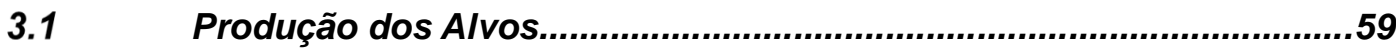

3.2 Limpeza das Lâminas de Silício...........................................................63

3.3 Deposição de Filmes Finos por Co-Sputtering ......................................64

3.4 Tratamento Térmico.......................................................................67

3.5 Produção das Estruturas MIS (Metal - Isolante - Semicondutor) ........68

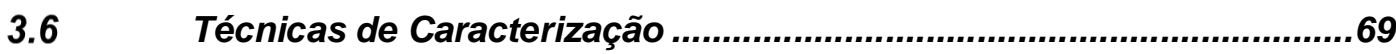

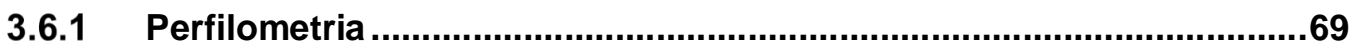

3.6.2 Microscopia Eletrônica de Transmissão (TEM) ...................................70

3.6.3 Espectrometria por Retroespalhamento de Rutherford (RBS) ............72

3.6.4 Corrente x Tensão (I-V) ....................................................................73

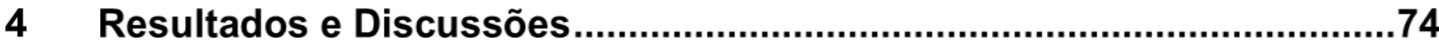

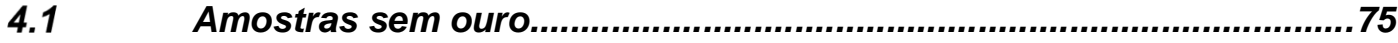

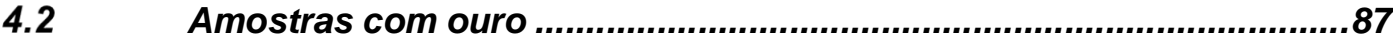

5 Conclusões......................................................................................117

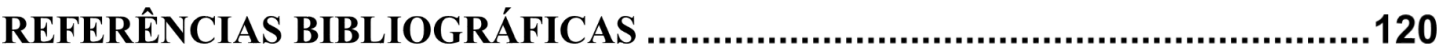

APÊNDICE A - Publicações de trabalho no período do doutorado .........................127 


\section{Introdução}

Nas últimas décadas, muita pesquisa foi feita e muitos avanços foram obtidos no campo dos dispositivos eletrônicos. Dentre os modernos dispositivos eletrônicos, as memórias não voláteis são um dos componentes mais importantes [1,2,3,4]. A memória não volátil é capaz de armazenar e reter informações armazenadas mesmo quando energia não é fornecida ao dispositivo, por isso, é usada no armazenamento permanente de dados.

Houve muita mudança na tecnologia de armazenamento permanente de dados durante os últimos 20 anos. Unidades de armazenamento como fitas magnéticas, discos compactos (CD - Compact Disk e DVD - Digital Versatile Disc) e disquetes, amplamente usados para o armazenamento de dados pessoais, foram substituídos por unidades de armazenamento do estado sólido, isto é, unidades de armazenamento sem partes móveis e que são tipicamente construídos com base em circuitos integrados semicondutores. As memórias não voláteis de estado sólido se tornaram cada vez mais importantes com o uso generalizado de aparelhos eletrônicos portáteis, uma vez que tais memórias devem ser integradas aos dispositivos eletrônicos de consumo, como por exemplo, telefones celulares, câmeras digitais, reprodutores de mídia portáteis, computadores portáteis, tablets, etc. Portanto, esforços têm sido feitos rumo ao desenvolvimento de memórias do estado sólido com alta densidade de armazenamento e baixo custo $[5,6,7,8,9,10,11,12,13]$.

Dentre os muitos dispositivos de memória não voláteis do estado sólido disponíveis, os dispositivos de memória flash recebem destaque devido à sua enorme capacidade de memória e facilidade de gravação/apagamento, que são necessários em muitas aplicações $[1,2,3,5,8]$.

Dispositivos de memória flash têm uma estrutura simples, que é baseada em um único transistor, de modo que é mais fácil escaloná-los do que escalonar outros dispositivos de memória $[2,10,14]$, já que o escalonamento de transistores é bem conhecido. O escalonamento de dispositivos de memória, por sua vez, está diretamente relacionado à densidade de memória. Assim, a escalabilidade é essencial na era de dispositivos eletrônicos móveis e pessoais que requerem cada vez mais capacidade de armazenamento permanente de dados.

Os dispositivos de memória flash possuem uma estrutura interna chamada 'porta flutuante', que é utilizada como camada de armazenamento de cargas elétricas. As memórias flash podem ser classificadas de acordo com o tipo de estruturas e materiais utilizados na 
porta flutuante, como, por exemplo, porta flutuante contínua, baseada em nitreto (SONOS Silicon-Oxide-Nitride-Oxide-Silicon) ou em nanopartículas [4,14,15].

Os dispositivos de memória com camada de captura de carga elétrica baseada em nanopartículas têm vantagens em relação aos dispositivos de memória flash com porta flutuante contínua, uma vez que a camada de captura de carga é constituída por nanopartículas discretamente distribuídas. Essa característica evita problemas originados pela utilização de portas flutuantes contínuas, tais como o aumento da interferência de célula para célula, diminuição da relação de acoplamento, espessura de óxido de tunelamento não escalável e tolerância decrescente para perda de carga. Além disso, as propriedades das nanopartículas podem ser ajustadas controlando-se as condições sob as quais elas são sintetizadas, o que reflete diretamente nas propriedades elétricas da memória. Portanto, pesquisas têm sido realizadas em dispositivos com camada de captura de carga discreta, como os baseados em nanopartículas (também conhecidos como dispositivos de memória com porta nano-flutuante) $[16,17,18,19,20]$. Paralelamente, dispositivos de memória flash com camadas de captura de carga elétrica contínua, porém com composição química diferente da tradicional, como os dispositivos SONOS [10,21,22,23,24], também recebem atenção de pesquisadores.

Ainda outro campo em crescente estudo é o das memórias orgânicas não voláteis com camada de captura de carga elétrica baseada em nanopartículas. Em comparação com as memórias flash (inorgânica), essas memórias orgânicas têm estrutura mais simples, baseadas em um capacitor de placas paralelas [25] ou MOS (Metal - Óxido - Semicondutor) [26], e o mecanismo de condução de cargas associado à gravação, desgravação e leitura da memória é diferente [27].

A fabricação de dispositivos eletrônicos semicondutores é constituída de uma série de etapas. Em geral, uma das primeiras etapas é a limpeza RCA, que tem o intuito de remover íons metálicos, como os íons de sódio $\left(\mathrm{Na}^{+}\right)$, e também os íons de metais pesados, como os íons de chumbo e estanho, dentre outros. Essas impurezas são capazes de criar níveis energéticos indesejáveis, prejudicando ou impossibilitando o funcionamento do dispositivo final. A limpeza RCA ainda remove possíveis contaminações orgânicas, como contaminação por óleos e gorduras [28].

Uma etapa fundamental na produção de dispositivos eletrônicos é a formação de filmes finos, que desempenham importante função na microeletrônica. Os dispositivos que hoje existem só foram produzidos devido ao avanço nas técnicas de produção dos filmes 
finos. As melhorias vão desde a qualidade dos filmes produzidos, com a diminuição de contaminantes e o controle da composição, até a deposição de novos materiais.

Os dispositivos microeletrônicos são constituídos por diversas camadas de filmes finos, que são produzidos através de variadas técnicas de deposição e crescimento. Em um único dispositivo podemos encontrar filmes isolantes, semicondutores e condutores, que desempenham diversas funções. Eles podem ser utilizados como camada dielétrica, contato elétrico, camada de armazenamento de carga elétrica, dentre outras aplicações.

As nanoestruturas, por sua vez, fazem parte de um campo de pesquisa que tem ganhado grande força e interesse nos últimos anos, o da nanotecnologia. Como o próprio nome sugere, a nanotecnologia está relacionada com dimensões da ordem de $10^{-9} \mathrm{~m}$. A nanotecnologia está se difundindo em diversos campos da ciência, como na física, química e na biológica. Contudo, a miniaturização não é uma novidade, mas sim um rumo natural da tecnologia. Um grande exemplo é a evolução dos computadores e dispositivos móveis, causada pela diminuição dos componentes, possibilitando maior integração em mesma área, e também maior velocidade. Outro exemplo são os dispositivos mecânicos em escala micrométrica (MEMS), com diversas aplicações tecnológicas.

Resultados preliminares obtidos recentemente no Laboratório de Tecnologia em Materiais Fotônicos e Optoeletrônicos (LTMFO) da Faculdade de Tecnologia de São Paulo (FATEC-SP) mostraram altos valores de constante dielétrica para filmes finos de telureto [29,30,31,32] e de germanato [33], estando próximos aos obtidos na literatura [34]. Também foi possível observar o comportamento semi-isolante dos filmes finos de telureto.

Este trabalho é então motivado pelas características dos filmes finos de telureto com nanopartículas de ouro. O telureto utilizado nesse trabalho, de composição química $\mathrm{TeO}_{2}$ $\mathrm{ZnO}$, é um vidro, e hospeda em sua rede vítrea as nanopartículas metálicas de ouro. Esse compósito apresenta comportamento elétrico que pode ser modulado a partir do controle das nanopartículas de ouro, tais como: concentração, tamanho, forma, distribuição e outros. Assim, para aplicação em memórias como camada de armazenamento de carga elétrica, esse é um material promissor.

No laboratório LTMFO da FATEC-SP têm sido produzidas e caracterizadas inúmeras composições de vidros de óxido de metal pesado, germanatos e teluretos, dopados com íons de terras-raras, desde o ano de 1998.

Em 2002, em colaboração com o Laboratório de Sistemas Integráveis (LSI) da Escola Politécnica da Universidade de São Paulo (EPUSP), o laboratório LTMFO da FATEC-SP 
iniciou pesquisa com filmes finos feitos a partir de alvos vítreos de óxido de metal pesado. Com isto foi possível produzir e estudar diversas propriedades de filmes finos depositados por sputtering a partir de alvos vítreos de $\mathrm{PbO}-\mathrm{Bi}_{2} \mathrm{O}_{3}-\mathrm{Ga}_{2} \mathrm{O}_{3}$ [35] e de $\mathrm{GeO}_{2}-\mathrm{PbO}[36,37,38]$.

Em 2005 o grupo de pesquisa do laboratório LTMFO iniciou pesquisa em vidros nanoestruturados [39]. Os resultados das várias pesquisas que se seguiram, a partir desses materiais vítreos de óxido de metal pesado, visando aplicações em Nanotecnologia, foram publicados em 2008 em capítulo intitulado "Germanate and tellurite glasses for photonic applications" no livro: Photonics Research and Developments (Editora Nova Science Publisher, New York) [40].

Recentemente foi desenvolvida pelo grupo tecnologia para a nucleação de nanopartículas metálicas em filmes finos de germanato [33,36] e de telureto [32].

Os materiais germanatos e teluretos produzidos e estudados pelo grupo apresentam ótimos resultados no campo da fotônica [41,42,43,44], inclusive em ensaios de não linearidade óptica [45], mas pouco se sabe com respeito às suas características elétricas, sendo este o trabalho pioneiro no estudo das características elétricas de filmes finos de telureto dopado com nanopartículas de ouro para aplicação como camada de armazenamento de carga elétrica em memórias.

A técnica de deposição por sputtering tem sido usada com sucesso nos materiais produzidos pelo grupo de pesquisas do laboratório LTMFO para a deposição de filmes finos [36,37,38]. Esse trabalho é continuidade da pesquisa de Iniciação Científica e do Mestrado [29,30,31,32] e tem como objetivo a produção e a caracterização elétrica de filmes finos de teluretos com nanopartículas de ouro, depositados pela técnica sputtering, para produção de memórias com características biestáveis e reversíveis na condução eletrônica, tendo como camada ativa o material produzido. A originalidade do presente trabalho pauta-se no fato de que não há materiais desta natureza, para aplicações em memórias, que tenham sido reportados na literatura até o presente momento.

Os filmes finos foram produzidos por sputtering a partir de alvos cerâmicos de telureto $\left(\mathrm{TeO}_{2}-\mathrm{ZnO}\right)$ e foram nucleadas nanopartículas de ouro, por meio de tratamento térmico, com a finalidade de observar a influência nas propriedades elétricas dos filmes e identificar as melhores condições para aplicação em memórias. Estruturas MOS, tendo como camada de armazenamento de carga (óxido da estrutura MOS) os filmes em estudo, foram produzidas e utilizadas na caracterização do material. 
Os filmes foram caracterizados por técnicas como: Microscopia Eletrônica de Transmissão (TEM), Perfilometria, Espectrometria por Retroespalhamento de Rutherford (RBS) e extração de curvas de Corrente elétrica x Tensão elétrica (I-V).

A estrutura da tese é apresentada da seguinte forma:

O capítulo 1 apresenta uma breve introdução e justificativa para situar o tema da presente pesquisa. O capítulo 1 ainda apresenta os objetivos específicos deste trabalho.

O capítulo 2 apresenta a revisão bibliográfica pertinente ao tema abordado. Faz menção às características estruturais dos materiais amorfos e seus métodos de obtenção. Aborda sobre a formação de filmes finos, as características elétricas dos dispositivos MOS e discorre sobre os dispositivos de memória.

O capítulo 3 apresenta a metodologia utilizada na produção das amostras e as técnicas de caracterização realizadas neste trabalho.

O capítulo 4 apresenta os resultados obtidos e as discussões das características observadas.

O capítulo 5 apresenta as conclusões, seguido das referências bibliográficas e das publicações do trabalho no período do doutorado. 


\section{Revisão Bibliográfica}

\subsection{Estado da Arte}

Nesta seção serão apresentados os resultados recentes reportados na literatura acerca de memórias orgânicas e inorgânicas, bem como alguns resultados obtidos com o uso de vidros de teluretos com a composição estudada neste trabalho.

Durante as últimas décadas, muitas técnicas foram utilizadas na produção de amostras para o estudo de materiais armazenadores de carga elétrica, visando aplicações em dispositivos de memória não voláteis. O uso da estrutura MOS é favorável aos estudos, uma vez que são facilmente fabricadas, sem a necessidade das usuais junções de fonte e dreno de um transistor. Assim, muitos materiais com potencial para aplicação em memórias, reportados na literatura, foram estudados através da estrutura MOS [15].

Existem várias maneiras de se sintetizar as nanopartículas para captura de carga elétrica. Além disso, muitos tipos de nanopartículas metálicas têm sido utilizados para as aplicações nos dispositivos de memória baseados em nanopartículas [15]. Entre as várias espécies de nanopartículas metálicas, o ouro tem sido relatado como sendo o mais usado, devido às suas propriedades favoráveis que garantem boas características à memória [15].

Muitos estudos relatam a síntese de nanopartículas de ouro através do modelo de crescimento de partículas denominado Ostwald ripening, além da síntese por métodos de solução química [46].

As nanopartículas de ouro são normalmente ligadas aos substratos de silício recobertos com óxido. A formação da camada de captura de carga elétrica é feita principalmente por

processos de automontagem. É possível sintetizar uma camada de nanopartículas de ouro através da deposição de uma fina camada de ouro sobre um substrato de silício recoberto previamente com óxido. Após a deposição da fina camada de ouro, um processo de recozimento em alta temperatura é adotado para sintetizar nanopartículas de ouro, crescidas pelo modelo Ostwald ripening. Neste caso, a fina camada de ouro é convertida em nanopartículas devido à minimização da energia de superfície [19]. Ao adotar este método, dispositivos de memória não voláteis baseados em nanopartículas de ouro podem ser fabricados.

Esta é uma maneira muito simples de fabricar dispositivos de memória com base em nanopartículas de ouro, e o desempenho do dispositivo é relatado como bom, quanto sua 
característica de gravação/desgravação. No entanto, pode ocorrer contaminação metálica na camada do óxido isolante e/ou difusão de componentes metálicos nas interfaces do dispositivo de memória durante a síntese das nanopartículas metálicas [47]. Além disso, a dispersão na distribuição de tamanho das nanopartículas metálicas é normalmente muito alta, o controle de tamanho é difícil, e geralmente há algumas nanopartículas indetectáveis. Portanto, o cálculo da densidade de armadilhas é muito difícil. No entanto, o processo é compatível com a fabricação de dispositivos semicondutores convencionais e pode-se conseguir camadas de nanopartículas de densidade muito alta, assim, muitos estudos foram realizados utilizando este método. Diferentes materiais dielétricos são utilizados para abrigar as nanopartículas. Foi reportado o uso de óxido de silício, além de materiais de alta constante dielétrica (high-k) $[48,49]$.

A produção de nanopartículas por métodos de solução química é usualmente aplicada em dispositivos de memórias não voláteis orgânicas. Nesses casos, muitas vezes os dispositivos não são produzidos visando à disposição de nanopartículas metálicas em uma camada discreta no interior do filme dielétrico, mas elas ficam distribuídas ao longo do volume todo. Muitos trabalhos reportam o uso de poliestireno como material dielétrico para a formação dos filmes finos com nanopartículas incorporadas [50,51,25]. Entretanto, outros materiais também foram reportados com esse propósito [52,26,53,54,55,56]. No caso das memórias orgânicas, o tratamento dispensado na compreensão dos mecanismos de transporte de corrente e operação da memória é diferente do empregado no caso das memórias flash (inorgânica) [27].

Desde 1995 dispositivos de memória baseados em nanopartículas atraem atenção para pesquisa. Tiwari et al. propôs uma memória flash com porta flutuante composta por nanopartículas de silício [57]. O uso de porta flutuante composta por nanopartículas discretas pode reduzir os problemas de perda de carga elétrica que ocorrem nos dispositivos de porta flutuante convencionais. No entanto, as nanopartículas discretas de silício tiveram insuficiente retenção de carga (retenção de dados - não volatilidade), devido à alta corrente de fuga através do óxido de tunelamento. As nanopartículas de metal foram usadas para melhorar a retenção de dados, pois, quando comparadas às nanopartículas de silício, têm maior função de trabalho [58]. As memórias de nanopartículas de metal têm várias vantagens, incluindo alta velocidade de operação, boa escalabilidade, confiabilidade superior e uma ampla gama de funções de trabalho disponíveis [59]. Dentre a variedade de nanopartículas metálicas, Au, Ag, Pt e Al são as mais utilizadas como centros de armazenamento de carga elétrica para 
aplicações em memória não volátil [15,59,60,61]. Em particular, as nanopartículas de ouro são as mais investigadas, pois são quimicamente estáveis, facilmente sintetizadas e consideradas como tendo alta função de trabalho [15]. Muitos estudos reportados na literatura abordaram o preparo de nanopartículas de ouro em substratos para produzir filmes com alta uniformidade de distribuição de partículas, e assim obter boas características de memória.

Chang et al. [59] e Liu et al. [62] depositaram uma camada metálica de 1-5 nm, que foi então recozida em temperatura adequada e atmosfera inerte, para transformar a fina camada metálica em uma estrutura de nanopartículas. O tamanho das nanopartículas é influenciado pela espessura da camada metálica, bem como pela temperatura e duração do tratamento térmico [19,59]. Chan et al. fabricou também nanopartículas de ouro incorporadas em um dispositivo de memória através da deposição de filme fino de ouro por laser pulsado a $550{ }^{\circ} \mathrm{C}$ com $2 \mathrm{~Pa}$ de gás $\mathrm{O}_{2}$ sob condições de alto vácuo [63]. Neste método, no entanto, os gases contaminam os dispositivos de memória.

Outro método comum consiste em cobrir a superfície do substrato de Si com uma camada de moléculas ligantes contendo grupos funcionais, antes da deposição das nanopartículas metálicas, para imobilizá-las no substrato de Si. Essas nanopartículas metálicas possuem reatividade superficial passível de imobilização em superfícies quimicamente funcionalizadas. Por exemplo, nanopartículas de ouro ligam-se fortemente a polímeros carregados positivamente através de atrações eletrostáticas, e aos grupos funcionais de amina, tiol e fosfina através de ligação covalente. Hurst et al. usou p-aminofenil trimetoxisilano e 3mercaptopropil trimetoxisilano para imobilizar nanopartículas de ouro em substratos de silício para formar filmes monocamadas automontados (SAM - self-assembled monolayer) [64]. Os filmes SAM são preparados usando um método químico úmido simples, sem a necessidade de equipamentos caros ou sofisticados. No entanto, os filmes SAM com nanopartículas de ouro ainda são limitados pela instabilidade térmica associada a SAM orgânicos.

O spin coating é outra abordagem favorável para a deposição de nanopartículas de ouro. Yang et al. sintetizou filmes altamente ordenados com nanopartículas de ouro/sílica através da automontagem de micelas de nanopartículas de ouro e sílica, solúveis em água, usando a técnica de spin coating sol-gel [65]. Das et al. [66] produziu em substrato de Si nanopartículas de ouro não encapsuladas através do spin coating. No entanto, essa abordagem pode causar a formação de grandes gotículas de líquido devido à centrifugação. Essas gotículas de líquido afetam a uniformidade da distribuição das nanopartículas de ouro, o que pode prejudicar as propriedades de memória do dispositivo [67]. 
Langmuir blodgett é outro processo de montagem. No estudo de Li et al., as nanopartículas de ouro encapsuladas por dodecanethiol foram montadas no substrato pelo espalhamento do precipitado de nanopartículas dissolvidas em clorofórmio, que se depositaram na lâmina após a evaporação do solvente [68]. O filme fino pode ser transferido para o substrato por dip coating, processo onde um filme fino sólido é formado após evaporação da camada de solvente subjacente [69], e a densidade planar da monocamada pode ser controlada através de compressão mecânica ou expansão do filme. Langmuir blodgett é um processo simples para a preparação de matrizes ordenadas de nanopartículas metálicas, mas tem problemas em termos de controle da homogeneidade da distribuição das nanopartículas [70].

Recentemente, $\mathrm{Ng}$ et al. [26] produziu dispositivos de memória orgânica com nanopartículas de ouro. A camada ativa tem como dielétrico a matriz orgânica polimetilsilésquioxano (PMSSQ), depositada pela técnica spin coating, e as nanopartículas de ouro, formadas a partir do precursor $\mathrm{HAuCl}_{4}$, foram obtidas através do método de reação hidrotérmica sacrificial. Para a caracterização do comportamento I-V, foram produzidas estruturas Metal - Isolante - Semicondutor (MIS).

$\mathrm{O}$ estudo demonstra que quanto maior é a concentração do precursor $\mathrm{HAuCl}_{4}$ no banho hidrotérmico, maior será o tamanho da nanopartícula de ouro formada. Para a concentração de $0,01 \mathrm{M}$ de $\mathrm{HAuCl}_{4}$, referente à melhor situação relatada quanto ao comportamento de memória, foi obtida distribuição bimodal de tamanho das nanopartículas de ouro de $42 \pm 7 \mathrm{~nm}$ e $82 \pm 5 \mathrm{~nm}$. O dispositivo produzido dessa forma apresentou comportamento de memória biestável, e o mecanismo de corrente associado à transição entre os estados de condução eletrônica foi relacionado às cargas elétricas das nanopartículas de ouro. A tensão elétrica de transição do estado de baixa condutividade para o de alta condutividade foi de 2,2V. A Figura 2.1 apresenta o comportamento I-V da amostra produzida com concentração de $0,01 \mathrm{M}$ de $\mathrm{HAuCl}_{4}$. 
Figura 2.1 - Comportamento I-V da amostra produzida com concentração de 0,01 M de HAuCl4 em matriz orgânica PMSSQ [26].

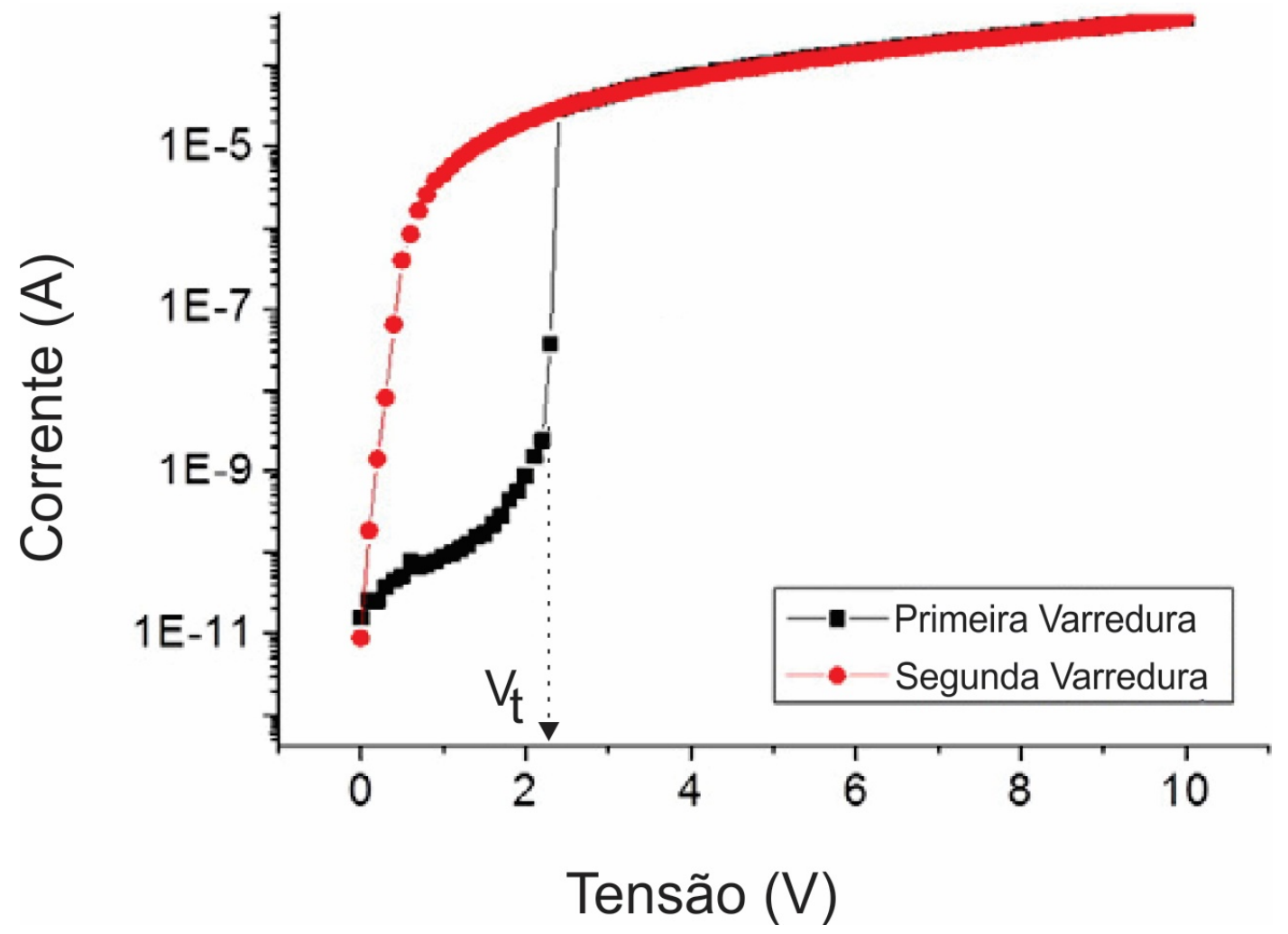

Fonte: $\mathrm{Ng}$, el al., 2016.

A curva $\mathrm{I}-\mathrm{V}$ associada à primeira varredura exibe aumento abrupto da corrente na tensão de transição $(\mathrm{Vt})$, indicando a transição biestável de um estado de baixa condutividade (estado $O F F$ ) para um estado de alta condutividade (estado $O N$ ). A transição biestável do estado $O F F$ para $O N$ é equivalente ao processo de "gravação" em um dispositivo de memória.

A curva I-V associada à segunda varredura exibe maior nível de corrente para tensões baixas $(<2,2 \mathrm{~V})$, quando comparado com o nível de corrente no mesmo intervalo de tensão da primeira varredura. Isso acontece porque as nanopartículas de ouro, dispersas aleatoriamente na camada isolante de PMSSQ, capturaram os elétrons injetados durante a primeira varredura, e por isso, desde o início da segunda varredura o dispositivo já está cheio de elétrons armazenados (estado $O N$ - alta condutividade).

Através de medidas de capacitância em função da tensão elétrica $(\mathrm{C}-\mathrm{V})$, também realizadas por $\mathrm{Ng}$ et al. [26] neste estudo, foi possível verificar que o número de elétrons armazenados pelas nanopartículas de ouro aumentou com o aumento da concentração de $\mathrm{HAuCl}_{4}$. O tamanho das nanopartículas de ouro formadas é proporcional à concentração do 
precursor $\mathrm{HAuCl}_{4}$ no banho hidrotérmico. Assim, os resultados $\mathrm{C}-\mathrm{V}$ mostraram que nanopartículas maiores armazenaram maior quantidade de carga elétrica em comparação com as menores. Por outro lado, foi constatado que o armazenamento de cargas elétricas diminuiu para nanopartículas maiores, produzidas com concentração de 0,02M de $\mathrm{HAuCl}_{4}$, quando comparado à amostra produzida com concentração de $0,01 \mathrm{M}$ de $\mathrm{HAuCl}_{4}$. Esse comportamento foi atribuído à distribuição não uniforme das nanopartículas de ouro (aglomeradas), como mostrado nas imagens de microscopia eletrônica de varredura (Figura 2.2). Conclui-se que tamanho e a uniformidade da distribuição das nanopartículas desempenham papel fundamental no armazenamento de cargas elétricas.

Figura 2.2 - Nanopartículas de ouro crescidas com variação na concentração de $\mathrm{HAuCl}_{4}$ : (a) 0,01 M e (b) 0,02 M [26].
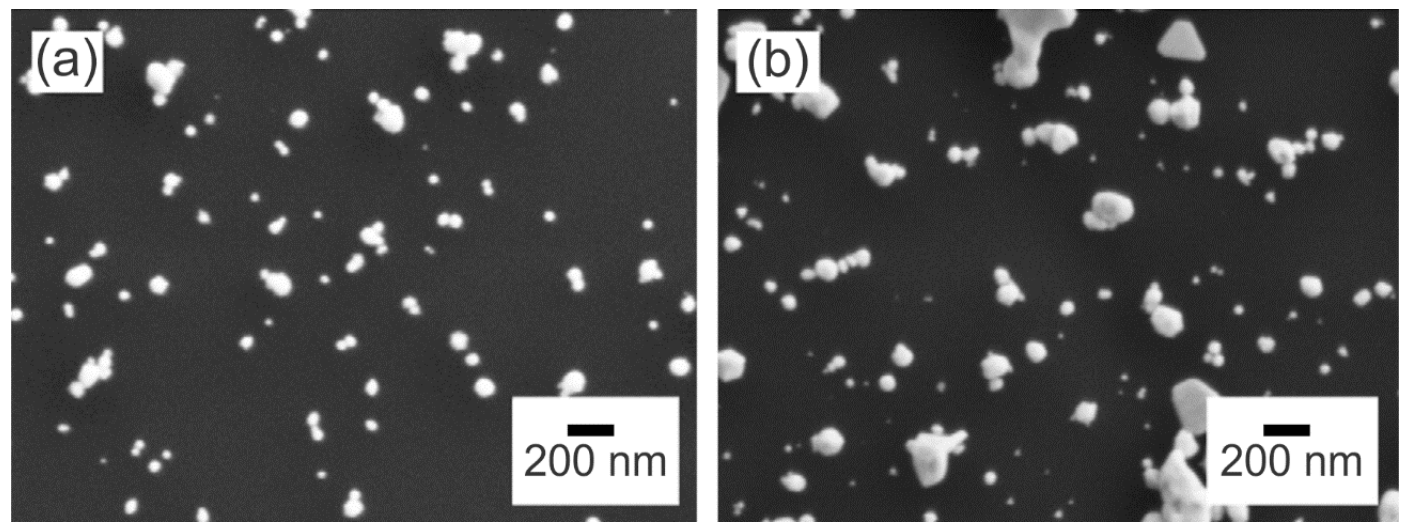

Fonte: $\mathrm{Ng}$, el al., 2016.

Tseng et al. [56] produziu um dispositivo de memória não volátil com base em nanofibras de polianilina com nanopartículas de ouro. O dispositivo possui estrutura simples que consiste de um filme fino orgânico entre dois eletrodos de alumínio (metal / isolante / metal - MIM). A camada ativa é criada pelo crescimento de nanopartículas de ouro dentro das nanofibras de polianilina usando uma reação de redox com ácido cloroáurico. A Figura 2.3 mostra que a tensão elétrica aplicada é capaz de comutar os estados de baixa e alta condutividade do dispositivo ( $O F F$ e $O N$, respectivamente), que são separados por diferença de 3 ordens de grandeza $\left(10^{-4}\right.$ a $10^{-7} \mathrm{~A}$ ) (Na Figura 2.3, A e B representam a primeira e a segunda varreduras). Após o reset do dispositivo (recuperação da memória) com aplicação de tensão negativa, o estado de baixa condutividade é reestabelecido (Na Figura 2.3, C representa a primeira varredura após a recuperação da memória). O dispositivo possui tempo 
de retenção de carga elétrica prolongado, de vários dias, depois de ter sido gravado (estado $O N)$. O mecanismo de comutação entre os estados de baixa e alta condutividade foi atribuído a transferência de carga elétrica, induzida por campo elétrico, das nanofibras de polianilina para as nanopartículas de ouro.

Figura 2.3 - Comportamento I-V do dispositivo de nanofibras de polianilina com nanopartículas de ouro: (A) primeira varredura, (B) segunda varredura e (C) primeira varredura após o reset [56].

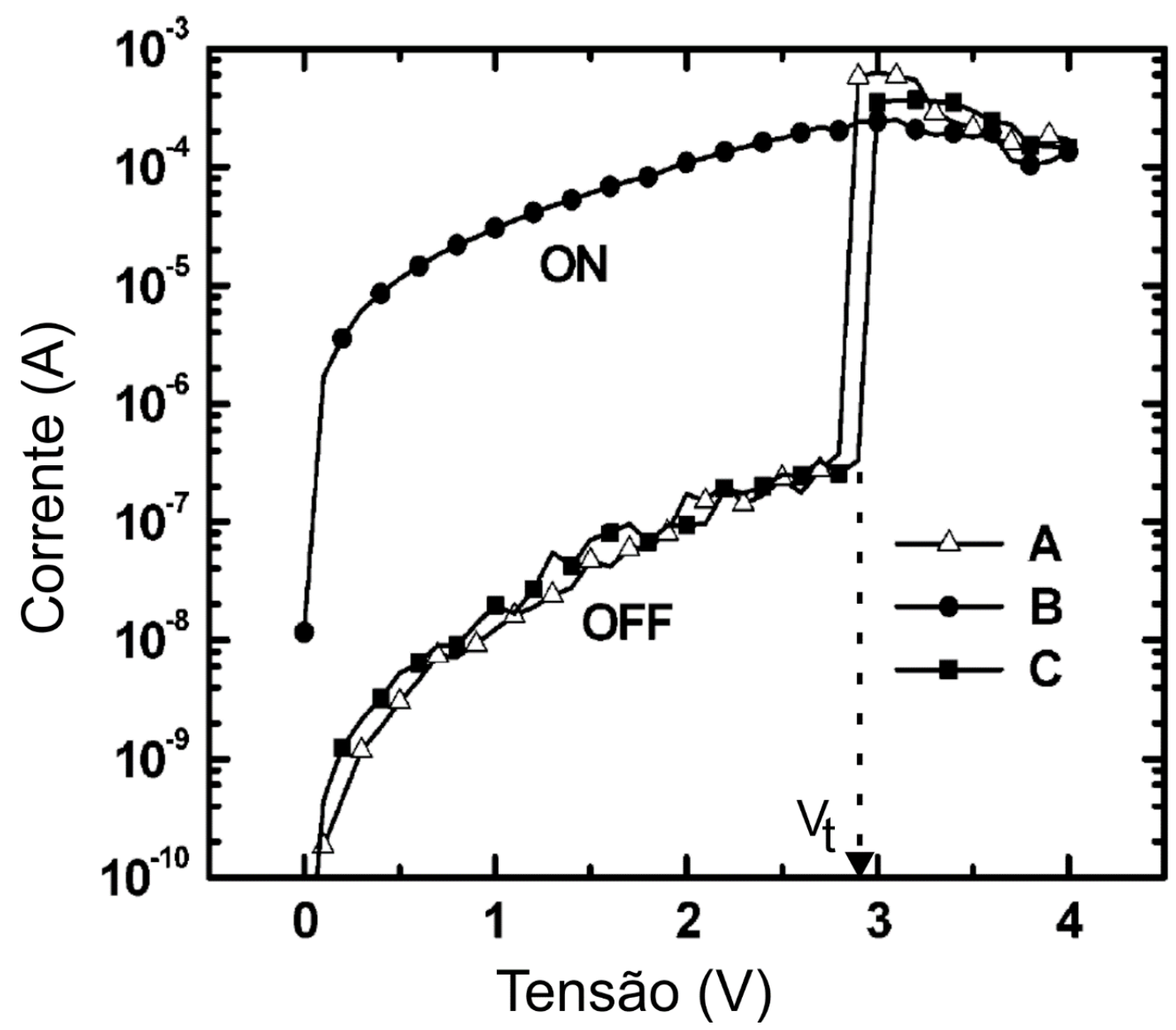

Fonte: Tseng, et al., 2005.

Aw et al. [54] fabricou um dispositivo de memória transparente e flexível com estrutura MIM constituída por: eletrodo de ouro / parileno-C - nanopartículas de ouro parileno-C / polietileno tereftalato (PET) revestido de óxido de índio-estanho (ITO). As nanopartículas de ouro foram produzidas através do método de redução de citrato, e o uso de parileno como camada dielétrica foi importante para garantir que não houvesse tensão térmica induzida no substrato flexível de ITO / PET, já que o parileno não requer cura em alta 
temperatura. Além disso, a deposição de parileno não perturba as nanopartículas de ouro depositadas.

O gráfico I-V (Figura 2.4) mostra a capacidade de armazenamento de carga elétrica e o comportamento de memória. Observa-se aumento abrupto na corrente quando 2,6 V são aplicados no eletrodo de ouro do dispositivo. Os estados de alta e baixa condutividade são separados por diferença de 4 ordens de grandeza $\left(10^{-4}\right.$ a $\left.10^{-8} \mathrm{~A}\right)$. O dispositivo fabricado por Aw et al. apresentou comportamento semelhante ao já conhecido dispositivo de memória com gravação única e leitura múltipla (write-once-read-many) e pôde ser programado com tensão de polarização positiva ou negativa. No entanto, o dispositivo de memória demonstrou estados de corrente instáveis quando curvado sob diferentes ângulos (dispositivo flexível).

Figura 2.4 - Comportamento I-V do dispositivo de parileno com nanopartículas de ouro [54].

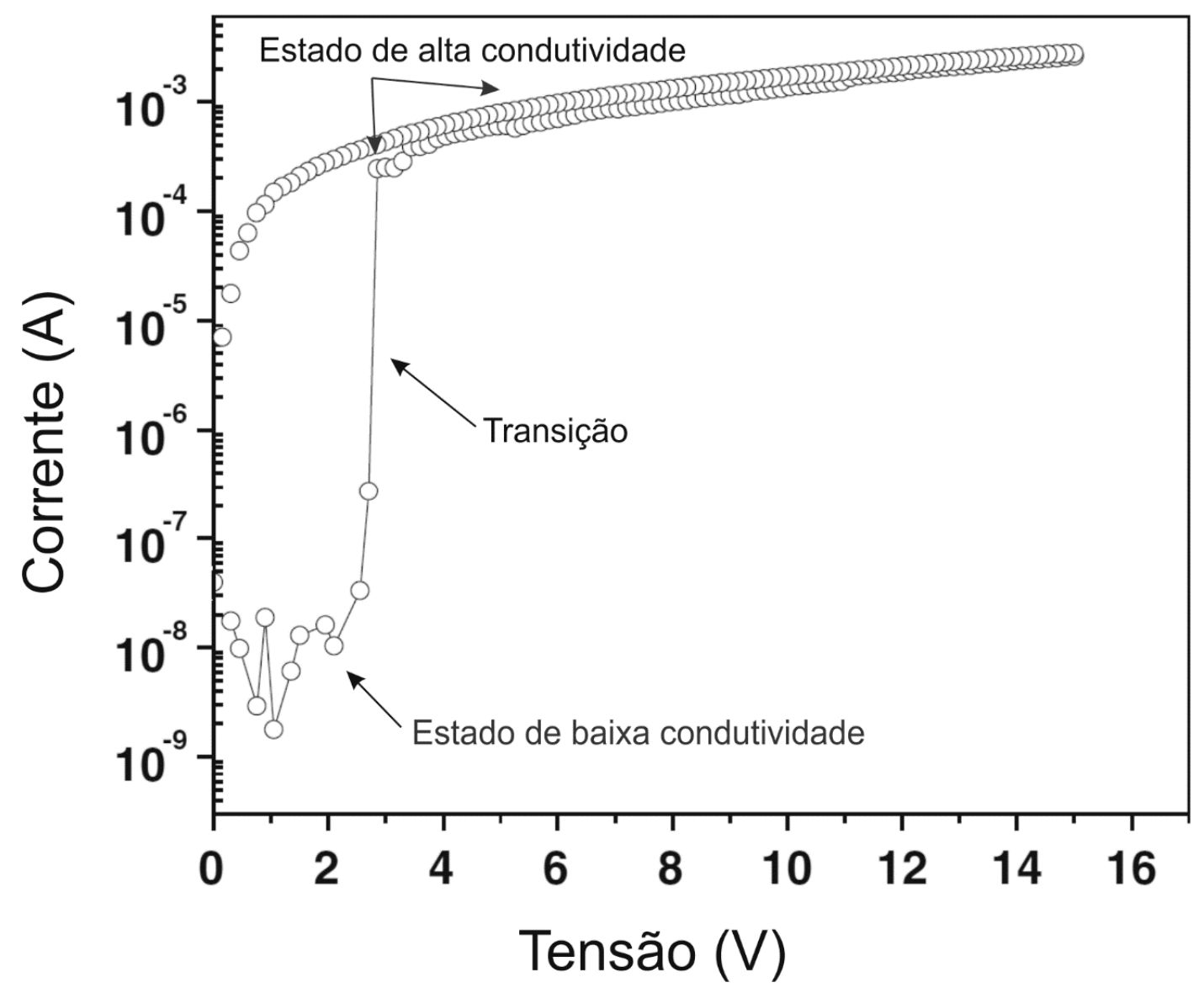

Fonte: Aw, et al., 2013. 
Neste trabalho serão utilizadas as características das nanopartículas de ouro associadas à uma camada dielétrica high- $k$, de composição $\mathrm{TeO}_{2}-\mathrm{ZnO}$, muito caracterizada em termos ópticos, porém pouco estudada quanto aos seus parâmetros elétricos. Este trabalho é pioneiro quanto à produção e caracterização de filmes de $\mathrm{TeO}_{2}-\mathrm{ZnO}$ para aplicações em memória não voláteis. Encontra motivação nos resultados anteriormente obtidos, expostos abaixo.

Vários resultados foram reportados na literatura pelo grupo do laboratório LTMFO fazendo uso desta matriz à base de $\mathrm{TeO}_{2}-\mathrm{ZnO}$; todos mostraram potencial do material para aplicações em fotônica. A matriz demonstrou-se boa hospedeira para íons de terras raras e para nucleação de nanopartículas metálicas. Foram obtidas com esta matriz amostras vítreas fabricadas pela técnica de fusão seguida de resfriamento rápido. A nucleação das nanopartículas metálicas foi sempre obtida através de tratamento térmico realizado em temperatura próxima à de transição vítrea. Por exemplo, a ação laser foi reportada em vidros de $\mathrm{TeO}_{2}-\mathrm{ZnO}$ dopados com $\mathrm{Nd}^{3+}$ [71], com limiar de potência de $8 \mathrm{~mW}$ (laser de bombeio de $806 \mathrm{~nm})$. Aumento significativo da luminescência foi verificado na presença de nanopartículas de prata em vidro de mesma composição dopado com $\mathrm{Tm}^{3+}$ [72]; efeito similar da prata foi observado para co-dopagem com $\mathrm{Yb}^{3+}$ e $\mathrm{Tm}^{3+}$ em vidros à base de $\mathrm{TeO}_{2}-\mathrm{ZnO}$ [73]. Nucleação de nanopartículas de silício foi realizada por tratamento térmico em vidros de $\mathrm{TeO}_{2}-\mathrm{ZnO}$ dopados com $\mathrm{Er}^{3+}$. Demonstrou-se então a possibilidade de técnica mais simples e mais barata para obtenção de nanocristais de silício [74] que propiciem o aumento das emissões eletromagnéticas do $\mathrm{Er}^{3+}$ nas regiões do visível e infravermelho por mecanismos de transferência de energia. A referida matriz dopada com $\mathrm{Tb}^{3+}$ e $\mathrm{Yb}^{3+}$ mostrou-se promissora para aplicações em células solares [75]. Escrita com laser de femtosegundo, para produção de guias de onda que atuem na terceira janela de telecomunicações $(\sim 1530 \mathrm{~nm})$, foi obtida em vidros de $\mathrm{TeO}_{2}-\mathrm{ZnO}$ dopados com $\mathrm{Er}^{3+}$ [76].

\subsection{Vidros de Telureto}

Os materiais, de modo geral, podem apresentar estrutura atômica com alto grau de organização, conhecida como estrutura cristalina, ou podem apresentar estrutura atômica com organização restrita a poucas unidades atômicas, conhecida como estrutura amorfa. $\mathrm{O}$ alto grau de organização característico da estrutura cristalina pode se estender até a escala macroscópica do material cristalino, assim é possível encontrar cristais com o formato tridimensional macroscópico que reflete a subjacente estrutura atômica. O material amorfo, 
por não possuir estrutura com ordenação espacial de longa distância (em termos atômicos), não exibe tal comportamento.

Os materiais amorfos são geralmente obtidos a partir do resfriamento rápido de materiais fundidos. O resfriamento rápido faz com que os átomos/moléculas percam mobilidade antes de se ordenarem, e a taxa de resfriamento empregada pode alterar as propriedades do material amorfo em formação. Desde que o material não tenha alta resistência à fusão (como cerâmicos) ou baixa energia de cristalização (como os polímeros), a preparação de um sólido amorfo deve ser extremamente rápida. Metais, por exemplo, são geralmente muito difíceis de serem preparados como sólidos amorfos, já que a taxa de resfriamento deve ser muito alta.

Vidros são materiais amorfos, e embora os vidros possam ser produzidos por uma grande variedade de métodos, a maioria continua sendo obtida pela fusão dos seus componentes em elevadas temperaturas e resfriamento rápido até a solidificação [77]. Por serem materiais amorfos, não apresentam ordem atômica de longa distância, e por isso, os átomos de um material no estado vítreo possuem arranjo similar aos átomos de um líquido. Esse arranjo será muito próximo daquele que o líquido (material fundido) tinha imediatamente antes de atingir um intervalo de temperatura conhecida como temperatura de transição vítrea (Tg, "glass transition") [78].

A Tg não corresponde a um valor definido, mas a uma faixa de valores de temperaturas, e depende da taxa de aquecimento ou resfriamento utilizada. A Tg é, mais rigorosamente, o intervalo de temperaturas em que se tem início a chamada relaxação estrutural, quando algumas propriedades como viscosidade, capacidade calorífica e expansão térmica começam a manifestar um comportamento diferente do padrão verificado até então. A relaxação estrutural ocorre em consequência do impedimento (durante a solidificação) ou desimpedimento (durante a fusão) dos movimentos das cadeias atômicas, umas em relação às outras (movimento translacional) [77].

A temperatura de transição vítrea é ainda uma temperatura característica para os vidros, e define a passagem do estado vítreo para o estado viscoelástico, através da chamada relaxação estrutural, já mencionada. Os conceitos de estado vítreo e viscoelástico são emprestados da reologia (estudo das propriedades associadas à fluidez). O termo viscoelástico descreve o comportamento de um corpo que responde elasticamente a uma força aplicada, portanto, sem apresentar uma deformação permanente. Adicionalmente, tal resposta elástica não é instantânea, devido a um componente significativo de viscosidade. Em contrapartida, o 
comportamento vítreo está associado a um corpo que não pode ser deformado nem permanente nem elasticamente, sendo mais propenso a absorver a energia e dissipá-la, quebrando-se. Quando se aquece um vidro acima da Tg o comportamento viscoelástico tem início, devido à possibilidade das cadeias atômicas escoarem umas em relação às outras dentro do vidro. Sendo assim, quando uma força é aplicada as cadeias se movimentam, mas a atração que existe entre elas fazem-nas retornar elasticamente à situação inicial, com velocidade relativamente baixa devido à elevada viscosidade. Diz-se, neste caso, que ocorre o aumento da chamada entropia configuracional do sistema, o que significa que, à medida que as unidades formadoras do vidro adquirem a capacidade de escoamento, estas podem ser encontradas em um número cada vez maior de diferentes arranjos relativos [77].

É a partir da Tg que se determina a temperatura em que deve ser feito o resfriamento até a solidificação para um posterior tratamento térmico. A própria temperatura de tratamento térmico é determinada com base na Tg. [79].

A Figura 2.5 mostra as mudanças de volume de um líquido durante a solidificação. Um líquido pode solidificar-se como material cristalino com temperatura de cristalização (Tc), ou como material vítreo com temperatura de transição vítrea $(\mathrm{Tg})$.

Figura 2.5 - Formação dos cristais e dos vidros [78].

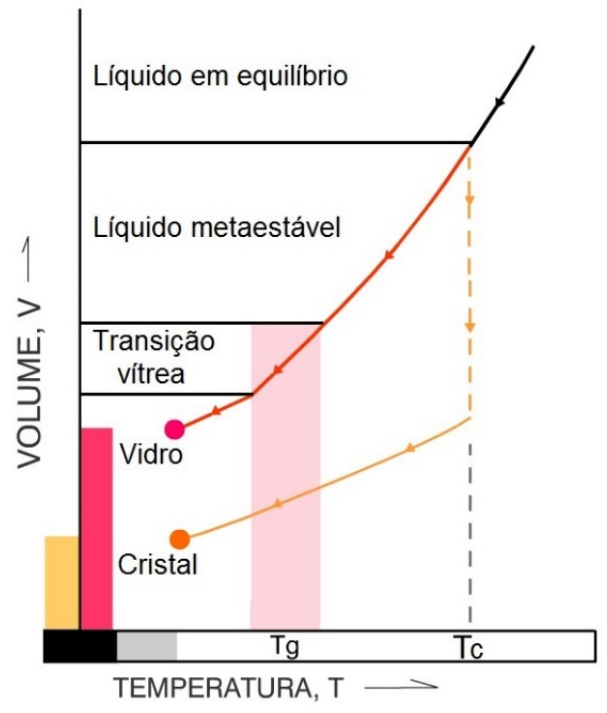

(a)

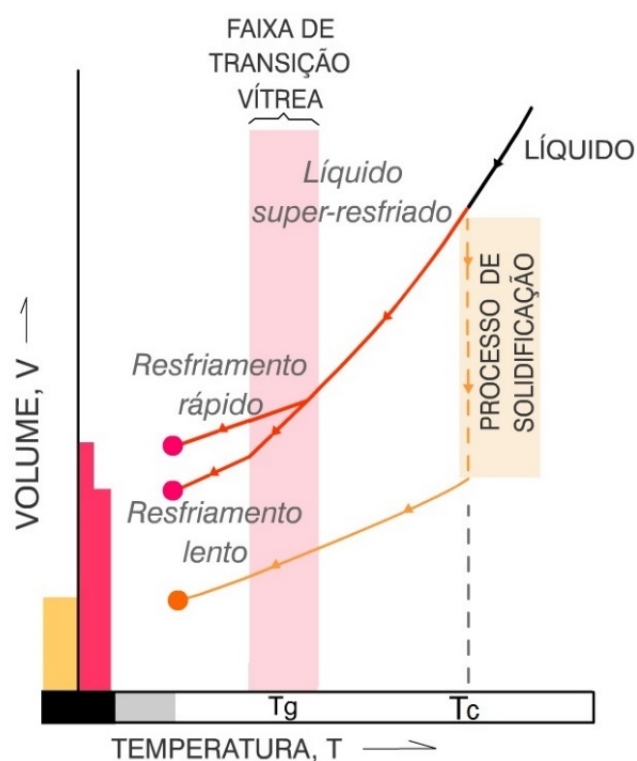

(b)

Fonte: CETEC-MG (www.cienciadosmateriais.org), 2017. 
Na Figura 2.5(a) observa-se que, em temperaturas acima de Tc, o material fundido permanece estável como líquido. Ao ser resfriado abaixo de Tc, o líquido atravessa uma região de equilíbrio metaestável, ou seja, uma situação de equilíbrio termodinâmico incipiente, podendo ceder frente a pequenas perturbações e, por exemplo, cristalizar-se. Durante o processo de cristalização, faz-se necessário certo tempo para que as pequenas unidades se orientem, até atingirem as posições adequadas para formar o cristal. É por isto que o resfriamento rápido faz com que as unidades percam mobilidade antes de se ordenarem. Durante o resfriamento, se a cristalização não ocorrer, o líquido permanecerá no estado de equilíbrio metaestável, abaixo de Tc [77].

Em muitos casos, líquidos formadores de vidros possuem alta viscosidade nas proximidades da temperatura de cristalização (Tc) e não se solidificam logo abaixo desta temperatura. Como não se solidifica, o líquido "super-resfriado" reduz seu volume (linha vermelha da Figura 2.5(b)), sendo o decréscimo de volume resultante da menor amplitude das vibrações atômicas mais restritas. A queda contínua da temperatura corresponde a um aumento crescente da viscosidade. O movimento de translação das moléculas é cada vez mais difícil até que, na faixa de temperaturas da transição vítrea, ocorra uma mudança brusca no material e sejam bloqueados os movimentos de translação das moléculas. Contudo, o volume abaixo da Tg continuará a diminuir como consequência das menores amplitudes vibracionais dos átomos em torno de suas posições fixas. A Figura 2.5(b) ilustra que o material solidificado pode adquirir características diferentes em função da taxa de resfriamento. A figura mostra que o volume final, por exemplo, é diferente para diferentes situações de resfriamento (linha vermelha). Por fim, este material rígido, cujas unidades estruturais não são mais capazes de se reorganizar como no líquido, é conhecido como vidro [78]. O vidro é, portanto, um material que se encontra numa condição de metaestabilidade, isto é, o estado mais estável de uma substância que é passível de formar vidro é o estado cristalino.

A estrutura dos sólidos amorfos não é completamente aleatória porque, na maioria deles, os átomos formam subunidades ordenadas. Isto é, existe ordem em curta distância, entre os primeiros vizinhos atômicos, mas não existe ordem em longa distância. Em outras palavras, os átomos se arranjam dentro das subunidades de modo ordenado e não aleatório, a ausência de ordem de longo alcance nos sólidos não-cristalinos acontece porque essas subunidades não se agregam de modo regular em três dimensões [78]. O conceito de ordem a curta distância pressupõe a existência de uma unidade formadora bem definida. Em um vidro de sílica, por exemplo, as cadeias são constituídas de unidades tetraédricas de $\mathrm{SiO}_{4}$, todas 
muito parecidas entre si, e ligadas umas às outras formando cadeias. Entretanto, não é possível localizar cadeias de tetraedros $\mathrm{de}^{\mathrm{SiO}_{4}}$ que estejam dispostas todas da mesma maneira, como se fossem repetições umas das outras [77].

Os vidros, de maneira geral, são compostos de óxidos, que são classificados como:

- óxidos formadores - são os compostos que sozinhos formam a estrutura básica da rede vítrea e tem caráter covalente, formam ligações muito fortes com o oxigênio, do tipo oxigênio ligante (bringing oxygen);

- óxidos modificadores - são formados, em geral, por óxidos alcalinos que tendem a fazer ligações iônicas com os ânions da rede, formam ligações do tipo oxigênio não ligante (nonbringing oxygen);

- óxidos intermediários - são compostos que podem substituir os óxidos formadores e modificadores, alterando as características do vidro [79].

Essa classificação, portanto, foi feita com base na eletronegatividade dos cátions presentes no vidro. Os cátions, cuja ligação com o oxigênio fosse algo em torno de $50 \%$ iônica e 50\% covalente, atuariam como formadores de rede. Outros, com eletronegatividade muito baixa, e cuja ligação com o oxigênio apresentasse um caráter fortemente iônico, causariam uma descontinuidade da rede, ou seja, sua quebra, sendo batizados de modificadores de rede. $\mathrm{E}$ os cátions que, por si só, não formam vidros com facilidade, mas que, misturados aos formadores típicos podem substituí-los na rede, foram classificados como intermediários [77].

A Figura 2.6 ilustra duas estruturas vítreas, uma formada apenas com o óxido formador $\mathrm{Si}-\mathrm{O}$ (a) e outra com o óxido modificador incorporado na rede $\mathrm{Si}_{-}^{-} \mathrm{O}^{-}{ }^{+}$(b). 
Figura 2.6 - Estrutura bidimensional de um vidro: (a) formado por $\mathrm{Si}-\mathrm{O}$ e (b) formado por $\mathrm{Si}^{-} \mathrm{O}^{-} \mathrm{Na}^{+}$.
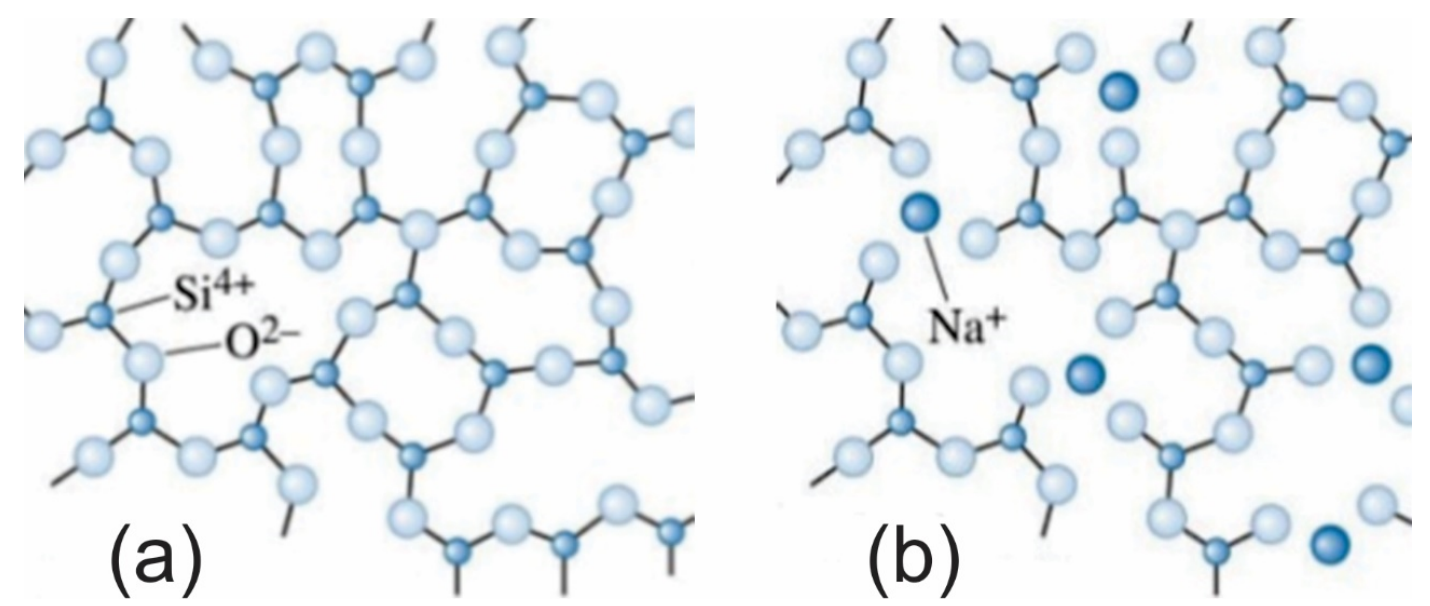

Fonte: Pessoa (pinterest.com), 2017.

Na Figura 2.6(b) nota-se a quebra da ligação Si-O-Si para a incorporação do sódio, formando estruturas do tipo $\mathrm{Si}-\mathrm{O}^{-} \mathrm{Na}^{+}$. Estas estruturas alteram as propriedades do vidro, como por exemplo, sua viscosidade, índice de refração e peso molecular.

$\mathrm{Na}$ década de 70 iniciou-se uma busca por novos materiais promissores para aplicação em dispositivos acústico-ópticos, tais como moduladores [80]. Dentre estes materiais destacaram-se os vidros de teluretos, por apresentarem boa qualidade óptica, baixa energia de fônon, quando comparados com outros vidros obtidos a partir de certos óxidos, e alta solubilidade para os óxidos $\mathrm{Er}_{2} \mathrm{O}_{3}[81,82]$. Na década de 80, os vidros de teluretos mostraramse ótimos hospedeiros para altas concentrações de íons de érbio. Com isso, foi possível a fabricação de dispositivos ópticos como fibras ópticas, amplificadores ópticos e dispositivos para sistemas de comunicações, como os lasers $[83,84,85]$.

O primeiro pesquisador a descobrir a estrutura básica de vidros de óxido de telúrio foi S. Neov, 1979, por intermédio da difração de nêutrons em um vidro de $\mathrm{TeO}_{2}-\mathrm{Li}_{2} \mathrm{O}$ [86]. As unidades básicas descobertas eram compostas por três estruturas básicas de poliedros, que incluíam átomos de telúrio com número de coordenação 4, 3+1 e 3, conforme mostrado na Figura 2.7: 
Figura 2.7 - Estruturas básicas presentes em vidros de telureto com números de coordenação 4, 3+1 e 3, respectivamente em (a), (b) e (c) [86].

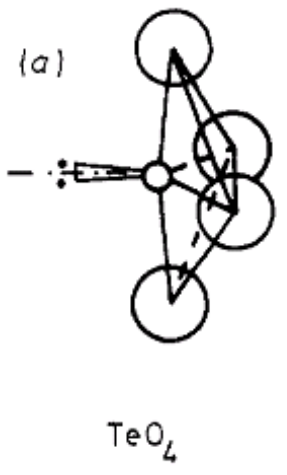

Oxigênio

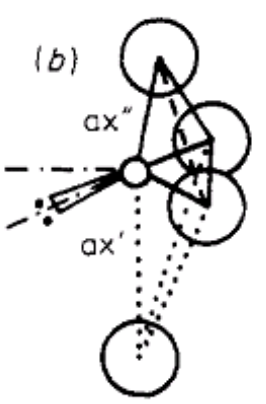

$R_{a x^{\prime}}>2 \cdot 30 \AA$

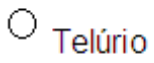

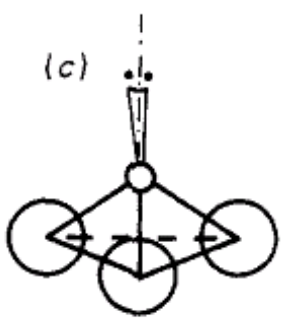

$\mathrm{TeO}_{3}$

Fonte: Neov, et al., 1980.

Estudos mais detalhados realizados por T. Sekiya em vidros binários do tipo $\mathrm{MO}_{1 / 2^{-}}$ $\mathrm{TeO}_{2}(\mathrm{M}=\mathrm{Li}, \mathrm{Na}, \mathrm{K}, \mathrm{Rb}, \mathrm{Cs}$ e $\mathrm{Tl})$, sobre a coexistência das unidades estruturais $\mathrm{TeO}_{4}$, $\mathrm{TeO}_{3+1}$ e $\mathrm{TeO}_{3}$, mostraram que as três estruturas básicas de $\mathrm{S}$. Neov podem ser obtidas através da introdução de óxidos alcalinos (óxidos modificadores) na rede, sendo elas:

- Bipirâmides trigonais $\mathrm{TeO}_{4}$ (tbp) que são compostas por 2 átomos de oxigênio axiais, dois átomos de oxigênio equatoriais e dois pares de elétrons isolados. A distância da ligação Te-O $\mathrm{O}_{\text {axial }}=2,08 \AA$, sendo maior que a ligação Te-O equatorial $=1,90 \AA$ (Figura 2.7 (a)). Neste caso não há introdução de óxido alcalino.

- Vidros com uma baixa concentração de óxidos alcalinos apresentam estruturas poliédricas assimétricas do tipo $\mathrm{TeO}_{3-1}(\mathrm{tp})$, onde a distância de uma das ligações Te$\mathrm{O}_{\text {axial }}$ apresenta maior distância (Figura 2.7 (b)).

- Em vidros com concentrações de óxidos alcalinos entre 20 e $30 \mathrm{~mol} \%$, são obtidas as estruturas $\mathrm{TeO}_{3}$, formada por três ligações curtas Te-O = 1,88 $\AA$ (Figura 2.7 (c)) $[87,88]$.

Para se obter a estrutura $\mathrm{TeO}_{3+1}$ (tp) é necessário que ocorra a quebra de ligação da estrutura bipirâmide trigonal $\mathrm{TeO}_{4}(\mathrm{tbp})$ pela adição de um óxido $\mathrm{M}_{2} \mathrm{O}$, formando um único oxigênio não ligante do tipo Te -- $\mathrm{O}^{-}$estável, conforme a Figura 2.8: 
Figura 2.8 - Formação da estrutura $\mathrm{TeO}_{3+1}$ a partir de uma estrutura $\mathrm{TeO}_{4}$.

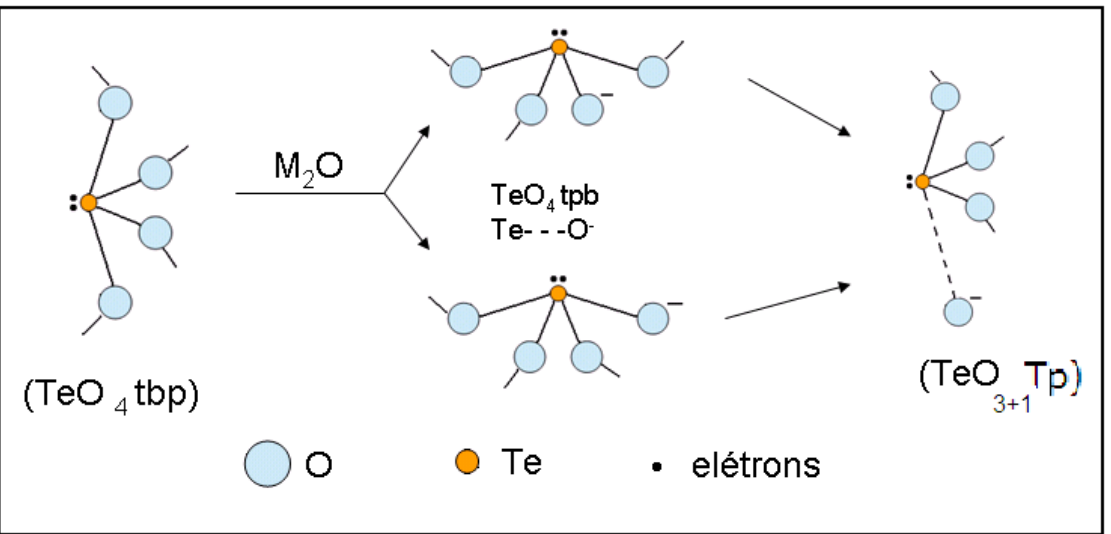

Fonte: Sakida, et al., 1999.

$\mathrm{Na}$ quebra da estrutura $\mathrm{TeO}_{4}$ pela adição de $\mathrm{M}_{2} \mathrm{O}$, existe a possibilidade da formação de estruturas Te- $\mathrm{O}_{\text {axial }}$ ou Te-O $\mathrm{O}_{\text {equatorial. }}$. Devido à estrutura $\mathrm{Te}$-- $\mathrm{O}^{-}$axial ser instável, esta se distorce e transforma-se na unidade estrutural $\mathrm{TeO}_{3+1}$, formando uma ligação oxigênio não ligante. A outra unidade que pode ser formada é a $\mathrm{Te}$-- $\mathrm{O}^{-}$equatorial que pode sofrer pequena distorção, dependendo da concentração de $\mathrm{M}_{2} \mathrm{O}[87,88]$.

A estrutura $\mathrm{TeO}_{3}$ é formada a partir do alongamento das ligações $\mathrm{Te}$-- $\mathrm{O}$ da estrutura $\mathrm{TeO}_{3+1}$ e da clivagem devido à transferência de elétrons e dos íons modificadores, conforme a Figura 2.9:

Figura 2.9 - Formação da estrutura $\mathrm{TeO}_{3}$ a partir da estrutura $\mathrm{TeO}_{3+1}$.

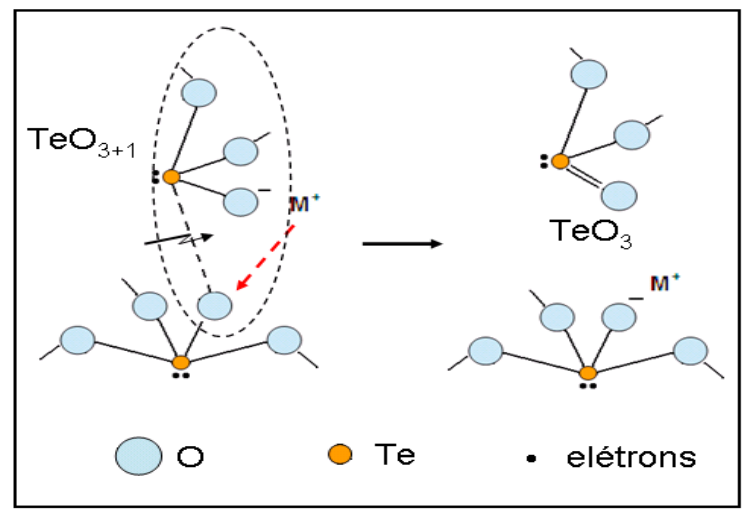

Fonte: Sakida, et al., 1999.

A estrutura $\mathrm{TeO}_{3}$ apresenta uma ligação dupla, formada devido à transferência de elétrons do íon modificador. 


\subsection{Filmes Finos}

Os filmes finos têm sido amplamente utilizados nos mais diversos setores da indústria, como cobertura de lentes, coberturas de ferramentas de corte, proteção ambiental, na indústria de semicondutores, na tecnologia de gravação de dados, entre outras. Dentre as áreas citadas, a de semicondutores foi a que teve praticamente todo o seu desenvolvimento baseado na tecnologia de filmes finos.

Os estudos sobre filmes finos tiveram início na década de 20, por pesquisadores dos laboratórios Cavendish, na Inglaterra [89,90]. Entretanto, os estudos relacionados a filmes finos ficaram praticamente estagnados até a década de 50, quando interesses industriais reanimaram as pesquisas. Nas duas décadas seguintes, o interesse por filmes finos cresceu e na década de 70 já eram bem estabelecidos os modelos teóricos de crescimento de filmes finos.

Os filmes finos podem ser preparados por vários métodos diferentes, dependendo da composição, estrutura, espessura e aplicação. Todos eles se baseiam na deposição gradual de átomos ou moléculas do material desejado sobre a superfície de outro material, que serve de apoio, chamado substrato. Dentre os métodos mais utilizados estão a deposição em alto vácuo, para filmes mais finos (de algumas camadas atômicas até $1000 \AA$ ), a deposição eletroquímica, a deposição química de fase de vapor e a epitaxia de fase líquida, para filmes mais espessos [91].

A grande evolução das técnicas de vácuo nas últimas décadas possibilitou o aperfeiçoamento dos processos de deposição de filmes muito finos. Atualmente é possível fazer vácuo em câmaras com volumes da ordem de $1 \mathrm{~m}^{3}$, atingindo rotineiramente pressões tão baixas quanto $10^{-11}-10^{-9}$ Torr (1Torr $=1 \mathrm{~mm}$ de $\mathrm{Hg}$ ). Isto possibilita fabricar filmes finos através de deposição de camadas individuais de átomos ou moléculas, uma sobre a outra, por meio de diversas técnicas. Em todas as técnicas de deposição de filmes muito finos, o processamento é feito em uma câmara de alto vácuo e consta de três etapas. Na primeira etapa os materiais que servem de matéria prima são fragmentados em átomos neutros, íons ou moléculas, por meio da ação de fontes térmicas, de plasma, de laser, ou pelo bombardeio de elétrons ou íons acelerados. Na segunda etapa, os fragmentos de matéria são transportados na direção do substrato. Finalmente, na terceira etapa, os fragmentos depositados no substrato interagem física e quimicamente entre si, nucleando e formando porções maiores de material, resultando no filme desejado. As principais diferenças entre os diversos métodos estão na 
primeira etapa. Um dos métodos mais simples é o da evaporação térmica, no qual a substância original é aquecida em alta temperatura até evaporar. O aquecimento é feito, por exemplo, por meio de corrente elétrica em um fio ou elemento resistivo de material que suporte altas temperaturas, como o tungstênio. Este método é utilizado para depositar filmes simples de metais ou substâncias simples, para fazer espelhos ou contatos metálicos, por exemplo [91].

\subsubsection{Processos para Produção de Filmes Finos}

O processo de formação dos filmes finos pode ser dividido em duas classes [92]:

1) A formação do filme se dá a partir do próprio substrato, por meio de reação química com o reagente que se encontra na superfície do substrato.

2) A formação do filme ocorre sem reação com o substrato, sendo esta classe dividida em três grupos:

- Deposição em fase líquida (LPD - Liquid Phase Deposition);

- Deposição química em fase de vapor (CVD - Chemical Vapor Deposition);

- Deposição física em fase vapor (PVD - Physical Vapor Deposition).

Dentre os filmes que se formam a partir do próprio substrato, um bom exemplo é a oxidação do silício. Esta ocorre em um forno à alta temperatura, onde existe fluxo de oxigênio (oxidação seca) ou ainda de vapor d'água (oxidação úmida). Devido à presença de um desses gases na atmosfera do forno e à alta temperatura, ocorre o consumo de silício para a formação do óxido de silício $\left(\mathrm{SiO}_{2}\right)$.

Dentre os processos onde ocorre a formação do filme sem reação com o substrato, está o LPD. Dentro das técnicas de LPD estão a spin-coating e a dip-coating. O spin-coanting é realizado a partir do gotejamento de um líquido sobre a superfície do substrato e sua posterior centrifugação para a uniformização do filme. Já a técnica dip-coating é realizada através da imersão do substrato no líquido que produzirá o filme. Neste caso, o substrato é retirado da imersão à taxa constante, o que determina a espessura do filme depositado.

No processo CVD ocorrem reações químicas em fase de vapor. Para o mesmo são utilizados gases precursores, que com a aplicação de energia (térmica, magnética, etc.) reagem produzindo o filme a ser depositado, sobre a superfície do substrato (reação heterogênea), e não no ambiente da câmara (reação homogênea). No processo CVD, é 
importante que os subprodutos da reação sejam voláteis, para que esses possam ser eliminados da câmara de deposição pelo sistema de bombeio. O processo CVD depende de muitos parâmetros, sendo que a variação de alguns desses determina o tipo de CVD. Dentre os principais tipos de CVD estão:

- $\mathrm{APCVD}$ (atmospheric-pressure CVD);

- $\quad$ LPCVD (low-pressure CVD);

- PECVD (plasma-enhanced CVD);

- LECVD (laser-enhanced CVD);

- HDPCVD (high-density plasma CVD).

Por fim, o último grupo de deposições para os quais não ocorrem reações com o substrato é o PVD, que tem duas técnicas principais: a evaporação e o sputtering. Na evaporação, o material a ser depositado é evaporado para a superfície do substrato. Para isso, é necessário que tanto o material do filme quanto o substrato estejam em alto-vácuo. Neste caso, o material a ser depositado é aquecido (termicamente, por laser, feixe de elétrons, etc.) até alcançar a temperatura de evaporação. O material é então depositado em todas as direções de forma rápida, devido ao grande livre caminho médio dentro da câmara de vácuo [33]. A técnica de sputtering será vista com detalhes na seção seguinte, pois foi utilizada para a produção dos filmes deste trabalho.

\subsubsection{Deposição por Sputtering}

O princípio de funcionamento do equipamento de deposição por sputtering (ou vaporização catódica) baseia-se no bombardeamento de íons (em geral íons de argônio) sobre a superfície de um alvo (material que se quer depositar). Esses íons, ao colidirem com o alvo, podem sofrer diversos processos. Dentre esses processos está a ejeção de átomos do alvo, que se espalham por todas as direções. Esse tipo de espalhamento gera uma distribuição esférica a partir do alvo. Essa é uma característica importante do processo de deposição e deve ser levada em conta ao se planejar a uniformidade do filme. A Figura 2.10 apresenta um eletrodo, onde o alvo é acondicionado, utilizado na construção de um sistema para deposição por sputtering. 
Figura 2.10 - Eletrodo usado na construção de um equipamento para deposição por sputtering.

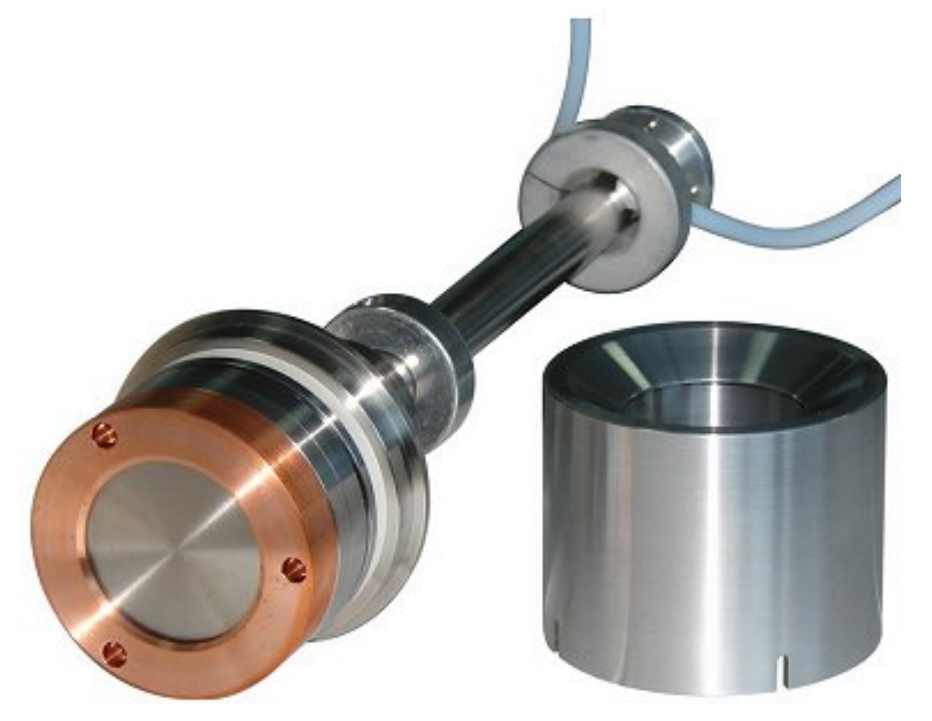

Fonte: da Silva, 2012.

Antes de iniciar o processo de deposição é feito vácuo na câmara, e esta permanece em baixa pressão (tipicamente igual ou menor que $10^{-5}$ Torr) para eliminar gases residuais e vapor d'agua. Em seguida o gás de processo é injetado na câmara. Gases reativos também podem ser injetados. A pressão da câmara aumenta e permanece na ordem de $10^{-3}$ Torr, formando uma atmosfera favorável à formação do plasma. Para a obtenção dos íons é então necessária a geração do plasma, que pode ser obtido por dois métodos principais: o método de corrente contínua - DC (utilizado principalmente para vaporizar metais) e o método de corrente alternada - via RF (mais adequado para materiais isolantes) $[93,94,95]$. No método DC, uma fonte de corrente contínua possibilita a geração do plasma, já no método via RF, uma fonte de corrente alternada. Nos dois casos, o responsável pelo bombardeamento do alvo pelos íons é a diferença de tamanho entre o eletrodo do alvo e o eletrodo do substrato, sendo que o eletrodo do alvo é bem menor que o eletrodo do substrato. A diferença de tamanho proporciona uma densidade de cargas muito maior no alvo, o que gera a criação de um potencial na superfície do alvo, produzindo a chamada bainha do plasma. Essa bainha é responsável pelo processo de bombardeamento, pois quando um íon entra nessa região, este sente grande força em direção ao alvo, provocando a aceleração do íon nesta direção.

A deposição de filmes finos pela técnica RF sputtering, criada com o propósito de fazer deposição de materiais isolantes, é largamente utilizada devido a sua relativa simplicidade, especialmente quando comparada com outras técnicas. Além disso, baseia-se na 
utilização de alvos sólidos, que são bem menos perigosos que os gases tóxicos/pirofóricos usualmente empregados em outras técnicas. Os aperfeiçoamentos recentes na técnica de deposição por sputtering a tem tornado cada vez mais poderosa, contribuindo para disseminar seu uso no processamento de dispositivos eletrônicos, tanto na pesquisa em laboratório quanto em plantas industriais.

Assim, a deposição por sputtering é uma técnica assistida por plasma, que pode ser definida basicamente como uma coleção de átomos ou moléculas ionizados além de partículas neutras. Os íons são acelerados em direção ao alvo por uma diferença de potencial e, por transferência de momento, as partículas da superfície do alvo são extraídas e "pulverizadas" sob a forma de vapor [96], como ilustra a Figura 2.11:

Figura 2.11 - Diagrama esquemático de um sistema de sputtering com demonstração da formação dos íons, bombardeamento do alvo e os gases de processo.

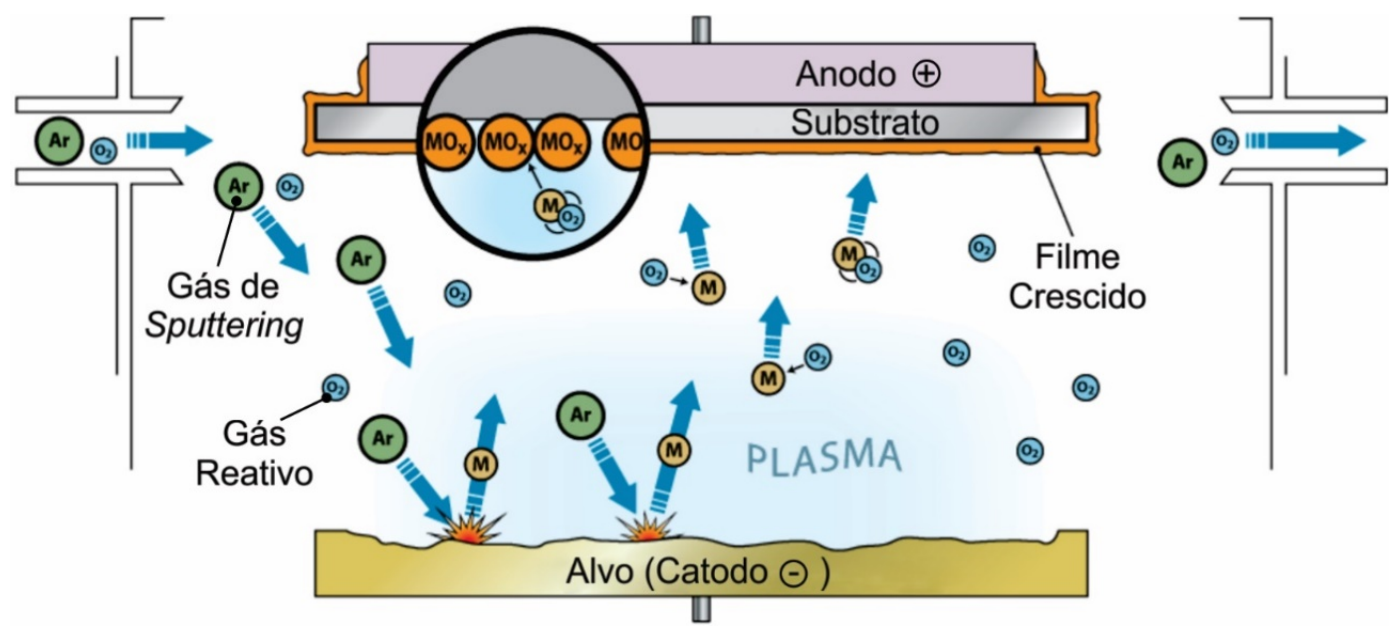

Fonte: clearmetalsinc.com, 2017.

Na Figura 2.11 é possível perceber que, além do gás de sputtering (no caso Ar), é também possível injetar na câmara um gás reativo (no caso $\left.\mathrm{O}_{2}\right)$. Esse gás reativo poderá reagir com o material "pulverizado" do alvo e criar novas espécies químicas para a formação do filme. No caso da Figura 2.11 o oxigênio $\left(\mathrm{O}_{2}\right)$ reage com o material proveniente do alvo $(\mathrm{M}) \mathrm{e}$ gera uma nova espécie química que formará no substrato um filme de material diferente $\left(\mathrm{MO}_{\mathrm{x}}\right)$ daquele do alvo $(\mathrm{M})$. Assim, em função do tipo de filme esperado e da composição do alvo, há necessidade de injeção de gases reativos.

Para deposição de filmes de óxidos, o gás $\mathrm{O}_{2}$ é utilizado juntamente com o gás Ar para compensar o oxigênio perdido durante o sputtering [97]. A razão para isso é que a taxa de 
sputtering é diferente para cada elemento químico. Por exemplo, a taxa de átomos de chumbo removidos por íon incidente (sputter yield) é três vezes maior que a do germânio [98].

\subsubsection{Deposição por Co-sputtering}

$\mathrm{Na}$ deposição por co-sputtering existem dois ou mais alvos a serem depositados, diferentemente do sputtering, no qual a deposição se dá a partir de um único alvo. No decorrer da deposição, o filme formado no substrato é proveniente da composição dos elementos dos diversos alvos, e a estequiometria do filme depende dos parâmetros usados durante o processo de deposição. A Figura 2.12 demonstra um sistema de deposição por cosputtering. Neste caso, é possível a deposição independente do material oriundo de cinco alvos.

Figura 2.12 - Sistema para deposição por co-sputtering.

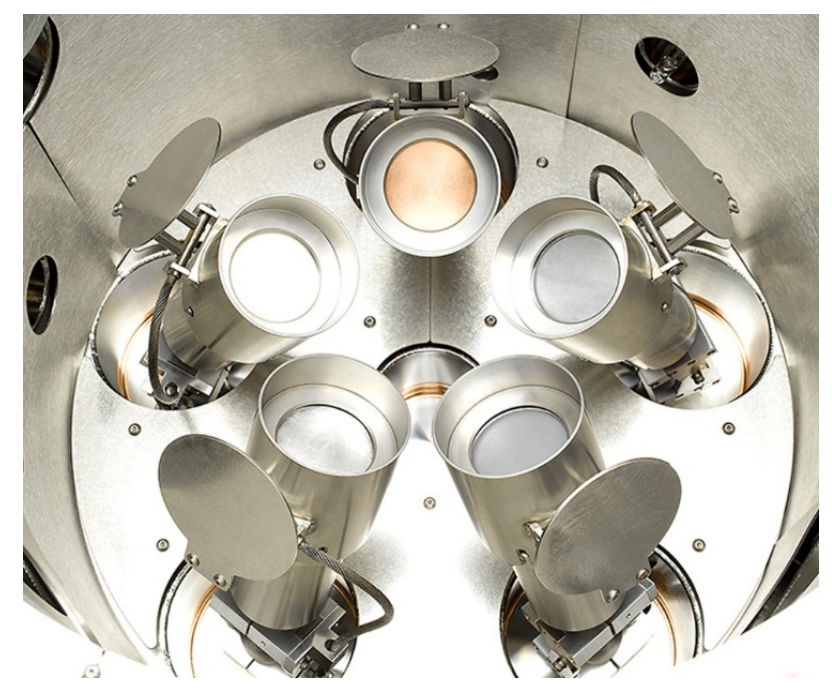

Fonte: PVD Products, 2017.

\subsubsection{Magnetron Sputtering}

Em um sistema de sputtering convencional, a diferença de potencial é aplicada entre o alvo e o substrato, fazendo com que as reações de ionização ocorram por toda câmara, como é mostrado esquematicamente na Figura 2.13(A). Neste caso, muitos dos íons formados não alcançam a superfície do alvo, o que resulta em baixas taxas de deposição. Além disso, os átomos perdem energia em sua trajetória até o substrato devido às colisões com o plasma, 
comprometendo a aderência do filme. Outro inconveniente é o aquecimento do substrato, uma vez que os elétrons secundários são continuamente acelerados em direção a ele [99].

O magnetron sputtering representa uma melhoria do equipamento sputtering pela adição de um ímã permanente, ou de um eletroímã, colocado no eletrodo do alvo, que confina o plasma em um anel circular junto à superfície do alvo, como é mostrado esquematicamente na Figura 2.13(B). Essa adição proporciona a geração de um campo magnético que se encontra perpendicular ao campo elétrico do RF, causando aumento da densidade do plasma. O aumento da densidade é causado pelo espiralamento da trajetória dos elétrons e íons que se encontram na região do alvo. Esse fenômeno provoca o aumento da probabilidade de ionização, gerando assim mais pares elétrons-íons. Devido a esse aumento, a pressão em que ocorre o processo de sputtering pode ser menor, já que em baixas pressões o processo cessa devido à baixa taxa de ionização. Com a diminuição da pressão do processo, o livre caminho médio das partículas aumenta, o que proporciona um significativo aumento na taxa de deposição, tornando o Magnetron Sputtering RF uma excelente técnica para a deposição dos mais variados materiais.

Figura 2.13 - Cinética de partículas: (A) sputtering convencional e (B) magnetron sputtering.

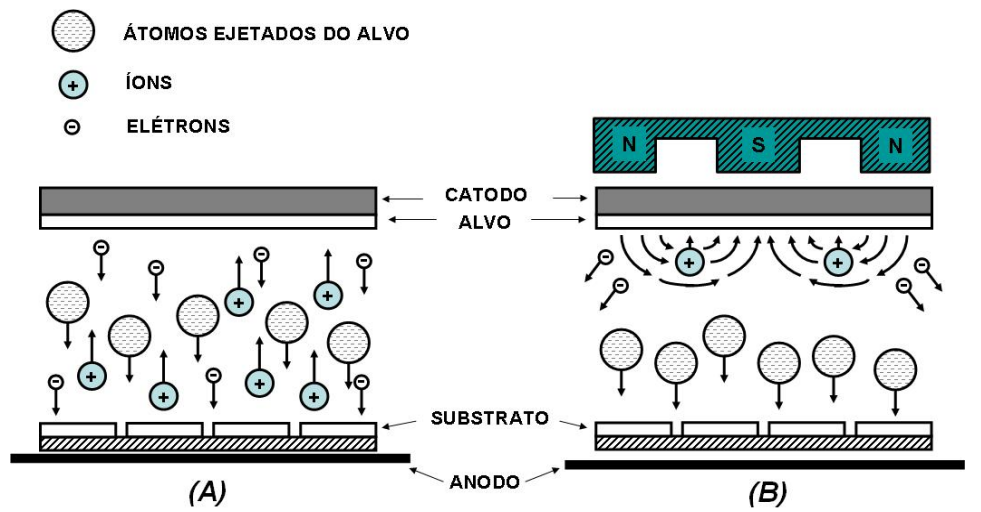

Fonte: Del Cacho, 2010.

A Figura 2.14 ilustra duas situações reais da configuração do plasma no (A) sputtering convencional e no (B) magnetron sputtering. 
Figura 2.14 - Configuração do plasma: (A) Sputtering convencional (B) Magnetron Sputtering.

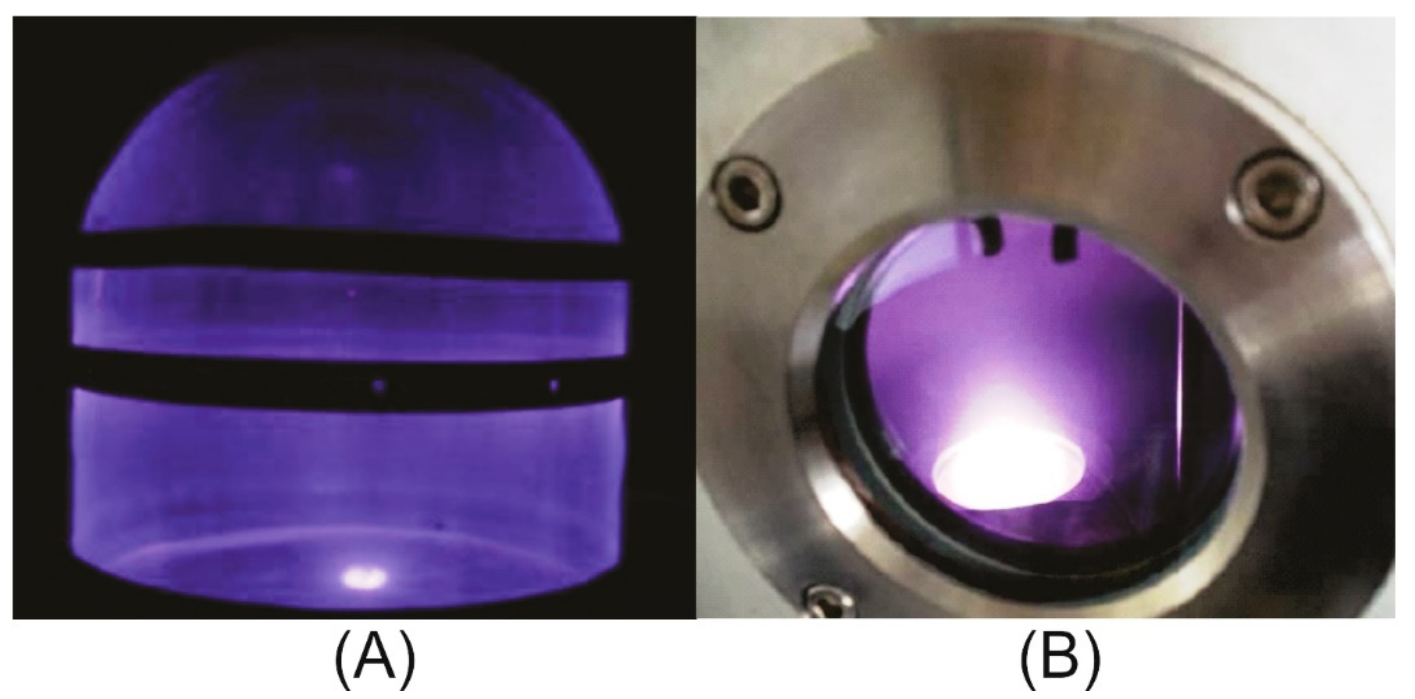

Fonte: Del Cacho, 2010.

Fica evidente na Figura 2.14(A) que o plasma se distribui por toda a câmara de deposição. Por outro lado, na Figura 2.14(B), existe o confinamento do plasma na região imediatamente acima do alvo.

\subsection{Propriedades Elétricas}

\subsubsection{Capacitor MOS}

O capacitor MOS diferencia-se de um capacitor de placas paralelas comum, pois ao invés de ser composto por dois metais separados por um isolante, ele possui um material semicondutor no lugar de um dos metais. Com a substituição de um metal por um semicondutor, é produzida uma nova capacitância que é adicionada à estrutura, o que produz uma série de peculiaridades $[100,101]$ com um grande interesse prático, tal como a construção de transistores MOS, que utilizam como base o capacitor MOS.

Para a compreensão do funcionamento do dispositivo é necessária a análise dos três regimes de operação do capacitor MOS: acumulação, depleção e inversão. Duas tensões de porta $\left(V_{G}\right)$ definem a mudança de um regime de operação para o outro, denominadas: tensão de banda plana $\left(V_{F B}\right)$ e tensão de limiar $\left(V_{T}\right)$. Na tensão de banda plana ocorre a ausência de encurvamento de bandas no semicondutor, e no caso de um capacitor ideal (sem cargas no óxido, $\left.Q_{S s}=0\right)$ é representada pela diferença entre a função trabalho do metal da porta $\left(\phi_{M}\right)$, e a 
função trabalho do silício $\left(\phi_{s i}\right)$. Enquanto $V_{F B}$ define a mudança do regime de acumulação para o de depleção, $V_{T}$ é a tensão que define a mudança do regime de operação do capacitor de depleção para inversão. A Figura 2.15 mostra o diagrama de cargas espaciais no capacitor MOS para o caso de um capacitor tipo $p$, ou seja, o silício é dopado com impurezas aceitadoras $\left(N_{A}\right)$.

Figura 2.15 - Diagrama de cargas espaciais para um capacitor PMOS: a) acumulação b) depleção e c) inversão.

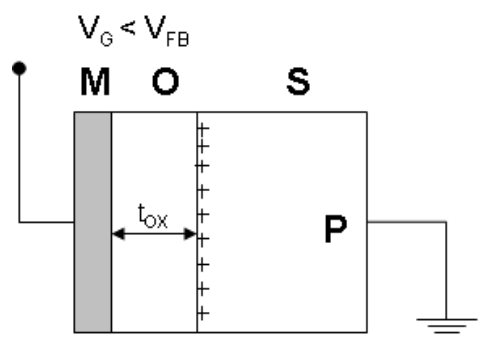

(a)

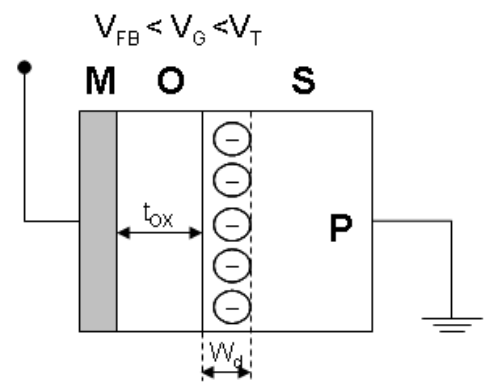

(b)

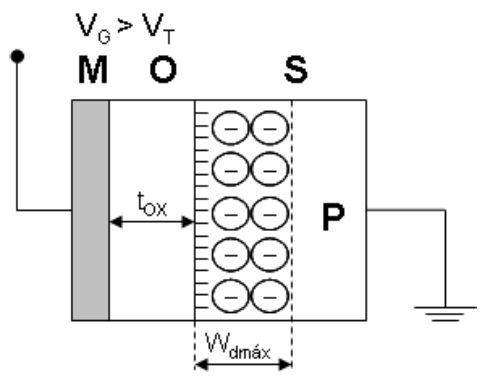

(c)

Fonte: Hora, 2008.

Na Figura 2.15, $t_{o x}$ representa a espessura do óxido, $W_{d}$ a largura da região de depleção e $W_{\text {dmáx }}$ a largura máxima que a região de depleção atinge. É possível observar através da Figura 2.15 o que ocorre com as cargas em cada um dos regimes. Na acumulação as cargas majoritárias, ou seja, cargas do mesmo tipo da dopagem do substrato (nesse caso lacunas), formam uma fina camada no semicondutor junto à interface semicondutor-óxido, devido à tensão na porta ser inferior à tensão de banda plana $\left(V_{G}<V_{F B}\right)$. Durante o regime de depleção $\left(V_{F B}<V_{G}<V_{T}\right)$ ocorre a depleção dos portadores majoritários do semicondutor, e como a dopagem é aproximadamente uniforme em todo o semicondutor, à medida que $V_{G}$ aumenta, $W_{d}$ também aumenta, já que ocorre a depleção em maior profundidade. Contudo, o aumento da região de depleção tem um valor máximo denominado $W_{d m a ́ x}$. A partir deste ponto, o incremento da tensão $V_{G}$ resulta no acúmulo de cargas minoritárias do semicondutor junto à interface semicondutor-óxido, entrando assim no regime de inversão, onde $V_{G}>V_{T}$.

Devido à variação de cargas no semicondutor, a capacitância total varia conforme a distribuição das mesmas. A Figura 2.16 representa a capacitância do óxido $\left(C_{o x}\right)$ e a capacitância do silício $\left(C_{S i}\right)$ de um capacitor MOS [101]. 
Figura 2.16 - Representação da capacitância do óxido $\left(C_{o x}\right)$ e da capacitância do silício $\left(C_{S i}\right)$ de um capacitor MOS.

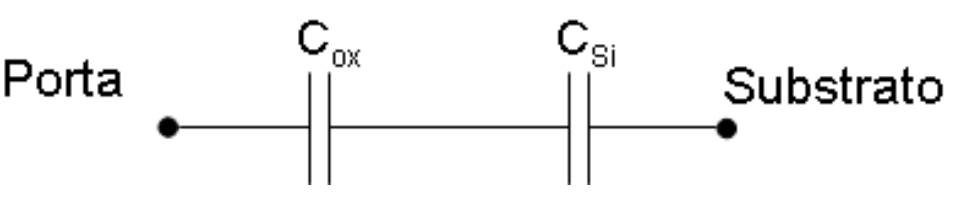

Fonte: Hora, 2008.

A capacitância do óxido $C_{o x}$ é obtida através da equação (2-1), enquanto a capacitância do silício $C_{S i}$ varia de acordo com o regime de operação em que o capacitor MOS se encontra [101].

$$
\mathrm{C}_{\mathrm{ox}}=\frac{\varepsilon_{\mathrm{o}} \varepsilon_{\mathrm{ox}} \mathrm{A}}{\mathrm{t}_{\mathrm{ox}}}
$$

$\mathrm{Na}$ equação (2-1), $\varepsilon_{o}$ representa a permissividade elétrica do vácuo $\left(8,84 \times 10^{-14} \mathrm{~F} / \mathrm{cm}\right)$, $\varepsilon_{o x}$ representa a permissividade elétrica do óxido (também conhecido por k), $A$ representa a área do capacitor e $t_{o x}$ a espessura do óxido. A permissividade elétrica é a grandeza física que indica a quantidade de carga elétrica armazenada em um material para um dado campo elétrico, sendo um indicador da eficácia do material quando este armazena energia. Em um capacitor, por exemplo, a alta permissividade do dielétrico faz com que uma mesma quantidade de carga elétrica seja armazenada com um campo elétrico menor e, portanto, a um potencial menor, elevando a capacitância.

Devido a associação série das capacitâncias $C_{o x}$ e $C_{S i}$, conforme mostrado na Figura 2.16, o valor da capacitância total $\left(C_{T}\right)$ é dado pela equação (2-2):

$$
\mathrm{C}_{\mathrm{T}}=\frac{1}{\frac{1}{\mathrm{C}_{\mathrm{ox}}}+\frac{1}{\mathrm{C}_{\mathrm{Si}}}}
$$

$\mathrm{Na}$ acumulação o comportamento do capacitor MOS é o mesmo de um capacitor de placas paralelas, ou seja, $C_{T}=C_{o x}$. Contudo, durante o regime de depleção, ocorre mudança no potencial dentro do semicondutor devido à região de depleção. Nessa situação $C_{s i}=C_{D}$, onde $C_{D}$ é a capacitância de depleção dada pela equação (2-3). 


$$
C_{D}=\frac{\varepsilon_{\mathrm{o}} \varepsilon_{\mathrm{Si}} \mathrm{A}}{\mathrm{W}_{\mathrm{d}}}
$$

$\mathrm{Na}$ equação (2-3), $\varepsilon_{S i}$ representa a permissividade relativa do silício $(11,7)$ e $W_{d}$ a largura da região de depleção, que varia de acordo com $V_{G}$.

Já no regime de inversão, um potencial devido à região de inversão é adicionado ao silício, ou seja, $C_{S i}=C_{D}+C_{I}$, onde $C_{I}$ é a capacitância devido a inversão. Substituindo esta expressão na equação (2-2), a equação (2-4) é obtida:

$$
\mathrm{C}_{\mathrm{T}}=\frac{1}{\frac{1}{\mathrm{C}_{\mathrm{ox}}}+\frac{1}{\mathrm{C}_{\mathrm{D}}+\mathrm{C}_{\mathrm{I}}}}
$$

Conforme mencionando anteriormente, existe mudança na capacitância total do dispositivo com a alteração do regime de operação do capacitor, que por sua vez depende da tensão $V_{G}$ aplicada. Essa variação da capacitância em função de $V_{G}$ gera a curva C-V característica do capacitor MOS. A Figura 2.17 mostra as curvas C-V em baixa frequência (BF) e alta frequência (AF).

Figura 2.17 - Curva C-V em baixa frequência (BF) e alta frequência (AF) de um capacitor MOS.

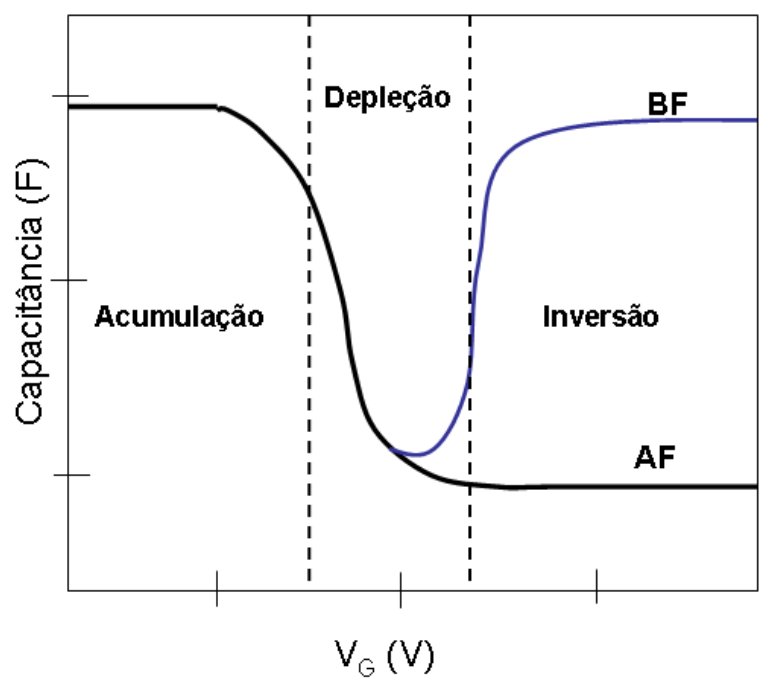

Fonte: Hora, 2008. 
Como pode ser notado na Figura 2.17, existem dois tipos de curva C-V: a realizada em baixa frequência $(\mathrm{BF})$ e a realizada em alta frequência (AF) [101]. De uma maneira simples, na medida $\mathrm{C}-\mathrm{V}$ em alta frequência os portadores minoritários, responsáveis pelo aparecimento da região de inversão, não respondem à alta frequência. Assim, a região de inversão não responde, a capacitância de inversão não aparece com o aumento de $V_{G}$, e a capacitância do silício é simplesmente representada pela capacitância de depleção $\left(C_{S i}=C_{D}\right)$. No caso da curva $\mathrm{C}-\mathrm{V}$ em baixa frequência, existe o surgimento da camada de inversão, e assim $C_{S i}=C_{D}$ $+C_{I}$. Vale ressaltar que foi dado tratamento simples com relação às curvas $\mathrm{C}-\mathrm{V}$ BF e C-V AF. Para a compreensão mais detalhada do que ocorre na curva $\mathrm{C}-\mathrm{V}$ AF é necessário um maior detalhamento com relação ao comportamento da curva $[102,103]$.

\subsubsection{Equações Básicas do Capacitor MOS}

Essa seção tem o objetivo de mostrar o equacionamento básico de um capacitor MOS para a obtenção de alguns parâmetros importantes. Um dos primeiros parâmetros que devem ser extraídos de uma curva C-V AF é a resistência série $\left(R_{s}\right)$, que pode surgir de diversas fontes tais como: contatos elétricos durante a medida, resistência do substrato e presença de filme contaminante no contato entre a lâmina e o equipamento de medida. A resistência série, dependendo do valor, produz uma grande interferência na medida no regime de acumulação. Desse modo é necessária a sua correção, o que é realizado ao se considerar a capacitância medida $\left(C_{m a}\right)$ e a condutância medida $\left(G_{m a}\right)$. O modelo físico equivalente ao modelo medido é indicado na Figura 2.18.

Figura 2.18 - Modelo utilizado para o cálculo de $R s$.

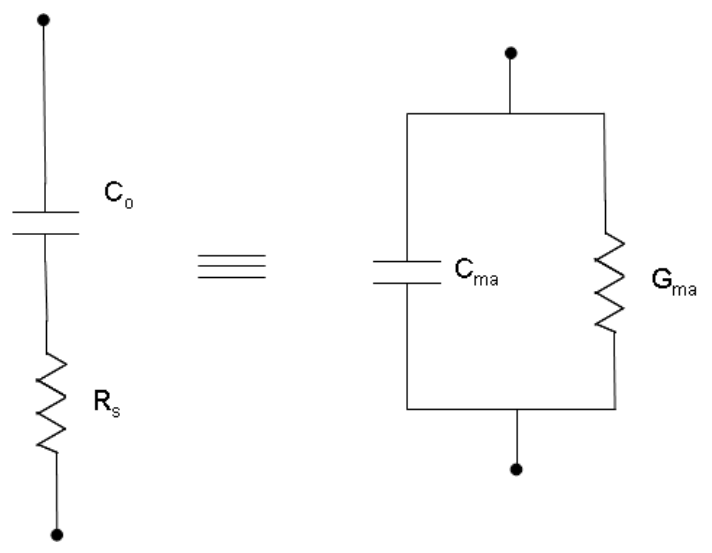

Fonte: Rajab, 2006. 
Pelo modelo, o cálculo de $R_{S}$ é obtido através da equação (2-5) [103].

$$
R_{s}=\frac{G_{m a}}{{G_{m a}}^{2}+\left(\omega C_{m a}\right)^{2}}
$$

onde

$$
\omega=2 \pi f
$$

Na equação (2-6), $f$ é a frequência em que a medida $\mathrm{C}-\mathrm{V}$ é realizada.

Contudo, o modelo real dos dispositivos inclui a admitância $\left(Y_{c}\right)$ em paralelo à capacitância do óxido. Essa admitância se deve ao fato de o óxido do capacitor não ser perfeito, permitindo a passagem de corrente de fuga. $\mathrm{O}$ modelo utilizado para o cálculo de $Y_{c}$ é mostrado na Figura 2.19.

Figura 2.19 - Modelo utilizado para o cálculo de $Y_{c}$.

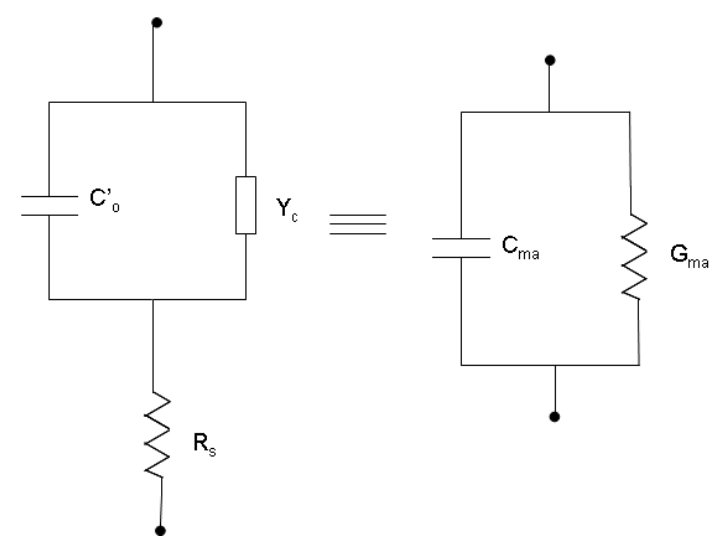

Fonte: Rajab, 2006.

A admitância $\left(Y_{c}\right)$ é dada pela equação (2-7), que segue [103].

$$
Y_{c}=\sqrt{\omega C^{\prime}{ }_{o}\left(-\omega C^{\prime}{ }_{o}+\omega C_{m a}\left(1+\frac{G_{m a}{ }^{2}}{\left(\omega C_{m a}\right)^{2}}\right)\right)}
$$


Na equação (2-7), $C^{\prime}{ }_{o}$ é dado pela equação (2-8) [103].

$$
C_{o}^{\prime}=\frac{C_{m a}\left(\left(\omega C_{m a}\right)^{2}+G_{m a}{ }^{2}\right)}{\left(\omega C_{m a}\right)^{2}+\left(G_{m a}-R_{s}\left(\left(\omega C_{m a}\right)^{2}+G_{m a}{ }^{2}\right)\right)}
$$

A admitância é um parâmetro que demonstra a qualidade dos capacitores MOS, pois quanto maior seu valor, melhor é o desempenho do capacitor, já que em condições ideais não deveria existir corrente através do isolante do capacitor [100,103].

\subsubsection{Memória Não Volátil}

A memória não volátil é capaz de reter informações armazenadas mesmo quando energia não é fornecida ao dispositivo e as informações podem ser gravadas ou apagadas até certo número de operações. As memórias não voláteis apresentam dois (ou mais) estados estáveis. Cada estado é energeticamente estável, portanto, é possível reter estados correspondentes sem fornecer energia externa. São exemplos de estados estáveis em memórias:

- cargas elétricas em um poço de potencial - memória de leitura (ROM), ROM eletricamente programável (EPROM), ROM apagável eletricamente e programável (EEPROM) e memória flash;

- polarização remanescente - memória de acesso aleatório ferroelétrica;

- mudança na fase - memória de mudança de fase amorfa ou cristalina;

- mudança de resistência - resistência alta ou baixa (memória de comutação resistiva).

A seguir, mostra-se o comportamento das memórias flash, feitas a partir de materiais inorgânicos.

As memórias flash são compostas por transistores e têm sido os mais importantes dispositivos de memória, pois o escalonamento de transistores, que compõem essa memória, é muito conhecido, tornando-as adequadas para aplicações de memórias de alta densidade. A estrutura de uma unidade de memória flash consiste em um transistor MOS com uma porta de controle e uma porta flutuante, como mostrado na Figura 2.20 [2]. 
A porta flutuante é aquela onde os portadores de carga podem ser armazenados, e a porta de controle é aquela que pode controlar a captura/liberação dos portadores de carga da porta flutuante. Se os portadores de carga estão armazenados na porta flutuante no estado gravado ou não estão armazenados nela no estado apagado, é possível verificar se a célula de memória está gravada ou apagada ao se medir a corrente de dreno (Id) em algum valor de tensão $\left(\mathrm{Vth}_{\mathrm{x}} ; \mathrm{Vth}_{1}<\mathrm{Vth} \mathrm{x}_{\mathrm{x}}<\mathrm{Vth}\right.$; como mostra a Figura 2.20) $[4,14,15]$. Nenhuma corrente flui através da fonte para o dreno quando a célula de memória está gravada, uma vez que a condutância do canal é baixa (isto é, o transistor está desligado); por outro lado, a corrente flui através da fonte para o dreno quando a célula de memória está apagada (isto é, transistor está ligado). O transistor na célula de memória pode estar no estado ligado ou desligado quando a célula de memória está apagada ou gravada, respectivamente. O circuito para escrita e leitura da memória flash é então composto por conexões elétricas nos terminais de fonte, dreno e porta de controle (além do substrato aterrado).

Figura 2.20 - Estrutura e operação de um transistor MOS em comparação com a estrutura e operação de uma unidade de memória flash.
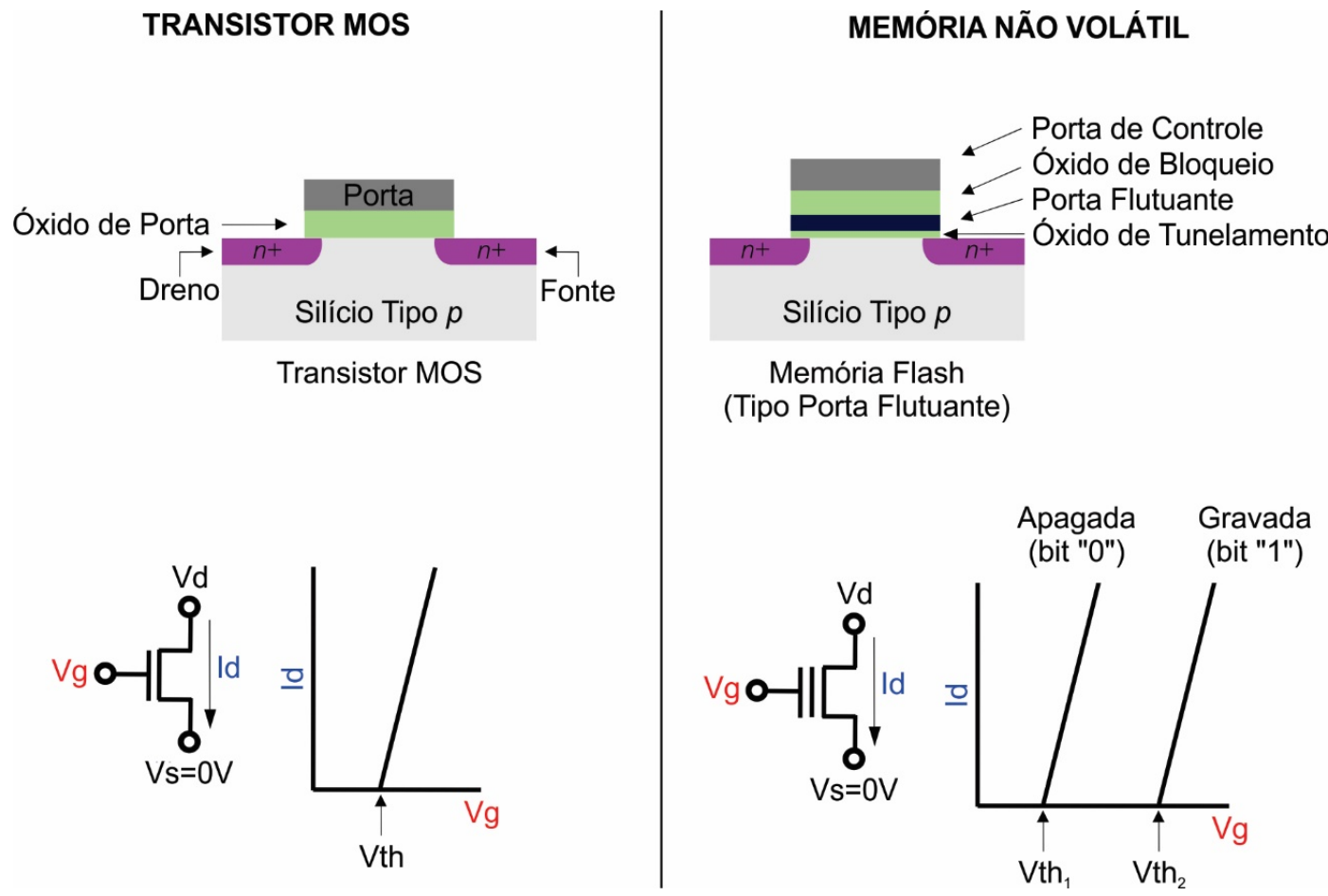

Fonte: O Autor. 
Os portadores de carga elétrica podem ser aprisionados por diferentes camadas de armazenamento de carga elétrica (porta flutuante) e os dispositivos de memória flash podem ser categorizados com base no material utilizado em sua porta flutuante. Embora a porta flutuante feita de silício policristalino altamente dopado seja convencionalmente utilizada como camada de armazenamento de carga, materiais como nitreto de silício ou nanomateriais distribuídos, como nanopartículas metálicas ou semicondutoras, também podem ser utilizados como material da porta flutuante $[4,14,15]$. A Figura 2.21 apresenta a estrutura de uma unidade de memória flash com porta flutuante baseada em nitreto (a) e outra baseada em nanopartículas (b).

Figura 2.21 - Estrutura de uma unidade de memória flash com porta flutuante baseada em (a) nitreto e (b) nanopartículas.

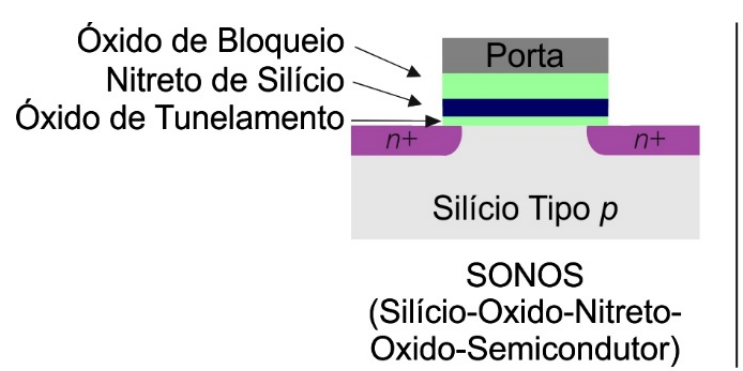

(a)

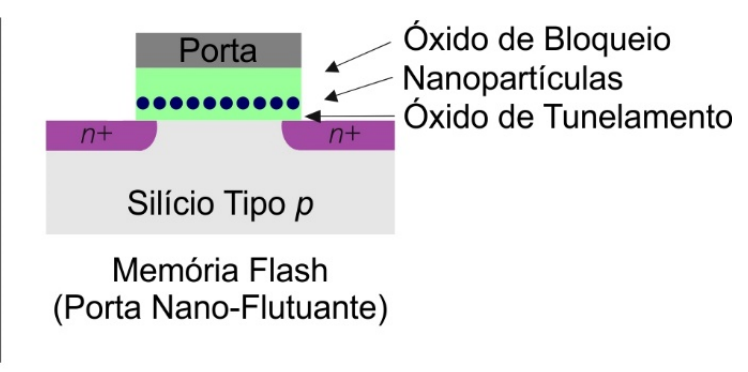

(b)

Fonte: O Autor.

Nos dois casos apresentados na Figura 2.21, a porta é localizada em camada bem definida e delimitada entre os óxidos de bloqueio e de tunelamento, mesmo para o caso das nanopartículas, que embora formem pontos discretos, ainda assim preservam essa característica.

\subsubsection{Memória Biestável de Matriz $\mathrm{TeO}_{2}-\mathrm{ZnO}$ com Nanopartículas de Ouro e o Mecanismo de Transporte de Portadores}

Mostra-se, a seguir, o mecanismo de transporte de portadores (condução eletrônica) em memória orgânica de poliestireno com nanopartículas de ouro. O referido mecanismo de transporte de corrente, baseado em transições abruptas de corrente [25], foi usado para fundamentar os resultados obtidos no presente trabalho, com a matriz de composição $\mathrm{TeO}_{2-}$ $\mathrm{ZnO}$ com nanopartículas de ouro distribuídas em toda a matriz, portanto, de forma diferente 
da usada em memórias inorgânicas (Figura 2.21(b)) que faz uso de camada discreta de nanopartículas ouro. Foi observado que o material $\mathrm{TeO}_{2}-\mathrm{ZnO}$ com nanopartículas de ouro opera em determinadas condições de maneira similar ao material orgânico de poliestireno, ou seja, o mesmo mecanismo de transporte de portadores é válido para os dois casos.

Diversos mecanismos são usados para explicar a transição abrupta de corrente em dielétricos. Um modelo empregado para explicar o mecanismo de transporte de cargas elétricas em matrizes contendo nanopartículas metálicas é o modelo SCLC (space-chargelimited current), proposto por Lampert e Mark [104]. Este modelo teórico da corrente afetada por defeitos através de uma camada dielétrica, posicionada entre dois eletrodos, onde o nível de Fermi do dielétrico se encontra abaixo do nível superficial das armadilhas, é descrito pelas duas equações seguintes, para a situação "com armadilhas" e "armadilhas cheias". Neste modelo as nanopartículas de ouro atuam como as armadilhas para os portadores de carga elétrica.

$$
\begin{aligned}
& J=\frac{9 n \varepsilon \mu}{8 n_{t}}\left(V^{2} / L^{3}\right) \quad \text { (com armadilhas) } \\
& J=\frac{9 \varepsilon \mu}{8}\left(V^{2} / L^{3}\right) \quad \text { (armadilhas cheias) }
\end{aligned}
$$

Nas equações (2-9) e (2-10), $J$ representa o transporte de corrente, $n$ é a concentração de portadores livres e é proporcional a $\exp (\mathrm{qV} / \mathrm{KT}), n_{t}$ representa a concentração de cargas armadilhadas, $\varepsilon$ é a constante dielétrica da camada dielétrica, $\mu$ é a mobilidade do portador livre, $V$ é a tensão aplicada, e $L$ é a espessura da camada dielétrica. As representações deste mecanismo são esquematicamente mostradas na Figura 2.22(a) a (d). Em tensões baixas, como mostrado na Figura 2.22(a), a corrente é devida aos portadores livres gerados termicamente, que têm dependência linear com a tensão. Sob tensão maior, como mostrado na Figura 2.22(b), os portadores injetados no dielétrico são provenientes de um processo termiônico através da barreira. Consequentemente, $\mathrm{n}$ é muito menor do que $n_{t}$. A corrente apresenta dependência com $V^{2}$. Com maior tensão aplicada, como mostrado na Figura 2.22(c), além da tensão de emissão termiônica, o tunelamento Fowler-Nordheim [105] pode ocorrer, e os portadores injetados $(n)$ aumentam rapidamente e as armadilhas ficam quase cheias. A corrente, portanto, tem dependência exponencial com a tensão em vez de dependência dada 
por $V^{2}$. No último estágio, com maior tensão aplicada, como mostrado na Figura 2.22(d), as armadilhas ficam completamente cheias e as características I-V seguem o modelo com “armadilhas cheias" [25] e aplica-se a equação (2-10).

Figura 2.22 - Diagramas de banda esquemáticos do mecanismo de transporte SCLC: (a) Condução por portadores gerados termicamente; (b) com armadilhas; (c) armadilhas quase cheias e (d) armadilhas cheias [25].

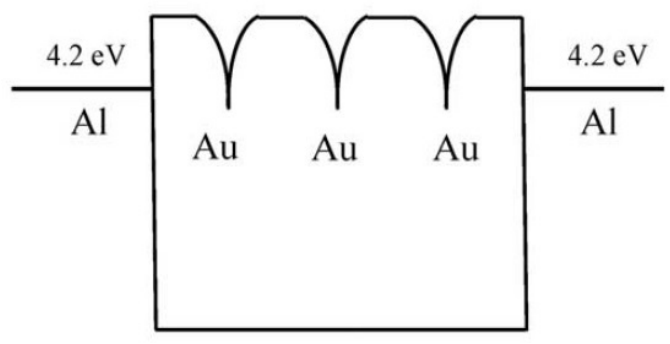

(a)

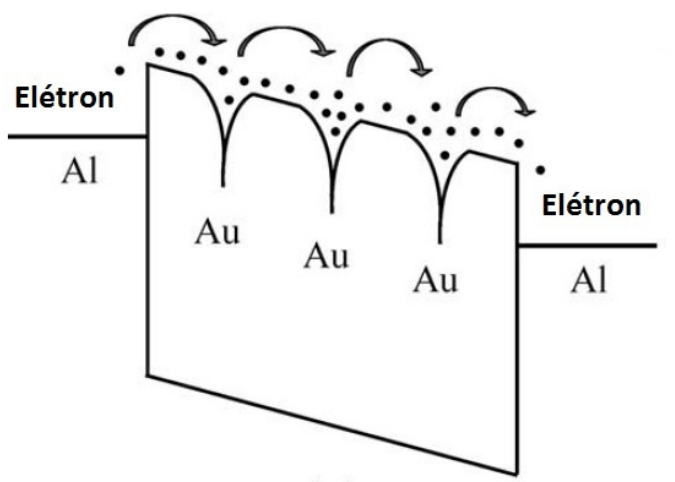

(c)

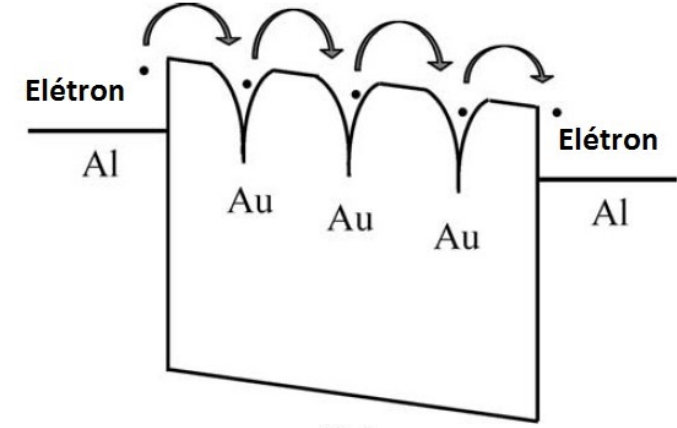

(b)

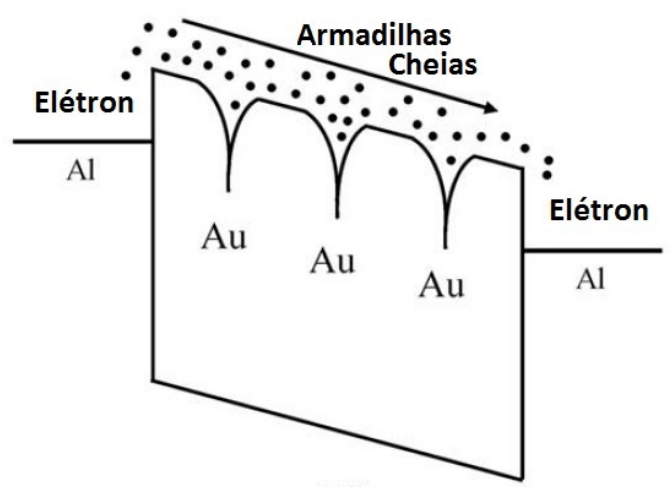

(d)

Fonte: Lin et al., 2007.

A Figura 2.23 mostra o comportamento I-V do material orgânico de poliestireno com e sem nanopartículas de ouro, reportado na literatura [25]. Para o caso do filme com nanopartículas de ouro (PS+Au-NPS) é possível observar o estado de baixa condutividade $\left(10^{-9} \mathrm{~A}\right)$ entre 0 e $3 \mathrm{~V}$ (estado “0” da memória biestável) e em seguida uma mudança abrupta ocorre de $10^{-9}$ (estado de baixa condutividade) para $10^{-4}$ A (estado de alta condutividade). Após esta transição, a corrente através da memória permanece em $10^{-4} \mathrm{~A}$, mesmo quando se aplica baixa tensão. Esta condição representa um estado de alta condutividade e corresponde ao estado "1" da memória. A janela de transição (variação da condutividade entre os estados 
de menor e maior condutividade) é de 4 a 5 ordens de magnitude e a tensão em que a corrente altera-se abruptamente corresponde a tensão de transição (tensão em que as armadilhas estão totalmente preenchidas). Para comparação foi produzido um filme de poliestireno sem nanopartículas de ouro (PS). Neste caso não é observada mudança abrupta da corrente e a janela de transição da memória é muito pequena, quando comparada com a do filme com nanopartículas de ouro (PS+Au-NPS). Isto significa que a transição abrupta da corrente depende das nanopartículas de ouro.

Figura 2.23 - Resultado I-V da memória PS+Au-NPs (linha sólida) e da memória PS (linha tracejada) [25].

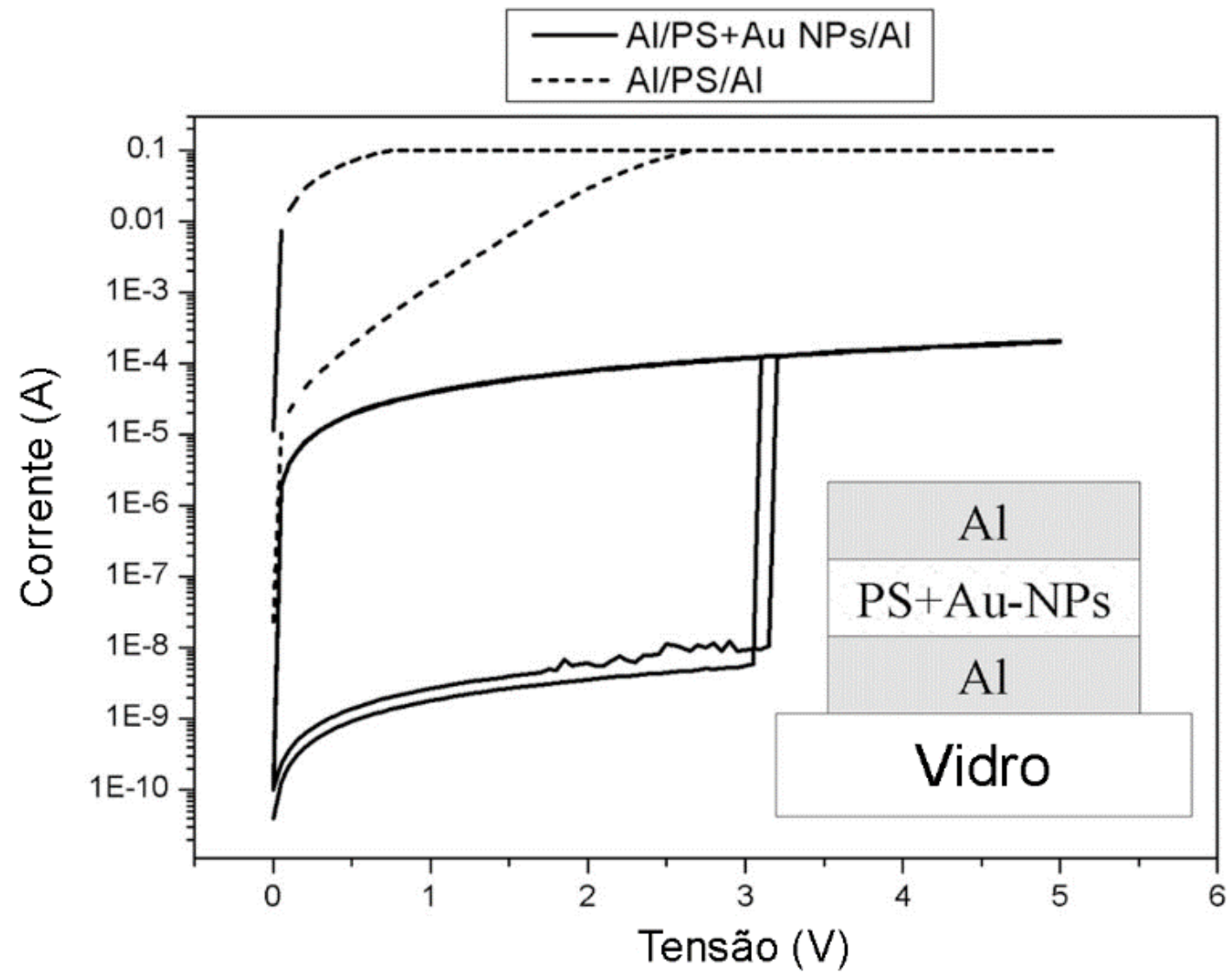

Fonte: Lin, et al., 2007.

Analisando a Figura 2.23 é possível notar que a memória pode estar no estado de baixa condutividade (bit 0) ou no estado de alta condutividade (bit 1). Para gravar o bit 1 na memória, basta aplicar tensão maior que a tensão de transição (no caso, de aproximadamente 3 V). Em memórias reversíveis, o estado de baixa condutividade pode ser recuperado através da aplicação de tensão negativa. A leitura da informação armazenada (bit 0 ou 1) ocorre 
através de polarização com tensão inferior à tensão de transição e sensoriamento da corrente de fuga. Nessa situação de polarização, a memória com bit 1 armazenado permitirá a passagem de maior corrente de fuga em comparação com a situação de bit 0 armazenado. Quanto maior a janela de transição, maior será a diferença entre os níveis de corrente, o que conduz a memórias mais confiáveis. Esse tipo de memória, portanto, necessita de uma única conexão elétrica (além do substrato aterrado) para executar as ações de gravação e leitura da memória.

O comportamento I-V apresentado na Figura 2.23 é apresentado na Figura $2.24 \mathrm{em}$ gráfico $\log \mathrm{I}$ - $\log \mathrm{V}$. O insert apresenta o gráfico referente à amostra sem nanopartículas de ouro, para efeito de comparação. Quatro regiões principais podem ser facilmente distinguidas. Em baixas tensões, de 0 a cerca de $0,5 \mathrm{~V}$, a corrente aumenta linearmente com o aumento da tensão de polarização (região I). Na região II, para a tensão de polarização entre aproximadamente 0,5 e 1,5 V, a corrente mostra dependência com $V^{2}$. Com o aumento da tensão de polarização, a corrente aumenta exponencialmente até atingir a tensão de transição $\left(\mathrm{V}_{\mathrm{T}}\right)$, onde a corrente aumenta abruptamente (região III). Após $\mathrm{V}_{\mathrm{T}}$ (região IV), e também no estado de alta condutividade, a corrente mostra novamente dependência com $V^{2}$. Esse comportamento se enquadra no previsto pelo modelo SCLC (space-charge-limited current), esquematicamente mostrado na Figura 2.22. 
Figura 2.24 - Curva $\log \mathrm{I}$ - $\log \mathrm{V}$ do comportamento de memória da amostra PS+Au-NPS. O insert mostra o comportamento $\log \mathrm{I}-\log \mathrm{V}$ da amostra PS.

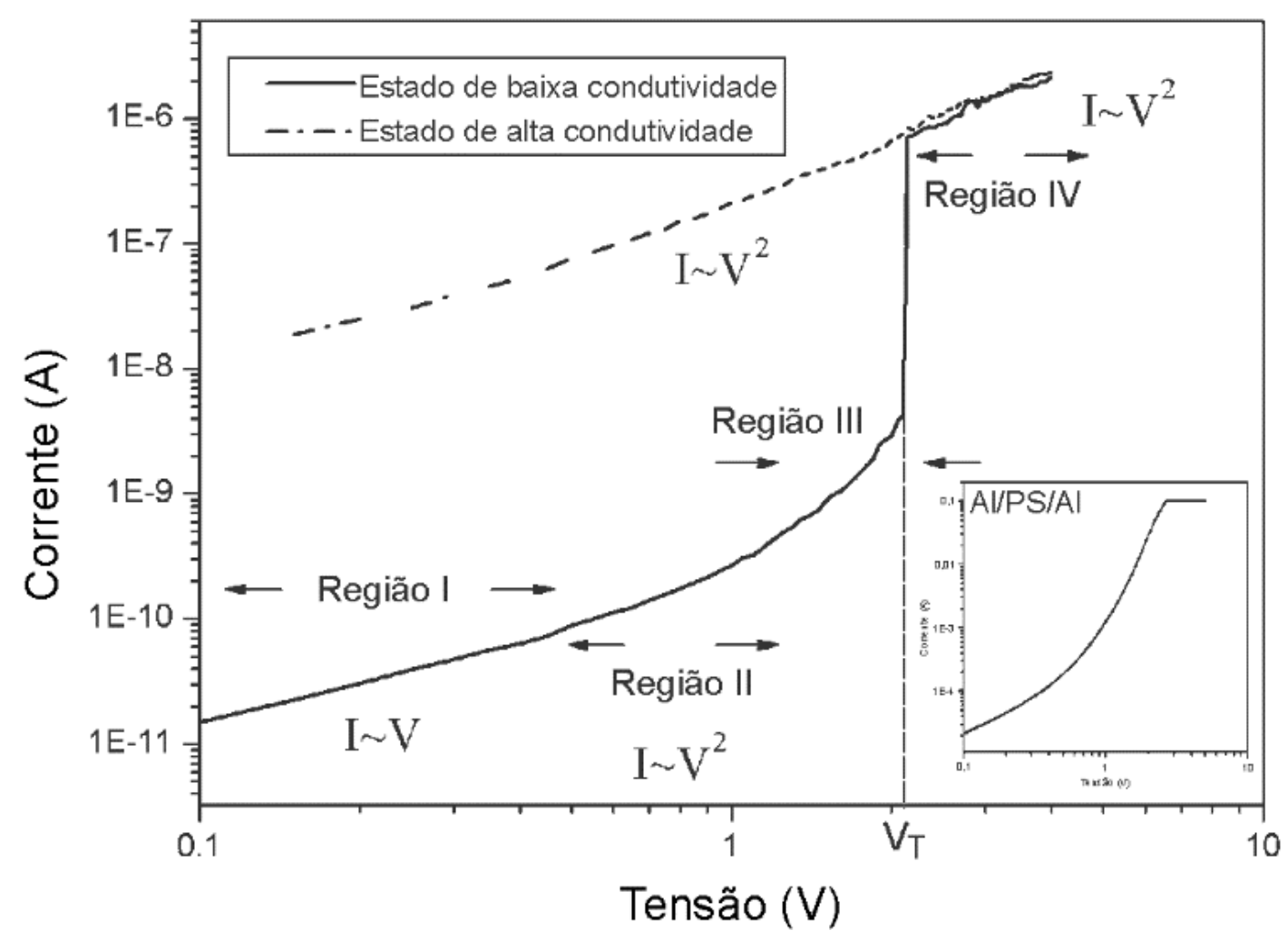

Fonte: Lin, et al., 2007.

Huang et al. [106] mostrou a influência do tamanho das nanopartículas de ouro em filmes finos de poliestireno. Foi mostrado que com o aumento do tamanho das nanopartículas ocorre a diminuição da corrente de fuga. A corrente de fuga medida foi de $10^{-2} \mathrm{~A} / \mathrm{cm}^{2} \mathrm{em}$ filme sem nanopartículas de ouro. Com nanopartículas de $2 \mathrm{~nm}$ de diâmetro a corrente passa a ser $10^{-4} \mathrm{~A} / \mathrm{cm}^{2}$, e com nanopartículas de $20 \mathrm{~nm}$ de diâmetro a corrente foi de $10^{-7} \mathrm{~A} / \mathrm{cm}^{2}$. Isso aconteceu pois, nanopartículas maiores têm maior capacidade de armazenamento de carga, dificultando assim o transporte no dielétrico (filmes finos de poliestireno). Isto pode ser mostrado pela equação [106]: $C=4 \pi \varepsilon a$, onde $a$ representa o diâmetro da nanopartícula. Como conclusão, os autores informaram que nanopartículas podem ser usadas para suprimir o transporte de corrente, permitindo a fabricação de transistores com maior desempenho e que operem em tensões mais baixas.

Conforme será discutido, neste trabalho foi observado pela primeira vez comportamento similar, mas em material inorgânico $\left(\mathrm{TeO}_{2}-\mathrm{ZnO}\right.$ com nanopartículas de ouro). 


\section{Metodologia}

\subsection{Produção dos Alvos}

A produção dos alvos utilizados no processo de sputtering foi aperfeiçoada visando atingir maior estabilidade física no decorrer dos processos de deposição, além de maior reprodutibilidade e praticidade no processo de produção dos alvos. Os primeiros alvos eram produzidos a partir da fusão dos reagentes e posterior solidificação em molde de grafite, resultando em alvos no estado vítreo, que não possuíam estabilidade física no decorrer do processo de sputtering, pois trincavam. Produzir os alvos através da compactação do pó obtido do alvo vítreo moído foi uma alternativa que aumentou a estabilidade física do alvo e sua durabilidade. O fluxograma da Figura 3.1 apresenta as etapas principais para produção dos alvos mencionados: os alvos vítreos e os alvos de vidro moído prensado.

Figura 3.1 - Fluxograma das principais etapas utilizadas na produção dos alvos vítreos e dos alvos de vidro moído prensado.

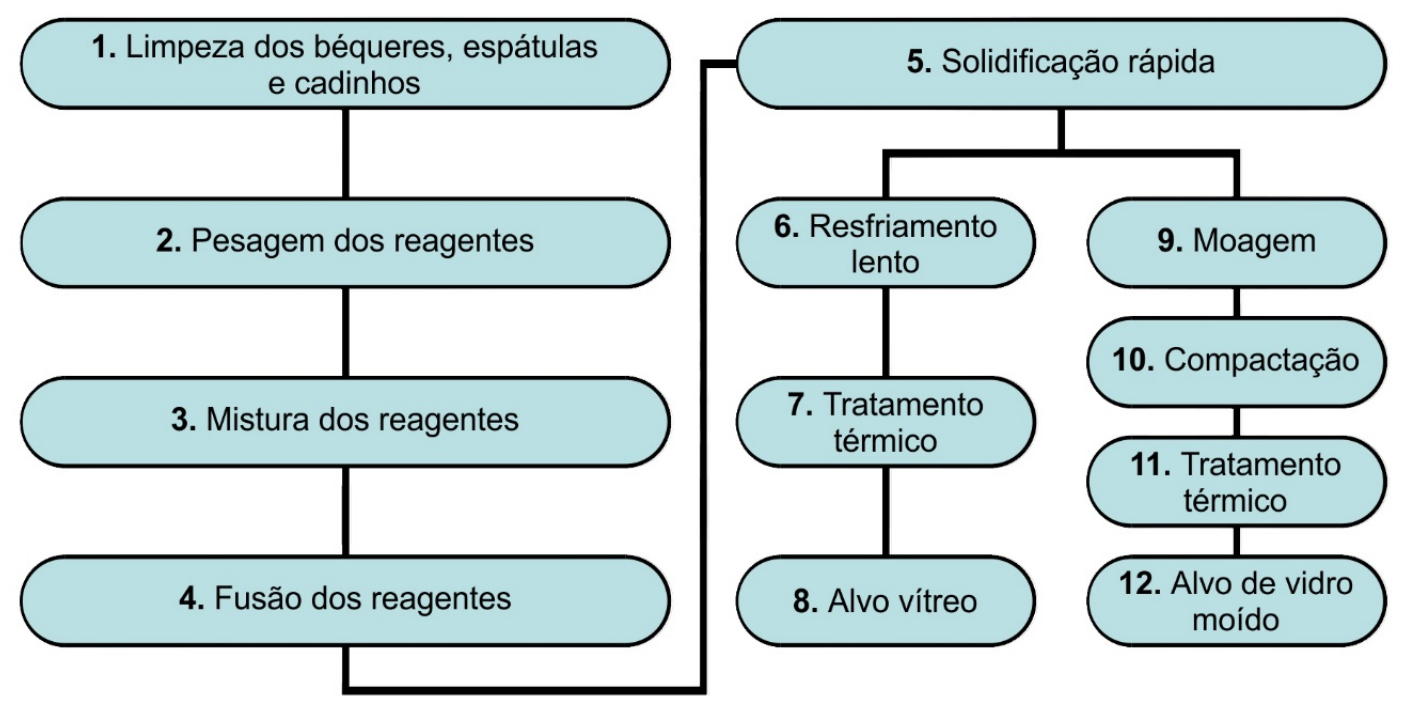

Fonte: O Autor.

As etapas 1 a 5 são comuns aos dois métodos de fabricação. A produção dos alvos vítreos se dá pelas etapas 6 a 8 , e a produção dos alvos de vidro moído prensado por meio das etapas 9 a 12. A Figura 3.2 apresenta a aparência dos alvos produzidos pelas técnicas referidas. 
Figura 3.2 - (A) Alvo vítreo (B) alvo de vidro moído prensado.

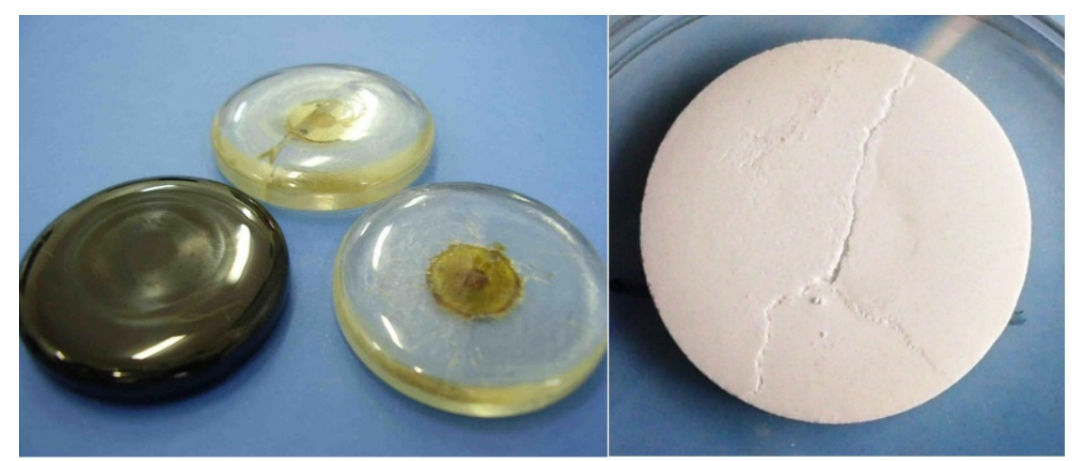

A

B

Fonte: O Autor.

O alvo de vidro moído prensado apresentou boa estabilidade física, o que nos permitiu a deposição satisfatória de filmes finos. Entretanto, visando a praticidade e maior reprodutibilidade, foi desenvolvida a metodologia necessária para produção de alvos cerâmicos, que foram produzidos a partir da compactação dos óxidos constituintes do vidro. Os alvos cerâmicos foram utilizados para realizar as deposições dos filmes apresentados neste trabalho. O fluxograma da Figura 3.3 apresenta as etapas principais para produção dos alvos cerâmicos.

Figura 3.3 - Fluxograma das principais etapas utilizadas na produção dos alvos cerâmicos.
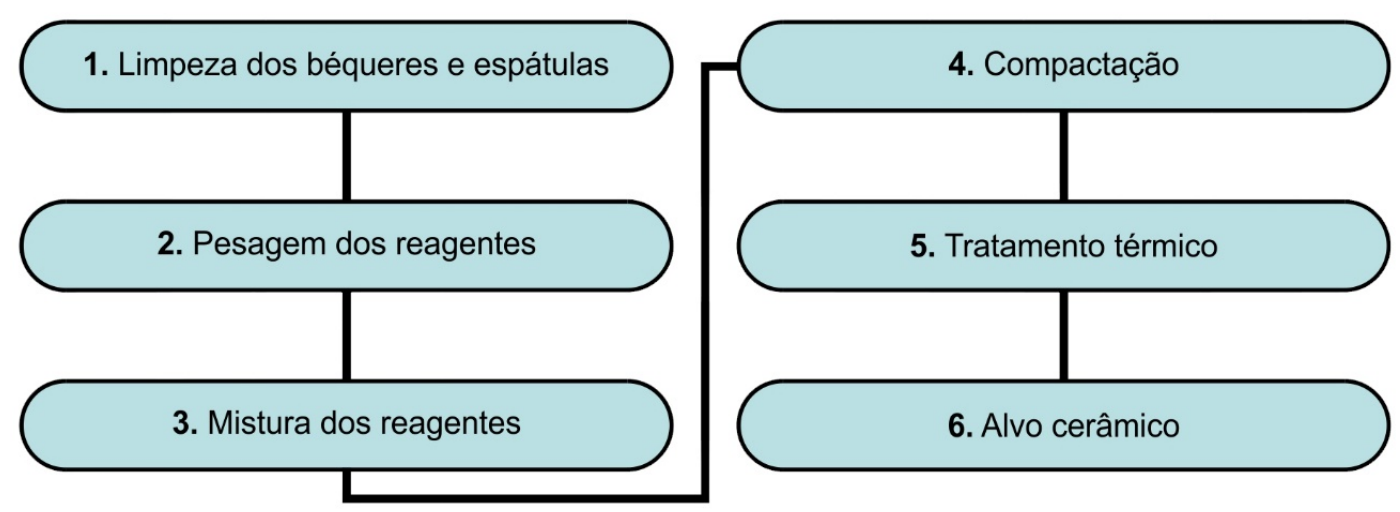

Fonte: O Autor.

As etapas de maior dificuldade (fusão, solidificação e moagem) foram removidas do processo, proporcionando a praticidade e reprodutibilidade esperadas.

A Figura 3.4 apresenta a foto de um alvo cerâmico. 
Figura 3.4 - Alvo cerâmico.

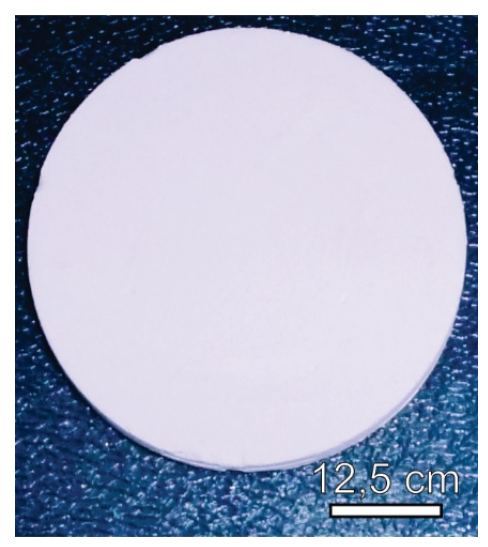

Fonte: O Autor.

Para a produção dos alvos cerâmicos foi escolhida a composição $85,5 \mathrm{TeO}_{2}-14,5 \mathrm{ZnO}$ (\% em peso), pois além de bastante conhecida e estudada em trabalhos anteriores realizados pelo grupo do Laboratório de Tecnologia em Materiais Fotônicos e Optoeletrônicos (LTMFO) da Faculdade de Tecnologia de São Paulo, apresentaram propriedades muito interessantes para a produção de memórias.

A Figura 3.5 apresenta a foto do alvo de ouro utilizado na deposição por co-sputtering. Este alvo foi utilizado juntamente com o alvo apresentado na Figura 3.4.

Figura 3.5 - Alvo de ouro.

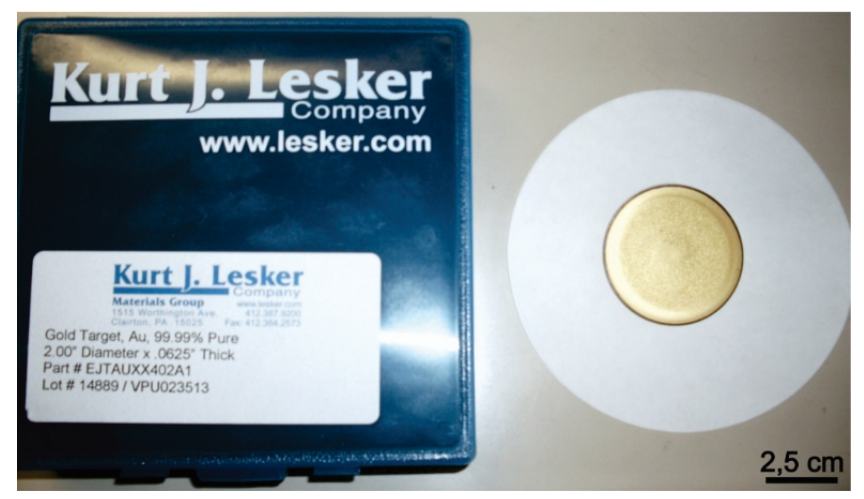

Fonte: O Autor.

As etapas realizadas na produção dos alvos cerâmicos, apresentadas no fluxograma da Figura 3.3, são detalhadas abaixo. A Figura 3.6(a) ilustra esquematicamente o processo de fabricação dos alvos cerâmicos. 
1. Pesagem e mistura dos reagentes:

Inicialmente, os béqueres, espátulas, almofariz e o molde de aço inoxidável, utilizados nesta etapa de produção, são lavados com detergente neutro e enxaguados em água corrente. Depois de secos, são limpos com álcool isopropílico. Este procedimento inicial é importante, pois evita a contaminação dos reagentes e do alvo em produção. Os reagentes (óxido de telúrio e óxido de zinco) são então pesados em balança analítica com precisão de $\pm 0,0001 \mathrm{~g}$, utilizando-se béqueres individuais e exclusivos. Para cada reagente utiliza-se uma espátula, evitando contaminação cruzada. Depois de pesados, os reagentes são misturados mecanicamente em um almofariz de ágata e colocados no molde de aço inoxidável para prensagem uniaxial (Figura 3.6(b)).

2. Prensagem uniaxial:

Nesta etapa, o molde de aço inoxidável confere as dimensões e o formato desejados ao alvo. A mistura colocada no molde passa então pelo processo de prensagem, onde é utilizada prensa hidráulica uniaxial e pressão máxima em torno de $4000 \mathrm{kgf} / \mathrm{cm}^{3}$. A pressão é elevada lentamente para que haja homogeneidade na compactação da mistura.

3. Tratamento térmico (sinterização):

Após a prensagem, o alvo é extraído do molde e colocado em uma base cerâmica (Figura 3.6(c)). O conjunto (alvo + base cerâmica) é então levado ao forno elétrico resistivo para tratamento térmico, sob aquecimento de $2{ }^{\circ} \mathrm{C} / \mathrm{min}$ até a temperatura final de $515{ }^{\circ} \mathrm{C}$, e sinterizado por 20 horas. A sinterização promove o aumento da resistência mecânica e confere menor fragilidade ao alvo. A temperatura utilizada na sinterização corresponde a $70 \%$ da menor temperatura de fusão dos constituintes do alvo e foi estabelecida em trabalhos anteriores do grupo. 
Figura 3.6 - (a) Processo de fabricação dos alvos cerâmicos. (b) Reagentes constituintes do alvo no molde antes da prensagem. (c) Alvo cerâmico após o tratamento térmico de sinterização [107].

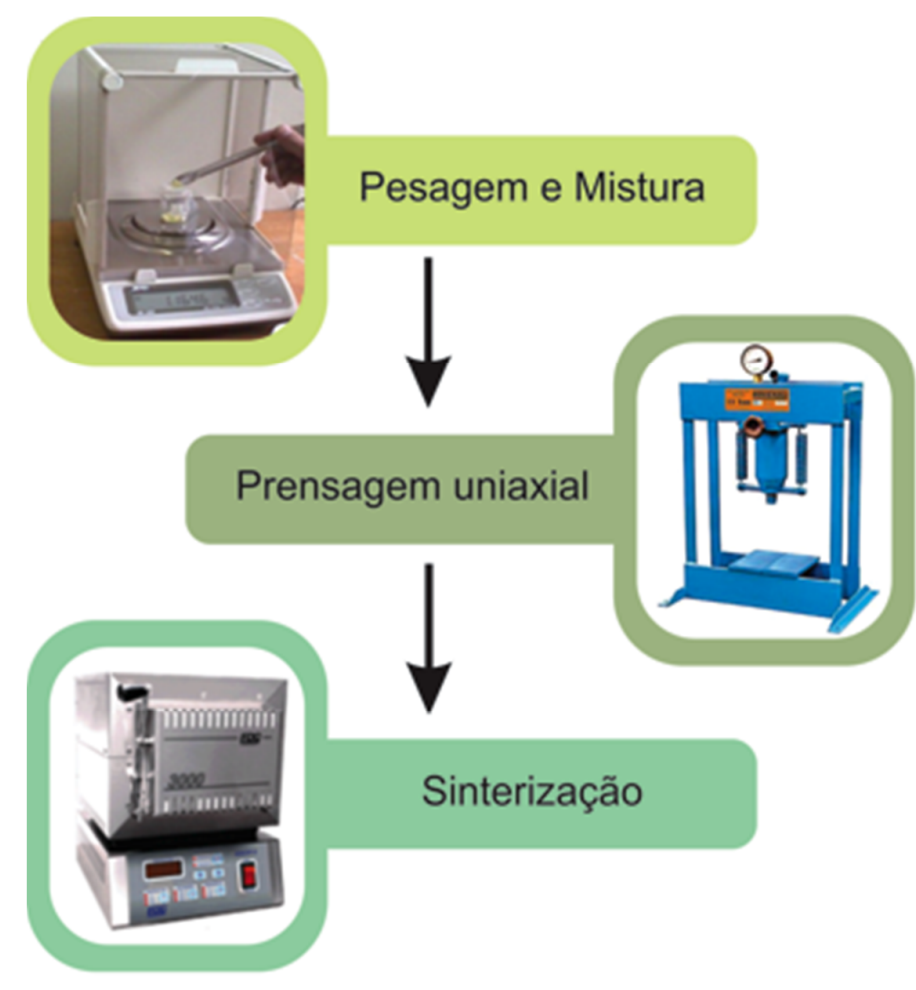

(a)

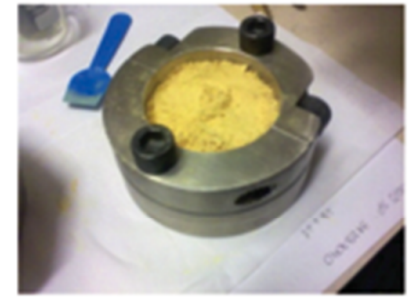

(b)

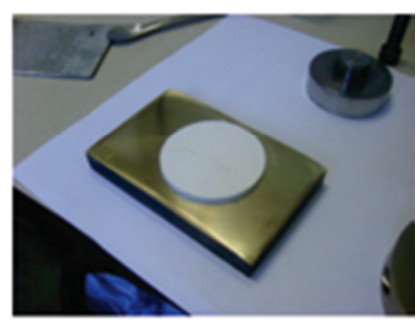

(c)

Fonte: Camilo, 2014.

\subsection{Limpeza das Lâminas de Silício}

Para a deposição dos filmes finos, inicialmente deve-se realizar a limpeza das lâminas de silício. Essa limpeza tem a finalidade de remover da superfície da lâmina as impurezas orgânicas, inorgânicas e o particulado que ali estiverem, e ainda remover a camada de óxido de silício nativo que se forma naturalmente nas lâminas expostas ao ar atmosférico. Foi utilizada a limpeza completa [108] que é amplamente empregada na indústria de semicondutores. Essa limpeza consiste das seguintes etapas:

1. Lavagem em água deionizada (DI) por 5 minutos para remoção de particulados;

2. Imersão por 10 minutos em solução de ácido sulfúrico $\left(4 \mathrm{H}_{2} \mathrm{SO}_{4}\right)+$ peróxido de hidrogênio $\left(1 \mathrm{H}_{2} \mathrm{O}_{2}\right)$, cuja temperatura da solução é de $80{ }^{\circ} \mathrm{C}$. Nesta solução são 
removidos os compostos orgânicos e promove-se a oxidação da superfície da lâmina de silício;

3. Lavagem em água DI por 5 minutos para remoção da solução anterior;

4. Imersão em solução de ácido fluorídrico (1 HF) + água DI $\left(20 \mathrm{H}_{2} \mathrm{O}\right)$ por alguns segundos, até a lâmina sair seca. Esta etapa remove o óxido de silício formado na etapa 2;

5. Lavagem em água DI por 5 minutos para remoção da solução anterior;

6. Imersão por 15 minutos em solução de hidróxido de amônio $\left(1 \mathrm{NH}_{4} \mathrm{OH}\right)+$ peróxido de hidrogênio $\left(1 \mathrm{H}_{2} \mathrm{O}_{2}\right)$ + água DI $\left(5 \mathrm{H}_{2} \mathrm{O}\right)$, aquecida à $80^{\circ} \mathrm{C}$;

7. Lavagem em água DI por 5 minutos para remoção da solução anterior;

8. Imersão por 15 minutos em solução de ácido clorídrico (1 HCL) + peróxido de hidrogênio $\left(1 \mathrm{H}_{2} \mathrm{O}_{2}\right)$ + água DI $\left(5 \mathrm{H}_{2} \mathrm{O}\right)$, aquecida à $80{ }^{\circ} \mathrm{C}$;

9. Lavagem em água DI por 5 minutos para remoção da solução anterior;

10. Imersão em solução de ácido fluorídrico $(1 \mathrm{HF})$ + água DI $\left(20 \mathrm{H}_{2} \mathrm{O}\right)$ por alguns segundos, até a lâmina sair seca. Esta etapa remove o óxido de silício formado nas etapas 6 e 8 ;

11. Lavagem em água DI por 5 minutos para remoção da solução anterior.

Com a remoção do óxido de silício as lâminas saem totalmente secas da solução (etapas 4 e 10), devido ao efeito hidrofóbico da superfície do silício. A etapa 2 é conhecida como "Limpeza Piranha". As etapas 5 a 9 são conhecidas como "Limpeza RCA" e promovem a remoção de íons metálicos através de reações de complexação e a oxidação da superfície da lâmina de silício.

As lâminas de silício utilizadas nesse trabalho foram do tipo $p$, com orientação

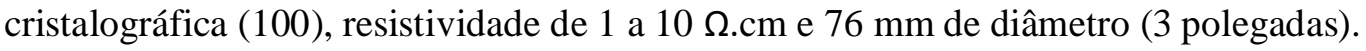

\subsection{Deposição de Filmes Finos por Co-Sputtering}

Para deposição dos filmes foi utilizado o equipamento de magnetron co-sputtering do Laboratório de Tecnologia em Materiais Fotônicos e Optoeletrônicos da Faculdade de Tecnologia de São Paulo, FATEC-SP (Modelo PrestVácuo PV-300). A Figura 3.7 apresenta o referido equipamento de co-sputtering. 
Figura 3.7 - Equipamento de magnetron co-sputtering do Laboratório de Materiais Fotônicos e Optoeletrônicos da FATEC-SP.

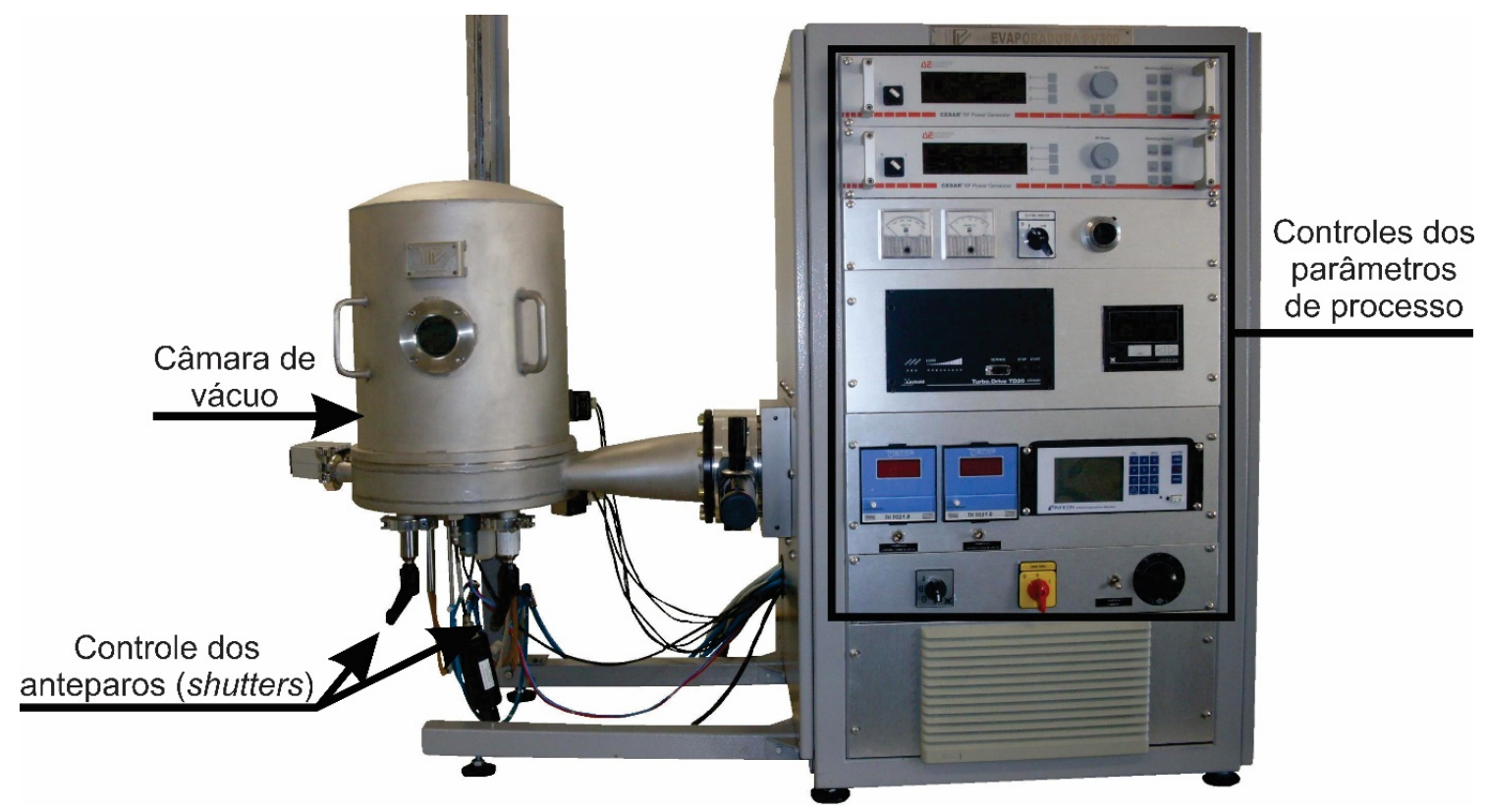

Fonte: O Autor.

A Figura 3.8 apresenta o interior da câmara onde ocorre a deposição. Os elementos numerados na Figura 3.8 são:

1. Porta amostra: acomoda 4 lâminas de silício de 3 polegadas. O porta amostra gira para promover maior uniformidade na deposição e reduzir o efeito de sombras.

2. Medidor de espessura: é possível medir in-situ a espessura do filme depositado tendo como base a densidade do material.

3. Anteparo (Shutter): elemento móvel que controla a quantidade de material ejetado do alvo a atingir o substrato. Na Figura 3.8 o shutter está totalmente fechado, essa posição impossibilita a chegada de material ao substrato. Durante a deposição o shutter permanece total ou parcialmente aberto. Cada porta alvo possui seu shutter.

4. Porta alvo 1: acomoda o primeiro alvo. Na Figura 3.8 um alvo cerâmico está acomodado no porta alvo 1 .

5. Porta alvo 2: acomoda o segundo alvo. Na Figura 3.8 um alvo de aço-inoxidável está acomodado no porta alvo 2 . 
Figura 3.8 - Interior da câmara de deposição do equipamento de co-sputtering.

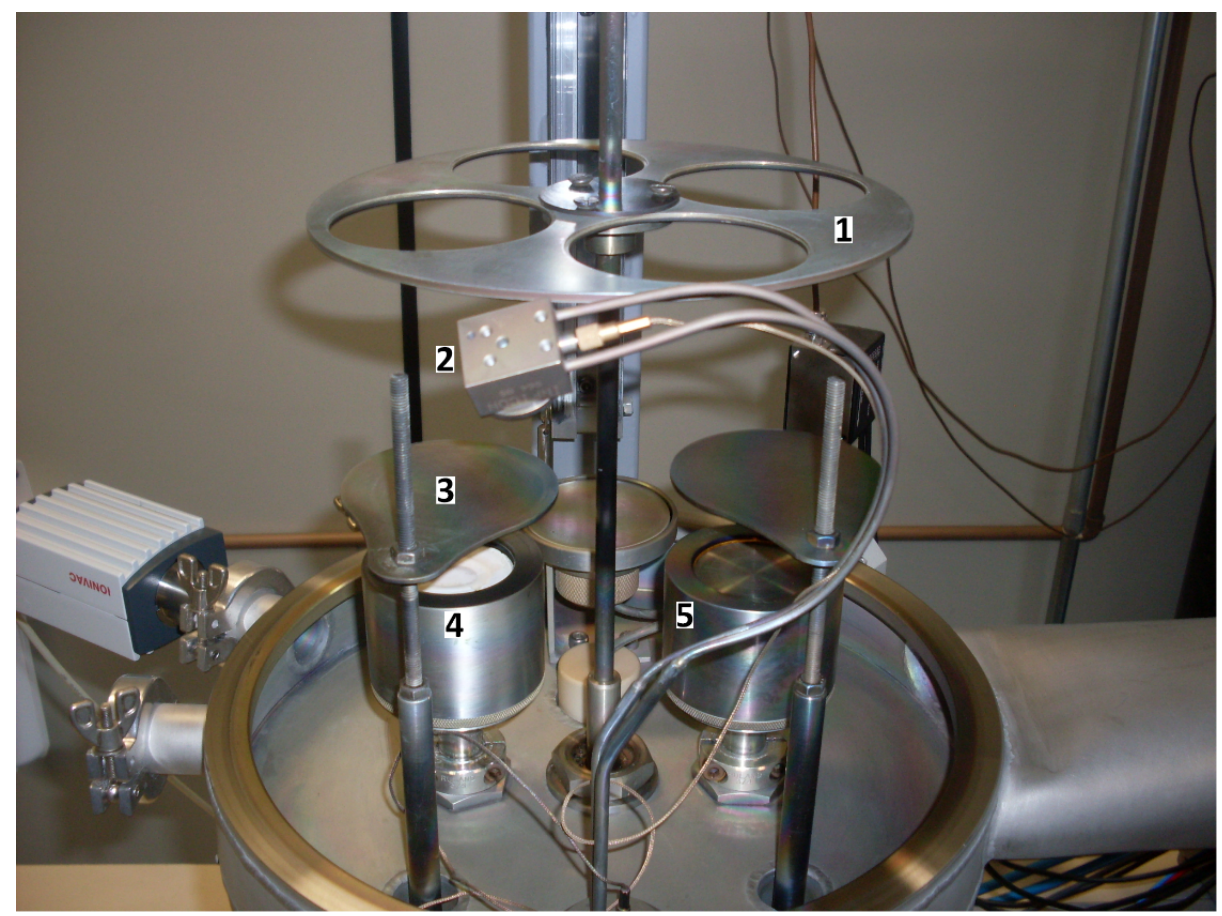

Fonte: O Autor.

A produção dos filmes consiste na deposição por co-sputtering de um alvo de telureto $\mathrm{TeO}_{2}+\mathrm{ZnO}$ e outro alvo de ouro com alta pureza. O primeiro fornece o material para a formação da matriz vítrea e o segundo para a formação das nanopartículas. A Tabela 3-1 apresenta os parâmetros utilizados na deposição. Foram produzidos filmes variando a abertura do shutter do ouro e potência aplicada nesse alvo, além do fluxo de oxigênio durante o processo de deposição.

Tabela 3-1 - Parâmetros utilizados na deposição.

\begin{tabular}{l|c|c}
\hline & Alvo 1 & Alvo 2 \\
\hline Material & $\mathrm{TeO}_{2}-\mathrm{ZnO}$ & $\mathrm{Au}$ \\
Potência (W) & 50 & \\
Abertura do Shutter (u.a.) & total & $35,40,45,50,60$ e total \\
Fluxo de Argônio (sccm) & & 18 \\
Fluxo de Oxigênio (sccm) & & $0-7$ \\
Pressão de Base (Torr) & & $5 \times 10^{-5}$ \\
Pressão de Processo (Torr) & & $5 \times 10^{-3}$ \\
\hline
\end{tabular}

Fonte: O Autor. 
O fluxo de oxigênio durante a deposição pode controlar a estequiometria do filme depositado, interferir nas propriedades elétricas e ainda alterar a concentração do ouro depositado. A Tabela 3-2 apresenta todas as amostras estudadas no presente trabalho.

Tabela 3-2 - Amostras produzidas.

\begin{tabular}{|c|c|c|c|c|}
\hline $\begin{array}{c}\text { Espessura } \\
\text { aproximada } \\
(\mathbf{n m}) \\
\end{array}$ & $\begin{array}{c}\text { Abertura } \\
\text { do shutter } \\
\text { do ouro }\end{array}$ & $\begin{array}{c}\text { Fluxo de } \\
\text { oxigênio } \\
\text { (sccm) }\end{array}$ & $\begin{array}{l}\text { Tempo de } \\
\text { tratamento } \\
\text { térmico }(h)\end{array}$ & $\begin{array}{l}\text { Potência no } \\
\text { alvo de ouro } \\
\text { (W) }\end{array}$ \\
\hline 100 & - & 0 & 0,10 & - \\
\hline 100 & - & 0,5 & 0,10 & - \\
\hline 100 & - & 1 & 0,10 & - \\
\hline 100 & - & 2 & 0,10 & - \\
\hline 100 & - & 7 & 0,10 & - \\
\hline 100 & \multirow{2}{*}{35} & \multirow{2}{*}{4} & \multirow{4}{*}{0,10 e 20} & \multirow{9}{*}{6} \\
\hline 500 & & & & \\
\hline 100 & 40 & \multirow{4}{*}{4} & & \\
\hline 500 & 40 & & & \\
\hline 100 & \multirow{2}{*}{45} & & \multirow{2}{*}{10 e 20} & \\
\hline 500 & & & & \\
\hline 100 & \multirow{2}{*}{50} & $1,2,4$ e 7 & \multirow{4}{*}{0,10 e 20} & \\
\hline 500 & & 1 & & \\
\hline \multirow{2}{*}{100} & 60 & 2,6 e 7 & & \\
\hline & total & 7 & & 7 \\
\hline
\end{tabular}

Fonte: O Autor.

\subsection{Tratamento Térmico}

Os filmes finos depositados são submetidos a tratamento térmico para nucleação das nanopartículas de ouro. A etapa referente ao tratamento térmico para nucleação é descontínua, isto é, são feitos sucessivos tratamentos até que seja atingido o tempo desejado. Este procedimento foi usado em decorrência de vários experimentos feitos anteriormente pelo grupo que demonstraram que os tratamentos não contínuos evitam a produção de agregados [109].

A Figura 3.9, como exemplo, ilustra esquematicamente a nucleação no processo de tratamento térmico, cuja finalidade consiste em reduzir os íons metálicos em átomos metálicos ou fornecer a energia necessária para difusão dos átomos metálicos, e assim nuclear as nanopartículas. Cabe acrescentar que a nucleação depende do tratamento térmico e também 
da matriz utilizada, que limita e controla o processo de crescimento das nanopartículas, facilitando ou dificultando a difusão dos íons e átomos metálicos. Os tratamentos térmicos para nucleação são realizados nos filmes já depositados e usam temperatura de $325{ }^{\circ} \mathrm{C}$ estabelecida em trabalhos anteriores do grupo [29]. Os alvos, por sua vez, recebem tratamento térmico apenas para sinterização.

Figura 3.9 - Processo de nucleação por tratamento térmico.
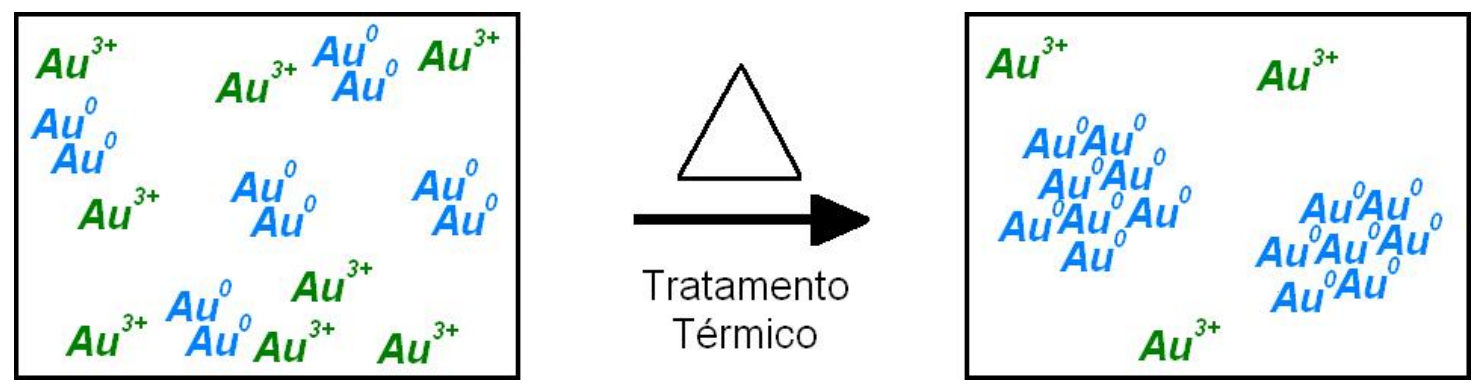

Fonte: O Autor.

\subsection{Produção das Estruturas MIS (Metal - Isolante - Semicondutor)}

Para a realização das medidas elétricas, foi necessária a produção de capacitores MOS, que têm a estrutura metal - isolante - semicondutor (estrutura MIS). As estruturas foram produzidas por evaporação de alumínio, através de uma máscara mecânica, sobre o filme de telureto já depositado em lâmina de silício. Cada estrutura MIS tem o formato circular de diâmetro aproximado de $1 \mathrm{~mm}$. Foi também realizada a deposição de alumínio no substrato, do lado oposto aos dispositivos, com objetivo de promover o contato elétrico do substrato durante as medidas.

O processo de produção dos capacitores para a caracterização elétrica dos filmes foi realizado na evaporadora do Laboratório de Processamento e Caracterização de Materiais (LPCM) da Faculdade de Tecnologia de São Paulo e na evaporadora do Laboratório de Sistemas Integráveis da Escola Politécnica da Universidade de São Paulo (Modelo Edwards Auto 306). Uma máscara mecânica foi utilizada como delimitadora das regiões que receberiam o alumínio. A massa de alumínio necessária foi calculada como base na espessura média de $1 \mu \mathrm{m}$, suficiente para o processo de caracterização elétrica.

A Figura 3.10 demonstra a máscara mecânica utilizada (a) e as estruturas MIS obtidas em uma lâmina de silício com filme fino depositado nos lados direito e esquerdo (b). A faixa 
no centro da lâmina (faixa cinza) não recebeu deposição de filme fino, pois para a medida de espessura é necessária a formação de um degrau (desnível), conforme é explicado no Capítulo 4.

Figura 3.10 - (a) Máscara mecânica e (b) estruturas MIS.
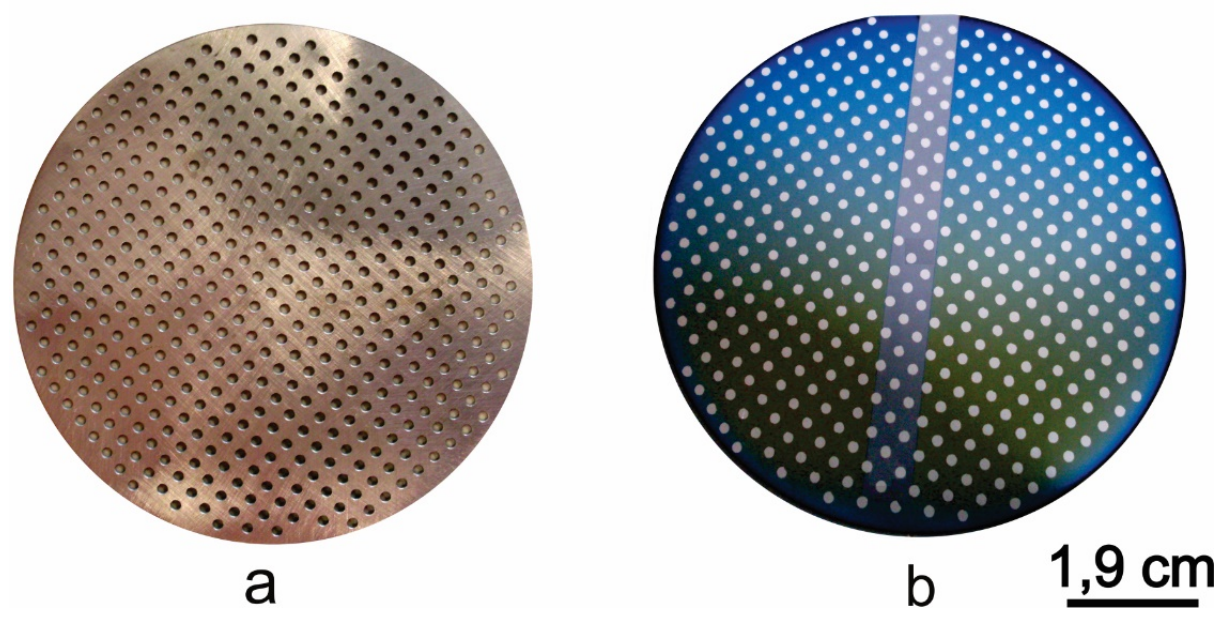

Fonte: O Autor.

\subsection{Técnicas de Caracterização}

\subsubsection{Perfilometria}

A perfilometria consiste de uma medida mecânica para a obtenção da topografia de um material através do movimento de uma ponta. Essa ponta é chamada de ponteira. A ponteira é feita de diamante e sua extremidade, utilizada para a medida, tem $12,5 \mu \mathrm{m}$ de diâmetro. A técnica de perfilometria possui algumas limitações:

- Caso o diâmetro da ponteira seja maior que o diâmetro do furo a ser medido, a medida será distorcida.

- Alta rugosidade no filme a ser medido, pois dependendo do passo horizontal do equipamento, podem ocorrer saltos da ponteira, que distorcem a medida.

- Vibração no equipamento. Esse parâmetro é de grande importância devido à alta precisão do sistema de medida do equipamento; pequenas vibrações causam alterações na medida [90]. Para solucionar esse problema, os equipamentos são colocados em mesas que evitam essas vibrações. 
As medidas de perfilometria foram realizadas no perfilômetro Dektak-3030 do LSI/EPUSP para verificar as espessuras do alumínio depositado na etapa de produção dos capacitores e dos filmes finos.

\subsubsection{Microscopia Eletrônica de Transmissão (TEM)}

O microscópio eletrônico de transmissão é utilizado para obtenção de imagens de materiais que são suficientemente finos para transmitir elétrons, dentre esses materiais estão os filmes finos. O TEM possui dois modos básicos de operação: o de imagem e o de difração. O modo imagem é utilizado para observar a amostra, podendo revelar aspectos físicos da mesma em uma escala muito reduzida. O modo de difração é utilizado para verificar o tipo de estrutura do material: cristalino, amorfo ou com ambas as fases. Além disso, através do padrão de difração é possível determinar os materiais que compõem as fases cristalinas da amostra. $\mathrm{O}$ equipamento de TEM permite ainda a análise da composição química em regiões selecionadas da amostra através de um detector EDS (Energy Dispersive Spectroscopy Espectroscopia de Energia Dispersiva).

Neste trabalho as medidas de TEM foram utilizadas para a verificação da nucleação das nanopartículas metálicas nos filmes, além de extrair o tamanho e a morfologia das mesmas. Os microscópios utilizados neste trabalho foram: Philips CM 200 pertencente ao Laboratório de Microscopía Eletrônica do Instituto de Física da Universidade de São Paulo (IFUSP); o JEOL-3010 de alta resolução pertencente ao Laboratório Nacional de Nanotecnologia (LNNano) do Centro Nacional de Pesquisas em Energias e Materiais (CNPEM); e o JEOL 2100 de alta resolução pertencente ao Instituto de Química da Universidade de São Paulo (IQ-USP). A Figura 3.11 mostra os microscópios utilizados. 
Figura 3.11 - Microscópios eletrônico de transmissão utilizados: (a) IQ-USP (b) IFUSP e (c) LNNano.

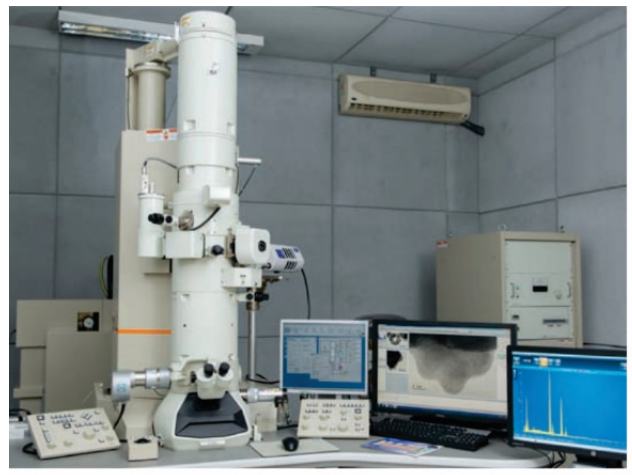

(a)

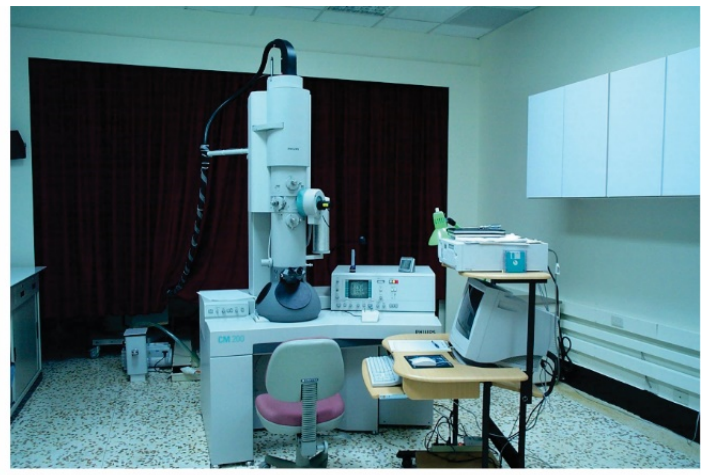

(b)

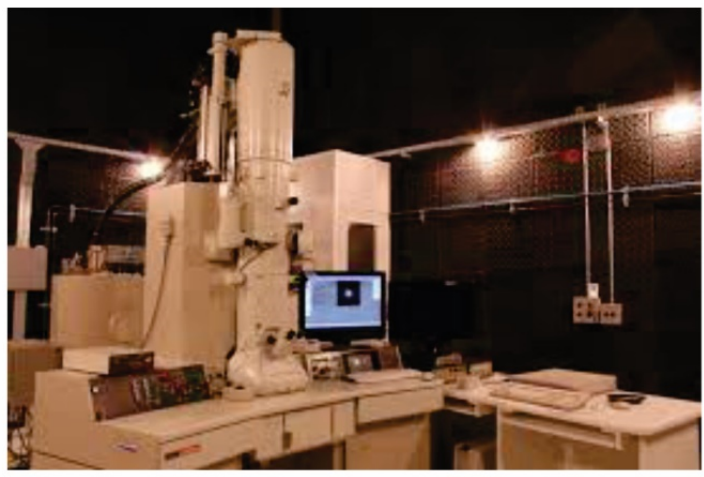

(c)

Fonte: (a) ca.iq.usp.br, 2017; (b) Hora, 2008 e (c) lnnano.cnpem.br, 2017.

Para a realização das medidas de TEM nos filmes finos produzidos, foi necessário o desenvolvimento de um método próprio para a extração do material da superfície do substrato. A metodologia consistiu da remoção do filme da superfície do substrato com o auxílio de uma ponta de quartzo. Após esse procedimento, uma gota de água deionizada foi colocada sobre o material "raspado", e em seguida, coletada com uma pipeta de vidro. Por conta da tensão superficial da água e do arraste causado pela coleta com a pipeta, apenas o material mais fino é coletado. Utilizando-se de uma rede de cobre recoberta com carbono ultrafino (Ultrathin Carbon of $\sim 3 \mathrm{~nm}$ on Carbon Holey Support Film), o material coletado é depositado, utilizando-se a própria pipeta. Após a secagem da gota de água depositada sobre a rede de cobre, a mesma pode ser submetida a alto-vácuo para remoção da umidade residual, e pré-análise em Microscopia Eletrônica de Varredura (MEV), para verificação da preparação [110]. 
Esse método foi definido após outras tentativas de preparo do material para a análise de TEM, como a raspagem da superfície do filme com ponta de diamante que, apesar de remover o filme com maior eficiência, também removia uma grande quantidade de silício do substrato. A raspagem com ponta de diamante acabava inviabilizando a análise final, pois ao realizar a medida, quase não se encontrava material referente ao filme fino e sim ao silício do substrato.

\subsubsection{Espectrometria por Retroespalhamento de Rutherford (RBS)}

O método RBS (Rutherford Backscattering Spectrometry) consiste na utilização de feixes monoenergéticos de íons, que ao colidirem com a amostra são retroespalhados pelos núcleos de seus átomos. Quando estes íons saem da amostra, são detectados e é então construído um espectro de retroespalhamento, que consiste em um histograma da quantidade de partículas detectadas em função da energia, do qual são obtidas informações do alvo, tais como a sua espessura e composição [111]. O eixo das energias (abscissa) é dividido em 512 ou 1024 canais. Cada canal corresponde a um pequeno intervalo de energia, da ordem de 5 $\mathrm{keV} / \mathrm{canal}[112]$.

Para as medidas de RBS das amostras desse trabalho, foi utilizado o equipamento do Laboratório de Materiais e Feixes Iônicos (LAMFI) do Instituto de Física da Universidade de São Paulo. O LAMFI conta essencialmente com um acelerador eletrostático tipo PelletronTandem. Acopladas ao acelerador, existem duas câmaras de alto vácuo, sendo que uma delas é para análise de RBS.

A câmara para análise de RBS tem $43 \mathrm{~cm}$ de diâmetro interno e $15 \mathrm{~cm}$ de altura. A aquisição dos dados é controlada por computador através de um buffer multicanal. Para o cálculo e simulação de espectros de RBS utiliza-se o programa RUMP (Programa especialmente projetado para a análise e simulação de dados de RBS). O tamanho das amostras deve ser da ordem de 1 a $2 \mathrm{~cm}$. A área efetivamente analisada é essencialmente definida pelas dimensões do feixe, em geral, de 0,5 a $4 \mathrm{~mm}^{2}$ podendo chegar até $10 \mathrm{~mm}^{2}$.

Uma das informações que se obtém dos espectros de RBS refere-se à determinação da concentração planar. No espectro de RBS convencional (energia do feixe incidente da ordem de $2 \mathrm{MeV}$ ) a área sob determinada banda é proporcional ao número total de átomos por centímetro quadrado, ao longo de toda a profundidade da amostra, e definida como concentração planar, que corresponde ainda ao produto entre a densidade volumétrica e a 
espessura [113].

\subsubsection{Corrente x Tensão (I-V)}

As medidas de corrente $\mathrm{x}$ tensão foram realizadas no Analisador de Parâmetros Agilent 4156C do Laboratório de Sistemas Integráveis da Escola Politécnica da Universidade de São Paulo (LSI/EPUSP). Esse equipamento possui uma câmara escura onde é possível realizar as medidas na ausência de luz. As medidas foram realizadas em diferentes intervalos de tensão, chegando aos extremos de $-15 \mathrm{~V}$ e $40 \mathrm{~V}$, com passo de 15 e $40 \mathrm{mV}$ para as varreduras em tensão negativa e positiva, respectivamente. Foi selecionado o tempo médio de integração.

A Figura 3.12 apresenta a câmara escura utilizada durante a realização das medidas. É possível observar seis pontas de prova posicionadas ao redor do porta amostra. Neste trabalho, apenas uma ponta de prova foi utilizada para a aplicação de tensão no dispositivo. O porta amostra é aterrado.

Figura 3.12 - Câmara escura utilizada durante as medidas I-V.

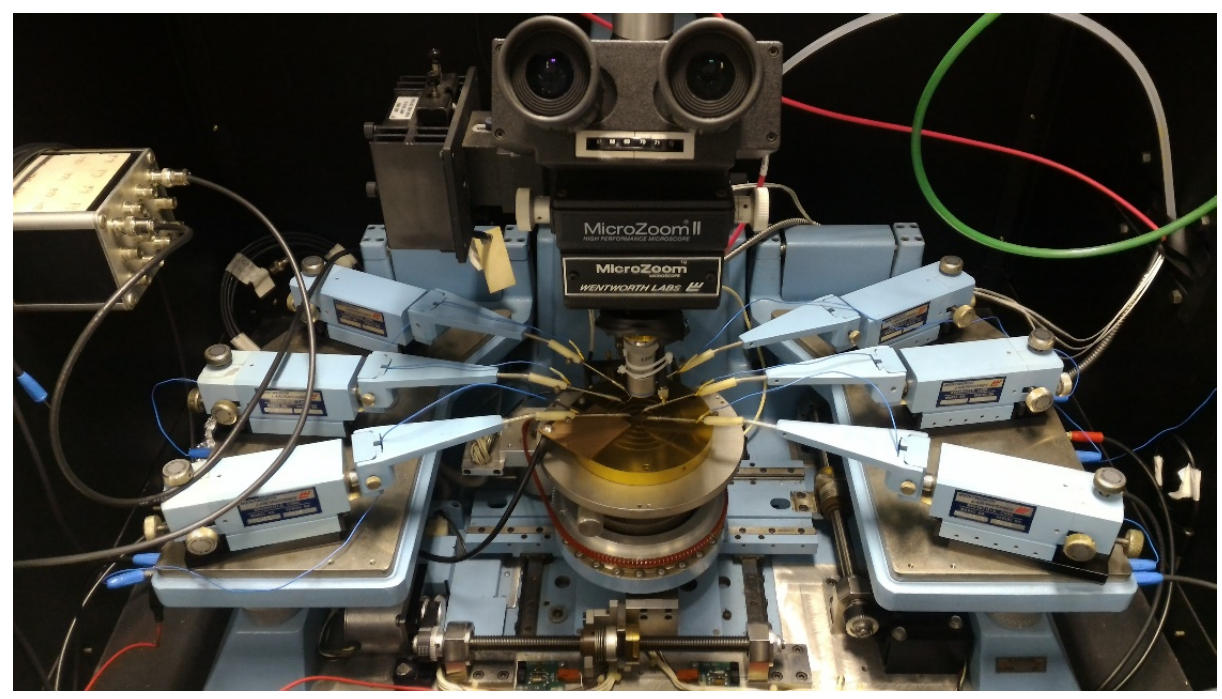

Fonte: O Autor. 


\section{Resultados e Discussões}

Os resultados serão apresentados em dois grandes tópicos: amostras sem ouro (matrizes) e amostras com ouro. Para cada caso serão feitas as correlações entre as características estruturais e elétricas dos filmes produzidos. Também serão estabelecidas correlações entre os comportamentos obtidos nas amostras com ouro e suas respectivas matrizes.

As medidas de espessura dos filmes depositados nesse trabalho foram realizadas por perfilometria, próximo às ilhas de alumínio (Figura 4.1). Para garantir maior precisão, três medidas foram realizadas em cada ponto, e a média dos valores obtidos foi considerada como a espessura aproximada dos processos.

Figura 4.1 - Exemplo de local utilizado para medida de espessura.

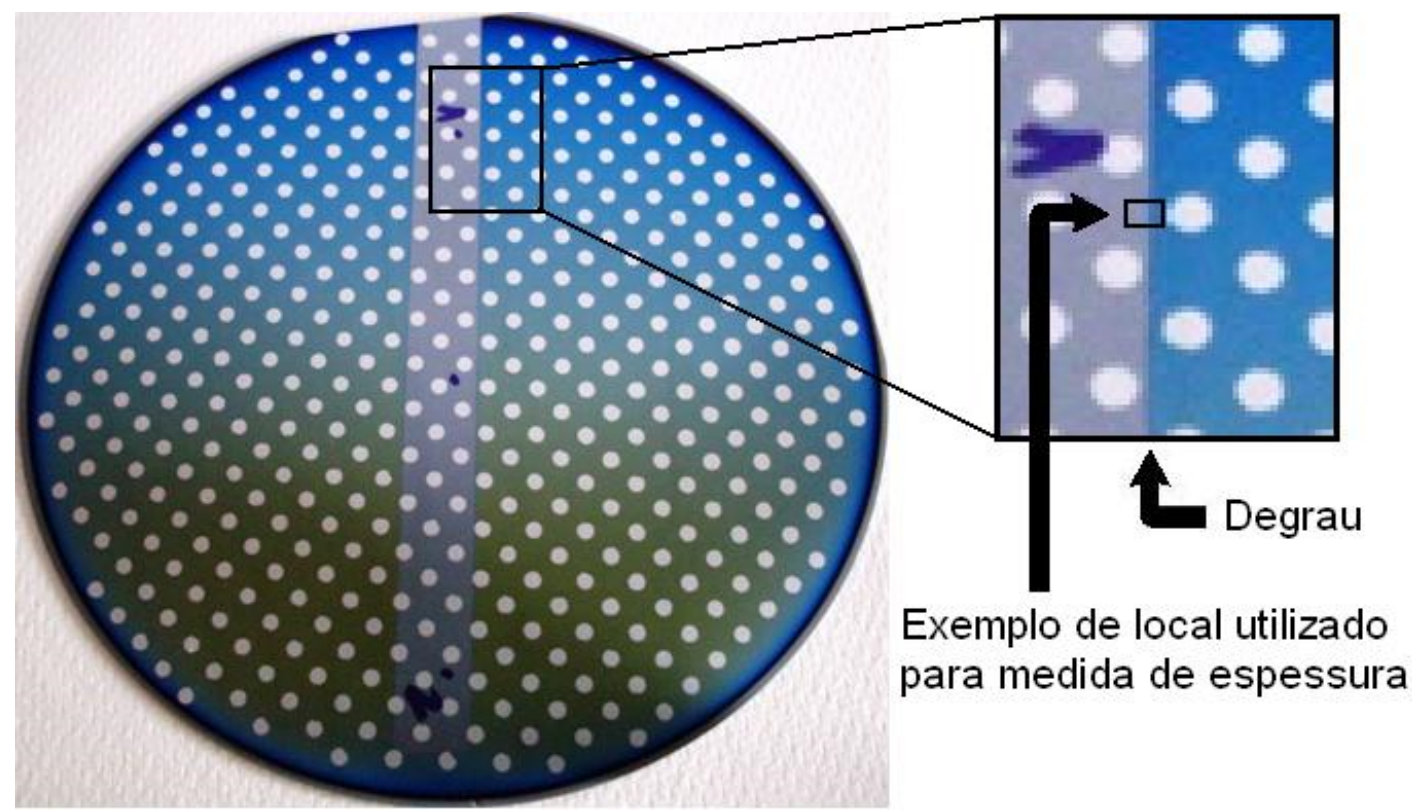

Fonte: O Autor.

De acordo com a metodologia apresentada, a média dos valores de espessura obtidos para os filmes depositados por 75 e 360 min foram de $(102 \pm 10) \mathrm{nm}$ e $(485 \pm 20) \mathrm{nm}$, respectivamente. Dessa forma, os valores de espessura aproximados de 100 e $500 \mathrm{~nm}$ serão utilizados para referir-se à espessura do filme depositado, conforme o tempo de deposição. 


\subsection{Amostras sem ouro}

As amostras sem ouro foram produzidas com diferentes fluxos de oxigênio durante a deposição. A mudança do fluxo de oxigênio pode alterar a estequiometria e ainda interferir nas propriedades elétricas do material depositado.

Para as matrizes foram depositados filmes com espessura de $100 \mathrm{~nm}$. Nestes casos foram estudados os filmes tratados termicamente por 10 horas, bem como os sem tratamento térmico.

A Tabela 4-1 apresenta as referidas amostras e os respectivos fluxos de oxigênio utilizados. As condições de deposição gerais foram apresentadas no item 3.3, e por facilidade estão indicados na Tabela 4-1 apenas os fluxos de oxigênio empregados. Os números que acompanham os códigos estão associados ao fluxo de oxigênio usado.

Tabela 4-1 - Amostras produzidas sem ouro, com espessura de $100 \mathrm{~nm}$, tratadas termicamente por 0 e 10 horas e com diferentes fluxos de oxigênio.

\begin{tabular}{c|c}
\hline Amostra & $\begin{array}{c}\text { Fluxo de } \\
\text { oxigênio } \\
\text { (sccm) }\end{array}$ \\
\hline M0 & 0 \\
\hline M0,5 & 0,5 \\
\hline M1 & 1 \\
\hline M2 & 2 \\
\hline M7 & 7 \\
\hline
\end{tabular}

Fonte: O Autor.

A Tabela 4-2 apresenta os resultados de RBS para as amostras apresentadas na Tabela 4-1. O tempo de tratamento térmico empregado em cada caso é indicado junto ao nome da amostra por: 0h (caso sem tratamento térmico) e 10h (caso com tratamento térmico de 10 horas). Por exemplo, a amostra M0 sem tratamento térmico será chamada de M0 - Oh. É importante destacar na Tabela 4-2 que a espessura média de $(102 \pm 10) \mathrm{nm}$ corresponde à uma concentração planar média de $(651 \pm 43)$ x $10^{15}$ átomos $/ \mathrm{cm}^{2}$ para as estequiometrias atômicas indicadas em porcentagem (a soma resulta em 100\%). 
Tabela 4-2 - Dados extraídos por RBS das amostras sem ouro.

\begin{tabular}{|c|c|c|c|c|}
\hline Amostra & $\begin{array}{c}\text { Concentração } \\
\text { planar } \\
\left(\mathbf{1 0}^{15} \text { átomos } / \mathrm{cm}^{2}\right)\end{array}$ & $\operatorname{Te}(\%)$ & $\operatorname{Zn}(\%)$ & $\mathbf{O}(\%)$ \\
\hline M0 - 0h & 680 & 33,7 & 9 & 57,3 \\
\hline M0 - 10h & 670 & 29,5 & 8,3 & 62,2 \\
\hline M0,5 - 0h & 690 & 22,5 & 6,1 & 71,4 \\
\hline M0,5 - 10h & 710 & 20,5 & 5,3 & 74,2 \\
\hline M1 - 0h & 665 & 20 & 5,4 & 74,6 \\
\hline M1 - 10h & 660 & 20,8 & 5,6 & 73,6 \\
\hline M2-0h & 650 & 20 & 5,4 & 74,6 \\
\hline M2-10h & 620 & 21 & 5,4 & 73,6 \\
\hline M7 - 0h & 600 & 18 & 4,5 & 77,5 \\
\hline M7 - 10h & 570 & 19,5 & 5 & 75,5 \\
\hline
\end{tabular}

Fonte: O Autor.

A Figura 4.2 mostra os resultados de RBS para as amostras M0, M0,5, M1, M2 e M7, sem tratamento térmico, a fim de apresentar o efeito de diferentes fluxos de oxigênio. Nota-se que maiores fluxos de oxigênio promovem maiores concentrações relativas de oxigênio no filme. A principal diferença ocorre para a concentração nula de fluxo de oxigênio, onde a concentração relativa de Te é substancialmente maior. Tal fato implica em $\mathrm{TeO}_{x} \operatorname{com} x$ substancialmente menor ( $x$ aproximadamente 1,4), considerado $\mathrm{ZnO}$ constante. Ainda, a concentração relativa de Te diminui progressivamente em menor escala para concentrações de oxigênio na faixa de 0,5 a $7 \mathrm{sccm}$. 
Figura 4.2 - RBS das amostras M0, M0,5, M1, M2 e M7. Efeito do fluxo de oxigênio na concentração dos elementos das matrizes sem tratamento térmico.

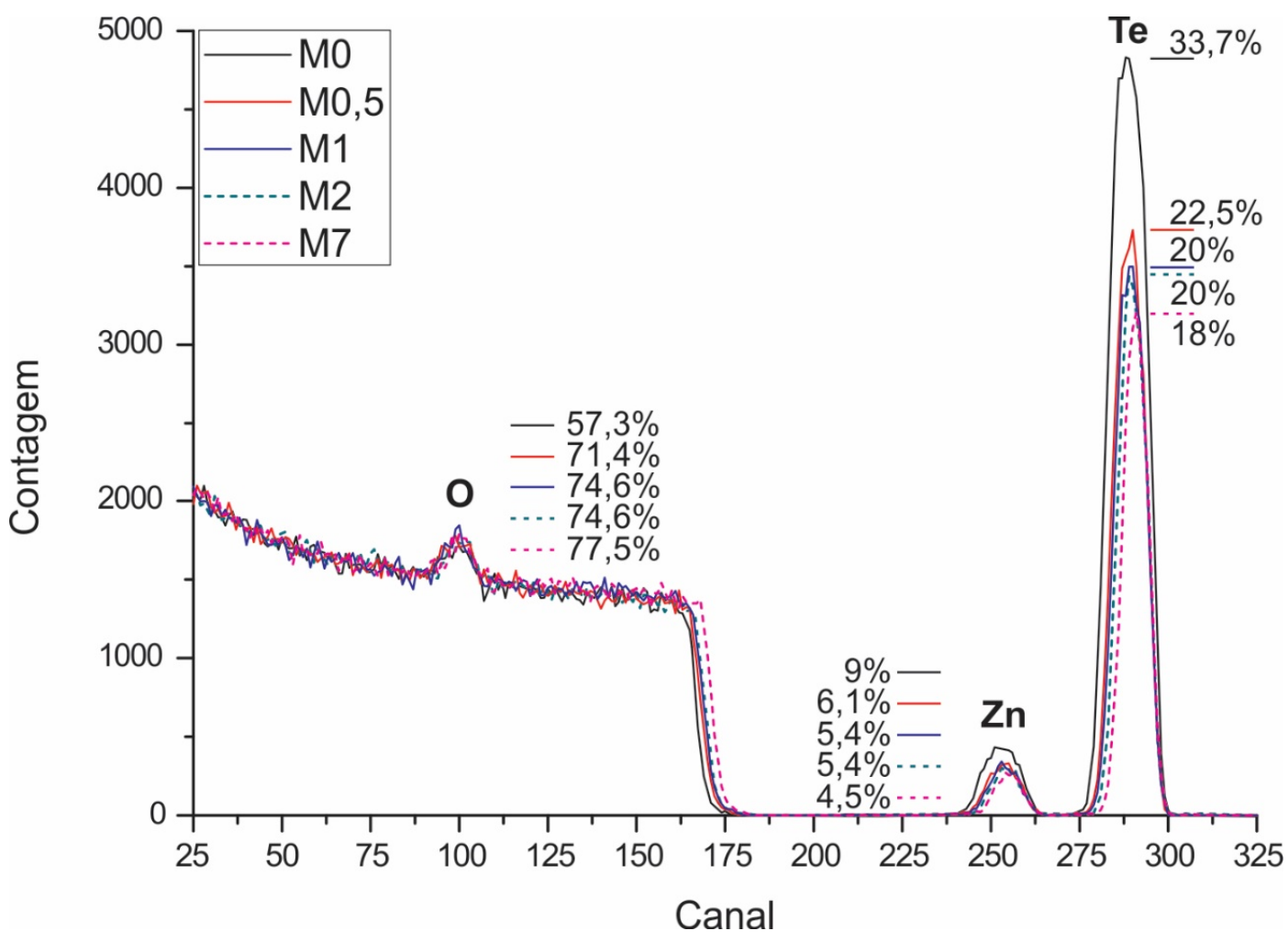

Fonte: O Autor.

A Figura 4.3 mostra os resultados de RBS para as amostras M0, M0,5, M1, M2 e M7, a fim de apresentar o efeito do tratamento térmico de 10 horas na concentração dos elementos das matrizes. A principal diferença ocorre para a concentração nula de fluxo de oxigênio, onde a concentração relativa de Te é substancialmente maior, como no caso sem tratamento térmico. Tal fato implica em $\mathrm{TeO}_{x} \operatorname{com} x$ menor ( $x$ aproximadamente 1,8 ), considerado $\mathrm{ZnO}$ constante. Para concentrações de oxigênio correspondentes a fluxos na faixa de 0,5 a $7 \mathrm{sccm}$, não há diferença substancial na concentração relativa de Te e Zn, indicando que a estequiometria estabiliza em $\mathrm{TeO}_{3,4}-\mathrm{ZnO}$. 
Figura 4.3 - RBS das amostras M0, M0,5, M1, M2 e M7. Efeito do tratamento térmico na concentração dos elementos das matrizes tratadas termicamente por 10 horas.

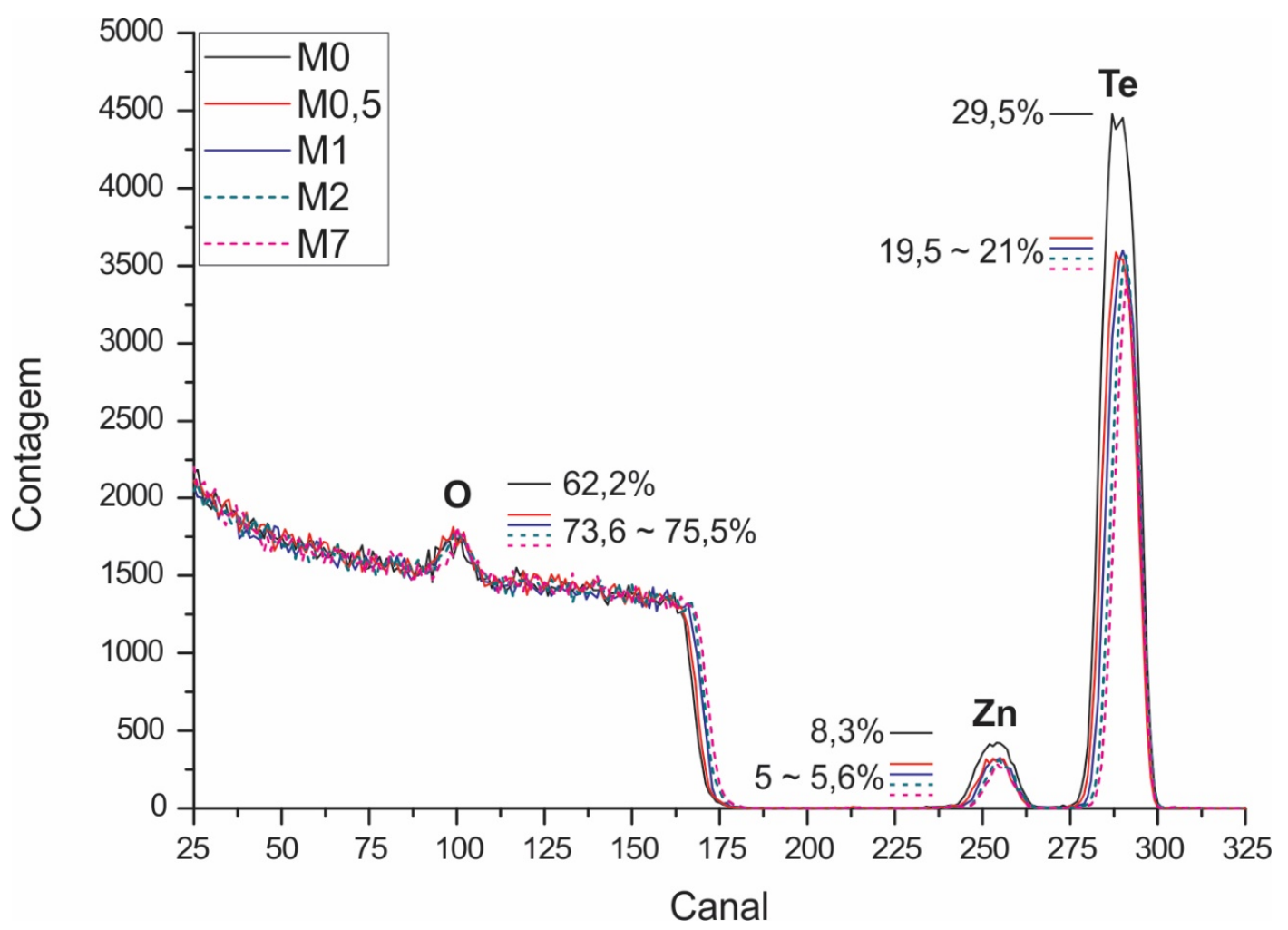

Fonte: O Autor.

A Figura 4.4 apresenta a corrente de fuga típica em função da tensão para a amostra M0. É possível observar que essa amostra, produzida sem adição de oxigênio durante a deposição e tratada termicamente por 0 e 10 horas, apresentou baixa corrente de fuga (da ordem de $10^{-7}$ a $10^{-9} \mathrm{~A}$, respectivamente). Nas medidas $\mathrm{I}-\mathrm{V}$, a tensão elétrica aplicada na amostra é chamada por Vg. 
Figura 4.4 - Corrente de fuga em função da tensão para as amostras M0 - 0h e 10h.

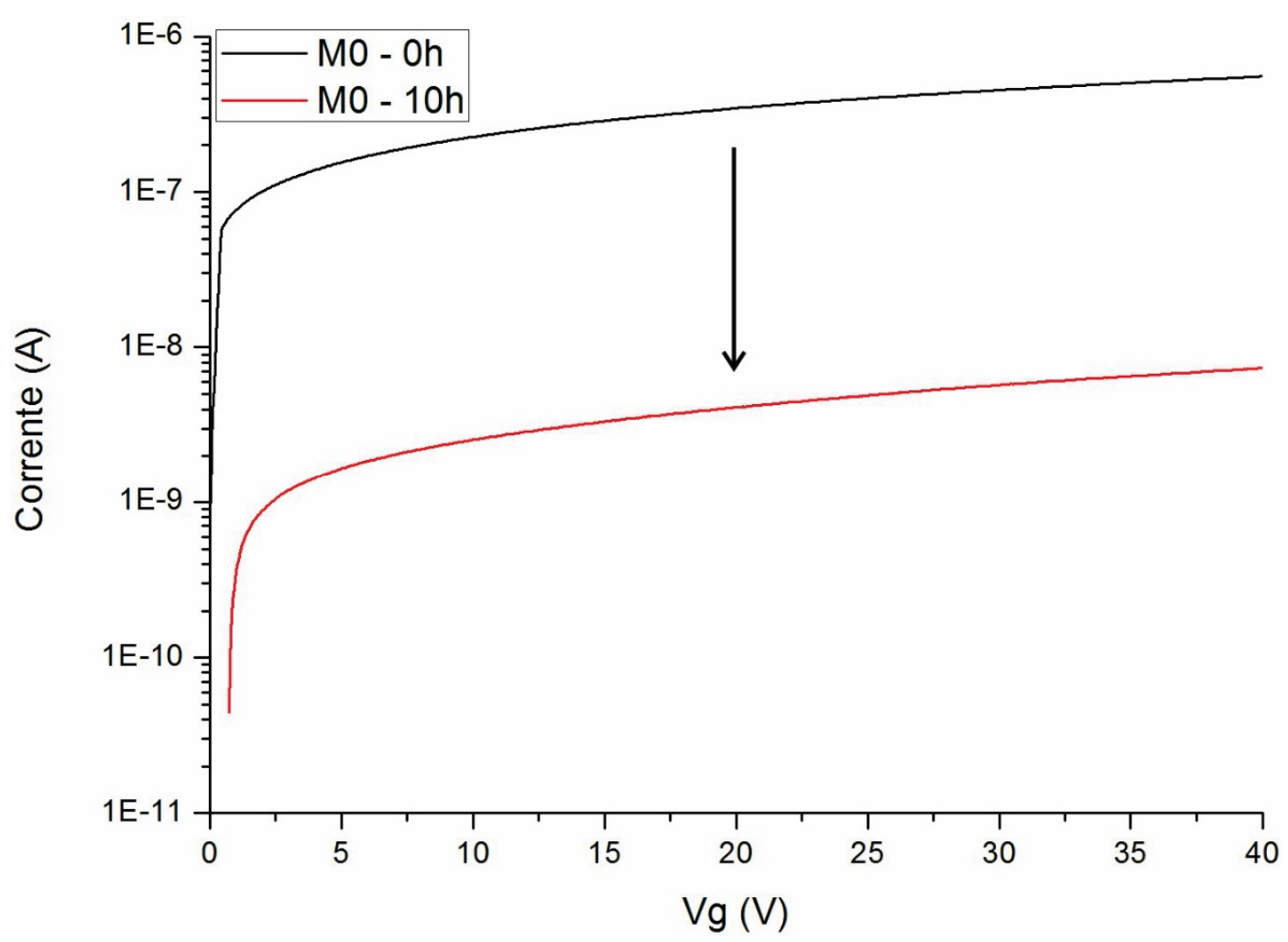

Fonte: O Autor.

Na Figura 4.4 é possível observar a diminuição da corrente de fuga em decorrência do tratamento térmico de 10 horas. O tratamento térmico causa provavelmente alívio das tensões internas do filme, que por sua vez organiza a estrutura interna do material, reduzindo a quantidade de defeitos e promovendo menor quantidade de portadores de carga, diminuindo assim a condutividade do material e explicando a redução da corrente vista na Figura 4.4. Esse comportamento em função do tratamento térmico foi sistematicamente observado para as amostras sem ouro.

As amostras produzidas com adição de baixo fluxo de oxigênio durante a deposição (M0,5, M1 e M2) e sem tratamento térmico apresentaram tipicamente aumento abrupto da corrente de fuga após ativação em valor de tensão $\mathrm{V}_{\mathrm{A}}$, conforme apresentado na Figura 4.5. A tensão de ativação representa o valor no qual a corrente de fuga aumenta de forma abrupta, indicando a passagem de um estado de baixa condutividade para outro de alta condutividade. 
Figura 4.5 - Corrente de fuga em função da tensão para as amostras M0,5, M1 e M2 sem tratamento térmico: $1^{\text {a }}$ varredura.

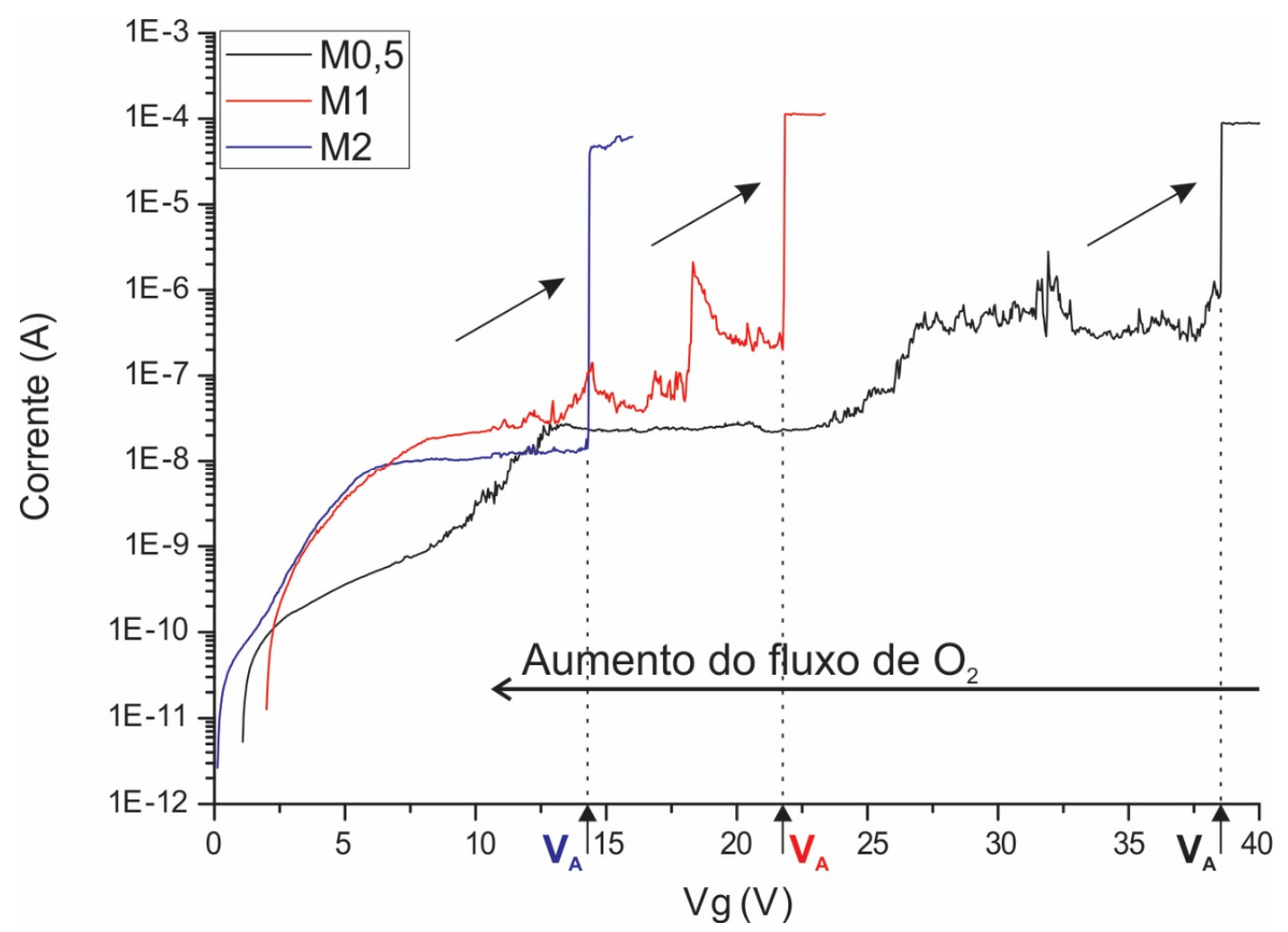

Fonte: O Autor.

É possível observar que o aumento gradual do fluxo de oxigênio promove a redução do valor de tensão $\mathrm{V}_{\mathrm{A}}$. Com o aumento do fluxo de oxigênio, nota-se também o aumento da variação da condutividade entre os estados de menor e maior condutividade (janela de transição). Existe mudança de até 2 ordens de grandeza entre os estados de baixa e alta condutividade para fluxo de oxigênio de $0,5 \mathrm{sccm}$, atingindo 4 ordens de grandeza para fluxo de $2 \mathrm{sccm}$. A Figura 4.6 apresenta esses resultados com aqueles obtidos na segunda varredura. É possível notar que após a ativação, que ocorre na primeira varredura, as amostras apresentam maior nível de corrente, mesmo para baixas tensões. 
Figura 4.6 - Corrente de fuga em função da tensão para as amostras M0,5, M1 e M2 sem tratamento térmico: $1^{\mathrm{a}}$ e $2^{\mathrm{a}}$ varreduras.

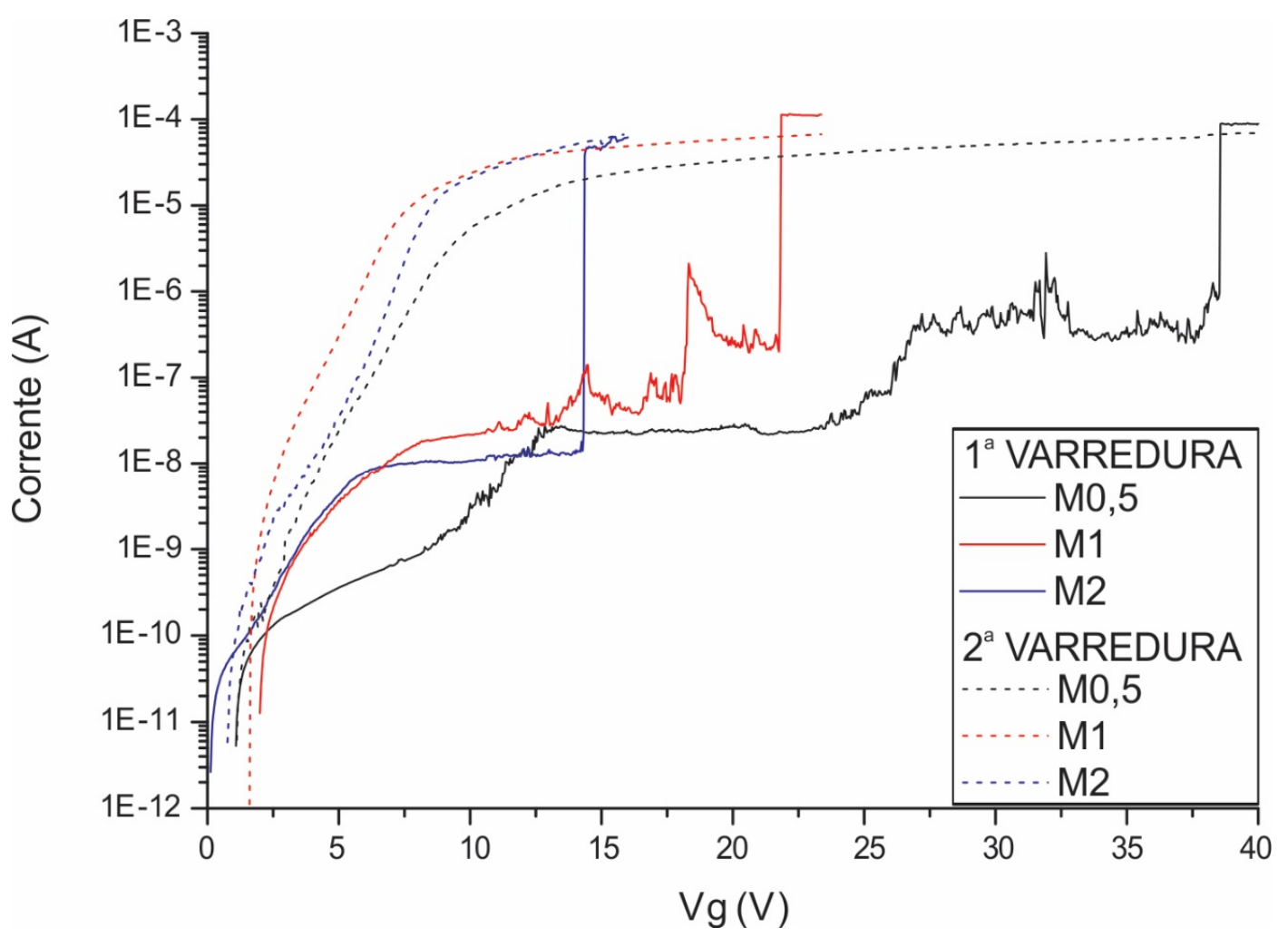

Fonte: O Autor.

As amostras M0,5 e M1, tratadas termicamente por 10 horas, apresentam redução no nível de corrente quando comparadas com as amostras não tratadas termicamente, como mostrado na Figura 4.7. Adicionalmente, para essas amostras (M0,5 e M1 tratadas termicamente por 10h) não foi observada a transição abrupta da corrente, conforme observado nos casos sem tratamento térmico (Figura 4.5). 
Figura 4.7 - Corrente de fuga em função da tensão para as amostras M0,5 e M1, sem tratamento térmico e com tratamento térmico de 10 horas.

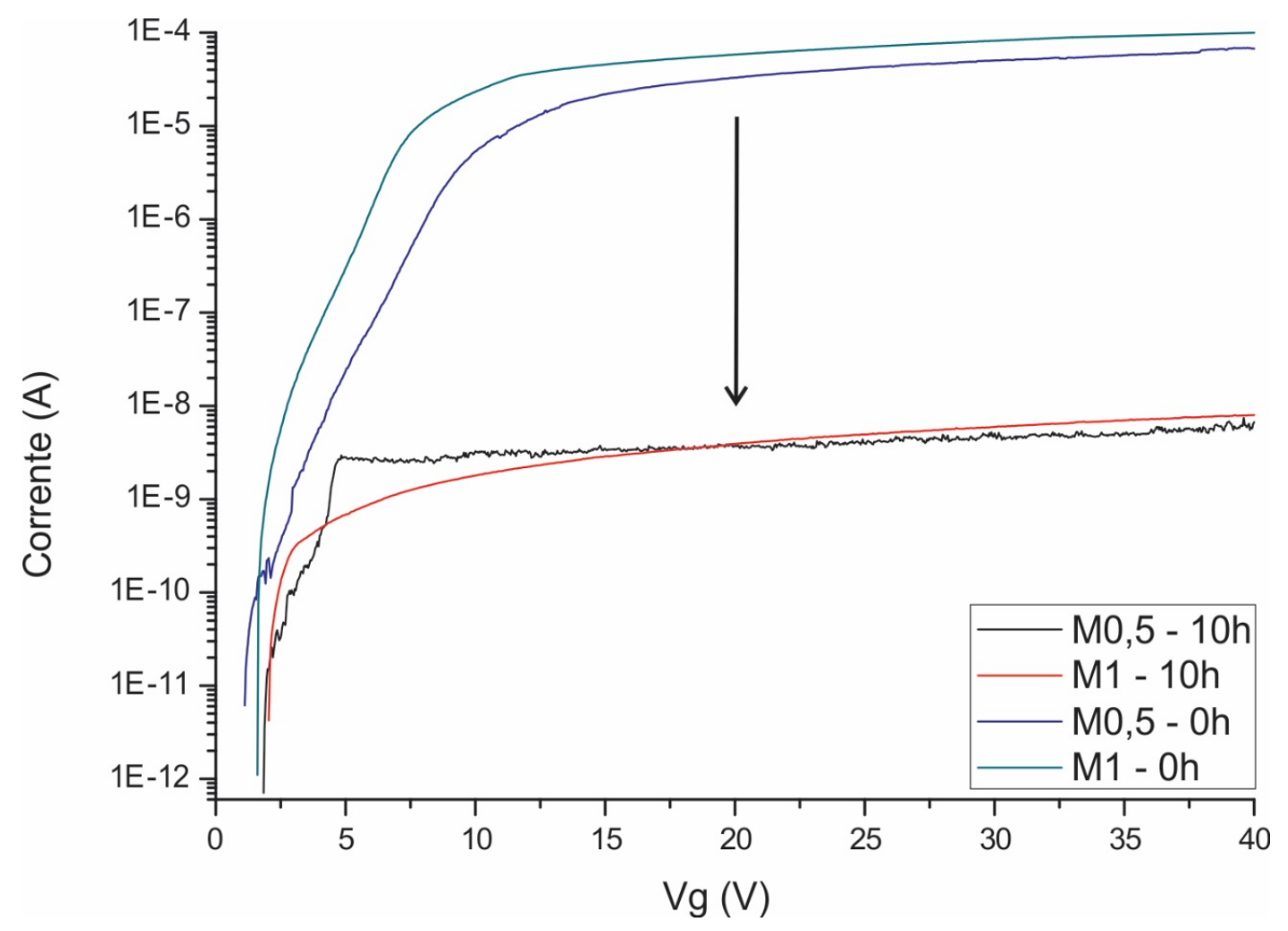

Fonte: O Autor.

A amostra M2 - 10h, diferentemente das outras amostras com baixo fluxo de oxigênio e também tratadas termicamente por 10 horas (Figura 4.7), apresenta comportamento I-V suscetível a rompimentos, como mostrado na Figura 4.8. 
Figura 4.8 - Corrente de fuga em função da tensão para a amostra M2 - 10h: $1^{\text {a }}$ varredura para três dispositivos.

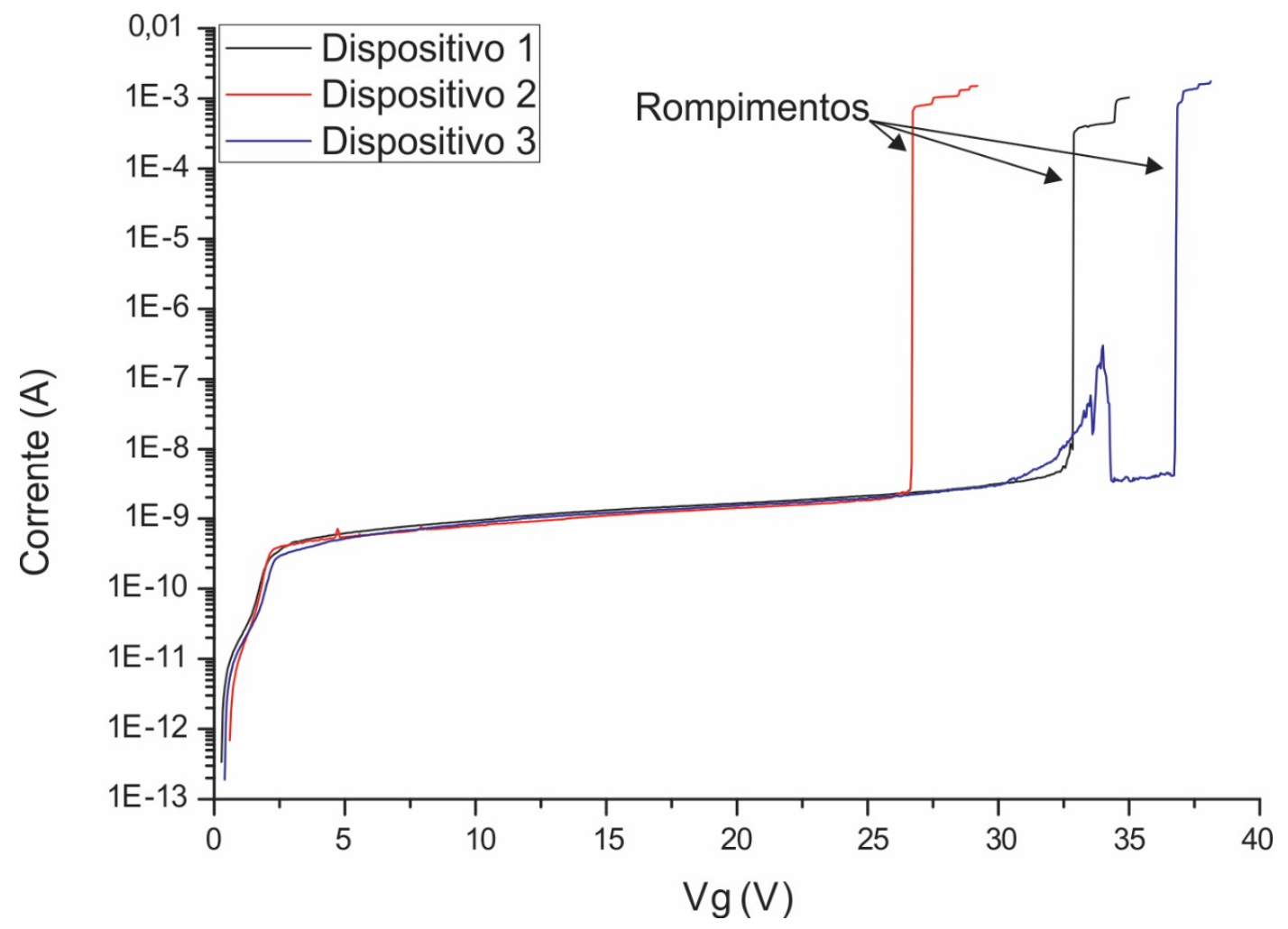

Fonte: O Autor.

Neste caso notam-se aspectos diferentes, como por exemplo, presença de rompimentos e altas correntes, maiores que nos casos anteriores, mesmo após o tratamento térmico. Estes rompimentos caracterizam-se pela presença de degradação do dispositivo, que se danificam, perdendo sua integridade e atingindo valores altos de corrente.

A seguir, a Figura 4.9 apresenta o comportamento I-V da amostra M1 - 0h, que foi submetida a uma segunda varredura, mas nesse caso após a aplicação de um ciclo de tensão negativa. $\mathrm{O}$ ciclo de tensão negativa foi feito pois, conforme será mostrado adiante, a amostra preparada nas mesmas condições da amostra M1, mas com nanopartículas de ouro, apresentou comportamento de memória não volátil reversível; por isso, foi verificado através desse condicionamento da matriz o possível valor a ser atingido pelo nível de corrente. Nas matrizes, foi observado experimentalmente que a obtenção de um nível de corrente da ordem de microampères é um indicativo do possível funcionamento do dispositivo como memória quando nanopartículas são adicionadas.

Nesse caso, foi aplicada ao dispositivo uma varredura de tensão partindo de 0 até -12 V. Após esse ciclo de tensão negativa, foi extraída a curva I-V para baixas tensões $(0-6 \mathrm{~V})$. 
A Figura 4.9 apresenta o comportamento I-V da amostra M1 - 0h, submetida a segunda varredura após aplicação do ciclo de tensão negativa (nesta figura, a $1^{\mathrm{a}}$ varredura é mostrada para efeito de comparação).

Figura 4.9 - Corrente de fuga em função da tensão para a amostra M1 - 0h: 2a varredura após aplicação de ciclo de tensão negativa.

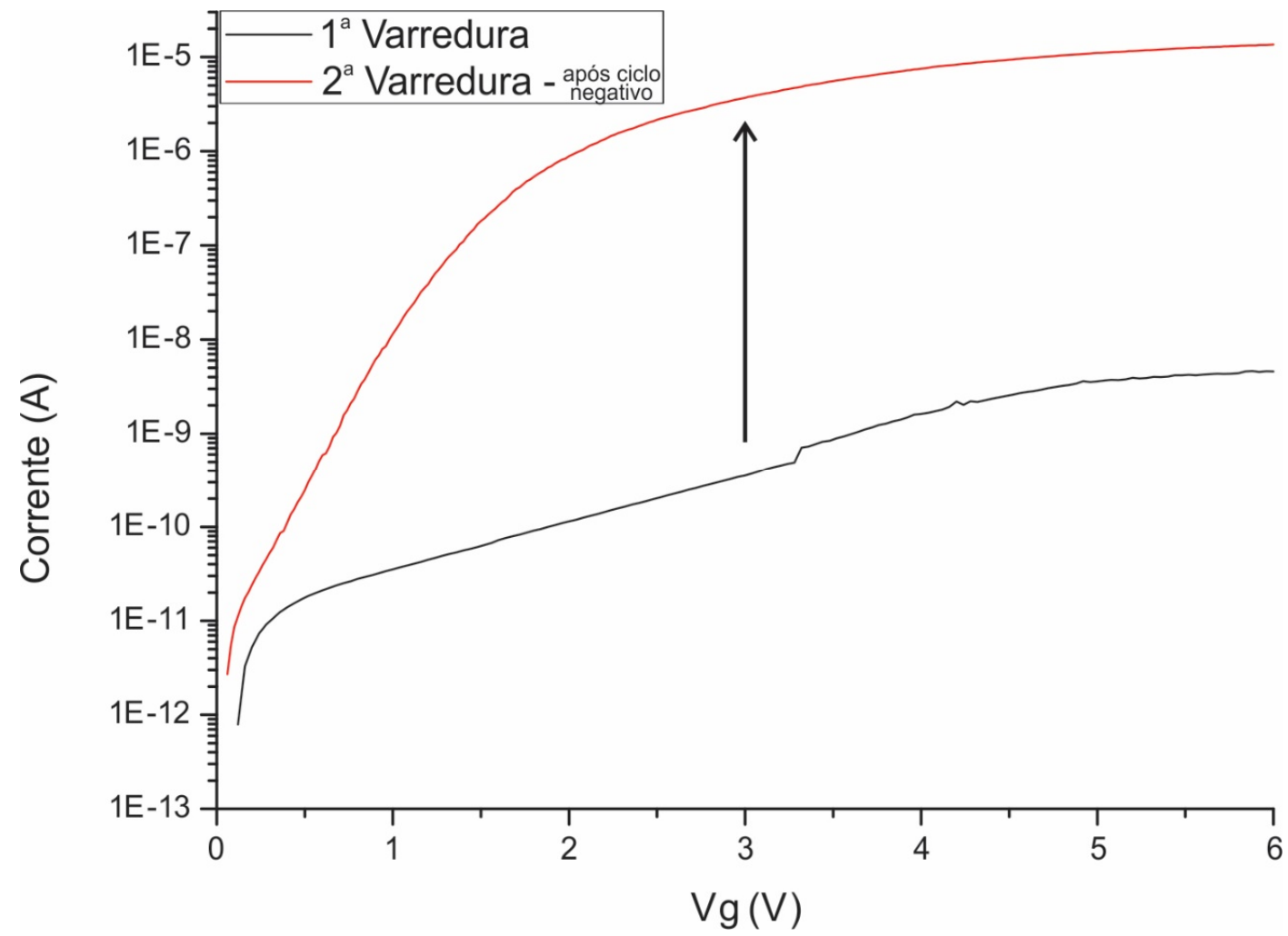

Fonte: O Autor.

Após a aplicação do ciclo de tensão negativa ocorre o aumento da corrente de fuga, mesmo em condições de pequenas tensões aplicadas antes da ativação. Por meio desse condicionamento da matriz M1 - 0h, foi possível obter valores de corrente superiores a $1 \mu \mathrm{A}$ a partir de $2 \mathrm{~V}$.

A Figura 4.10 apresenta o comportamento da corrente de fuga em função da tensão para o caso da amostra M7 - 0h. Essa amostra produzida com adição do maior fluxo de oxigênio durante a deposição (Tabela 4-1) e sem tratamento térmico, apresentou transição abrupta de corrente para tensão de ativação $\left(\mathrm{V}_{\mathrm{A}}\right)$ de aproximadamente $33 \mathrm{~V}$. 
Figura 4.10 - Corrente de fuga em função da tensão para a amostra M7 - 0h.

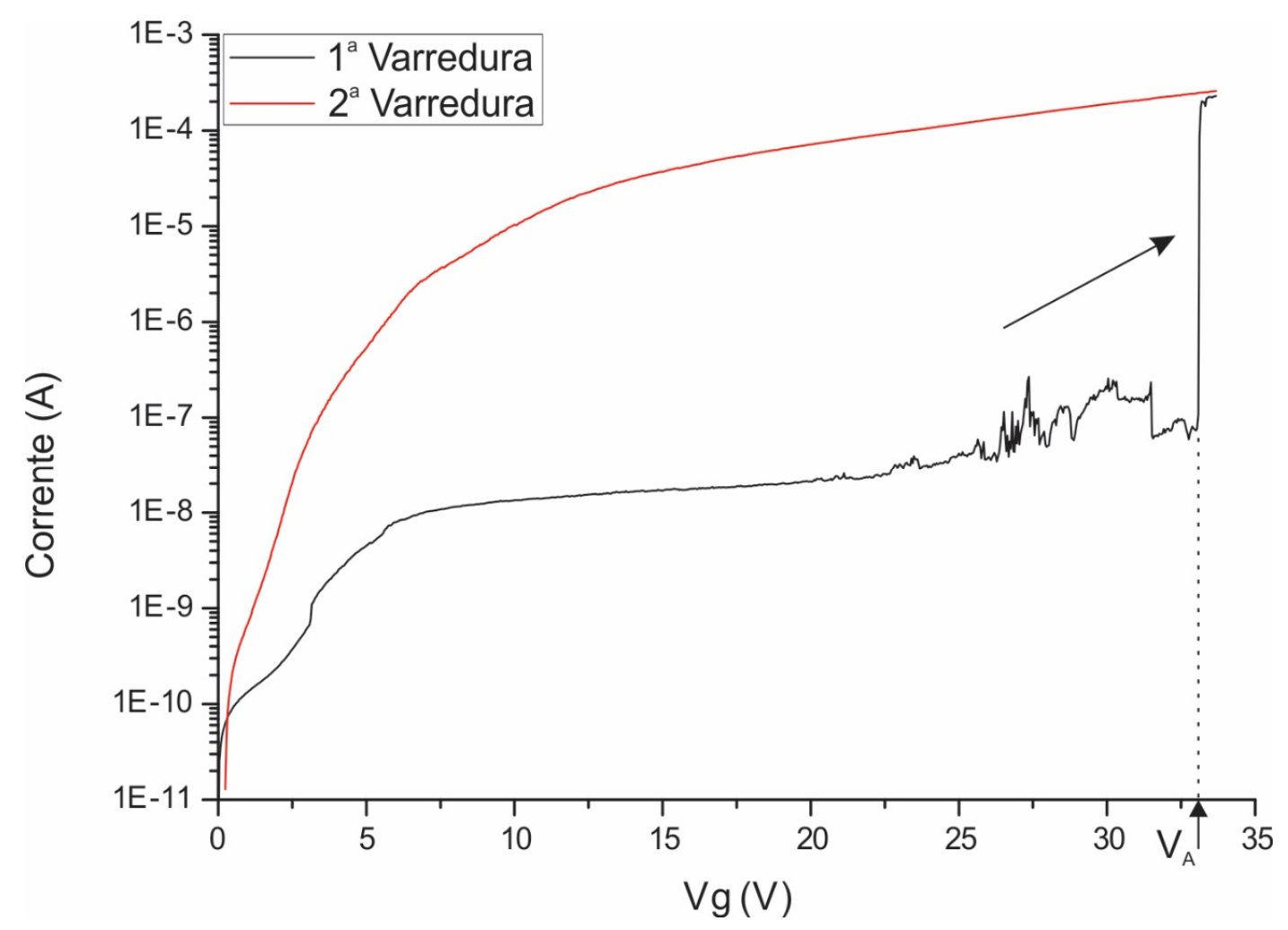

Fonte: O Autor.

Nas amostras com baixo fluxo de oxigênio (M0,5, M1 e M2) e sem tratamento térmico, o aumento gradual do fluxo de oxigênio promoveu a redução do valor de tensão $\mathrm{V}_{\mathrm{A}}$. A característica I-V extraída da amostra M7 - 0h indica que ocorre aumento da tensão de ativação quando comparado com a amostra M2 - 0h e manutenção dos valores da corrente (aproximadamente $10^{-4}$ A) e da janela de transição (4 ordens de grandeza). Esse comportamento distinto para a amostra M7 está associado à menor concentração planar obtida para 0 h, conforme indicado na Tabela 4-2, o que significa espessura um pouco abaixo de 100 nm e maior dificuldade de promover a ativação da matriz, fato que será discutido posteriormente.

A Figura 4.11 apresenta o comportamento da corrente de fuga em função da tensão para o caso da amostra M7 - 10h. 
Figura 4.11 - Corrente de fuga em função da tensão para a amostra M7 - 10h.

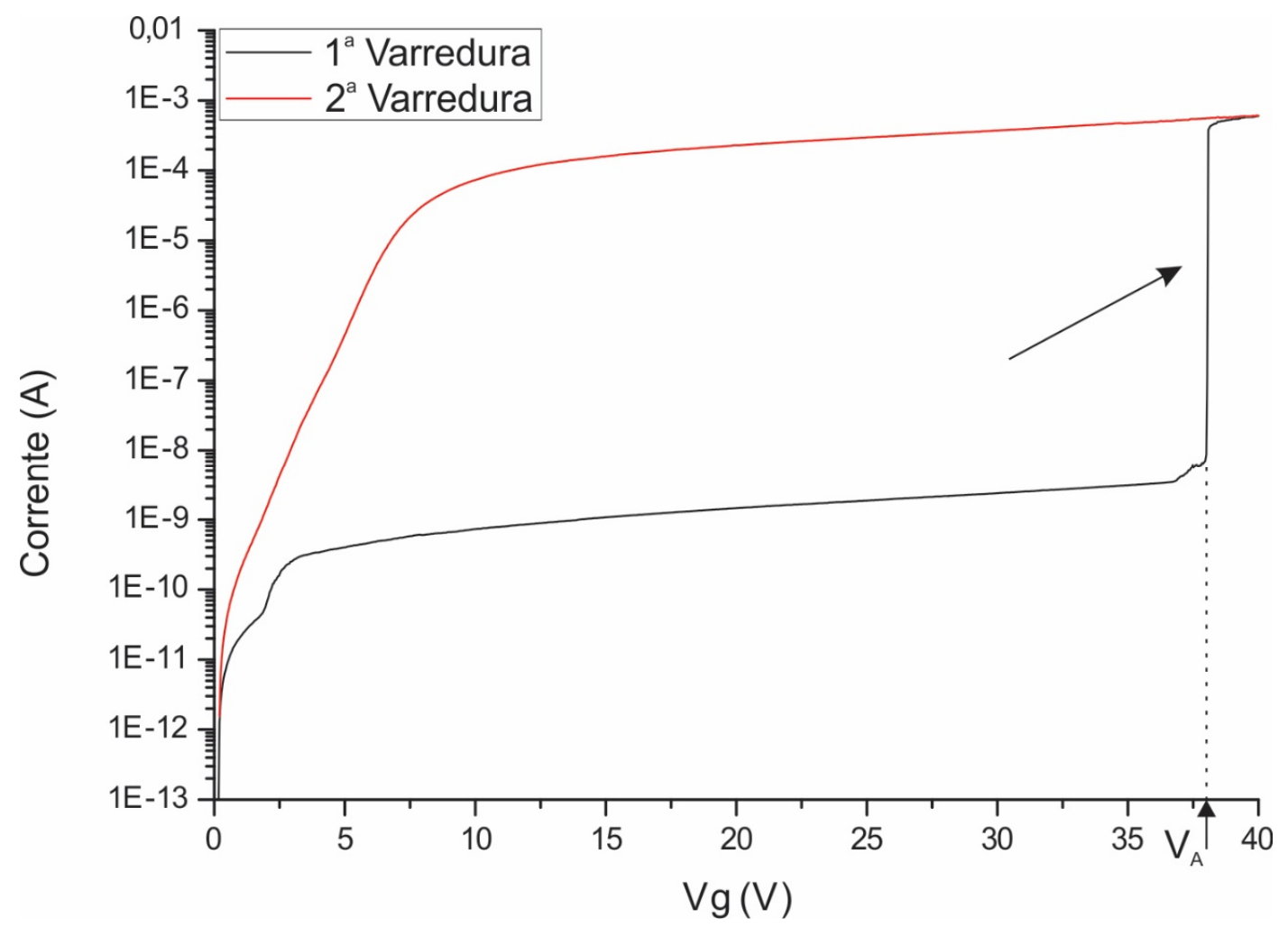

Fonte: O Autor.

Diferentemente da amostra M2 - 10h, que apresentou característica suscetível a rompimentos, a amostra M7 - 10h não apresenta rompimentos, pois a integridade do dispositivo é preservada, mas apresenta ativação em valor elevado de tensão (aproximadamente $38 \mathrm{~V}$ ).

Ressalta-se que a amostra M7 - 10h apresenta, para a segunda varredura, valor de corrente compatível à aplicação sugerida referente à construção de memórias; o mesmo aplica-se aos outros casos, anteriormente mostrados, para os quais há transição abrupta da corrente.

Observando todos os resultados, destacam-se as amostras M0,5, M1 e M2, sem tratamento térmico, e as amostras M7 - 0h e 10h. É possível observar que essas amostras apresentam transição abrupta de corrente (com janela de transição de até 6 ordens de grandeza), e na segunda varredura, mesmo para tensões baixas, a corrente já assume valores altos e comparáveis aos da primeira varredura após a transição (da ordem e $10^{-4} \mathrm{~A}$ ). Acrescenta-se ainda que a menor tensão de ativação é observada para a amostra M2 - 0h e as maiores para as amostras M7 - 0h e 10h e M0,5 - 0h. Dentre todas estas, o melhor 
comportamento refere-se a amostras M2 - 0h, pelo fato de possuir a menor tensão de ativação e na qual se dá expressiva mudança de corrente de fuga entre os estados de menor e maior condutividade.

Assim, conclui-se que os processos mais adequados para produção de memórias em matrizes de $\mathrm{TeO}_{2}-\mathrm{ZnO}$ são obtidos com fluxo de oxigênio baixo (1-2 sccm) e sem tratamento térmico, que apresentam tensão de ativação máxima de $22 \mathrm{~V}$. Para fluxo maior, de $7 \mathrm{sccm}$, a tensão de ativação aumenta para aproximadamente 33 e $38 \mathrm{~V}$, para tratamentos térmicos de 0 e 10 horas, respectivamente. As maiores janelas de transição referem-se aos casos M2 - 0h e M7 - 0h e 10h. Considerando que o uso de alta tensão para o fim proposto não é adequado, conclui-se que o melhor processo é o da amostra M2 - 0h.

Os dispositivos citados, uma vez ativados em tensão maior que $\mathrm{V}_{\mathrm{A}}$, não exibem perda do nível de corrente atingido. Tal comportamento é característico da formação de tubos de corrente localizados através do filme, que têm maior facilidade de se formar para menores concentrações de oxigênio e, possivelmente, maior dificuldade para menores espessuras [114]. Os tubos de corrente têm maior facilidade de estabelecer-se entre irregularidades ou asperezas interfaciais mais pontiagudas (efeito ponta) [115].

Baseados nos comportamentos típicos da corrente para cada concentração de oxigênio, é possível estabelecer, a partir das observações experimentais, que:

a) à medida que aumenta a concentração de oxigênio, diminuem as concentrações de Te e Zn, o que está associado a maior dificuldade na formação dos tubos de corrente através dos filmes, possivelmente porque os valores locais de campo elétrico diminuem.

b) se a espessura diminui ao mesmo tempo que a concentração de oxigênio aumenta (amostra M7), o campo local tem maior dificuldade de intensificar-se, muito provavelmente devido a menor distribuição volumétrica de átomos metálicos.

\subsection{Amostras com ouro}

As amostras com ouro foram produzidas sob diferentes condições de processo. Foram utilizados no processo de deposição dos filmes diferentes aberturas do shutter e potências no alvo de ouro (para controlar a concentração do ouro) além de diferentes fluxos de oxigênio. Foram depositados filmes com espessuras aproximadas de $500 \mathrm{~nm}$ (deposição de 360 minutos) e $100 \mathrm{~nm}$ (deposição de 75 minutos). Tempos de tratamento térmico de 10 e 20 
horas foram empregados em todos os casos, e na maioria deles as amostras sem tratamento térmico também foram estudadas.

A Tabela 4-3 apresenta as amostras produzidas de acordo com as condições de processo utilizadas.

Tabela 4-3 - Amostras produzidas com ouro e com diferentes espessuras, fluxos de oxigênio, tempos de tratamento térmico e aberturas do shutter. Em todos os casos foi usada potência de $50 \mathrm{~W}$ no alvo de $\mathrm{TeO}_{2}-\mathrm{ZnO}$.

\begin{tabular}{|c|c|c|c|c|c|}
\hline Amostra & $\begin{array}{c}\text { Espessura } \\
\text { aproximada } \\
(\mathrm{nm})\end{array}$ & $\begin{array}{c}\text { Abertura } \\
\text { do shutter } \\
\text { do ouro }\end{array}$ & $\begin{array}{c}\text { Fluxo de } \\
\text { oxigênio } \\
\text { (sccm) }\end{array}$ & $\begin{array}{l}\text { Tempo de } \\
\text { tratamento } \\
\text { térmico }(h)\end{array}$ & $\begin{array}{l}\text { Potência no } \\
\text { alvo de ouro } \\
\text { (W) }\end{array}$ \\
\hline \multirow{2}{*}{ S35 } & 100 & \multirow{2}{*}{35} & \multirow{2}{*}{4} & \multirow{4}{*}{0,10 e 20} & \multirow{9}{*}{6} \\
\hline & 500 & & & & \\
\hline \multirow{2}{*}{ S40 } & 100 & \multirow{2}{*}{40} & \multirow{4}{*}{4} & & \\
\hline & 500 & & & & \\
\hline \multirow{2}{*}{ S45 } & 100 & \multirow{2}{*}{45} & & \multirow{2}{*}{10 e 20} & \\
\hline & 500 & & & & \\
\hline \multirow{2}{*}{ S50 } & 100 & \multirow{2}{*}{50} & $1,2,4$ e 7 & \multirow{4}{*}{0,10 e 20} & \\
\hline & 500 & & 1 & & \\
\hline S60 & \multirow{2}{*}{100} & 60 & 2,6 e 7 & & \\
\hline$S_{\text {tot }}$ & & total & 7 & & 7 \\
\hline
\end{tabular}

Fonte: O Autor.

As amostras serão nomeadas segundo o padrão: S“abertura do shutter" _espessura"_fluxo de oxigênio" - "tratamento térmico". Por exemplo, a primeira amostra da tabela, com tratamento térmico de 10 horas, recebe o nome S35_100_4 - 10h. Quando necessário, a potência aplicada no alvo de ouro será indicada ao lado do tempo de tratamento térmico (por exemplo: Stot_100_7 - 0h-7W).

A abertura do shutter controla a quantidade de material ejetado do alvo que atingirá o substrato e que consequentemente fará parte do filme depositado; assim, é possível controlar a concentração de ouro do filme depositado através do controle da abertura do shutter do ouro. Quanto menor a abertura do shutter, menor é a concentração de ouro esperada no filme depositado.

Através das análises por RBS foi possível verificar a evolução da concentração de ouro no filme depositado em função da abertura do shutter do alvo de ouro. A Figura 4.12 ilustra esse fenômeno ao apresentar as análises por RBS de amostras produzidas com aberturas do shutter de $35,40,45,50,60$ e total, tratadas termicamente por 10 horas e com 
espessura aproximada de $100 \mathrm{~nm}$. Para o caso da abertura total, os resultados de duas amostras são mostrados: amostras produzidas com potências aplicada ao alvo de ouro de 6 e 7 W.

Figura 4.12 - RBS das amostras produzidas com diferentes aberturas de shutter, espessura de $100 \mathrm{~nm}$ e tratamento térmico de 10 horas.

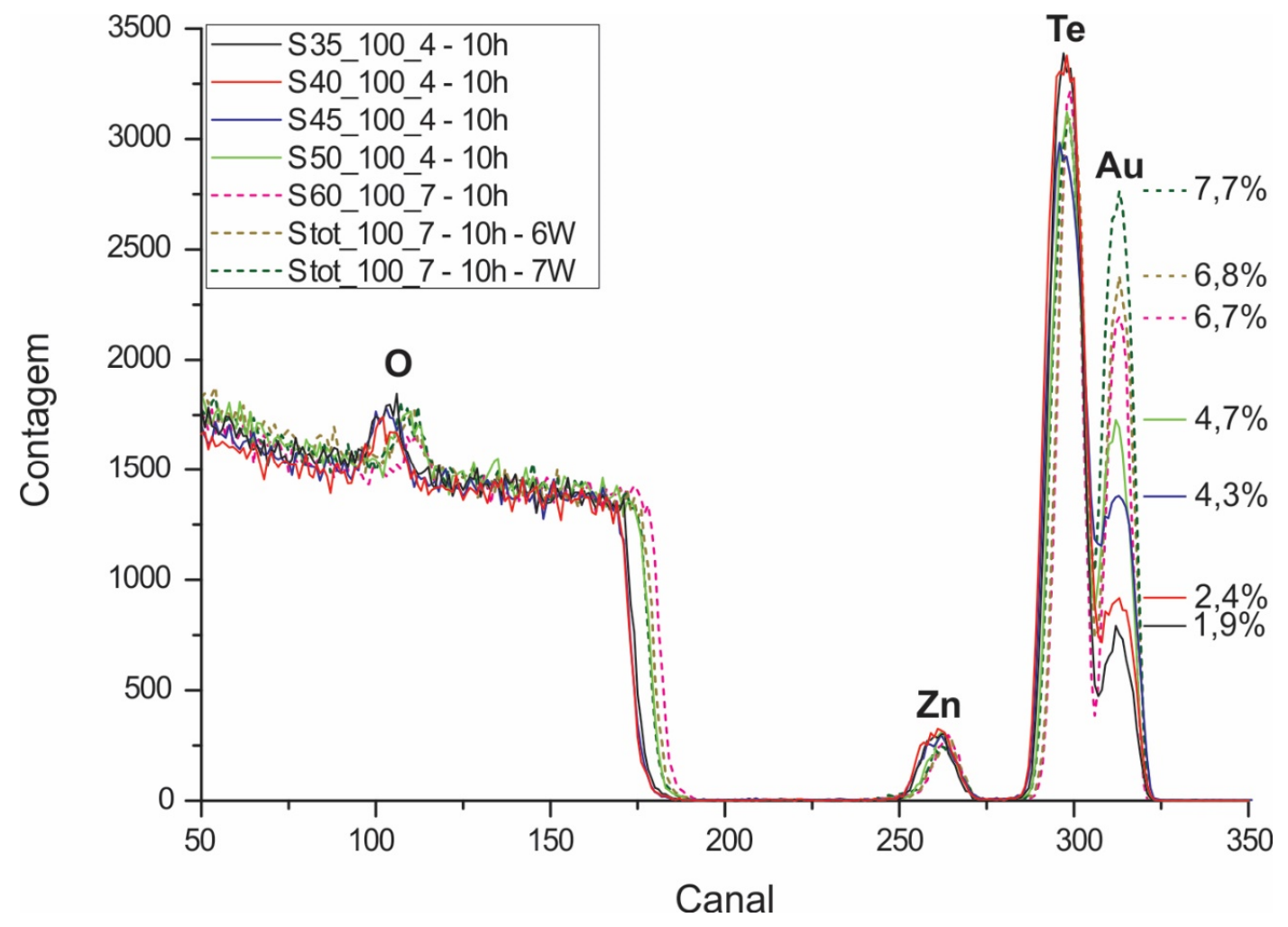

Fonte: O Autor.

Através da Figura 4.12 é possível observar o incremento da porcentagem de ouro no filme em função da maior exposição do alvo de ouro pela abertura do shutter. Com a abertura de 60 (amostra S60_100_7 - 10h) a superfície do alvo de ouro está quase completamente exposta, por isso não se observa aumento significativo na porcentagem de ouro para os casos de abertura 60 e total. A partir desse ponto, o aumento da potência aplicada no alvo de ouro foi necessário para produzir filmes com maior concentração de ouro.

Na Figura 4.12 ainda é possível observar os picos relacionados ao telúrio (Te) e zinco $(\mathrm{Zn})$ da matriz vítrea, do ouro $(\mathrm{Au})$, e do oxigênio $(\mathrm{O})$ incorporado ao filme; este último pôde ter sido incorporado a partir dos óxidos do alvo, ou do gás oxigênio utilizado durante a deposição. 
A Figura 4.13 apresenta as análises por RBS de amostras produzidas com aberturas do shutter de 35, 40 e 45, tratadas termicamente por 10 horas e com espessura aproximada de $500 \mathrm{~nm}$.

Figura 4.13 - RBS das amostras produzidas com diferentes aberturas de shutter, espessura de $500 \mathrm{~nm}$ e tratamento térmico de 10 horas.

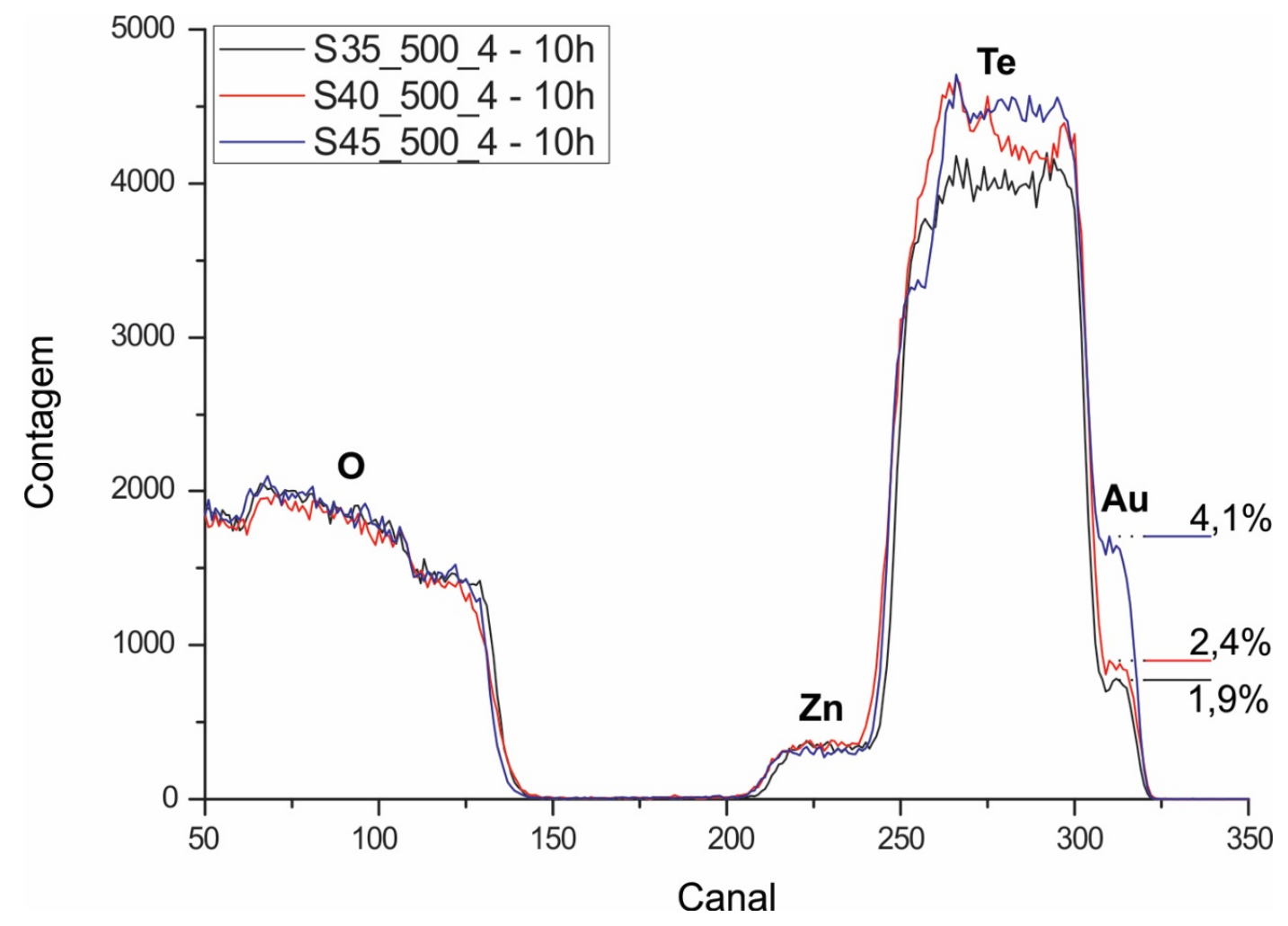

Fonte: O Autor.

Também nesse caso é possível observar o incremento da porcentagem de ouro no filme em função da maior exposição do alvo de ouro pela abertura do shutter. Os picos relacionados ao telúrio $(\mathrm{Te})$ e zinco $(\mathrm{Zn})$ da matriz vítrea, do ouro $(\mathrm{Au})$, e do oxigênio $(\mathrm{O})$, estão mostrados na figura.

A Figura 4.14 apresenta a influência do gás oxigênio utilizado durante o processo de deposição na incorporação do ouro e na concentração planar do filme. 
Figura 4.14 - RBS das amostras produzidas com mesma abertura de shutter, sem tratamento térmico, espessura de $100 \mathrm{~nm}$ e diferentes fluxos de oxigênio.

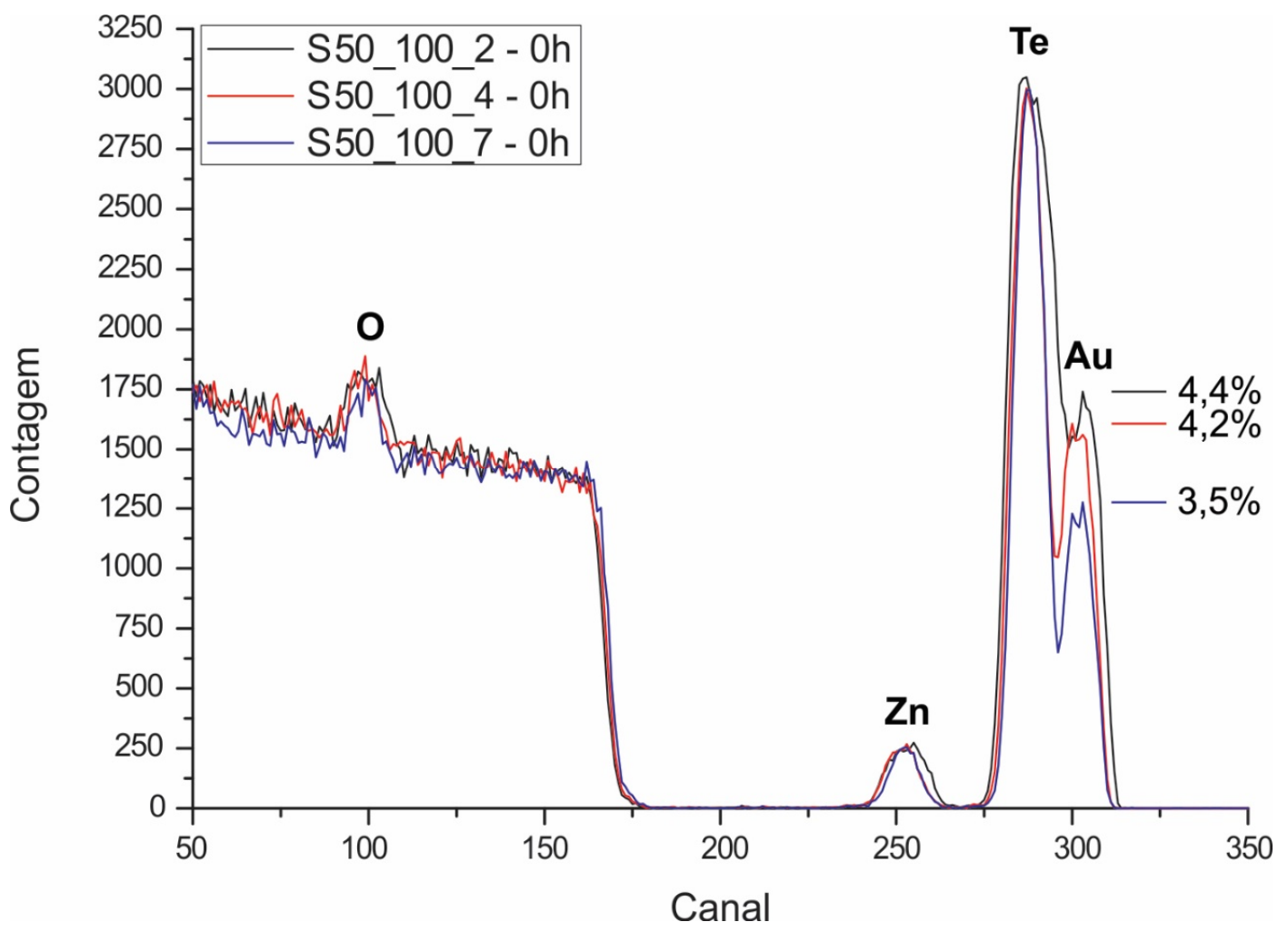

Fonte: O Autor.

O gás oxigênio dificulta a incorporação do ouro na matriz vítrea, quer por processos físicos/químicos na câmara de deposição, quer pela alteração estrutural do filme formado, tornando a matriz menos aceitadora. Para mesma abertura de shutter, a concentração de ouro cresce à medida que o fluxo de oxigênio diminui.

A Figura 4.15 apresenta o efeito do tratamento térmico nos filmes com ouro. No pico relacionado ao Au é possível observar que, para o filme sem tratamento térmico, o ouro está em maior concentração na região próxima à superfície do filme. Com o tratamento térmico de 10 horas, o ouro assume distribuição mais homogênea ao longo da espessura do filme, e com o tratamento térmico de 20 horas, esse efeito é ainda mais pronunciando.

A estequiometria do filme depositado se mantém em valor aproximadamente constante. A variação do percentual relativo da concentração do telúrio, mostrada na Figura 4.15, é na realidade o reflexo da variação efetiva da concentração de oxigênio do filme, que é liberado durante o processo de tratamento térmico. É possível observar que quanto maior é o tempo de tratamento térmico empregado, menor é a concentração de oxigênio do filme. Entre 
as situações sem tratamento térmico e com tratamento de 20 horas, há redução de pouco menos de $10 \%$ na concentração de oxigênio do filme tratado termicamente.

Figura 4.15 - RBS da amostra Stot_100_7, com diferentes tempos de tratamento térmico e 7 W de potência aplicada ao alvo de ouro.

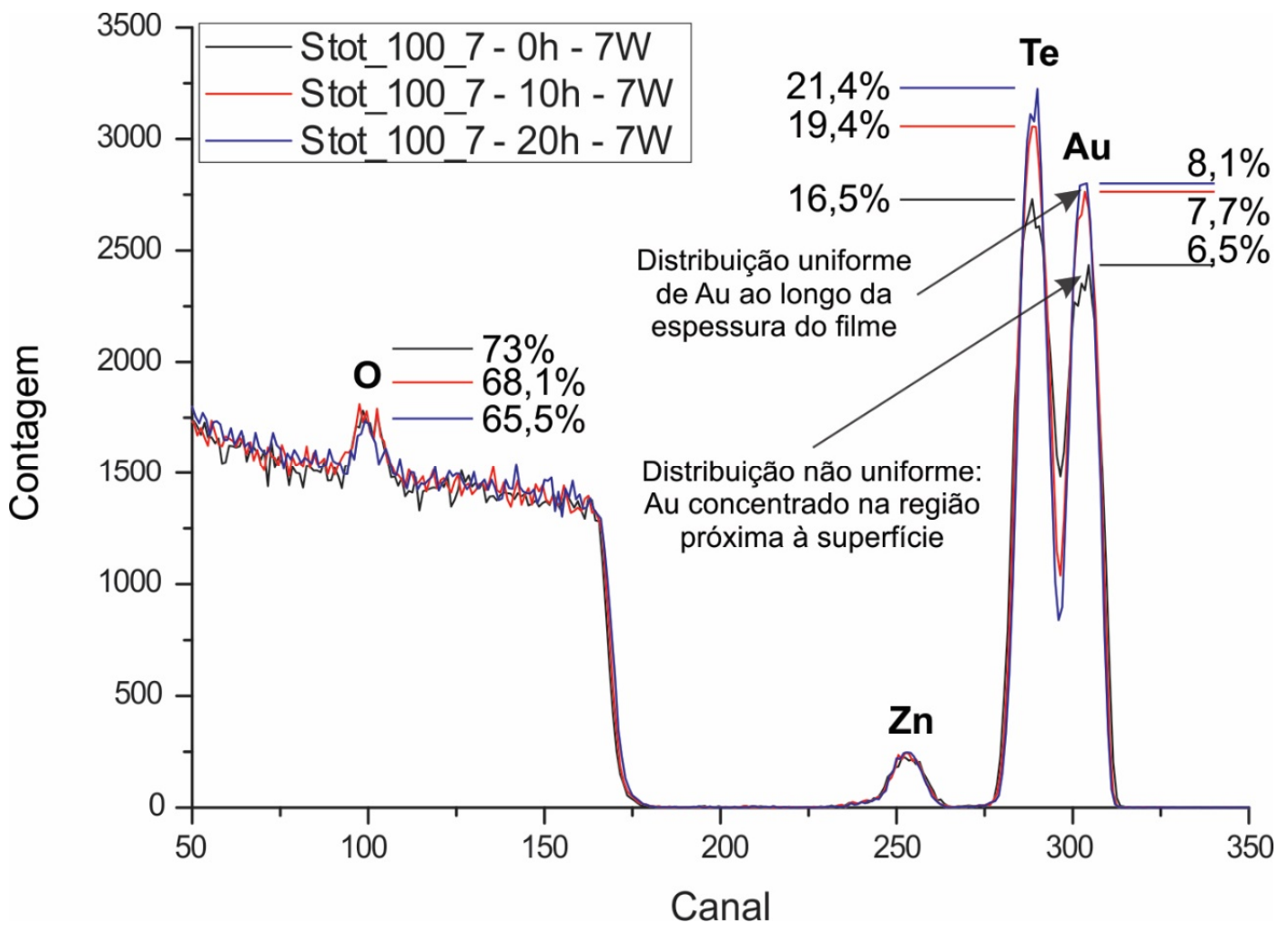

Fonte: O Autor.

A Tabela 4-4 apresenta o conjunto de dados extraídos por RBS dos filmes produzidos com ouro (Tabela 4-3). 
Tabela 4-4 - Dados extraídos por RBS das amostras com ouro.

\begin{tabular}{|c|c|c|c|c|c|}
\hline Amostra & $\begin{array}{c}\text { Concentração } \\
\text { planar } \\
\left(10^{15} \text { átomos } / \mathrm{cm}^{2}\right)\end{array}$ & $\operatorname{Te}(\%)$ & $\operatorname{Zn}(\%)$ & $\operatorname{Au}(\%)$ & $\mathbf{O}(\%)$ \\
\hline S35_100_4-0h & 716 & 21,5 & 5,5 & 1,95 & 71,05 \\
\hline S35_100_4-10h & 694 & 19,5 & 5,2 & 1,9 & 73,4 \\
\hline S35_100_4-20h & 676 & 21 & 5,5 & 1,9 & 71,6 \\
\hline S35_500_4-0h & 3250 & 19,2 & 5,5 & 1,8 & 73,5 \\
\hline S35_500_4-10h & 3212 & 18,4 & 5,4 & 1,9 & 74,3 \\
\hline S35_500_4-20h & 2877 & 19,9 & 5,9 & 2,2 & 72 \\
\hline S40_100_4-0h & 780 & 23,3 & 6 & 2,5 & 68,2 \\
\hline S40_100_4-10h & 740 & 20,7 & 5,6 & 2,4 & 71,3 \\
\hline S40_100_4-20h & 735 & 21 & 5,9 & 2,6 & 70,5 \\
\hline S40_500_4-0h & 3953 & 18,1 & 5,4 & 2,3 & 74,2 \\
\hline S40_500_4-10h & 3160 & 22 & 6,2 & 2,4 & 69,4 \\
\hline S40_500_4-20h & 3131 & 20,3 & 5,8 & 3 & 70,9 \\
\hline S45_100_4-10h & 750 & 21,2 & 5,6 & 4,3 & 68,9 \\
\hline S45_500_4-10h & 3366 & 16,3 & 5 & 4,1 & 74,6 \\
\hline S50_100_1-10h & 500 & 25,5 & 7 & 6,5 & 61 \\
\hline S50_100_1-20h & 560 & 23,1 & 6,8 & 6,7 & 63,4 \\
\hline S50_500_1-10h & 3150 & 19 & 6,7 & 5 & 69,3 \\
\hline S50_500_1-20h & 3010 & 18 & 6,4 & 5,1 & 70,5 \\
\hline S50_100_2-0h & 775 & 17,6 & 4,7 & 4,4 & 73,3 \\
\hline S50_100_2-10h & 735 & 23 & 6 & 5,7 & 65,3 \\
\hline S50_100_2-20h & 710 & 20 & 5,7 & 4,9 & 69,4 \\
\hline S50_100_4-0h & 660 & 18 & 5,1 & 4,2 & 72,7 \\
\hline S50_100_4-10h & 600 & 19,5 & 5,7 & 4,7 & 70,1 \\
\hline S50_100_4-20h & 580 & 19,5 & 5,7 & 4,7 & 70,1 \\
\hline S50_100_7-0h & 580 & 18,8 & 5,3 & 3,5 & 72,4 \\
\hline S50_100_7 -10h & 530 & 21 & 5,4 & 3,9 & 69,7 \\
\hline S50_100_7 -20h & 510 & 21 & 5,4 & 3,9 & 69,7 \\
\hline S60_100_2-0h & 756 & 14,7 & 5,4 & 7,8 & 72,1 \\
\hline S60_100_2-10h & 678 & 16,5 & 6 & 8,6 & 68,9 \\
\hline S60_100_2-20h & 640 & 16,5 & 6,4 & 8,9 & 68,2 \\
\hline S60_100_6-0h & 640 & 16 & 4,6 & 5,5 & 73,9 \\
\hline S60_100_6-10h & 560 & 18,4 & 5,3 & 6,4 & 69,9 \\
\hline S60_100_6-20h & 540 & 18,5 & 5,3 & 6,7 & 69,5 \\
\hline S60_100_7-0h & 610 & 17,9 & 5,1 & 5,4 & 71,6 \\
\hline S60_100_7-10h & 440 & 22,7 & 6,5 & 6,7 & 64,1 \\
\hline S60_100_7-20h & 440 & 22,7 & 6,5 & 6,7 & 64,1 \\
\hline Stot_100_7-0h-6W & 615 & 21,8 & 5,1 & 7 & 66,1 \\
\hline Stot_100_7-10h-6W & 545 & 20,3 & 5,2 & 6,8 & 67,7 \\
\hline Stot_100_7-20h-6W & 505 & 22 & 5,5 & 7 & 65,5 \\
\hline Stot_100_7 - 0h - 7W & 715 & 16,5 & 4 & 6,5 & 73 \\
\hline Stot_100_7 -10h $-7 \mathrm{~W}$ & 590 & 19,4 & 4,8 & 7,7 & 68,1 \\
\hline Stot_100_7 - 20h $-7 \mathrm{~W}$ & 540 & 21,4 & 5 & 8,1 & 65,5 \\
\hline
\end{tabular}

Fonte: O Autor. 
Para a caracterização das nanopartículas de ouro foram realizadas medidas de TEM. Por meio dessa técnica foi possível avaliar a presença, forma e distribuição de tamanhos das nanopartículas nos filmes. Durante as medidas também foram realizadas difrações de elétrons, que permitiram identificar a provável constituição das nanopartículas (cristalina, policristalina ou amorfa) bem como identificar se são constituídas apenas por átomos de ouro ou se formaram ligas com outros elementos da matriz/processo.

Na Tabela 4-5 são apresentados alguns resultados obtidos para algumas amostras. Nesta tabela são apresentados os resultados de concentração planar, extraídos por RBS (Tabela 4-4), além das médias dos diâmetros das nanopartículas extraídas por TEM. Com base nesta tabela e nas imagens de TEM apresentadas na sequência, será possível estabelecer correlações importantes que nos ajudam a entender o processo de formação dos filmes finos de $\mathrm{TeO}_{2}-\mathrm{ZnO}$ e a influência do tratamento térmico nas nanopartículas.

Tabela 4-5 - Concentração planar de ouro e tamanho médio das nanopartículas para amostras com $100 \mathrm{~nm}$ (sem tratamento e tratadas termicamente por 10 e $20 \mathrm{~h}$ ) e $500 \mathrm{~nm}$ (tratadas termicamente por 10 e $20 \mathrm{~h}$ ).

\begin{tabular}{l|c|c}
\hline \multicolumn{1}{c|}{ Amostra } & $\begin{array}{c}\text { Concentração } \\
\text { planar de ouro } \\
\left(\mathbf{1 0}^{\mathbf{1 6}} \text { átomos/cm } \mathbf{~}\right)\end{array}$ & $\begin{array}{c}\text { Tamanho médio das } \\
\text { nanopartículas } \\
(\mathbf{n m})\end{array}$ \\
\hline S40_100_4-0h & $2,0 \pm 0,5$ & $5,88 \pm 1,26$ \\
\hline S40_100_4-10h & $1,78 \pm 0,1$ & $3,37 \pm 0,94$ \\
\hline S50_100_1-10h & $3,25 \pm 0,05$ & $2,2 \pm 0,3$ \\
\hline S50_100_1-20h & $3,75 \pm 0,07$ & $5,7 \pm 1,9$ \\
\hline S50_500_1-10h & $16,0 \pm 0,3$ & $2,7 \pm 0,7$ \\
\hline S50_500_1-20h & $15,4 \pm 0,3$ & $5,5 \pm 4,4$ \\
\hline
\end{tabular}

Fonte: O Autor.

A análise das imagens obtidas por TEM da amostra S40_100_4 - 0h (Figura 4.16) revelou a presença de nanopartículas. É também possível observar na Figura 4.16 o histograma de distribuição de tamanhos das nanopartículas, acompanhado do tamanho médio e desvio padrão. O tamanho médio das nanopartículas é de aproximadamente 5,88 nm com dispersão de $1,26 \mathrm{~nm}$.

Pela Figura 4.16 nota-se que nanopartículas são formadas durante o processo de deposição do filme, sem a necessidade de tratamento térmico. Entretanto, nesse estágio inicial de formação as nanopartículas aparecem aglomeradas e com distribuição não uniforme. Esse efeito observado está relacionado com a alta dispersão da concentração planar, quando 
comparada com a amostra do mesmo processo tratada por 10 horas (Tabela 4-5). Isto indica distribuição não uniforme do ouro ao longo da área da amostra, possivelmente devido à nucleação heterogênea do ouro durante o processo de co-sputtering.

Figura 4.16 - Imagens obtidas por TEM da amostra S40_100_4 - 0h e histograma de distribuição de tamanhos correspondente.

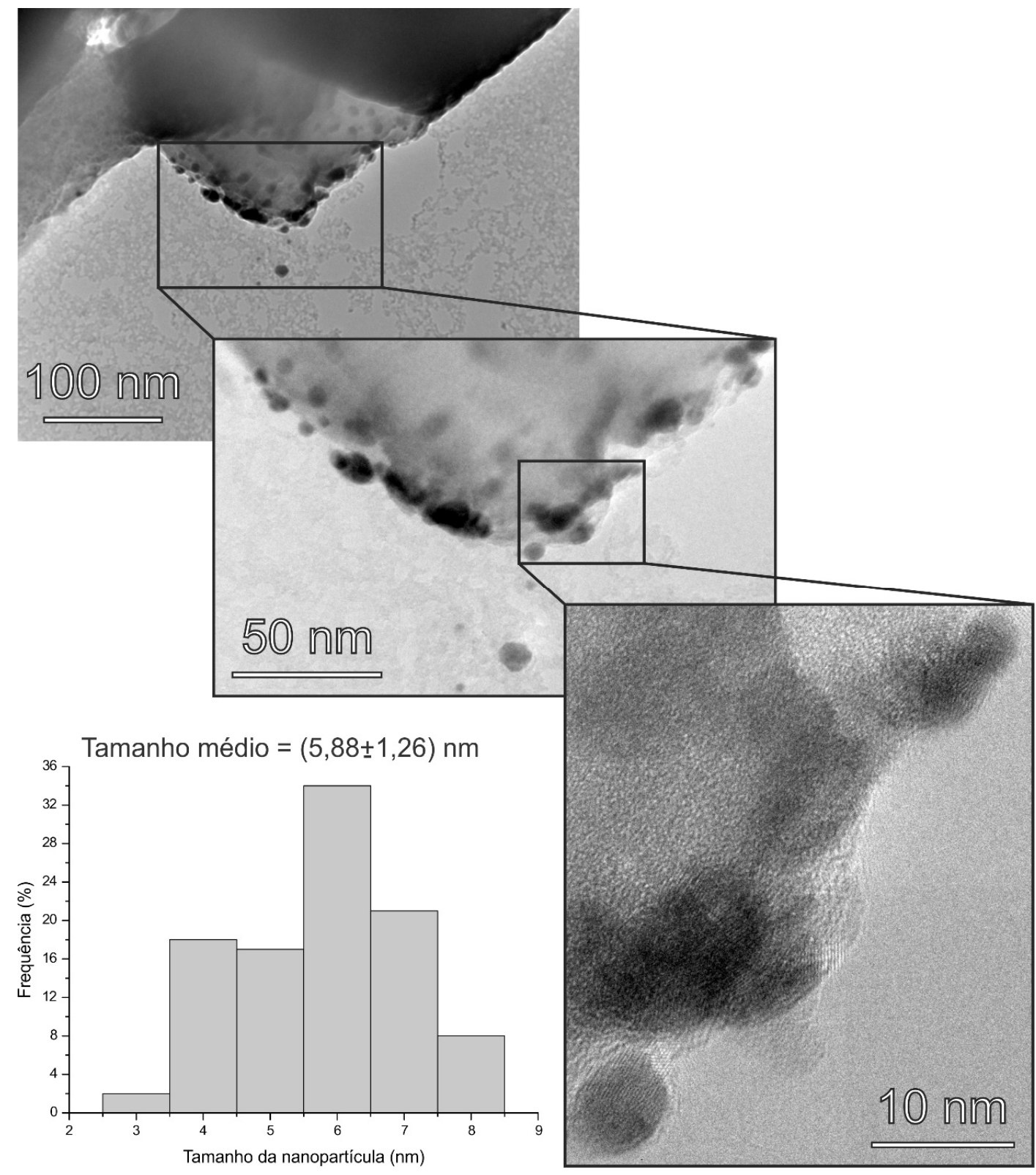

Fonte: O Autor. 
A Figura 4.17 destaca o efeito de empilhamento e espaçamento das nanopartículas característico desse estágio inicial de formação.

Figura 4.17 - Nanopartículas em processo inicial de formação. Imagens obtidas por TEM da amostra S40_100_4 $-0 \mathrm{~h}$.

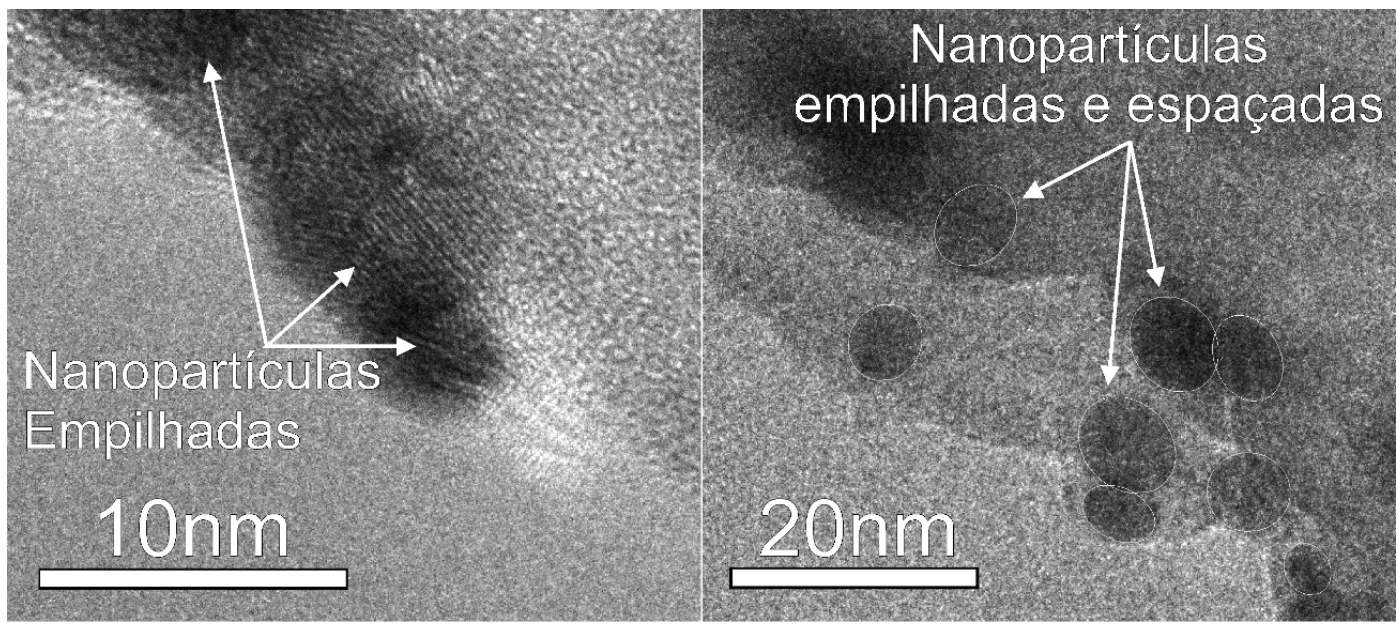

Fonte: O Autor.

Para a determinação dos contornos das nanopartículas, foi assumido o formato esférico, conforme sugerido pelas imagens. Em regiões de empilhamento essa aproximação é especialmente importante, dada a dificuldade de delimitação do contorno da partícula.

Através da análise das figuras de difração de elétrons foi possível verificar a natureza policristalina das nanopartículas formadas. Para a determinação da provável composição química das nanopartículas, foram extraídas as distâncias interplanares a partir dos anéis de difração. O procedimento adotado é ilustrado pela Figura 4.18. Nesta figura, os pontos brancos são obtidos pela difração de elétrons, já os círculos brancos, determinados graficamente, representam os máximos e mínimos de cada anel formado. Essa abordagem permite determinar a incerteza associada à medida. 
Figura 4.18 - Difração de elétrons da amostra S40_100_4 - 0h acompanhada da determinação dos anéis de difração.

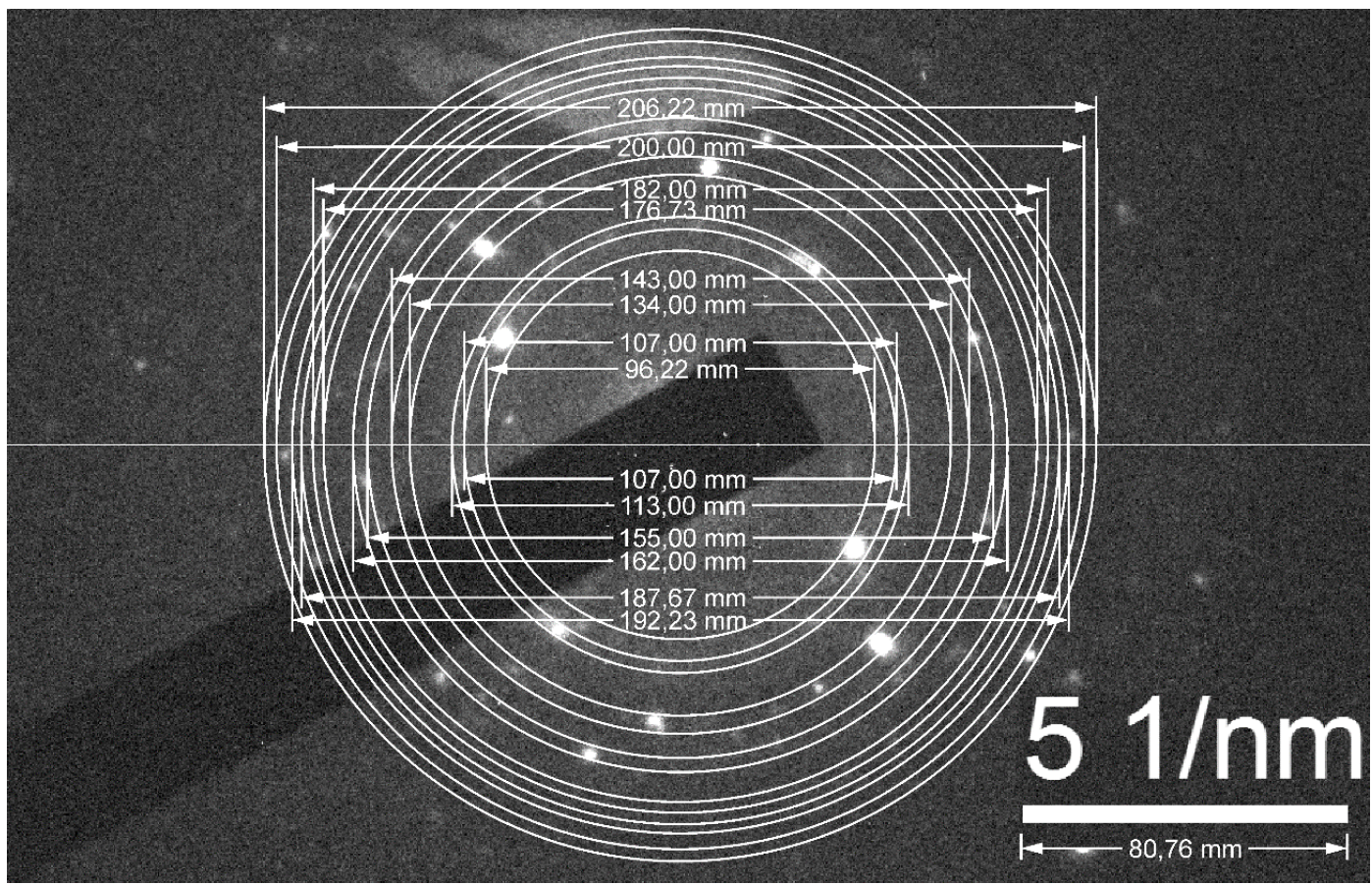

Fonte: O Autor.

Comparando-se as distâncias interplanares extraídas das difrações de elétrons com os picos mais intensos catalogados, obtidos do banco de dados das fichas JCPDS-ICDD [116] para as ligas possíveis, foi constatado que, para a situação sem tratamento térmico, existe grande probabilidade de formação de nanopartículas de $\mathrm{Au}$ juntamente com pequena quantidade de partículas de AuO. A formação de nanopartículas de $\mathrm{Au}$ é esperada. A formação de $\mathrm{AuO}$ pode ocorrer, já que durante o processo de deposição, além do gás de processo (argônio), o gás oxigênio é inserido na câmara como gás reativo [117,118]. Além disso, o alvo cerâmico é composto de óxidos, fato que provavelmente colabora com a formação inicial de nanopartículas de $\mathrm{AuO}$ durante o processo de sputtering para a formação do filme.

A Figura 4.19 apresenta a região de interface entre o substrato de silício (A) e o filme depositado (B), também para a amostra S40_100_4 - 0h. Na região B é possível observar a presença de pontilhado mais escuro (destacado na figura) em relação ao material do filme, indicando a formação de nanopartículas durante a deposição. Na região A, conforme esperado, não se observa nucleação de partículas. 
Figura 4.19 - Imagens obtidas por TEM da amostra S40_100_4 - 0h.

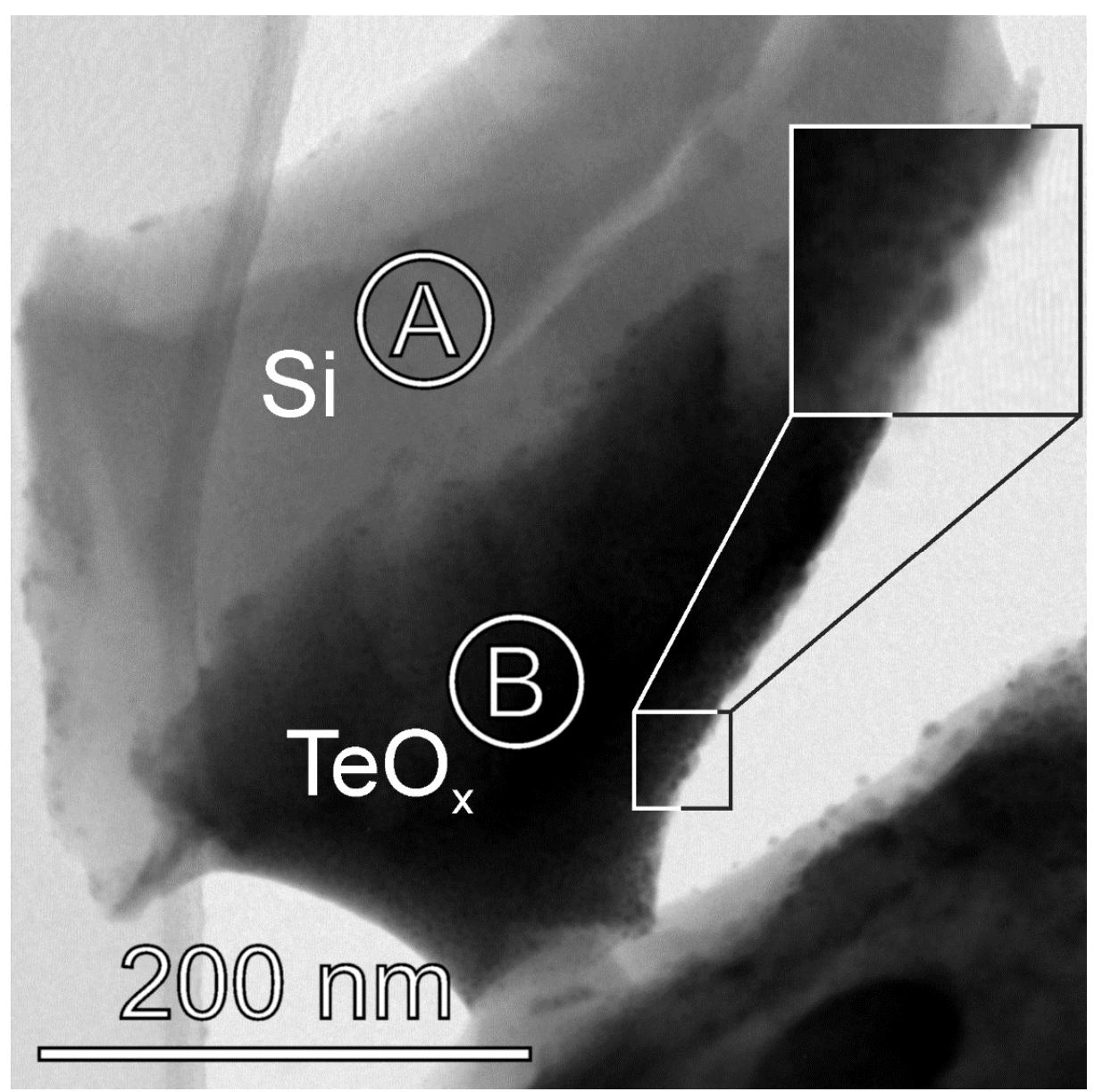

Fonte: O Autor.

As regiões A e B foram submetidas à análise de Espectroscopia por Dispersão de Energia de Raios X (EDS), a fim de identificar porções do filme e do substrato.

A Figura 4.20 apresenta o espectro de EDS da região A. É possível observar a presença dos picos relativos aos elementos $\mathrm{Si}, \mathrm{Cu}$ e $\mathrm{C}$. O pico do $\mathrm{Si}$ comprova a região do substrato e os picos do $\mathrm{Cu}$ e $\mathrm{C}$ aparecem, pois, a rede (porta amostra) utilizada no microscópio é feita desses materiais. Essa rede sustenta o particulado analisado. 
Figura 4.20 - Espectro de EDS extraído da Região A mostrada na Figura 4.19.

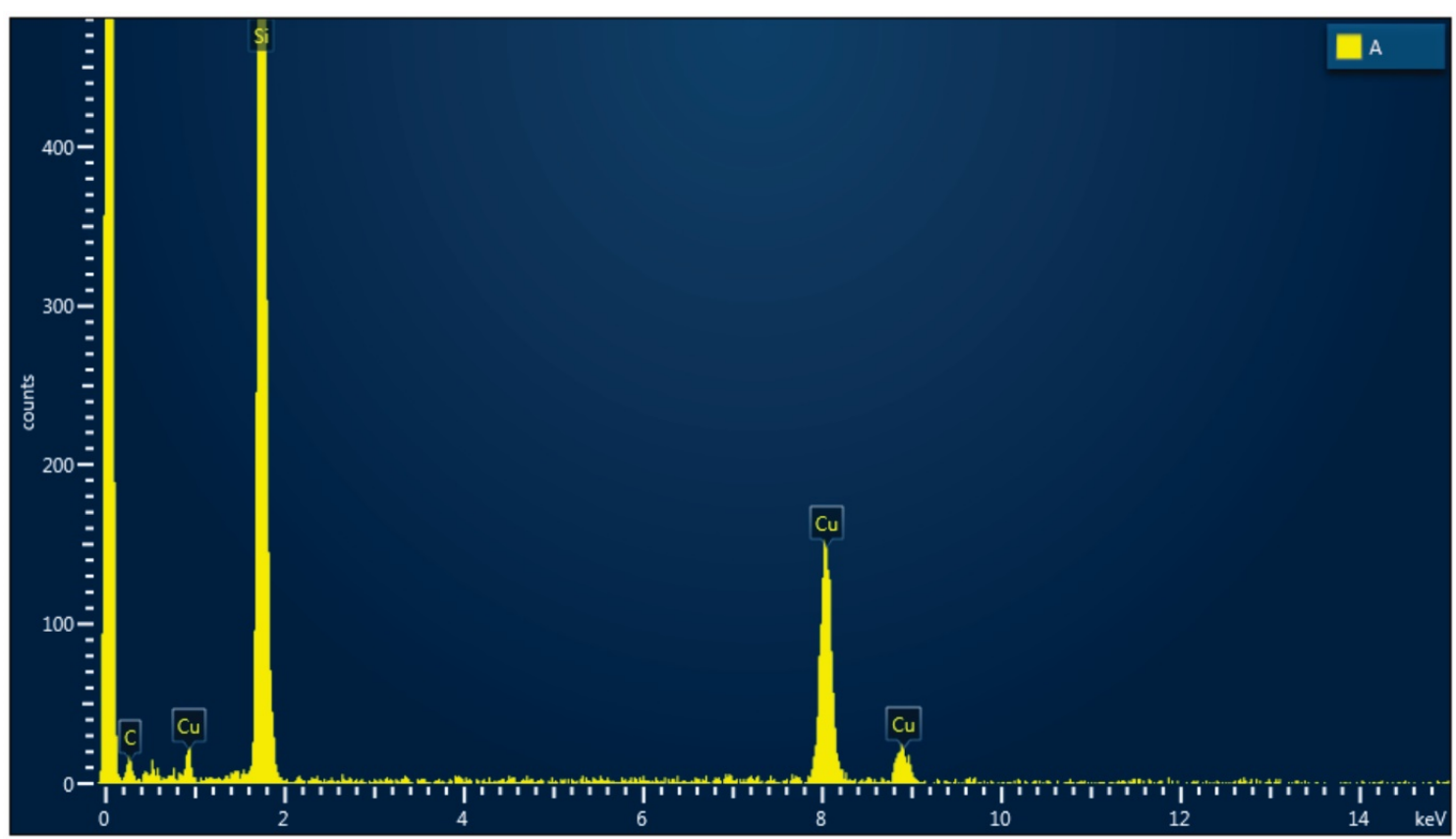

Fonte: O Autor.

A Figura 4.21 apresenta o espectro de EDS da região B.

Figura 4.21 - Espectro de EDS extraído da Região B mostrada na Figura 4.19.

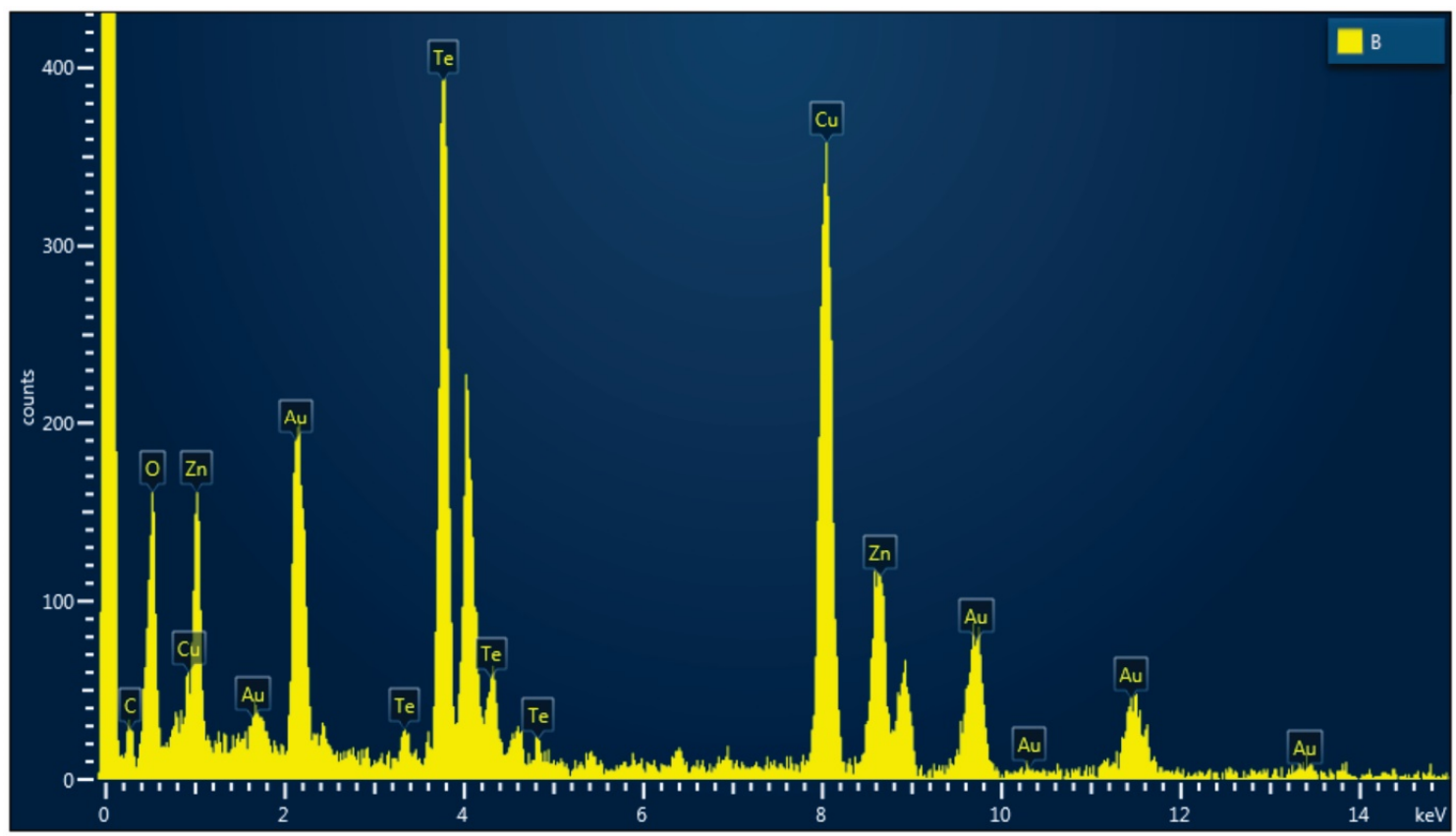

Fonte: O Autor. 
É possível observar a presença dos picos relativos aos elementos Te, $\mathrm{Zn}, \mathrm{Au}, \mathrm{O}, \mathrm{Cu}$ e C. Também nesse caso os picos do $\mathrm{Cu}$ e $\mathrm{C}$ são provenientes do porta amostra. Os picos do $\mathrm{Te}$, $\mathrm{Zn}$, Au e $\mathrm{O}$ comprovam a constituição da matriz vítrea $\left(\mathrm{TeO}_{2}-\mathrm{ZnO}\right)$ e ouro incorporado no filme.

Os filmes finos também foram tratados termicamente à temperatura de $325^{\circ} \mathrm{C}$ durante períodos de 10 e 20 horas. O tratamento térmico, além de alterar as características da matriz vítrea, também provoca alterações nas nanopartículas formadas. Com o objetivo de verificar as alterações nas nanopartículas, os filmes finos tratados termicamente foram submetidos a análises por TEM, e são apresentados a seguir.

A Figura 4.22 apresenta uma imagem extraída por TEM da amostra S40_100_4 - 10h, além do correspondente histograma de distribuição de tamanhos das nanopartículas, acompanhado do tamanho médio e desvio padrão. O tamanho médio das nanopartículas é de aproximadamente 3,37 nm com dispersão de 0,94 $\mathrm{nm}$.

$\mathrm{Na}$ imagem é possível verificar melhor homogeneidade na distribuição espacial das nanopartículas (Figura 4.15 - melhor distribuição do ouro ao longo da espessura do filme causado pelo tratamento térmico). Houve também diminuição no tamanho médio as nanopartículas e diminuição na dispersão dos valores, quando comparado com a amostra do mesmo processo sem tratamento térmico (Tabela 4-5). 
Figura 4.22 - Imagem obtida por TEM da amostra S40_100_4 - 10h e histograma de distribuição de tamanhos correspondente.
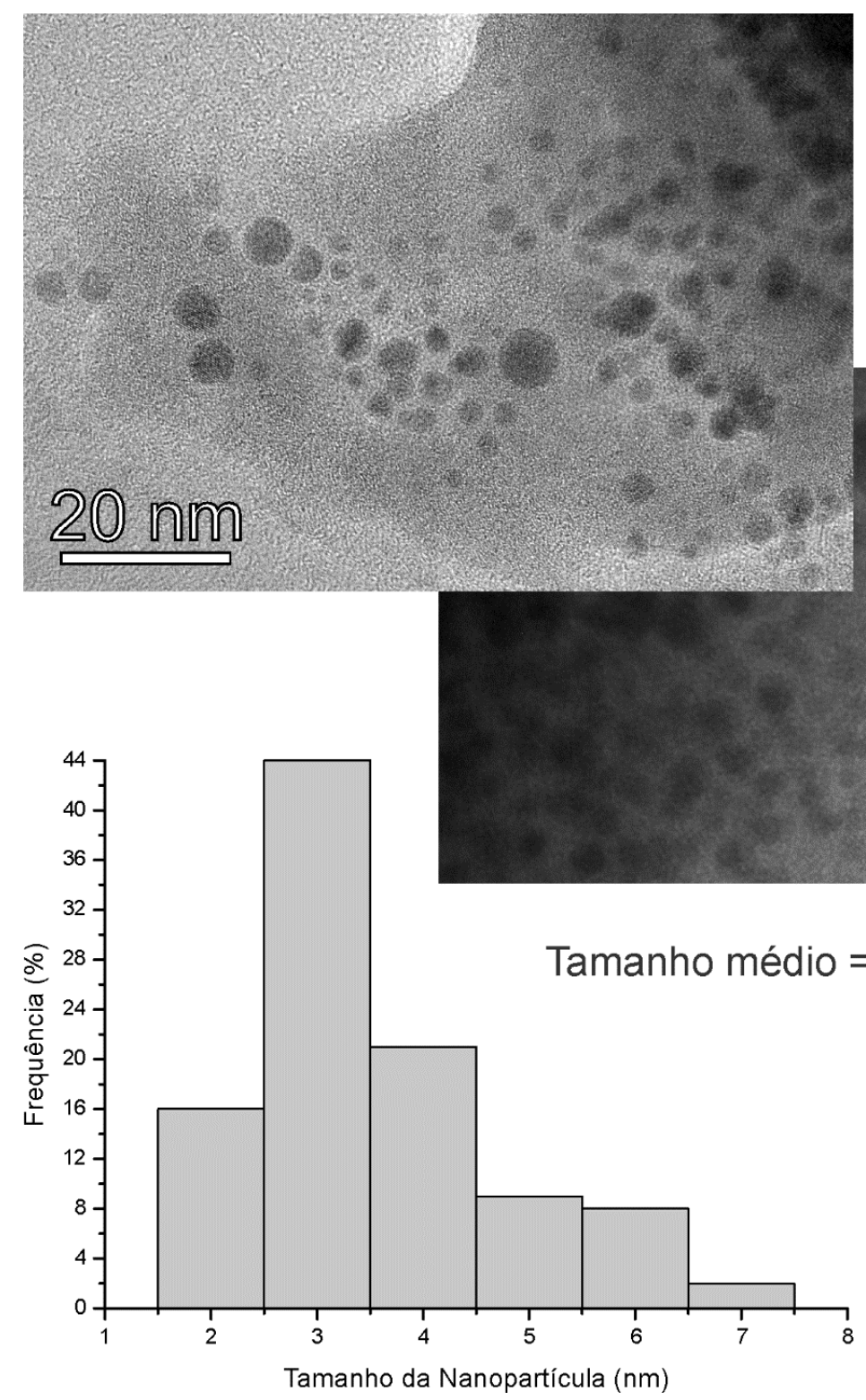

Fonte: O Autor.

Também neste caso, através da análise das figuras de difração de elétrons, foi possível verificar a natureza policristalina das nanopartículas formadas. As distâncias interplanares foram extraídas a partir dos anéis de difração (Figura 4.23(a)). A Figura 4.23(b) apresenta os pontos de difração, utilizados na determinação dos anéis de difração, marcados e numerados. Os anéis de aspecto difuso, visto na Figura 4.23 (b), indicam a natureza amorfa da matriz vítrea $\left(\mathrm{TeO}_{2}-\mathrm{ZnO}\right)$. 
Figura 4.23 - Difração de elétrons da amostra S40_100_4 - 10h acompanhada da (a) determinação dos anéis de difração e (b) pontos (spots) de difração numerados.

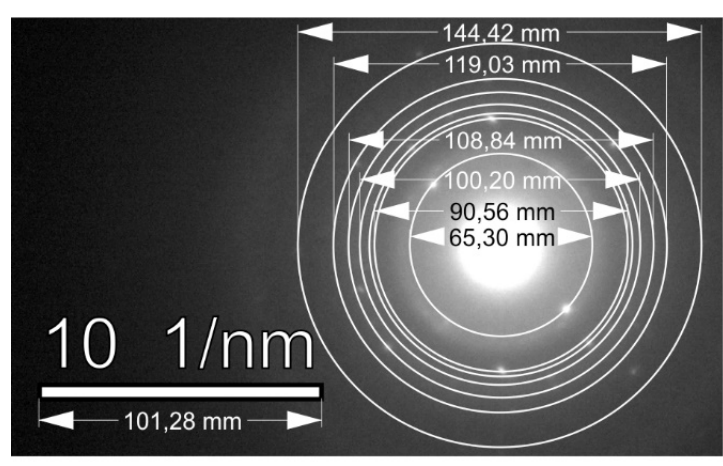

(a)

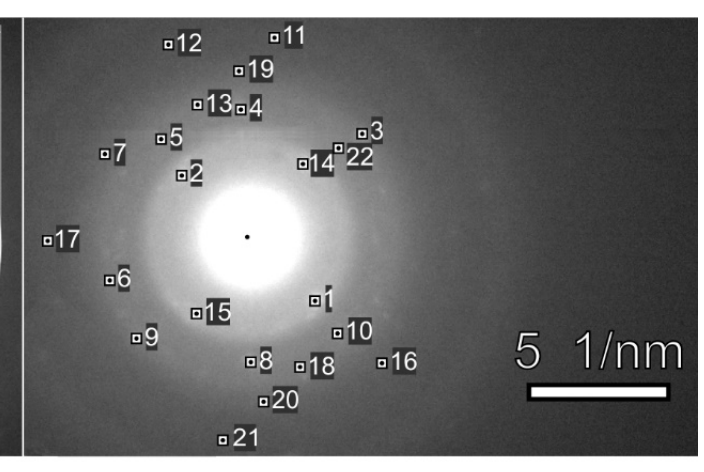

(b)

Fonte: O Autor.

Foi constatado que para a situação com tratamento térmico de 10 horas, em comparação com o caso sem tratamento térmico, houve diminuição dos picos relacionados ao $\mathrm{AuO}$ e predominância dos picos relacionados ao Au (Figura 4.15 - redução da concentração de oxigênio causado pelo tratamento térmico). $O$ tratamento térmico promoveu a desagregação das nanopartículas de ouro, o que levou à diminuição do tamanho das nanopartículas (de 5,9 para 3,37 nm) e à distribuição mais uniforme (dispersão de 1,26 para $0,94 \mathrm{~nm})$.

Conforme reportado por $\mathrm{Vu}$ e colaboradores [119], o ouro parcialmente oxidado (AuO) favorece a desagregação das nanopartículas de ouro durante o tratamento térmico [120]. Assim, essa desagregação leva à diminuição do tamanho médio das nanopartículas e origina melhor distribuição das nanopartículas ao longo da espessura do filme, comprovada pela redução do desvio padrão (Tabela 4-5). Vale salientar que não há variação expressiva da concentração planar de ouro para ambos os casos sem tratamento e com tratamento térmico de 10 horas.

A Figura 4.24 apresenta uma imagem extraída por TEM da amostra S50_100_1 - 10h, além do correspondente histograma de distribuição de tamanhos das nanopartículas, acompanhado do tamanho médio e desvio padrão. Na imagem é possível verificar boa homogeneidade de tamanho e distribuição das nanopartículas ao longo do filme analisado. $\mathrm{O}$ tamanho médio das nanopartículas é de aproximadamente $2,2 \mathrm{~nm}$, com dispersão de $0,3 \mathrm{~nm}$; e a concentração planar, associada a distribuição das nanopartículas ao longo do filme, tem baixo valor de dispersão (Tabela 4-5). 
Figura 4.24 - Imagem obtida por TEM da amostra S50_100_1 - 10h e histograma de distribuição de tamanhos correspondente.
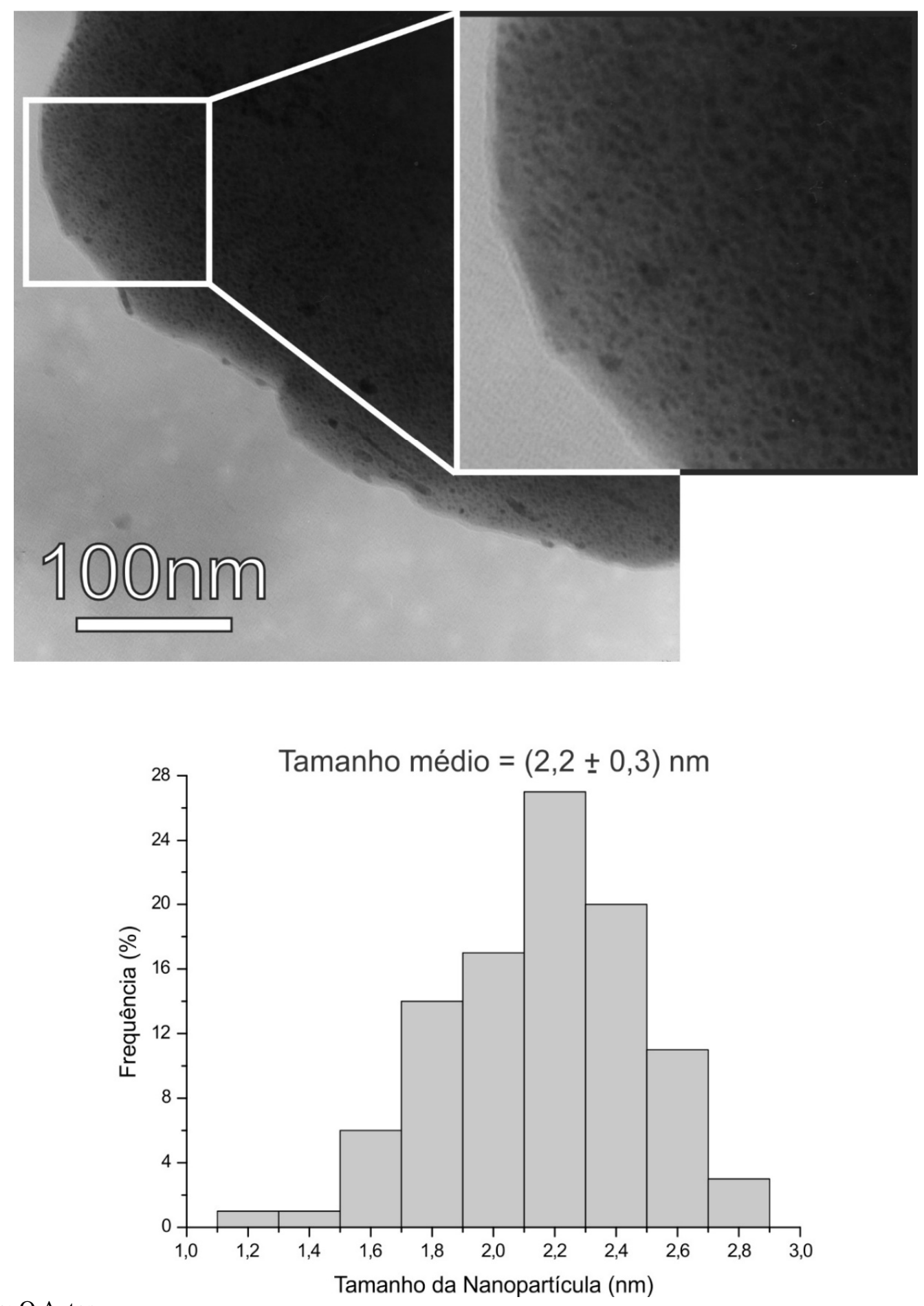

Fonte: O Autor.

Para o caso da amostra S50_100_1 - 10h a difração de elétrons é semelhante à apresentada para a amostra S40_100_4 - 10h (Figura 4.23) e conduz às mesmas conclusões. 
A Figura 4.25 apresenta uma imagem extraída por TEM da amostra S50_100_1 - 20h, além do correspondente histograma de distribuição de tamanhos das nanopartículas, acompanhado do tamanho médio e desvio padrão. O tamanho médio das nanopartículas é de aproximadamente 5,7 $\mathrm{nm}$ com dispersão de $1,9 \mathrm{~nm}$.

Figura 4.25 - Imagem obtida por TEM da amostra S50_100_1 - 20h e histograma de distribuição de tamanhos correspondente.
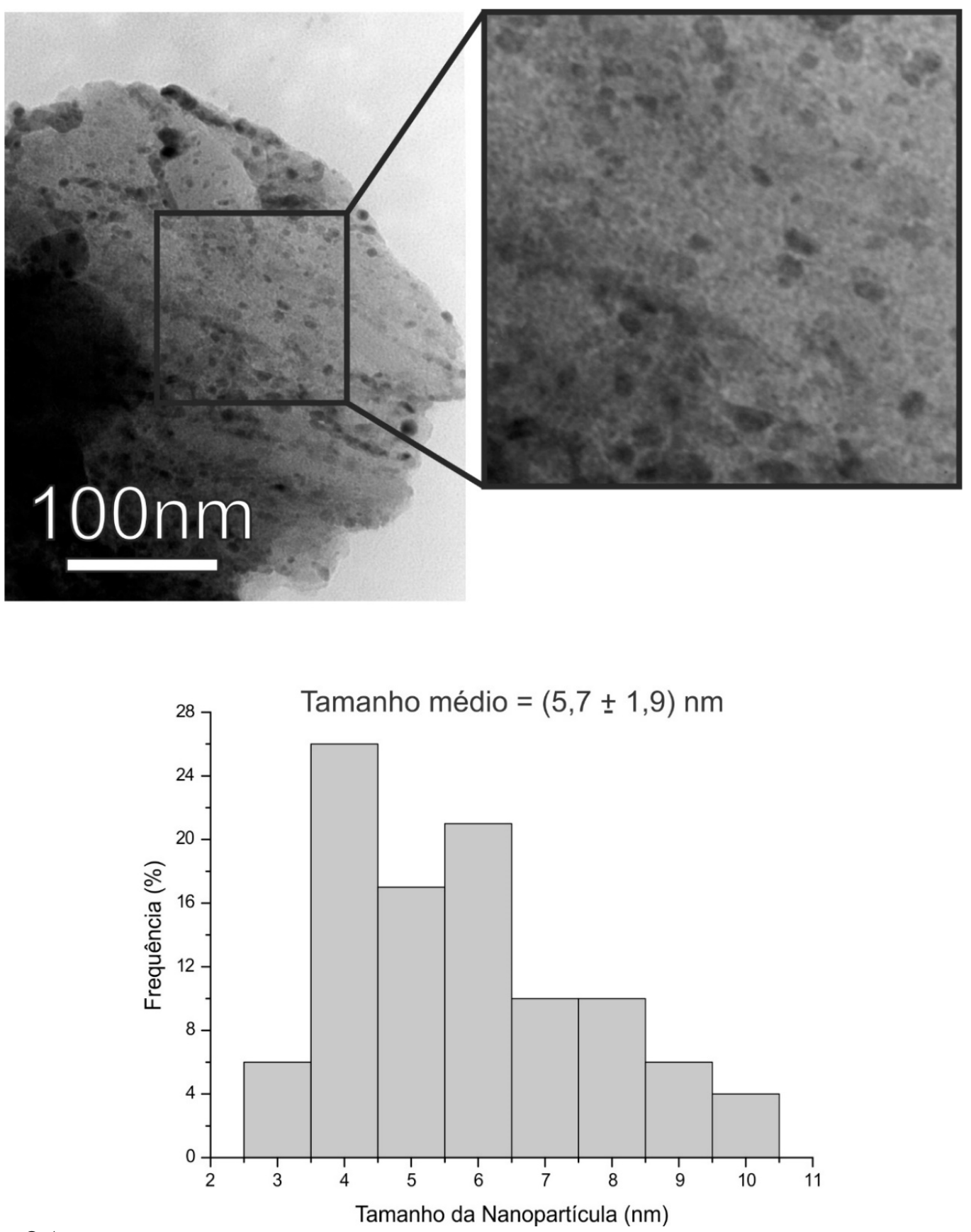

Fonte: O Autor. 
Através da análise das figuras de difração de elétrons, foi possível verificar a natureza policristalina das nanopartículas formadas na amostra S50_100_1 - 20h. As distâncias interplanares foram extraídas a partir dos anéis de difração mostrados na Figura 4.26. Nesta figura a imagem original extraída por difração é também mostrada para efeito de comparação.

Figura 4.26 - Difração de elétrons da amostra S50_100_1 - 20h. Imagem original à esquerda e determinação dos anéis de difração à direita.

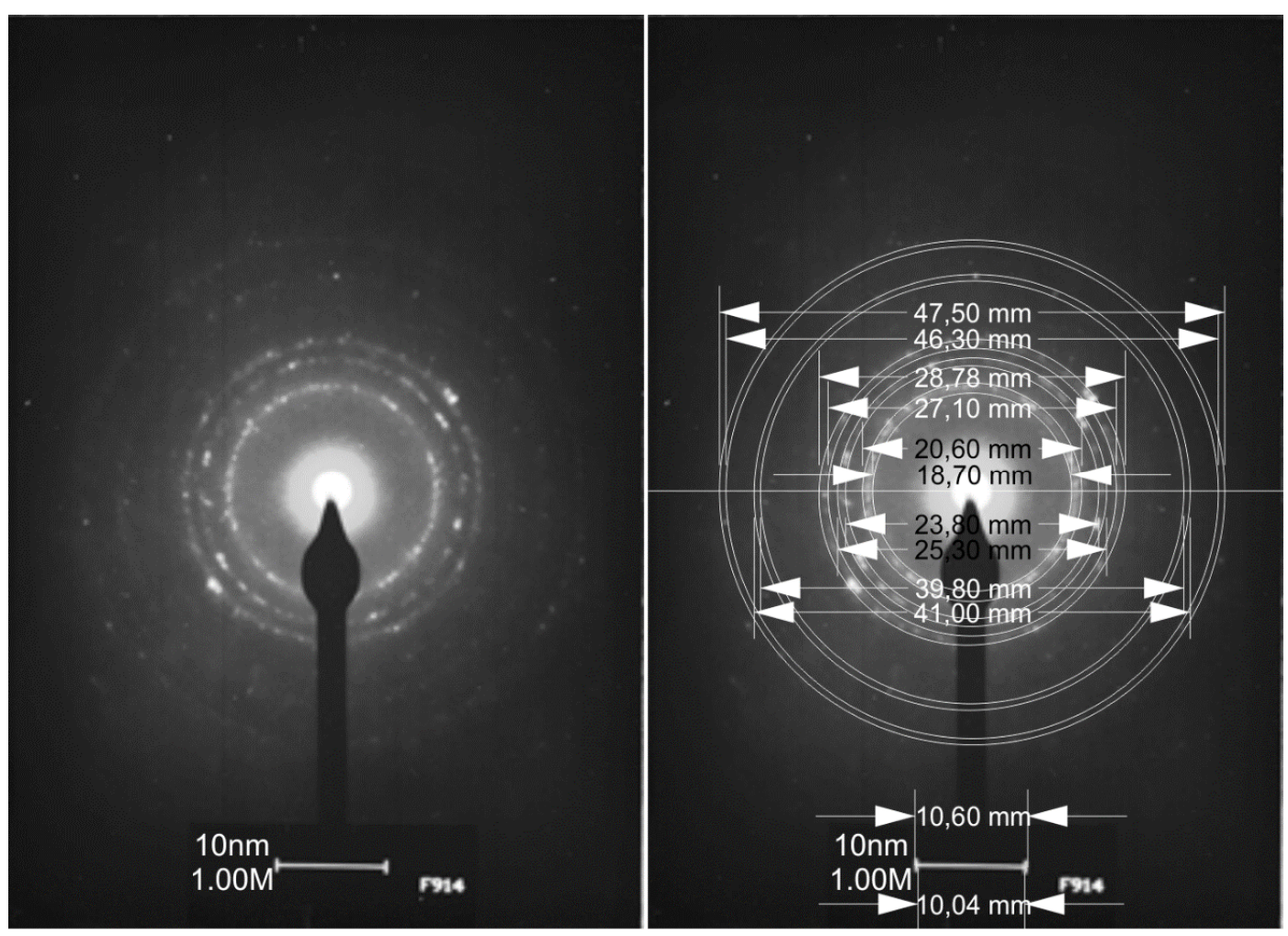

Fonte: O Autor.

A análise da difração de elétrons, para a situação com tratamento térmico de 20 horas, indica a presença de nanopartículas compostas apenas por Au. Isso significa que nesse estágio final de tratamento térmico (20h), a quantidade de ouro oxidado ( $\mathrm{AuO}$ ) tornou-se nula ou pequena o suficiente para não ser detectada.

Ao comparar os resultados obtidos para as amostras S50_100_1 - 10h e S50_100_1 20h, é importante notar que ocorre o aumento do tamanho médio das nanopartículas (aumento de $159 \%$ ), que significa o predomínio do mecanismo de coalescência [118], uma vez que a quantidade de $\mathrm{AuO}$, ainda alta para tratamento de 10h, possivelmente tornou-se desprezível durante o tratamento térmico de 20 horas e átomos de ouro juntaram-se formando partículas 
maiores. Como resultado, o tamanho das nanopartículas e a dispersão dos tamanhos aumentam para o caso de tratamento térmico de 20 horas (Tabela 4-5), quando comparado com o de 10 horas de tratamento térmico.

A Tabela 4-5 mostra que a concentração planar de ouro aumenta com o aumento da espessura $\left(t_{o x}\right)$ de 100 para $500 \mathrm{~nm}$, conforme esperado. Para o tratamento térmico de 10 horas, a concentração planar de ouro $\left(N_{p}\right)$ aumenta 4,9 vezes, enquanto a espessura aumenta 5 vezes, assim, a concentração volumétrica de ouro $\left(N_{v}\right)$ permanece praticamente a mesma para os casos com espessura de 100 e $500 \mathrm{~nm}$, já que $N_{v}=N_{p} / t_{o x}$. Entretanto, na Tabela 4-5 é possível observar que, para o tratamento térmico de 10 horas, o tamanho médio das nanopartículas $\left(d_{p}\right)$ aumenta em torno de $20 \%$, para o caso da amostra com $500 \mathrm{~nm}$ em comparação com a de $100 \mathrm{~nm}$. Como resultado, a concentração volumétrica de nanopartículas $\left(N_{v p}\right)$ diminui quando a espessura aumenta de 100 para $500 \mathrm{~nm}$, já que $N_{v p}$ é proporcional a $N_{v}$ (que permanece constante) e inversamente proporcional a $d_{p}$ (que aumenta). Isso indica que as nanopartículas, no caso da amostra com $500 \mathrm{~nm}$, estão maiores e mais distantes entre si levando a distribuição menos uniforme (comprovada pelo aumento do desvio padrão que duplica em relação ao da amostra com $100 \mathrm{~nm}$ de espessura, como mostrado na Tabela 4-5) o que dificultará o preenchimento das armadilhas e consequentemente a maior tensão de transição.

A seguir, serão apresentados os resultados da caracterização elétrica somente para as amostras que apresentaram efeito de memória.

A Figura 4.27 apresenta os resultados de I-V da amostra S40_100_4 - 0h. São mostrados os resultados da primeira e segunda varreduras, bem como do ciclo de recuperação (ciclo de tensão negativa), ou seja, o procedimento completo de gravação e recuperação do estado de baixa condutividade. Existe mudança de duas ordens de grandeza do estado de baixa condutividade para o estado de alta condutividade, em tensão de transição de aproximadamente $40 \mathrm{~V}$. Na segunda varredura, a partir da aplicação de baixa tensão, já é atingido o estado de alta condutividade (memória não volátil). Após a aplicação do ciclo de tensão negativa ( $3^{\mathrm{a}}$ varredura), é recuperado o estado de baixa condutividade, cuja próxima transição para o estado de alta condutividade se dá para valor de aproximadamente $30 \mathrm{~V}$, menor do que a primeira transição, de aproximadamente $40 \mathrm{~V}$, conforme mostrado na Figura 4.28 através da curva denominada $2^{\mathrm{a}}$ transição (nesta figura, a $1^{\mathrm{a}}$ transição é mostrada para efeito de comparação). Os fatos demonstram que a memória é não volátil e também reversível. 
Figura 4.27 - Corrente de fuga em função da tensão para a amostra S40_100_4 - 0h: ciclo completo.

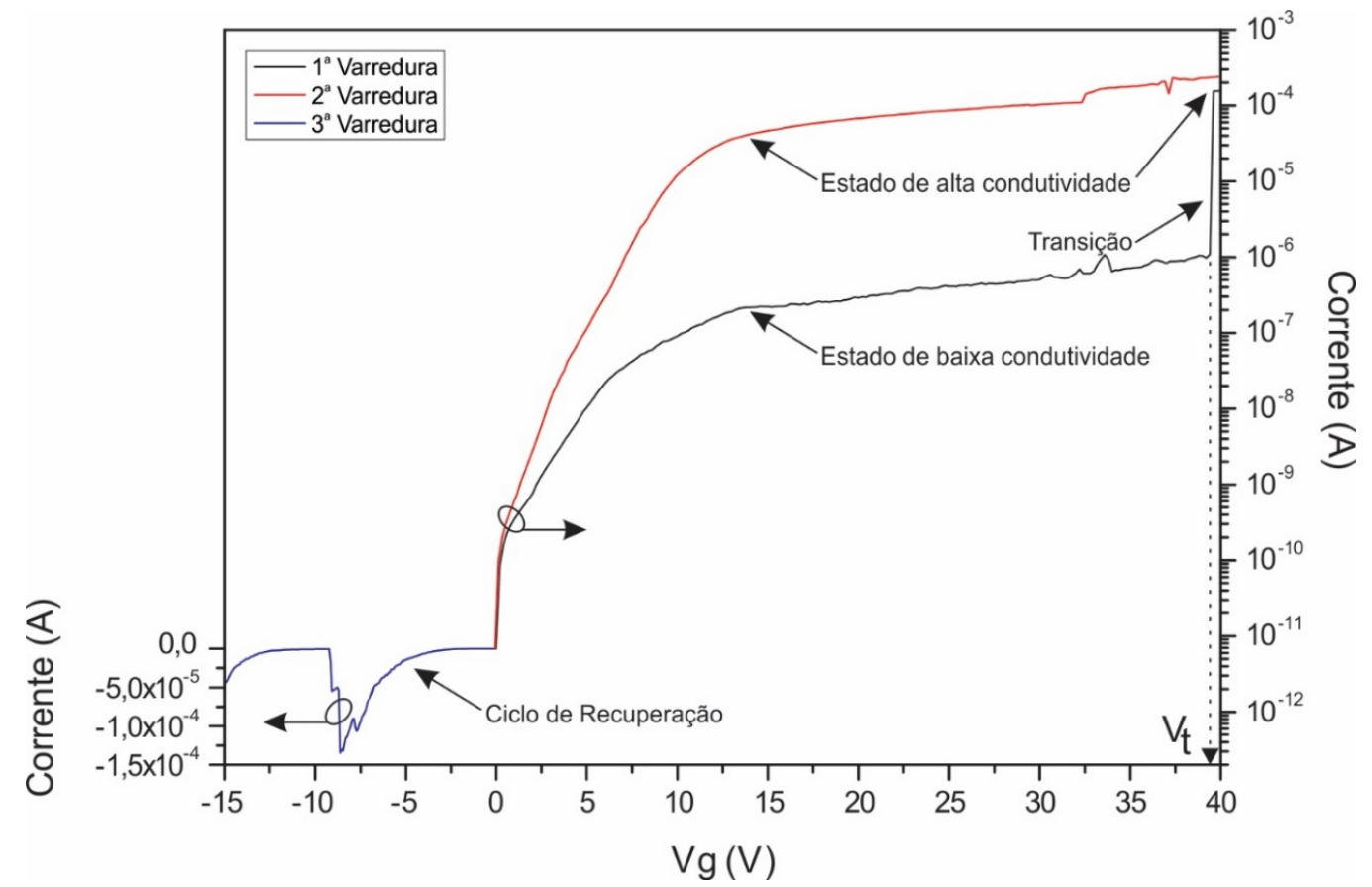

Fonte: O Autor.

Figura 4.28 - Corrente de fuga em função da tensão para a amostra S40_100_4 - 0h: 1ª e 2 $2^{\mathrm{a}}$ transições.

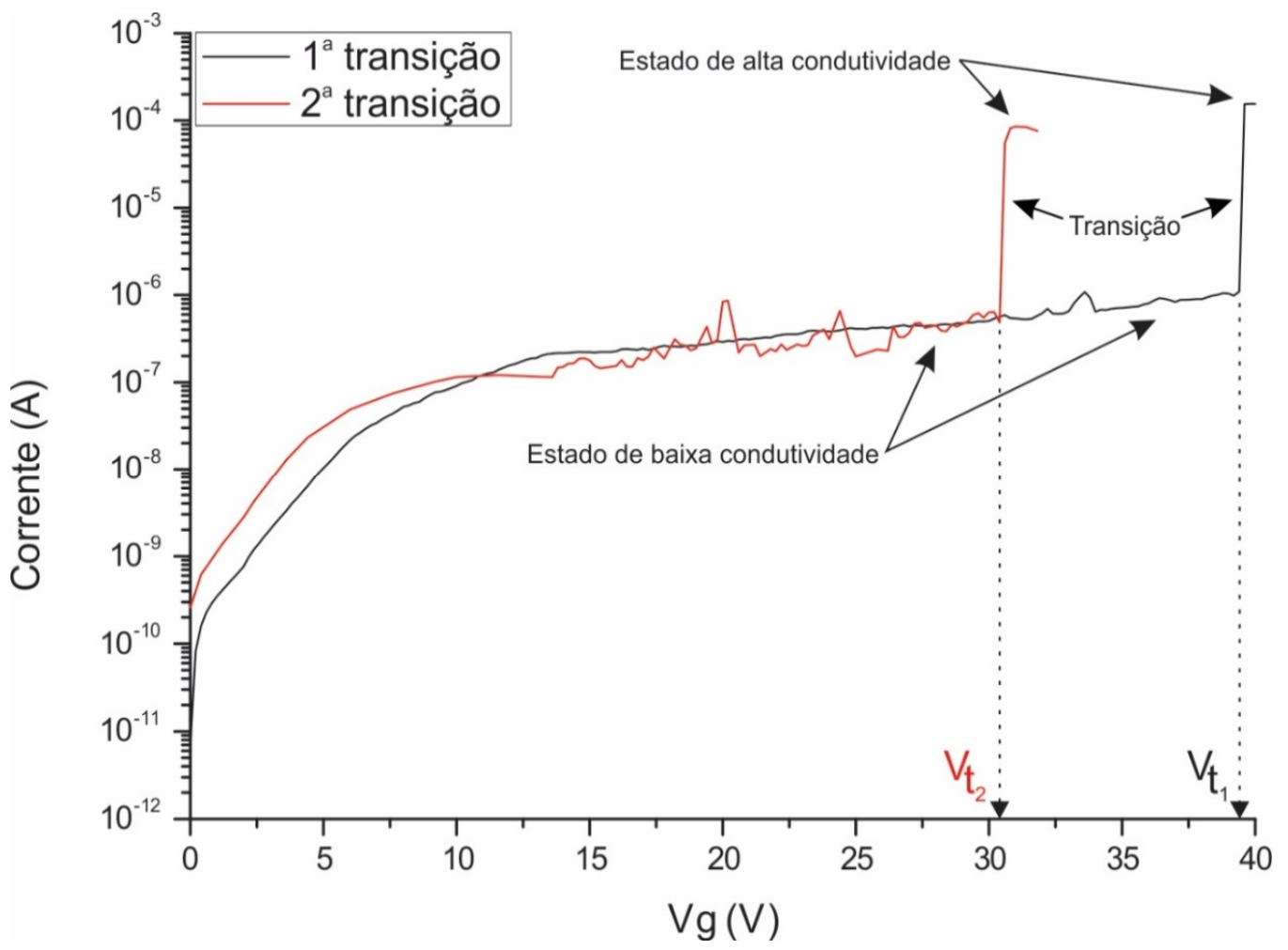

Fonte: O Autor. 
A Figura 4.29 apresenta os resultados de I-V da amostra S50_100_2 - 0h. São mostrados os resultados da primeira e segunda varreduras, bem como do ciclo de recuperação (ciclo de tensão negativa), ou seja, o procedimento completo de gravação e recuperação do estado de baixa condutividade. Existe mudança de duas ordens de grandeza do estado de baixa condutividade para o estado de alta condutividade, em tensão de transição de aproximadamente $15 \mathrm{~V}$. Na segunda varredura, a partir da aplicação de baixa tensão, já é atingido o estado de alta condutividade (memória não volátil), como no caso anterior. Após a aplicação do ciclo de tensão negativa ( $3^{\text {a }}$ varredura), é recuperado o estado de baixa condutividade, mostrando assim o comportamento reversível da memória. Este procedimento de gravação e recuperação pode ser repetido diversas vezes.

Figura 4.29 - Corrente de fuga em função da tensão para a amostra S50_100_2 - 0h.

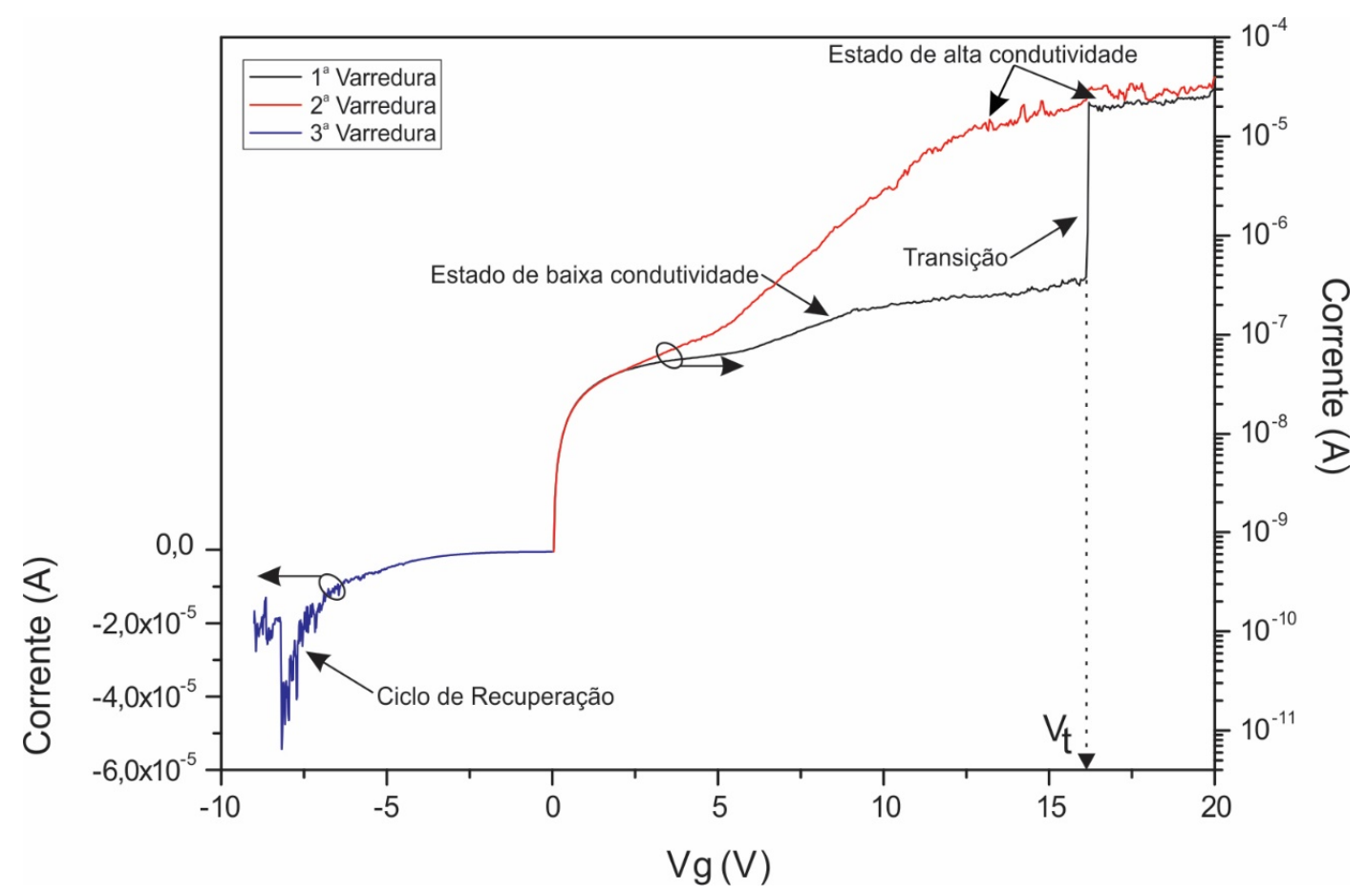

Fonte: O Autor.

A Figura 4.30 apresenta os resultados de I-V da amostra S60_100_7 - 10h. São mostrados os resultados da primeira e segunda varreduras, bem como do ciclo de recuperação (ciclo de tensão negativa), ou seja, o procedimento completo de gravação e recuperação do estado de baixa condutividade. Existe mudança de uma ordem de grandeza do estado de baixa condutividade para o estado de alta condutividade, em tensão de transição de 
aproximadamente $35 \mathrm{~V}$. Na segunda varredura, a partir da aplicação de baixa tensão, já é atingido o estado de alta condutividade (memória não volátil), como nos casos anteriores. Após a aplicação do ciclo de tensão negativa ( $3^{\text {a }}$ varredura), é recuperado o estado de baixa condutividade, cuja próxima transição para o estado de alta condutividade se dá para valor de aproximadamente $5 \mathrm{~V}$, muito menor do que a primeira transição, de aproximadamente $35 \mathrm{~V}$, conforme mostrado na Figura 4.31 através da curva denominada $2^{\mathrm{a}}$ transição (nesta figura, a $1^{\mathrm{a}}$ transição é mostrada para efeito de comparação). Existe, neste caso, aumento da janela de transição para 3 ordens de grandeza.

Figura 4.30 - Corrente de fuga em função da tensão para a amostra S60_100_7 - 10h: ciclo completo.

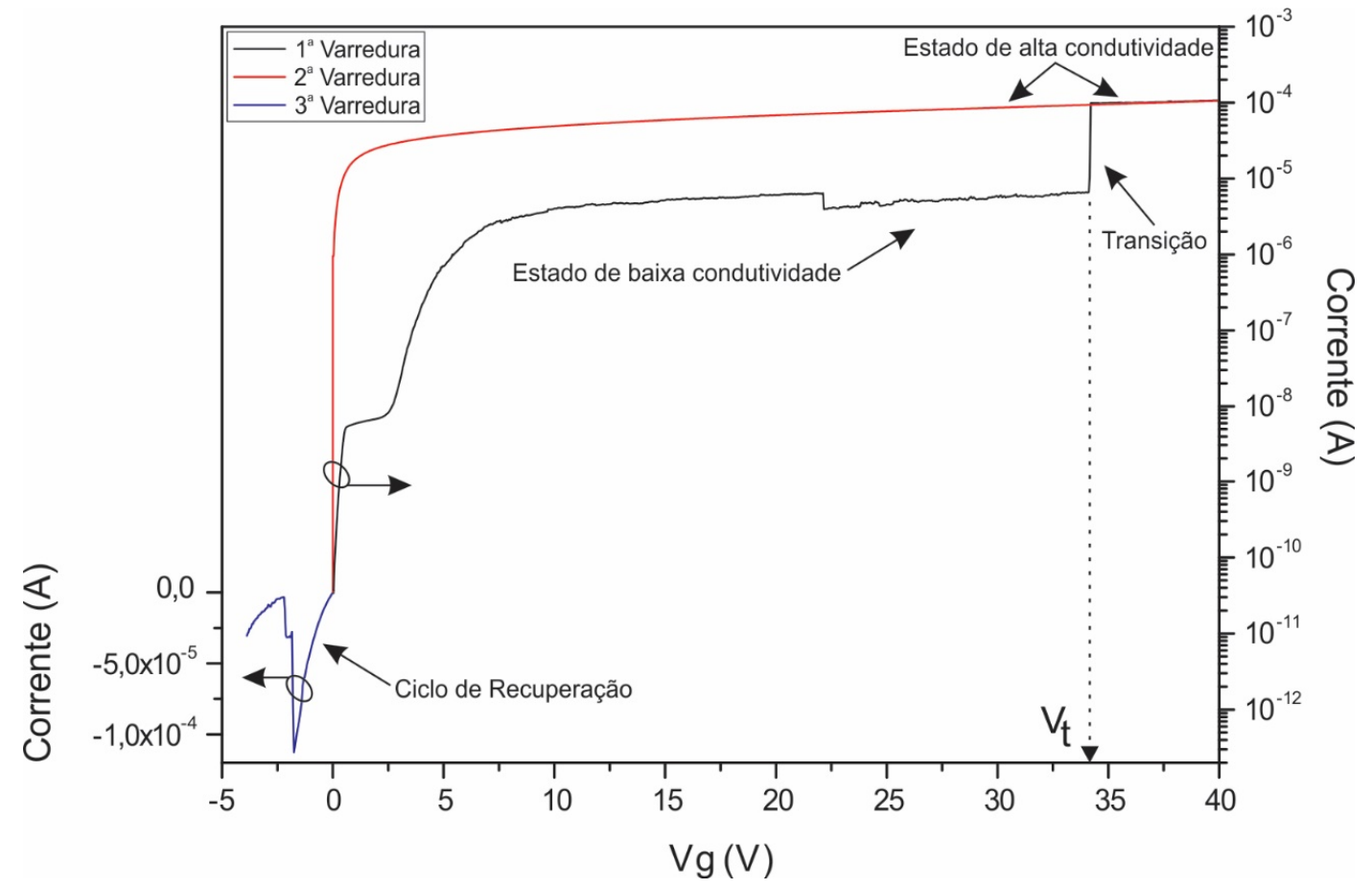

Fonte: O Autor. 
Figura 4.31 - Corrente de fuga em função da tensão para a amostra S60_100_7 - 10h: 1 e $^{\mathrm{a}}$ transições.

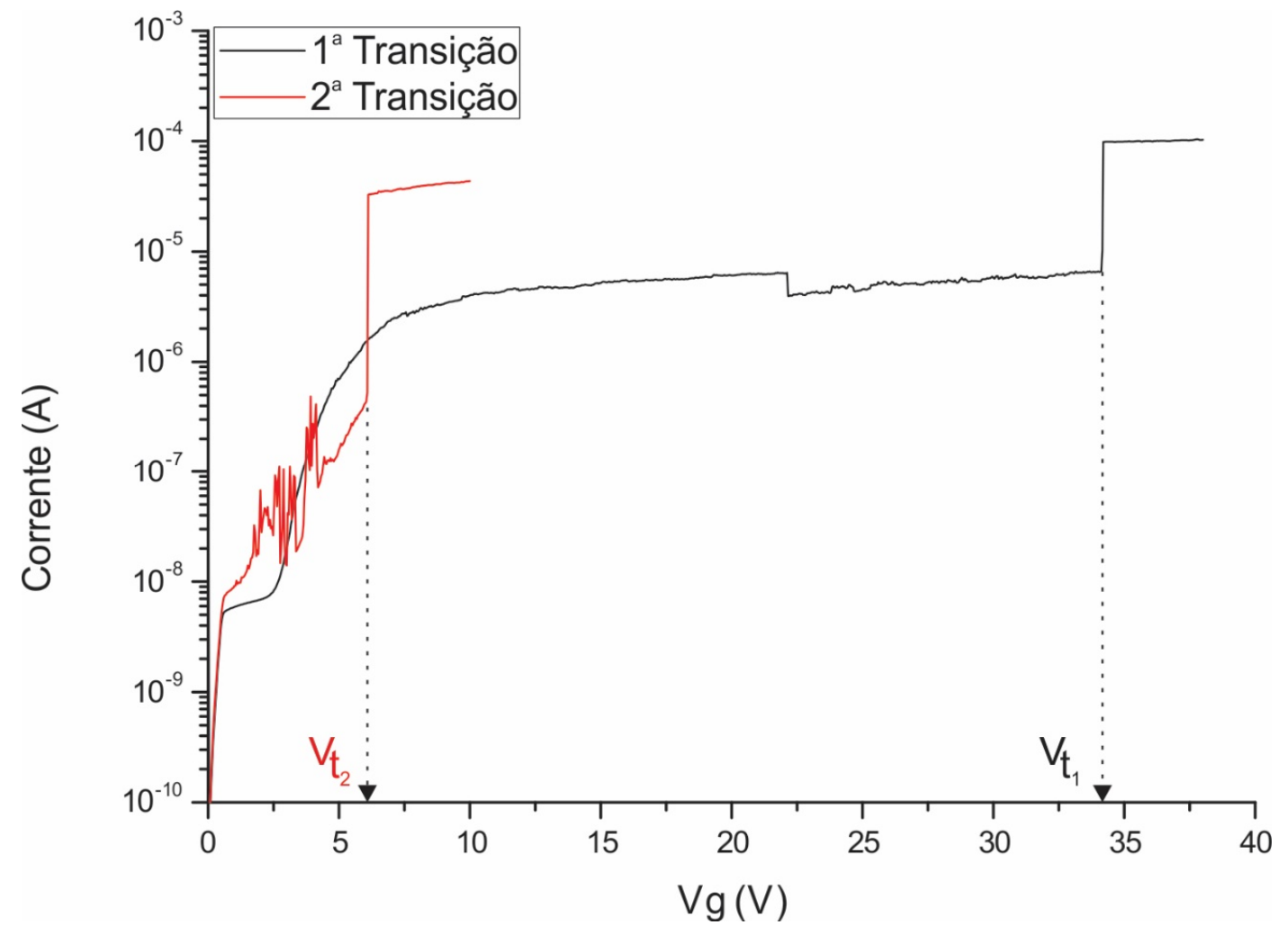

Fonte: O Autor.

O estabelecimento de mais ciclos de tensão negativa leva a resultados similares para a segunda transição (Figura 4.31), conforme mostra a Figura 4.32. Isto significa que a operação da memória passa a acontecer sempre da mesma forma, com tensão de transição de $5 \mathrm{~V}$. Neste caso, nota-se entretanto, a tendência de obtenção do estado de alta condutividade em duas etapas, e não através de uma única abrupta, como nos casos anteriores. Tal comportamento em duas etapas não foi observado nos casos anteriores e nem tampouco nos que serão mostrados a seguir. 
Figura 4.32 - Corrente de fuga em função da tensão para a amostra S60_100_7 - 10h: comportamento da memória após o estabelecimento de vários ciclos de operação.

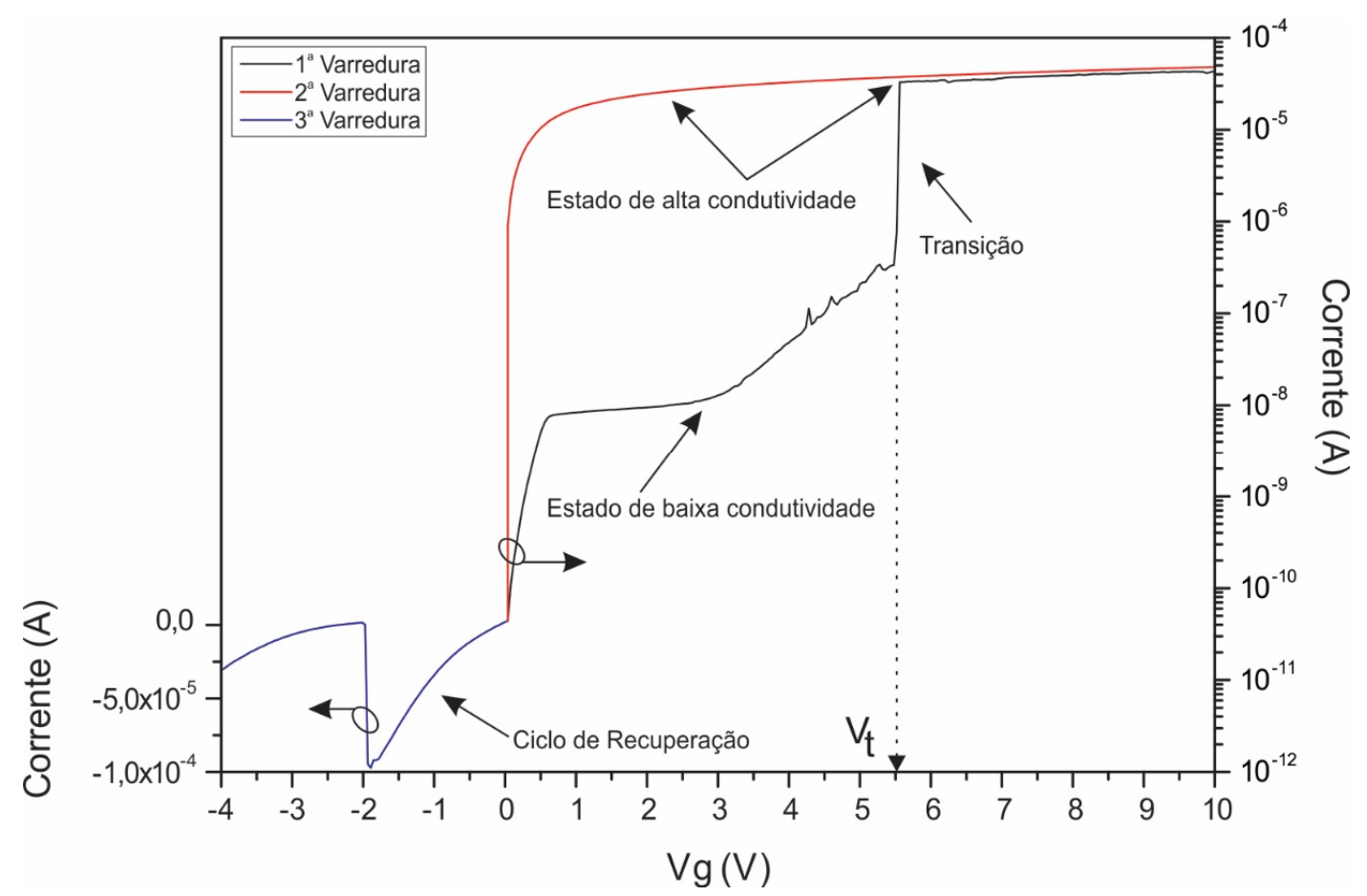

Fonte: O Autor.

A Figura 4.33 apresenta os resultados de I-V da amostra Stot_100_7 - 0h. São mostrados os resultados da primeira e segunda varreduras, bem como do ciclo de recuperação (ciclo de tensão negativa), ou seja, o procedimento completo de gravação e recuperação do estado de baixa condutividade. Existe mudança de três ordens de grandeza do estado de baixa condutividade para o estado de alta condutividade, em tensão de transição de aproximadamente $40 \mathrm{~V}$. Na segunda varredura, a partir da aplicação de baixa tensão, já é atingido o estado de alta condutividade (memória não volátil), como nos casos anteriores. Após a aplicação do ciclo de tensão negativa ( $3^{\mathrm{a}}$ varredura), é recuperado o estado de baixa condutividade. Novamente é observado comportamento de memória não volátil reversível. 
Figura 4.33 - Corrente de fuga em função da tensão para a amostra Stot_100_7 - 0h.

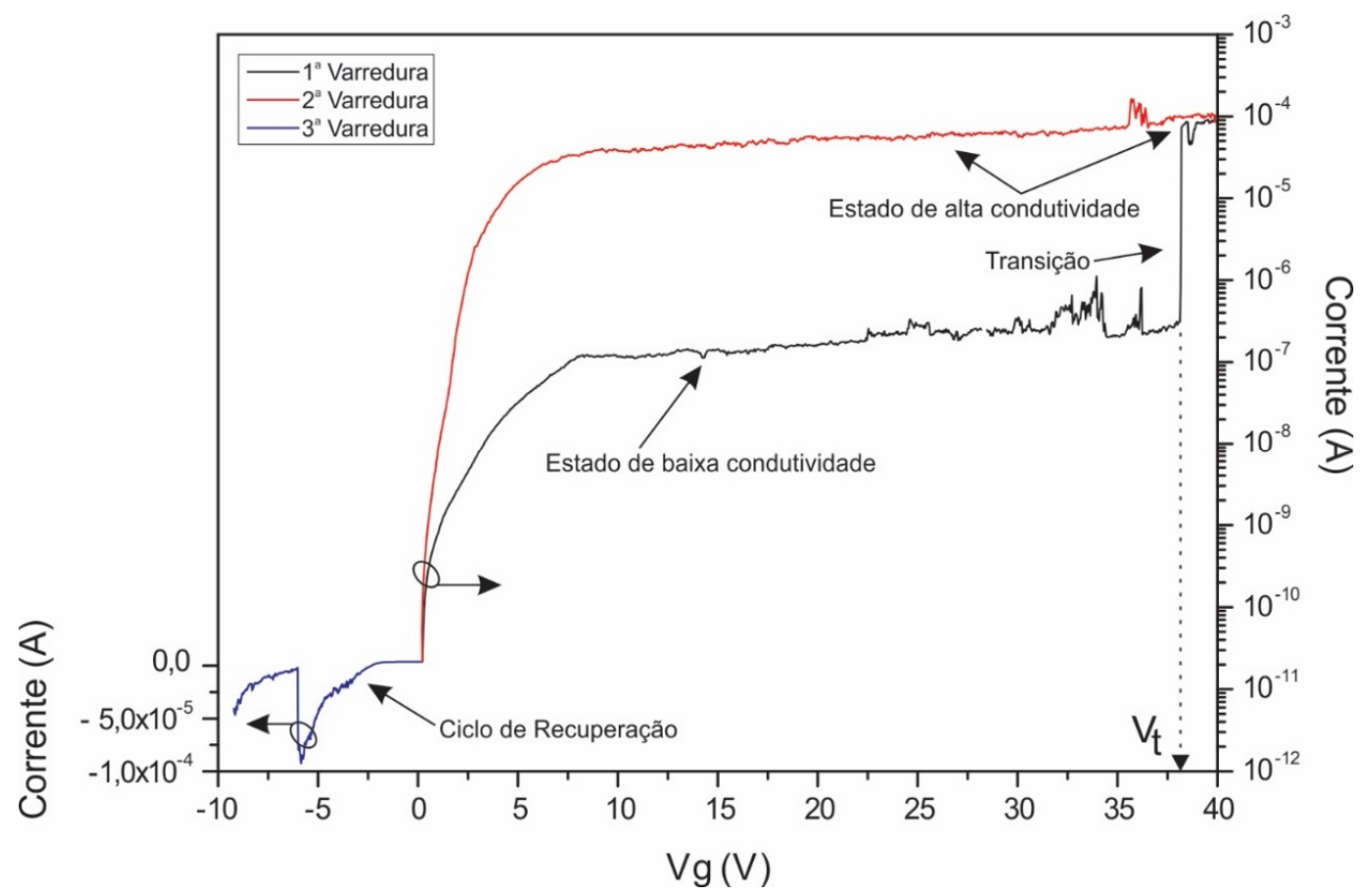

Fonte: O Autor.

A seguir são apresentados os resultados da amostra S50 com fluxo de oxigênio de 1 sccm. Essa amostra apresentou o melhor comportamento elétrico dentre as amostras estudadas, e por isso algumas considerações serão feitas com base nessa amostra.

A Figura 4.34 apresenta os resultados de I-V das amostras S50_100_1 - 10h e 20h. São mostrados os resultados da primeira e segunda varreduras para os casos tratados termicamente por 10 e 20 horas. Existe mudança de quatro ordens de grandeza do estado de baixa condutividade para o estado de alta condutividade, em tensão de transição de aproximadamente 6,5 e 3,5 V, para 10 e 20 horas, respectivamente (Figura 4.35). Na segunda varredura, a partir da aplicação de baixa tensão, já é atingido o estado de alta condutividade (memória não volátil), como nos casos anteriores. Após a aplicação do ciclo de tensão negativa (não mostrado), é recuperado o estado de baixa condutividade. Neste caso é também observado comportamento de memória não volátil reversível.

A Figura 4.35 apresenta os resultados de I-V da amostra S50_500_1 - 10h juntamente com os resultados das primeiras varreduras das amostras S50_100_1 - 10h e 20h (Figura 4.34). Para este caso, existe mudança de quatro ordens de grandeza do estado de baixa condutividade para o estado de alta condutividade, em tensão de transição de aproximadamente $8,5 \mathrm{~V}$. 
Figura 4.34 - Corrente de fuga em função da tensão para a amostra S50_100_1 - 10h e 20h: 1ª e 2a varreduras.

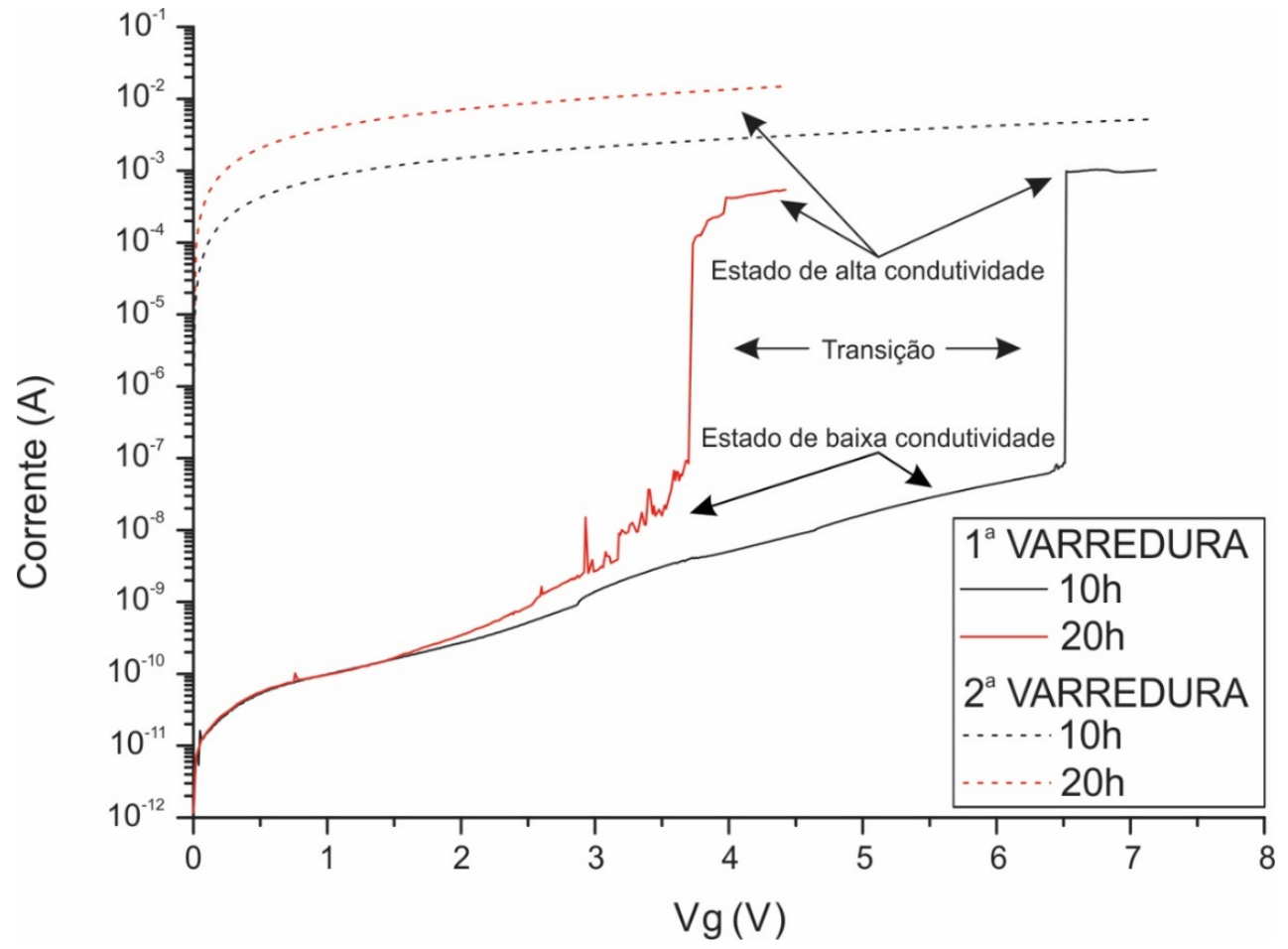

Fonte: O Autor.

Figura 4.35 - Corrente de fuga em função da tensão para a amostra S50_100_1 - 10h e 20h e S50_500_1 - 10h: $1^{\mathrm{a}}$ varredura.

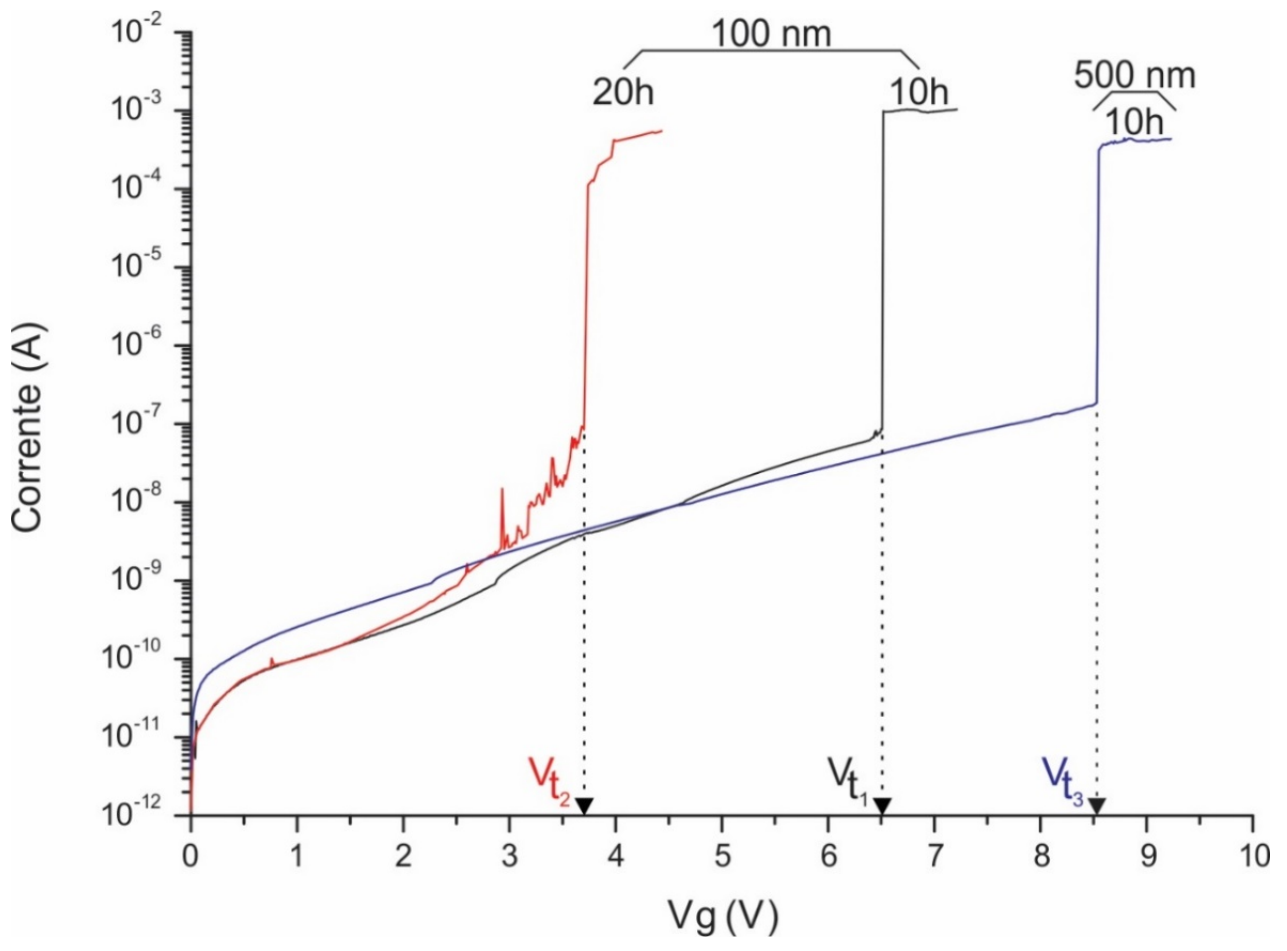

Fonte: O Autor. 
Com base nos resultados apresentados, as amostras S50_100_1 - 10h e 20h se destacam por apresentar os menores valores para tensão de transição, seguidas da amostra S50_100_2 - 0h. São também as amostras S50_100_1 - 10h e 20h que apresentam os maiores valores para as janelas de transição. Assim sendo, conclui-se que os parâmetros usados para fabricação destas amostras representam os mais adequados para produção de memórias não voláteis reversíveis.

Pelos resultados apresentados, nota-se que há dependência da tensão de ativação com a espessura e o tamanho das nanopartículas, conforme é exposto abaixo.

Quanto maior é a espessura, maior é a tensão de transição $\left(\mathrm{V}_{\mathrm{t}}=8,5 \mathrm{~V}\right.$ e $6,5 \mathrm{~V}$ para espessura de $500 \mathrm{~nm}$ e $100 \mathrm{~nm}$, respectivamente). Esse fenômeno é explicado pela maior dificuldade de preencher e saturar as armadilhas (nanopartículas de Au) nos filmes mais espessos $(500 \mathrm{~nm})$. Conforme discutido anteriormente, o aumento da espessura de 100 para $500 \mathrm{~nm}$ promove a diminuição da concentração volumétrica de nanopartículas $\left(N_{v p}\right)$, mesmo para concentração volumétrica de ouro $\left(N_{v}\right)$ constante (em função do aumento do tamanho médio das nanopartículas $d_{p}$ ). Por isso, as nanopartículas, no caso da amostra com $500 \mathrm{~nm}$, estão mais distantes entre si, originando uma tensão de transição mais alta, quando comparada com a amostra com $100 \mathrm{~nm}$ de espessura e mesmo tratamento térmico. Além disso, a amostra com espessura de $500 \mathrm{~nm}$ apresenta maior desvio padrão na concentração planar de ouro, quando comparada com a amostra com $100 \mathrm{~nm}$ de espessura de mesmo tratamento térmico. Isso indica que as nanopartículas de ouro estão distribuídas de forma não uniforme ao longo do filme. Conforme reportado por $\mathrm{Ng}$ e colaboradores [26], a não uniformidade na distribuição das nanopartículas causa maior dificuldade no preenchimento das mesmas com elétrons, contribuindo para o aumento do valor da tensão de transição.

Comparando os resultados da amostra com $100 \mathrm{~nm}$ de espessura e tratada por 10 e 20 horas, é possível observar que a tensão de transição é menor para tratamento térmico maior (3,7V para 20 horas e 6,5V para 10 horas). Isto ocorre pois, como mostrado na Tabela 4-5, com o aumento do tempo de tratamento térmico de 10 para 20 horas, há aumento do tamanho da nanopartícula (de 2,2 para 5,7 nm, aumento de aproximadamente $150 \%$ ), pouca alteração da concentração planar (de aproximadamente 15\%), e portanto, diminuição da quantidade de armadilhas de ouro. Assim, por estarem em número menor e serem maiores, o preenchimento das armadilhas é mais eficaz para tratamento térmico de 20 horas, e a transição abrupta da corrente ocorre então em tensão mais baixa do que para 10 horas de tratamento térmico. 
Para os casos das amostras sem tratamento térmico e com altos fluxos de oxigênio (amostras S40_100_4 -0h, Stot_100_7 - 0h), nota-se a tendência de apresentarem tensão de transição elevada, em torno de aproximadamente $40 \mathrm{~V}$. Tal fato tem explicação similar ao exposto para o aumento da espessura, pois a alta tensão indica dificuldade no preenchimento das armadilhas pelo fato de existir grande distância entre elas e falta de uniformidade na distribuição das nanopartículas de ouro. Isto pode ser visto pela imagem de TEM da Figura 4.16 e Tabela 4-5. Para o caso da amostra sem tratamento térmico, mas com baixo fluxo de oxigênio (S50_100_2 - 0h), foi obtida tensão de transição inferior $\left(\mathrm{V}_{\mathrm{t}}=15 \mathrm{~V}\right)$.

É possível observar que, para os casos de amostras com ouro produzidas com altos fluxos de oxigênio (> $4 \mathrm{sccm}$ ), a transição ocorre em alto valor de tensão (> $30 \mathrm{~V})$. Comportamento semelhante foi observado para as matrizes produzidas com alto fluxo de oxigênio (M7 - 0h e 10h).

Para o caso da amostra S60_100_7 - 10h, foi observada a diminuição do valor da tensão da $2^{\mathrm{a}}$ transição (de aproximadamente $35 \mathrm{~V}$ para aproximadamente $5 \mathrm{~V}$ ). Isto decorre do fato da matriz (M7 - 10h) apresentar alto valor de corrente após a ativação em valor de tensão elevado. De certa forma, a amostra com ouro segue o comportamento da matriz. Assim conclui-se que matrizes que permitem altos valores de corrente indicam tendência de possuir potencial para comportamento de memória na presença do ouro. Isto pôde ser observado para as amostras M1 - 0h, M2 - 0h, M7 - 0h e 10h. Por outro lado, para a matriz produzida sem fluxo de oxigênio a corrente é baixa, não tendo potencial para apresentar comportamento de memória na presença do ouro.

Com relação a influência do ouro, as melhores condições para produção de dispositivos de memória tendem ao uso do shutter na posição igual ou superior a 50, que corresponde à faixa de 4,7 a $6,8 \%$ de ouro. Destaca-se a posição 50 , que conduziu às amostras com melhores resultados elétricos. Para amostras produzidas com abertura do shutter em 35 e 45, não foi observado comportamento de memória.

A Figura 4.36 mostra os mecanismos de corrente ajustados ao comportamento I-V típico dos filmes finos de $\mathrm{TeO}_{2}-\mathrm{ZnO}$ com nanopartículas de ouro, tratados termicamente por 10 horas. Para tanto serão usadas as considerações apresentadas no item 2.4.4. Em baixas tensões (região 1), o transporte de corrente é devido ao movimento transitório de cargas através da estrutura, denominado como corrente de deriva. Com o aumento da tensão de polarização, a corrente é devida aos portadores de carga livres gerados termicamente, e apresenta dependência linear com a tensão (região 2). Em seguida, os portadores injetados no 
dielétrico vêm de processos termiônicos através da barreira, apresentando no início da região 3 , dependência quadrática com a tensão $\left(V^{2}\right)$ (Equação (2-9)), com $n$ muito menor que $n t$, e seguido por uma corrente que apresenta dependência exponencial com a tensão ( $V^{\mathrm{x}}$; onde $2<\mathrm{x}<5$ ), quando $n$ torna-se da ordem de $n t$ e a equação (2-9) não é mais aplicável [104]. Na última etapa (região 4), com a maior tensão aplicada, as armadilhas estão completamente preenchidas; então, o comportamento I-V segue o modelo de armadilhas cheias, descrito pela equação (2-10), onde a corrente tem novamente dependência quadrática com a tensão $\left(V^{2}\right)$.

Figura 4.36 - Mecanismos de corrente ajustados ao comportamento I-V típico dos filmes com 100nm de espessura, com nanopartículas de ouro e tratados termicamente por 10 horas.

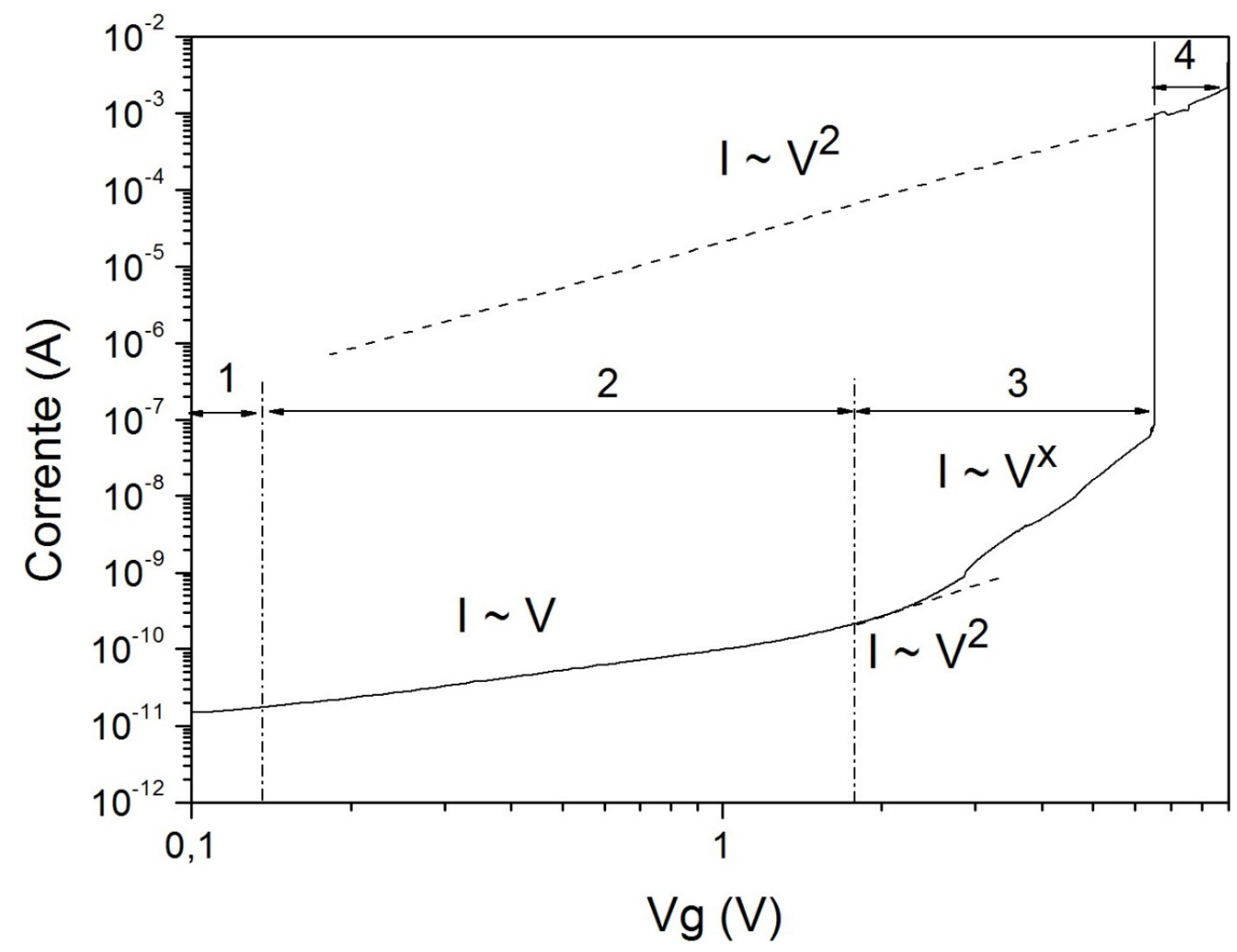

Fonte: O Autor. 


\section{Conclusões}

Através dos estudos realizados com as matrizes inorgânicas de telureto $\left(\mathrm{TeO}_{2}-\mathrm{ZnO}\right)$ que compõem os filmes dielétricos deste trabalho, foi possível concluir que o tratamento térmico empregado estabilizou a estequiometria dos filmes depositados por sputtering, mesmo quando o fluxo de oxigênio variou de 0,5 a $7 \mathrm{sccm}$ durante as deposições. Quando o tratamento térmico não foi realizado, foi possível identificar variação na estequiometria em função da maior ou menor incorporação de oxigênio no filme. Outra conclusão associada ao emprego de tratamento térmico foi a redução dos níveis de corrente. O tratamento térmico provavelmente causou alívio das tensões internas do filme, que por sua vez organizou a estrutura interna do material, reduzindo a quantidade de defeitos e promovendo menor quantidade de portadores de carga elétrica, diminuindo assim a condutividade do material e explicando a redução do nível de corrente.

Com respeito às matrizes de $\mathrm{TeO}_{2}-\mathrm{ZnO}$, foi ainda possível concluir que o aumento abrupto de corrente observado provavelmente está associado à formação de tubos de corrente, que se formam muito provavelmente em função do aumento do campo local promovido pelos átomos metálicos (Te e $\mathrm{Zn}$ ) que constituem a matriz. A tensão $\mathrm{V}_{\mathrm{A}}$ associada ao aumento abrupto de corrente indica maior ou menor facilidade na formação dos tubos de corrente. Entretanto, neste caso, estudos complementares são necessários para melhor compreensão do fenômeno observado.

Para as amostras de $\mathrm{TeO}_{2}-\mathrm{ZnO}$ com ouro, foi possível concluir que o percentual de ouro incorporado no filme dielétrico pode ser controlado através de um anteparo do sistema de sputtering (shutter) e também através do fluxo de oxigênio usado. Quanto maior o fluxo de oxigênio, menor é a incorporação de ouro no filme. O tratamento térmico feito a posteriori, para nucleação, conferiu maior homogeneidade de tamanho e melhor distribuição volumétrica das nanopartículas ao longo do filme, características importantes e que influenciam diretamente o comportamento de memória.

As análises de Microscopia Eletrônica de Transmissão demostraram que durante a deposição existe a formação de nanopartículas de $\mathrm{AuO}$ e Au policristalinas. Com o aumento do tempo de tratamento térmico empregado, a quantidade de $\mathrm{AuO}$ diminui. Análises em amostras com 20 horas de tratamento térmico não mais indicavam a presença de $\mathrm{AuO}$. $\mathrm{A}$ literatura tem reportado que, durante as primeiras horas de tratamento térmico, a parcela de 
$\mathrm{AuO}$ favorece a desagregação das partículas de Au. As medidas realizadas corroboraram tal fato.

Sobre o comportamento elétrico dos filmes com ouro, foi possível concluir que as nanopartículas controlam a corrente de fuga através dos filmes finos de $\mathrm{TeO}_{2}-\mathrm{ZnO}$. Elas atuam como armadilhas para os portadores de carga elétrica e têm capacidade de armazenálos, dificultando o transporte de corrente elétrica através do filme, reduzindo a corrente de fuga para níveis mais baixos.

Foi possível concluir que o tamanho, a concentração volumétrica e a distribuição das nanopartículas podem controlar o valor da tensão $\mathrm{V}_{\mathrm{t}}$ associada à transição brusca da corrente. Boa homogeneidade na distribuição das nanopartículas é especialmente importante para o bom funcionamento da memória. Filmes com distribuição não uniforme das nanopartículas tendem a apresentar valores de tensões de transição elevados, indicando dificuldade em preencher e saturar as armadilhas com portadores de carga elétrica.

Os melhores resultados obtidos foram observados para os filmes com nanopartículas de ouro, $100 \mathrm{~nm}$ de espessura, depositados com fluxo de oxigênio de $1 \mathrm{sccm}$ e tratados termicamente por 10 e 20 horas à $325^{\circ} \mathrm{C}$. Nestes casos foram obtidos os menores valores para tensão de transição dentre todas as amostras produzidas. Foi observada transição abrupta da corrente do estado de baixa para alta condutividade (3-4 ordens de grandeza) em tensões de 6,5 V (10 horas de tratamento térmico) e 3,7 V (20 horas de tratamento térmico). Observou-se ainda nestes casos que, mesmo com aplicação de baixa tensão, o estado de alta condutividade é atingido. Este estado de alta condutividade é memorizado até que seja apagado por aplicação de tensão negativa, o que caracteriza o comportamento de memórias não voláteis reversíveis.

Os resultados obtidos mostraram o excelente potencial de aplicação dos filmes finos produzidos, com nanopartículas de ouro incorporadas, para dispositivos de memória não volátil. Foi observado em material inorgânico, pela primeira vez, comportamento semelhante ao das memórias não voláteis orgânicas. O modelo teórico de condução de corrente, geralmente empregado em memórias orgânicas, pôde ser usado com sucesso. Assim, o presente trabalho é pioneiro, no que se refere à aplicação do modelo teórico de condução de corrente e ao comportamento semelhante ao das memórias não voláteis orgânicas.

As memórias obtidas através dos filmes de $\mathrm{TeO}_{2}-\mathrm{ZnO}$ com nanopartículas de ouro, quando comparadas com as memórias não voláteis inorgânicas usuais, possuem as vantagens de uma estrutura simplificada, facilidade no escalonamento, além de serem mais resistentes 
por apresentarem maior durabilidade ao longo do tempo. As unidades de memória inorgânica convencionais possuem estrutura baseada em um transistor MOS, com suas junções de fonte e dreno, além dos isolantes de porta e o substrato; conexões elétricas em todos esses terminais são necessárias para que o dispositivo funcione corretamente. A unidade de memória orgânica, por outro lado, possui estrutura simples baseada em um capacitor MOS. Apenas uma conexão elétrica (além do substrato aterrado) é necessária para a realização da gravação e leitura da memória. Nas memórias orgânicas, a ausência de um isolante de porta exclusivo, (que nas memórias inorgânicas é representado por camada de óxido de tunelamento extremamente fina, da ordem de poucos nanômetros), facilita o escalonamento do dispositivo, característica muito importante e que reflete diretamente na densidade de memória do produto final.

Os materiais estudados neste trabalho, formados por filmes finos de $\mathrm{TeO}_{2}-\mathrm{ZnO}$ com nanopartículas de ouro, mostram-se então promissores para aplicações em dispositivos de memória não volátil reversível com características similares as dos materiais orgânicos usados para o referido fim. O presente trabalho demonstra assim, a possibilidade de construir, a partir de materiais inorgânicos, formados por compósitos metal dielétrico, memórias não voláteis reversíveis, e abre novas perspectivas para desenvolvimento de pesquisa nesta área. 


\section{REFERÊNCIAS BIBLIOGRÁFICAS}

1. PAVAN, P. et al. Flash memory cells-an overview. Proceedings of the IEEE, v. 85, n. 8, p. 1248 - 1271, Agosto 1997.

2. CAPPELlETTI, P. et al. Flash Memories. Boston: Springer US, 1999.

3. BEZ, R. et al. Introduction to flash memory. Proceedings of the IEEE, v. 91, n. 4, p. 489 - 502, Abril 2003.

4. LEE, J. S. Progress in non-volatile memory devices based on nanostructured materials and nanofabrication. Journal of Materials Chemistry, v. 21, n. 37, p. 14097-14112, Abril 2011.

5. ARITOME, S. et al. Reliability issues of flash memory cells. Proceedings of the IEEE, v. 81, p. 776 - 788, Maio 1993.

6. ARAUJO, C. A.-P. D. et al. Fatigue-free ferroelectric capacitors with platinum electrodes. Nature, v. 374, p. 627 - 629, Abril 1994.

7. HWANG, C. G. Nanotechnology enables a new memory growth model. Proceedings of the IEEE, v. 91, n. 11, p. 1765 - 1771, Novembro 2003.

8. FAZIO, A. Flash Memory Scaling. MRS Bulletin, v. 29, n. 11, p. 814 - 817, Novembro 2004.

9. HAMANN, H. F. et al. Ultra-high-density phase-change storage and memory. Nature Materials, v. 5, p. 383 - 387, Maio 2006.

10. KIM, K.; LEE, S. Y. Memory technology in the future. Microelectronic Engineering, v. 84, n. 9-10, p. 1976 - 1981, Outubro 2007.

11. WASER, R.; AONO, M. Nanoionics-based resistive switching memories. Nature Materials, v. 6, p. 833 - 840, 2007.

12. KIM, Y. M.; LEE, J. S. Reproducible resistance switching characteristics of hafnium oxide-based nonvolatile memory devices. Journal of Applied Physics, v. 104, p. 114115, Dezembro 2008.

13. LEE, J. S.; JIA, Q. X. Comparative Study of Reliability Issues in La-doped Bismuth Titante Thin films According to the Bottom Electrode Materials. Electronic Materials Letters, v. 4, n. 3, p. 95-98, 2008.

14. LEE, J. S. Nano-floating gate memory devices. Electronic Materials Letters, v. 7, p. 175, Setembro 2011.

15. LEE, J. S. Recent progress in gold nanoparticle-based non-volatile memory devices. Gold Bulletin, v. 43, n. 3, p. 189 - 199, Setembro 2010.

16. HANAFI, H. I.; TIWARI, S.; KHAN, I. Fast and long retention-time nano-crystal memory. IEEE Transactions on Electron Devices, v. 43, n. 9, p. 1553 - 1558, Setembro 1996.

17. KAPETANAKIS, E.; NORMAND, P.; TSOUKALAS, D. Charge storage and interface states effects in Si-nanocrystal memory obtained using low-energy $\mathrm{Si}+$ implantation and annealing. Applied Physics Letters, v. 77, n. 21, p. 3450, 2016.

18. BLAUWE, J. D. Nanocrystal nonvolatile memory devices. IEEE Transactions on Nanotechnology, v. 99, n. 1, p. 72 - 77, Março 2002.

19. LIU, Z. et al. Metal nanocrystal memories. I. Device design and fabrication. IEEE Transactions on Electron Devices, v. 49, n. 9, p. 1606 - 1613, Setembro 2002. 
20. LIU, Z. et al. Metal nanocrystal memories-part II: electrical characteristics. IEEE Transactions on Electron Devices, v. 49, n. 9, p. 1614 - 1622, Setembro 2002.

21. EITAN, B. et al. NROM: A novel localized trapping, 2-bit nonvolatile memory cell. IEEE Electron Device Letters, v. 21, n. 11, p. 543 - 545, Novembro 2000.

22. WHITE, M. H.; ADAMS, D. A.; BU, J. On the go with SONOS. IEEE Circuits and Devices Magazine, v. 16, n. 4, p. 22 - 31, Julho 2000.

23. BU, J. K.; WHITE, M. H. Design considerations in scaled SONOS nonvolatile memory devices. Solid-State Electronics, v. 45, n. 1, p. 113-120, Janeiro 2001.

24. KING, Y. C.; KING, T. J.; HU, C. Charge-trap memory device fabricated by oxidation of Si/sub 1-x/Ge/sub x/. IEEE Transactions on Electron Device, v. 48, n. 4, p. 696 700, Abril 2001.

25. LIN, H. T.; PEI, Z.; CHAN, Y. J. Carrier Transport Mechanism in a NanoparticleIncorporated Organic Bistable Memory Device. IEEE Electron Device Letters, v. 28, n. 7, p. 569 - 571, Julho 2007.

26. NG, S. A. et al. Memory properties of Au nanoparticles prepared by tuning $\mathrm{HAuCl} 4$ concentration using low-temperature hydrothermal reaction. Thin Solid Films, v. 615, p. 84-90, 2016.

27. SANTONI, F. et al. Charge trapping models of resistance switching in organic bistable devices with embedded nanoparticles. Organic Electronics, v. 15, p. 2792-2801, 2014.

28. KERN, W.; PUOTINEN, D. A. Cleaning Solution Based on Hydrogen Peroxide for use in Silicon Semiconductor Technology. RCA Review, v. 31, p. 187-264, Junho 1970.

29. BONTEMPO, L. et al. Caracterização elétrica de filmes finos de $\mathrm{TeO} 2-\mathrm{ZnO}$ preparados com $\mathrm{Au} 2 \mathrm{O} 3$ por sputtering. Anais do XI Simpósio de Iniciação Científica da FATECSP, v. 27, p. 74, 2009.

30. BONTEMPO, L.; FERREIRA, E. D. S.; KASSAB, L. R. P. Caracterização Elétrica de Vidros de Telureto com Nanopartículas de Prata. Anais do X Simpósio de Iniciação Científica da FATEC-SP, São Paulo, v. 25, p. 116, 2008.

31. BONTEMPO, L.; FERREIRA, E. S.; P., K. L. R. Optical and electrical properties of $\mathrm{TeO} 2-\mathrm{ZnO}$ insulators with silver nanoparticles for microelectronic applications. Anais do 11 th International conference on advanced materials, Rio de Janeiro, 2009.

32. BONTEMPO, L. et al. Electrical characterization of $\mathrm{TeO} 2-\mathrm{ZnO}$ dielectrics containing Au nanoparticles. ECS transactions, v. 39, p. 137-144, 2011.

33. HORA, W. G. Produção e caracterização de filmes finos de GEO2-PBO Dissertação (Mestrado). Escola Politécnica da Universidade de São Paulo. São Paulo. 2008.

34. ROBERTSON, J. High dielectric constant gate oxides for metal oxide Si transistors. Reports on Progress in Physics, v. 69, p. 327-396, 2006.

35. KASSAB, L. R. P. et al. Semiconductor characteristics of Nd doped PbO-Bi2O3-Ga2O3 films. Brazilian Journal of Physics, v. 36, n. 2A, p. 451 - 454, 2006.

36. GÓMEZ, L. A. et al. Near-infrared third-order nonlinearity of $\mathrm{PbO}-\mathrm{GeO} 2 \mathrm{PbO}-\mathrm{GeO} 2$ films containing $\mathrm{Cu}$ and $\mathrm{Cu} 2 \mathrm{O}$ nanoparticles. Applied Physics Letters, v. 92, n. 14, p. 141916, 2008.

37. SILVA, D. M. D. et al. Frequency upconversion in Er 3+ doped $\mathrm{PbO}-\mathrm{GeO} 2$ glasses containing metallic nanoparticles. Applied Physics Letters, v. 90, n. 8, p. 081913, Fevereiro 2007. 
38. ARAÚJO, C. B. et al. Giant third-order nonlinearity of lead and germanium based films in the visible and in the infrared. Journal of Applied Physics, v. 101, n. 6, p. 066130, 2007.

39. NARANJO, L. P. et al. Enhancement of Pr3+luminescence in $\mathrm{PbO}-\mathrm{GeO} 2$ glasses containing silver nanoparticles. Applied Physics Letters, v. 87, n. 24, p. 241914, Outubro 2005.

40. KASSAB, L. R. P.; ARAÚJO, C. B. D. Germanate and tellurite glasses for photonic applications. New York: Nova Science Publishers, 2008.

41. SILVA, D. S. D. et al. Frequency upconversion in Nd 3+ doped PbO-GeO 2 glasses containing silver nanoparticles. Journal of Alloys and Compounds, v. 586, p. 516-519, Fevereiro 2014.

42. MARQUES, M. S. et al. Giant enhancement of phonon-assisted one photon excited frequency upconversion in a Nd3+ doped tellurite glass. Journal of Applied Physics, v. 113, p. 053102, 2013.

43. CAMILO, M. E. et al. Influence of silver nanoparticles on the infrared-to-visible frequency upconversion in $\mathrm{Tm} 3+/ \mathrm{Er} 3+/ \mathrm{Yb} 3+$ doped $\mathrm{GeO} 2-\mathrm{PbO}$ glass. Journal of Applied Physics, v. 113, n. 15, p. 153507, Abril 2013.

44. ARAUJO, C. B. et al. Enhanced Optical Properties of Germanate and Tellurite Glasses Containing Metal or Semiconductor Nanoparticles. The Scientific World Journal, v. 2013, p. 1-13, 2013.

45. ARAÚJO, C. B. D. et al. Nonlinear optical properties of $\mathrm{PbO}-\mathrm{GeO} 2$ films containing gold nanoparticles. Journal of Luminescence, v. 133, p. 180-183, Janeiro 2013.

46. TALAPIN, D. V. et al. Prospects of Colloidal Nanocrystals for Electronic and Optoelectronic Applications. Chemical Reviews, v. 110, n. 1, p. 389-458, 2010.

47. LEE, C. et al. Self-assembly of metal nanocrystals on ultrathin oxide for nonvolatile memory applications. Journal of Electronic Materials, v. 34, n. 1, p. 1-11, Janeiro 2005.

48. CHAN, K. C.; LEE, P. F.; DAI, J. Y. Study of tunneling mechanism of Au nanocrystals in HfAlO matrix as floating gate memory. Applied Physics Letters, v. 92, n. 22, p. 223105, Junho 2008.

49. LO, Y. S. et al. Bandgap engineering of tunnel oxide with multistacked layers of Al2O3/HfO2/SiO2 for Au-nanocrystal memory application. Applied Physics Letters, v. 93, n. 13, p. 132907, Outubro 2008.

50. OUYANG, J. et al. Programmable polymer thin fi $\mathrm{lm}$ and non-volatile memory device. Nature Materials, v. 3, p. 918-922, 2004.

51. TSENG, R. J. et al. Nanoparticle-induced negative differential resistance and memory effect in polymer bistable light-emitting device. Applied Physics Letters, v. 88, n. 12, 2006.

52. FAN, Z. et al. Silver-tetracyanoquinodimethane (Ag-TCNQ) nanostructures and nanodevice. IEEE, v. 2, p. 588-591, 2003.

53. BOZANO, L. . et al. Organic Materials and Thin-Film Structures for Cross-Point Memory Cells Based on Trapping in Metallic Nanoparticles. Advanced Functional Materials, v. 15, p. 1933-1939, 2005.

54. AW, K. C.; OOI, P. C.; RAZAK, K. A. A transparent and flexible organic bistable memory device using parylene with embedded gold nanoparticles. Journal of Materials Science: Materials in Electronics, v. 24, p. 3116-3125, 2013. 
55. LIN, Y. T.; LIN, T. Y.; HUNG, Y. C. Bistable Memory Device Based on DNA Biopolymer Nanocomposite. SPIE Proceedings, v. 9135, p. 913715, 2014.

56. TSENG, R. J. et al. Polyaniline Nanofiber/Gold Nanoparticle Nonvolatile Memory. Nano Letters, v. 5, n. 6, p. 1077-1080, 2005.

57. TIWARI, S. et al. A silicon nanocrystals based memory. Applied Physics Letters, v. 68, n. 10, p. 1377, 1996.

58. LEE, J. J.; KWONG, D. L. Metal nanocrystal memory with high-/spl kappa/ tunneling barrier for improved data retention. IEEE Transactions on Electron Devices, v. 52, n. 2, p. 507-511, 2005.

59. CHANG, T. C. et al. Developments in nanocrystal memory. Materials Today, v. 14, n. 12, p. 608-615, 2011.

60. KIM, Y. H. et al. Organic Memory Capacitor Device Fabricated With Ag Nanoparticles. Journal of Nanoscience and Nanotechnology, v. 11, n. 7, p. 6044-6048, 2011.

61. CHOI, H. et al. Memory characteristics of a self-assembled monolayer of $\mathrm{Pt}$ nanoparticles as a charge trapping layer. Nanotechnology, v. 19, n. 30, p. 305704, 2008.

62. LIU, F. K. et al. Rapid fabrication of high quality self-assembled nanometer gold particles by spin coating method. Microelectronic Engineering, v. 67-68, p. 702-709, 2003.

63. CHAN, K. C.; LEE, P. F.; DAI, J. Y. Mesoscopic phenomena in Au nanocrystal floating gate memory structure. Applied Physics Letters, v. 95, n. 11, p. 113109, 2009.

64. HURST, K. M. et al. Self - assembled monolayer - immobilized gold nanoparticles as durable, anti - stiction coatings for MEMS. Journal of Microelectromechanical Systems, v. 20, n. 2, p. 424, 2011.

65. YANG, K. et al. Optical and electrical properties of self-assembled, ordered gold nanocrystal/silica thin films prepared by sol-gel processing. Thin Solid Films, v. 491, n. 1-2, p. 38-42, 2005.

66. DAS, A.; DAS, S.; RAYCHAUDHURI, A. K. Growth of two-dimensional arrays of uncapped gold nanoparticles on silicon substrates. Bulletin of Materials Science, v. 31, n. 3, p. 277-282, 2008.

67. OOI, P. C. et al. Effects of metal electrodes and dielectric thickness on non-volatile memory with embedded gold nanoparticles in polymethylsilsesquioxane.

Microelectronic Engineering, v. 98, p. 74-79, 2012.

68. LI, W. et al. Superlattice Structure of Gold Nanoparticles Film Deposited by LangmuirBlodgett Technique. Molecular Crystals and Liquid Crystals Science and Technology, v. 337, n. 1, p. 185-188, 1999.

69. HUANG, J. et al. Spontaneous formation of nanoparticle stripe patterns through dewetting. Nature Materials, v. 4, n. 12, p. 896-900, 2005.

70. CHITU, L. et al. Modified Langmuir-Blodgett deposition of nanoparticles - measurement of 2D to 3D ordered arrays. Measurement Science Review, v. 10, n. 5, p. 162, out. 2010.

71. BELL, M. J. V. et al. Laser emission of a Nd-doped mixed tellurite and zinc oxide glass. Journal of the Optical Society of America B, v. 31, n. 7, p. 1590-1594, Julho 2014.

72. ASSUMPCÃO, T. A. A. et al. Frequency upconversion properties of Tm3+ doped $\mathrm{TeO} 2-\mathrm{ZnO}$ glasses containing silver nanoparticles. Journal of Alloys and Compounds, v. 536, p. 504-506, 2012. 
73. KASSAB, L. R. P. et al. Frequency upconversion properties of Ag: $\mathrm{TeO} 2-\mathrm{ZnO}$ nanocomposites codoped with Yb3+ and Tm3+ ions. Applied Physics B, v. 104, p. 1029-1034, 2011.

74. SILVA, D. S. et al. Enhanced Er3+ photoluminescence in $\mathrm{TeO} 2-\mathrm{ZnO}$ glass containing silicon nanocrystals. Applied Physics B, v. 121, p. 117 - 121, 2015.

75. FLORÊNCIO, L. A. et al. Efficiency enhancement in solar cells using photon downconversion in $\mathrm{Tb} / \mathrm{Yb}$-doped tellurite glass. Solar Energy Materials \& Solar Cells, v. 157, p. 468-475, 2016.

76. OLIVERO, M. et al. Amplification Properties of Femtosecond Laser-Written Er3+/Yb3+ Doped Waveguides in a Tellurium-Zinc Glass. Advances in Optical Technologies, v. 2013, p. 621018, 2013.

77. ALVES, O. L.; GIMENEZ, I. D. F.; MAZALI, I. O. Vidros. Cadernos Temáticos Química Nova na Escola, 2001. 9-20.

78. CETEC-MG. Ciência dos materiais. Ciência dos materiais, 2017. Disponivel em: $<$ http://www.cienciadosmateriais.org/index.php?acao=exibir\&cap=11>. Acesso em: 10 Janeiro 2017.

79. AMÂNCIO, C. T. Produção e Caracterização de Amostras Vítreas e Fibras Ópticas de Telureto Codopadas com Íons de Terras Raras. FATEC-SP. São Paulo. 2008.

80. YANO, T.; FUKOMOTO, A.; WATANABE, A. Tellurite glass: A new acousto-optic material. Journal of Applied Physics, v. 42, p. 3674, 1971.

81. BENDOW, B.; YING, S. C.; YUKON, S. P. Theory of Multiphonon Absorption due to Anharmonicity in Crystals. Physical Review B, v. 8, n. 4, p. 1679-1689, Agosto 1973.

82. IMMANUIL, L.; FABELINKII, L. Molecular Scattering of Light. New York: Plenum Press, 1968.

83. GONZALEZ, R. E. R. Guias de onda por troca iônica em vidros de teluritos dopados com érbio - Dissertação (Mestrado). Universidade de Campinas. Campinas. 2003.

84. REISFELD, R.; ECKESTEIN, Y. Intensities of electronic transitions and quantum efficiencies of the green luminescence of Er3+ in Tellurite glasses. Solid State Commun, v. 13, n. 7, p. 741 - 744, Outubro 1973.

85. HECKROODT, R. O.; RES, M. A. Erbium tellurite glasses. Physics and Chemistry of Glasses, v. 17, p. 217 - 219, 1976.

86. NEOV, S. et al. The structure of glasses in the TeO2-P2O5 system. Journal of Materials Science, v. 15, n. 5, p. 1153-1166, maio 1980.

87. SAKIDA, S.; HAYAKAWA, S.; YOKO, T. 125Te NMR study of tellurite crystals. Journal of Non-Crystalline Solids, v. 243, n. 1, p. 1-12, Janeiro 1999.

88. SAKIDA, S.; HAYAKAWA, S.; YOKO, T. 125Te NMR study of M 2O-TeO 2(M=Li, $\mathrm{Na}, \mathrm{K}, \mathrm{Rb}$ and $\mathrm{Cs}$ ) glasses. Journal of Non-Crystalline Solids, v. 243, n. 1, p. 13-25, Janeiro 1999.

89. OHRING, M. The Materials Science for Thin Films. [S.1.]: Academic Press, 1992.

90. CHINAGLIA, F. E. Caracterização Nanoestrutural de Filmes Finos do Grupo IV-B Depositados por Sputtering Magnetron - Tese (Doutorado). Universidade de São Paulo. São Paulo. 2002.

91. REZENDE, S. M. Materiais e Dispositivos Eletrônicos. 2a. ed. São Paulo: Livraria da Física, 2004.

92. TATSCH, P. J. Deposição de Filmes Finos, Oficina de Microfabricação: Projeto e 
Construção de CI's MOS. Centro de Componentes Semicondutores da Universidade Estadual de Campinas. Campinas. 2000.

93. ROBERTSON, G. R. J.; JESSOP, P. E. Optical waveguide laser using an. r.f. sputtered Ndzglass film. Applied Optics, v. 30, p. 276 - 278, 1991.

94. YIMITA, A. et al. Thin film composite optical waveguides for sensor applications: a review. Talanta, v. 65, n. 5, p. 1102 - 1109, Março 2005.

95. HUANG, C. H. J.; RABSON, T. A. Low-loss thin-film LiNbO3 optical waveguide sputtered onto a SiO2/Si substrate. Optics Letters, v. 18, n. 10, p. 811 - 813, 1993.

96. CHAPMAN, B. Glow Discharge Processes, Sputtering and Plasma Etching. [S.1.]: John Wiley \& Sons, 1980.

97. GAN, F.; XU, L. Photonic Glasses. Singapore: World Scientific Publishing, 2006.

98. MATSUNAMI, N. et al. Energy dependence of the yields of ion-induced sputtering of monatomic solids. Institute of Plasma Physics, v. IPPJ-AM-32, Setembro 1983.

99. CACHO, V. D. D. Produção e caracterização de guias de onda de telureto e germanato para aplicações em optoeletrônica - Tese (Doutorado). Escola Politécnica da Universidade de São Paulo. São Paulo. 2010.

100. ALBERTIN, K. F. Estudo e fabricação de capacitores MOS com camada isolante de SiOXNY depositadas por PECVD - Dissertação (Mestrado). Escola Politécnica da Universidade de São Paulo. São Paulo. 2003.

101. MARTINO, J. A.; PAVANELLO, M. A.; VERDONCK, P. B. Caracterização Elétrica de Tecnologia e Dispositivos Mos. 1. ed. São Paulo: Thomson, 2003.

102. SANTOS FILHO, S. G. Oxidação Térmica Rápida do Silício: Influência dos Procedimentos de Limpeza e dos Perfis Temporais de Temperatura na Qualidade dos Óxidos de Porta MOS - Tese (Doutorado). Escola Politécnica da Universidade de São Paulo. São Paulo. 1996.

103. RAJAB, S. M. Effect of the thermal annealing on the electrical and physical properties of $\mathrm{SiC}$ thin films produced by RF magnetron sputtering. Thin Solid Films, v. 515, p. 170 $175,2006$.

104. LAMPERT, M. A.; MARK, P. Current Injection in Solids. New York: Academic, 1970.

105. FOWLER, R. H.; NORDHEIM, L. Electron Emission in Intense Electric Fields. Proceeding of the Royal Society A, v. 119, n. 781, p. 173-181, 1928.

106. HUANG, T. H.; PEI, Z. Extensive Leakage Current Reduction in Polymer Dielectric Thin Film by Metal Nanoparticles Incorporation for Organic Thin Film Transistor. Japanese Journal of Applied Physics, v. 48, p. 04C171, 2009. ISSN 4S.

107. CAMILO, M. E. Produção de interferômetros mach-zehnder utilizando guias de onda do tipo pedestal e filmes finos de bi2o3-wo3-teo2 para aplicações em sensores ópticos integrados - Dissertação (Mestrado). Escola politécnica da Universidade de São Paulo. São Paulo. 2014.

108. KERN, W. The Evolution of Silicon Wafer Cleaning Technology. Journal of The Electrochemical Society, v. 137, p. 1887 - 1892, 1990.

109. ASSUMPÇÃO, T. A. Desenvolvimento de técnica para nucleação de nanopartículas metálicas em vidros de germanato dopados com íons de túlio para aplicações em dispositivos fotônicos - Dissertação (Mestrado). Escola Politécnica da Universidade de São Paulo. São Paulo. 2010. 
110. ASSUMPÇÃO, T. A. A. Produção e caracterização de filmes finos amorfos de germanato codopados com Tm3+ e Yb3+ contendo nanopartículas metálicas para a produção de guias de onda - Tese (Doutorado). Escola Politécnica da Universidade de São Paulo. São Paulo. 2015.

111. SILVA, A. A. Estudos sobre Efeitos de Rugosidade em Espectros RBS - Dissertação (Mestrado). Instituto de Física da Universidade de São Paulo. São Paulo. 2001.

112. TABACNIKS, M. H. Análise de filmes finos por PIXE e RBS. Site do Laboratório de Materiais e Feixes Iônicos, p. 1-17. Disponivel em:

<www2.if.usp.br/ lamfi/pixe\&rbs.pdf>. Acesso em: 24 ago. 2017.

113. CHU, W. K. Backscattering Spectrometry. New York: Academic Press, 1978.

114. DEWAN, N.; GUPTA, V.; SREENIVAS, K. Growth of amorphous TeOx (2-x-3) thin film by radio frequency sputtering. Journal of Applied Physics, v. 101, p. 084910, 2007.

115. KLEIN, N.; NEVANLINNA, O. Lowering of the breakdown voltage of silicon. Solid State Electronics, v. 26, n. 9, p. 883-892, 1983.

116. JCPDS. International Centre for Diffraction Data PDF 85-1330. PCPDFWIN 24, 2003.

117. AITA, C. R. AuO+ and AuO+2 gaseous ions formed during the sputter deposition of $\mathrm{Au}$ films in Ar-O2 discharges. Journal of Applied Physics, v. 61, n. 11, p. 5182-5183, 1987.

118. PAL, U. et al. Preparation of $\mathrm{Au} / \mathrm{ZnO}$ nanocomposites by radio frequency co-sputtering. Solar Energy Materials \& Solar Cells, v. 70, p. 363-368, 2001.

119. VU, T. H. Y. et al. Effect of the size of nanoparticles on their dissolution within metalglass nanocomposites under sustained irradiation. Journal of Applied Physics, v. 119, p. 034302, 2016.

120. FU, G. et al. Controllable optical properties of $\mathrm{Au} / \mathrm{SiO} 2$ nanocomposite induced by ultrasonic irradiation and thermal annealing. Applied Physics Letters, v. 83, n. 1, p. 36, 2003. 


\title{
APÊNDICE A - Publicações de trabalho no período do doutorado
}

\author{
ARTIGO COMPLETO PUBLICADO EM PERIÓDICO
}

Bontempo, Leonardo; dos Santos Filho, Sebastião Gomes; Kassab, Luciana Reyes Pires. Conduction and reversible memory phenomena in Au-nanoparticles-incorporated $\mathrm{TeO}_{2}-\mathrm{ZnO}$ films. Thin Solid Films, v. 611, p. 21-26, 2016.

\section{TRABALHOS COMPLETOS PUBLICADOS EM ANAIS DE CONGRESSOS}

Bontempo, Leonardo; dos Santos Filho, Sebastião Gomes; Kassab, Luciana Reyes Pires. $\mathrm{TeO}_{2}-\mathrm{ZnO}$ thin films with gold nanoparticles as passivating materials for power devices applications. 29th Symposium on Microelectronics Technology and Devices (SBMicro), 2014, Aracaju.

Bontempo, Leonardo; dos Santos Filho, Sebastião Gomes; Kassab, Luciana Reyes Pires. Characterization of the Semi-Insulating Properties of Sputtered-deposited Telluride Thin Films with Gold Nanoparticles. SEMINATEC 2014- IX Workshop on semiconductors and micro and nanotechnology, 2014, São Paulo.

\section{RESUMO PUBLICADO EM ANAIS DE CONGRESSOS}

Bontempo, Leonardo; dos Santos Filho, Sebastião Gomes; Kassab, Luciana Reyes Pires. Reversible memory phenomena in $\mathrm{TeO}_{2}-\mathrm{ZnO}$ films with Au nanoparticles. XV Brazilian Materials Research Society Meeting, 2016, Campinas.

\section{DIVULGAÇÃO DOS RESULTADOS EM CONGRESSO}

Bontempo, Leonardo; dos Santos Filho, Sebastião Gomes; Kassab, Luciana Reyes Pires. The Influence of Gold Nanoparticles on $\mathrm{TeO}_{2}-\mathrm{ZnO}$ Thin Films for Applications as Power Devices Passivation. NANOSMAT 2014 - IX International Conference on Surfaces, Coatings and Nanostructured Materials, 2014, Ireland. 


\section{CAPÍTULO DE LIVRO PUBLICADO}

Kassab, Luciana Reyes Pires; da Silva, Davinson Mariano; del Cacho, Vanessa Duarte; Bontempo, Leonardo; dos Santos Filho, Sebastião Gomes; Chavez, Marco Isaias Alayo. Tellurite Thin Films Produced by RF Sputtering for Optical Waveguides and Memory Device Applications. In: Rivera, V.A.G.; Manzani, Danilo. (Org.). Springer Series in Materials Science. 1ed.: Springer International Publishing, 2017, v. 254, p. 241-257. 